


\title{
CARBON NEUTRAL MANAGEMENT IN SPORT MARINAS
}

\author{
Juan Carlos Santamarta \\ Florin Ioras \\ Noelia Cruz-Pérez \\ Nicholas Christofides \\ Manfredi Bruccoleri
}

(Eds.) 
The authors of individual chapters are solely responsible for the ideas, views, data, figures, and geographical boundaries presented in the respective chapters of this book, and these have not been endorsed, in any form, by the publisher, the editor, and the authors of forewords, preambles, or other chapters.

\section{Carbon Neutral Management in Sport Marinas}

(C) The authors

Published by: Universidad de La Laguna (ULL)

Pabellón de Gobierno, c/ Padre Herrera, s/n

Apartado Postal 456

38200 San Cristóbal de La Laguna

Santa Cruz de Tenerife - España

Teléfono: (+34) 900432526

ISBN: 978-84-09-29858-7

Legal Deposit: TF 233-2021

$\mathbf{1}^{\text {a }}$ Ed: may 2021

DOI: https://doi.org/10.25145/b.CarbonMarinas.2021

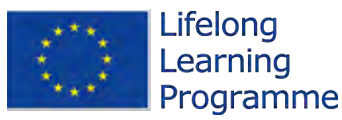

This work has been carried out with the financial support of the Erasmus+ Programme under grant agreement No 2018-1-UK01-KA203-047958 and grant agreement No 2017-1-UK01-KA203-036521. This reflects only the authors' view and that the Union is not liable for any use that may be made of the information contained therein.

How to cite this book:

Santamarta, J.C., Ioras, F., Cruz-Pérez, N., Christofides, N., Bruccoleri, M. (Eds.) (2021). Carbon Neutral Management in Sport Marines. Universidad de La Laguna. https://doi.org/10.25145/b.CarbonMarinas.2021

This book is intented for educational and scientific purposes only 
Chapter 1. Climate change impacts and adaptation. Technology, process and maintenance

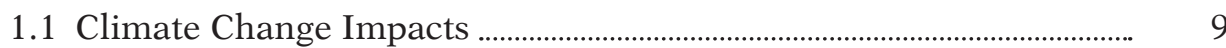

1.2 Climate Change in Coastal Areas .................................................................... 19

1.3 Adaptation Technologies and Practices ............................................................. 26

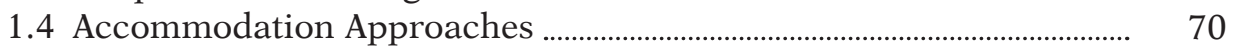

1.5 Prioritisation of Technologies and Practices ................................................ 81

1.6 Climate change mitigation ........................................................................ 83

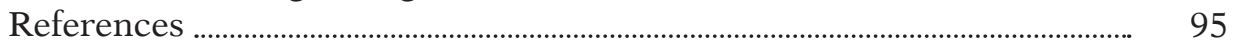

Chapter 2. Carbon economics: technology, process and planning .................... 101

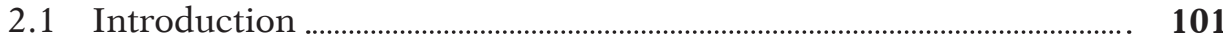

2.2 Definition of Carbon Economics ................................................................... 107

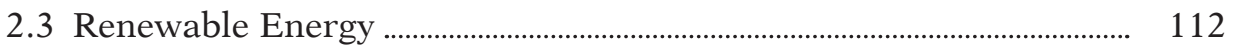

2.4 Environmental impact associated with the production and extraction of coal ................................................................................................................. 117

2.5 Carbon footprint .............................................................................................. 120

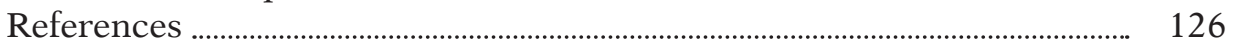

Chapter 3. Waste Management in Marinas ......................................................................... 129

3.1 Introduction ................................................................................................... 129

3.2 Regulatory Development ......................................................................................... 135

3.3 Characterization of Waste ................................................................................. 138

3.4 Management of Waste (Collection, Treatment \& Final Disposal) .... 146

3.5 Best Management Practices for Marinas ........................................................... 156

Bibliographical References ........................................................................................... 163

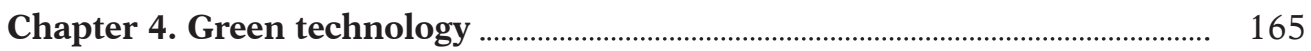

4.1 Photovoltaic systems for marinas and yachts ............................................. 166 
4.2 Small scale wind turbines ................................................................................... 200

4.2 References and on-line tools ............................................................................ 229

4.3 Appendix ....................................................................................................... 230

Chapter 5. Leisure sports marina management and logistics ............................ $\quad 235$

5.1 Introduction ......................................................................................... 235

5.2 Marina planning ..................................................................................................... 241

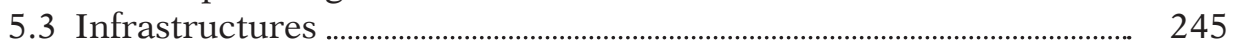

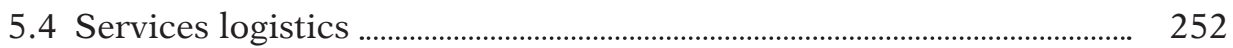

References .................................................................................................................... 256

Authors' profile ……..................................................................................................... 259 


\section{Executive summary}

Maritime transport emits around 1000 million tonnes of $\mathrm{CO} 2$ annually and is responsible for about $2.5 \%$ of global greenhouse gas emissions (3rd IMO GHG study). Shipping emissions are predicted to increase between $50 \%$ and $250 \%$ by 2050 - depending on future economic and energy developments. For nautical boats the "end of use" (in Europe 80,000 boats, reach their 'end of use's each year) is one of the main challenges for the industry which poses a threat to the environment and a recycling challenge.

Staff qualifications, the inability to attract young workers remain one of the crucial points in Europe. To boost the recruitment of highly prepared staff requires initiatives addressing learning to make the Environmental management and security related sectors attractive and to transform both the academic knowledge and high-level basic and transversal competences to be useful and applicable. This book seek to offer an adaptedcurriculum to equip the young generation with the specific, basic and transversal competences currently re-quired in the planning, climate change mitigation and vested industries. Book has been designed with the aim to support the development and the implemen-tation of an innovative practice, a new training path for the carbon neutral management of sport marinas.

This initiative complies with one of the principal aims of the Erasmus + program: Promoting synergies and cross fertilisation throughout the different fields of education, training and youth, removing artificial boundaries between the various actions and projects formats, fostering new ideas, such as a sec-toral multi campus, promoting cross border cooperation by attracting new ac-tors from the world of work to collaborate with universities and VET, but above all, with the target of stimulating new forms of cooperation 



\title{
Chapter 1 \\ Climate change impacts and adaptation. Technology, process and maintenance
}

\author{
INDRACHAPA BANDARA \& FLORIN IORAS
}

SUMARY: 1.1 Climate Change Impacts. 1.1.1 Climate change concept. 1.1.2 Factors for climate change. 1.1.3 Evidence of climate change.-1.2 Climate Change in Coastal Areas. 1.2.1 Socio-economic Impacts of SLR 1.2.2 Summary.-1.3 Adaptation Technologies and Practices. 1.3.1 Protection Approaches. 1.3.1.1 Beach Nourishment 1.3.1.2 Artificial Sand Dunes and Dune Rehabilitation. 1.3.1.3 Seawalls. 1.3.1.4 Sea Dikes. 1.3.1.5 Storm Surge Barriers and Closure Dams. 1.3.1.6 Land Claim.-1.4 Accommodation Approaches. 1.4.1 Flood-Proofing. 1.4.2 Wetland Restoration.-1.5 Prioritisation of Technologies and Practices.-1.6 Climate change mitigation. 1.6.1 Greenhouse gas concentrations and stabilization. 1.6.2 Methods and means. 1.6.3 Nuclear power. 1.6.4 Carbon intensity of fossil fuels. 1.6.5 Carbon capture and storage. 1.6.6 Energy efficiency and conservation. 1.6.7 Transport. 1.6.8 Urban planning. 1.6.9 Building design. 1.6.10 Eliminating waste methane. 1.6.11 Negative carbon dioxide emissions. 1.6.12 Geoengineering. 1.6.13 Societal controls. 1.6.14 Population. 1.6.15 Governmental action. 1.6.15.1 Subsidies. 1.6.15.2 Carbon emissions trading. 1.6.15.3 Emissions tax. 1.6.15.4 Implementation. References

\subsection{Climate Change Impacts}

\subsubsection{Climate change concept}

The climate of Earth is determined by the energy received from the sun and by the energy lost to space (on the broadest scale). This energy is distributed around the Earth by winds, ocean currents and other processes. Scientists generally define the five components of earth's climate system including atmosphere, hydrosphere, cryosphere, lithosphere and biosphere. The ocean is a fundamental part of the climate system, some changes in it occurring at longer timescales than in the atmosphere, massing hundreds of times more and having very high thermal inertia. Climate has been always dynamic by its nature and an assumption of "stabile climate" has never been valid for the past and will be probably wrong for the future also. Climate as phenomenon should be seen in large temporal and spatial scale and as variations and variability in smaller scale. 
Scientists work actively with past and future climate by using different methods and theoretical models. There have been developed methods for the climate of more or less distant past: borehole temperature profiles, ice cores, floral and faunal records, glacial and periglacial processes, stable isotope and other sediment analyses, sea level records etc. More recent data are provided by the instrumental record for the last centuries. Different models are used in theoretical approaches to match past climate data, make future predictions and to understand causes and effects of climate. Past and recent impacts are mainly assessed on observations. Models could only help in attributing them partly to climate change. On the contrary, expected impacts are mainly based on several kinds of models: Global Circulation (climatic) Models on a worldwide scale; regional climatic models that realize a downscaling of the previous models in order to take into account local factors influencing local climate; vegetation models that represent vegetation behaviour, including forest impacts in climate evolution; other models according to the objectives and the needs, concerning for example fauna. Moreover, all these models depend on expected atmospheric characteristics (different gas concentrations) and on climate parameters (temperature, precipitation...) that come from a given socioeconomic scenario for the future.

Climate change can be defined as a significant and lasting change in the statistical distribution of weather patterns over certain periods ranging from decades to millions of years. It may be a change in average weather conditions or in the distribution of extreme weather events. Climate change is caused by internal and external factors that include oceanic processes, patterns of solar radiation received by Earth, volcanic eruptions, plate tectonics and human-caused alterations of the nature. The most general definition of climate change is a change in the statistical properties of the climate system when considered over long periods of time, regardless of cause. Accordingly, fluctuations over periods shorter than a few decades do not represent climate change.

The general term "climate change" is often used to refer specifically to human-caused climate change. In this sense, this term is synonym for anthropogenic global warming, especially in the context of environmental policy. Within scientific community, global warming refers just only to increase of Earth's surface temperature.

\subsubsection{Factors for climate change}

Factors that design climate processes are called climate "forcing mechanisms", e.g. variations in solar radiation, variations in the Earth's orbit, mountain-building and continental drift, clouds and changes in greenhouse gas concentrations. There are a lot of factors that can either amplify or diminish the initial forcing. Oceans and glaciers respond slowly as well as some other parts of climate system respond more quickly in reaction to climate forcing.

Forcing mechanisms can be either "internal" or "external". Internal forcing mechanisms are natural processes within the climate system itself. External for- 
cing mechanisms can be natural or anthropogenic. The response of the climate system might be fast (e.g., a sudden cooling due to airborne volcanic ash reflecting sunlight), slow (e.g. thermal expansion of warming ocean water), or a combination (e.g., sudden loss of albedo in the arctic ocean as sea ice melts, followed by more gradual thermal expansion of the water). Therefore, the climate system can respond abruptly, but the full response to forcing mechanisms might not be fully developed for centuries or even longer.

Natural changes in the components of Earth's climate system and their interactions are the cause of internal climate variability, or internal forcings. Shortterm fluctuations (years to a few decades) represent climate variability rather than climate change. On longer time scales, alterations to ocean processes such as thermohaline circulation play a key role in redistributing heat by carrying out a very slow and extremely deep movement of water, and the long-term redistribution of heat in the world's oceans.

Slight variations in Earth's orbit lead to changes in the seasonal distribution of sunlight reaching the Earth's surface and how it is distributed across the globe. There is very little change to the area-averaged annually averaged sunshine; but there can be strong changes in the geographical and seasonal distribution. The three types of orbital variations are variations in Earth's eccentricity, changes in the tilt angle of Earth's axis of rotation, and precession of Earth's axis. Combined together, these produce Milankovitch cycles which have a large impact on climate and are notable for their correlation to glacial and interglacial periods, their correlation with the advance and retreat of the Sahara, and for their appearance in the stratigraphic record.

The Sun is the predominant source for energy input to the Earth. Both longand short-term variations in solar intensity are known to affect global climate. Three to four billion years ago the sun emitted only $70 \%$ as much power as it does today. If the atmospheric composition had been the same as today, liquid water should not have existed on Earth. However, there is evidence for the presence of water on the early Earth, in the Hadean and Archean eons, leading to what is known as the faint young Sun paradox. Hypothesized solutions to this paradox include a vastly different atmosphere, with much higher concentrations of greenhouse gases than currently exist. Over the following approximately 4 billion years, the energy output of the sun increased and atmospheric composition changed. The Great Oxygenation Event - oxygenation of the atmosphere around 2.4 billion years ago - was the most notable alteration.

Solar output also varies on shorter time scales, including the 11-year solar cycle and longer-term modulations. Solar intensity variations are considered to have been influential in triggering the Little Ice Age, and some of the warming observed from 1900 to 1950 . The cyclical nature of the sun's energy output is not yet fully understood; it differs from the very slow change that is happening within the sun as it ages and evolves. Research indicates that solar variability has had effects including the Maunder minimum from 1645 to 1715 A.D., part of the Little Ice Age from 1550 to 1850 A.D. which was marked by relative cooling and greater glacier extent than the centuries before and afterward. 
Volcanic eruptions release gases and particulates into the atmosphere. Eruptions large enough to affect climate occur on average several times per century, and cause cooling (by partially blocking the transmission of solar radiation to the Earth's surface) for a period of a few years. The eruption of Mount Pinatubo in 1991, the second largest terrestrial eruption of the 20th century (after the 1912 eruption of Novarupta) affected the climate substantially. Global temperatures decreased by about $0.5^{\circ} \mathrm{C}\left(0.9^{\circ} \mathrm{F}\right)$. The eruption of Mount Tambora in 1815 caused the Year Without a Summer. Much larger eruptions, known as large igneous provinces, occur only a few times every hundred million years, but may cause global warming and mass extinctions.

Volcanoes are also part of the extended carbon cycle. Over very long (geological) time periods, they release carbon dioxide from the Earth's crust and mantle, counteracting the uptake by sedimentary rocks and other geological carbon dioxide sinks. The US Geological Survey estimates are that volcanic emissions are at a much lower level than the effects of current human activities, which generate 100-300 times the amount of carbon dioxide emitted by volcanoes. A review of published studies indicates that annual volcanic emissions of carbon dioxide, including amounts released from mid-ocean ridges, volcanic arcs, and hot spot volcanoes, are only the equivalent of 3 to 5 days of human caused output. The annual amount put out by human activities may be greater than the amount released by super-eruptions, the most recent of which was the Toba eruption in Indonesia 74,000 years ago.Over the course of millions of years, the motion of tectonic plates reconfigures global land and ocean areas and generates topography. This can affect both global and local patterns of climate and atmosphere-ocean circulation.

The position of the continents determines the geometry of the oceans and therefore influences patterns of ocean circulation. The locations of the seas are important in controlling the transfer of heat and moisture across the globe, and therefore, in determining global climate. A recent example of tectonic control on ocean circulation is the formation of the Isthmus of Panama about 5 million years ago, which shut off direct mixing between the Atlantic and Pacific Oceans. This strongly affected the ocean dynamics of what is now the Gulf Stream and may have led to Northern Hemisphere ice cover.

The size of continents is also important. Because of the stabilizing effect of the oceans on temperature, yearly temperature variations are generally lower in coastal areas than they are inland. A larger continent will therefore have more area in which climate is strongly seasonal than will several smaller continents or islands.

In the context of climate variation, anthropogenic factors are human activities which affect the climate. Of most concern in these anthropogenic factors is the increase in $\mathrm{CO} 2$ levels due to emissions from fossil fuel combustion, followed by aerosols (particulate matter in the atmosphere) and cement manufacture. Other factors, including land use, ozone depletion, animal agriculture and deforestation, are also of concern in the roles they play - both separately and in conjunction with other factors - in affecting climate, microclimate, and measures of climate variables. 

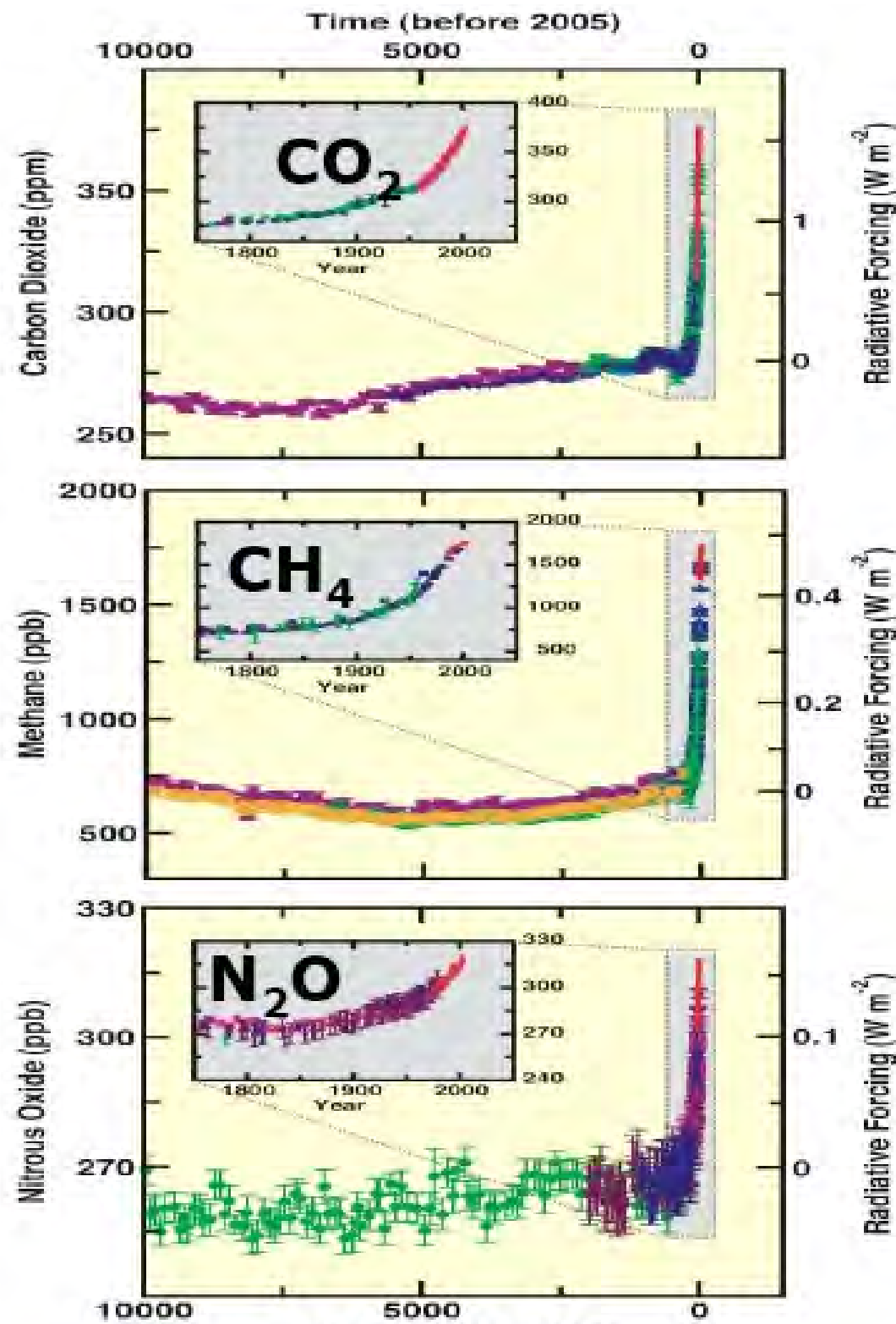

Figure 1.1. Greenhouse gases in the atmosphere (IPCC, 2007; Fischlin, 2007). 


\section{Anthropogenic Climatic Change?}

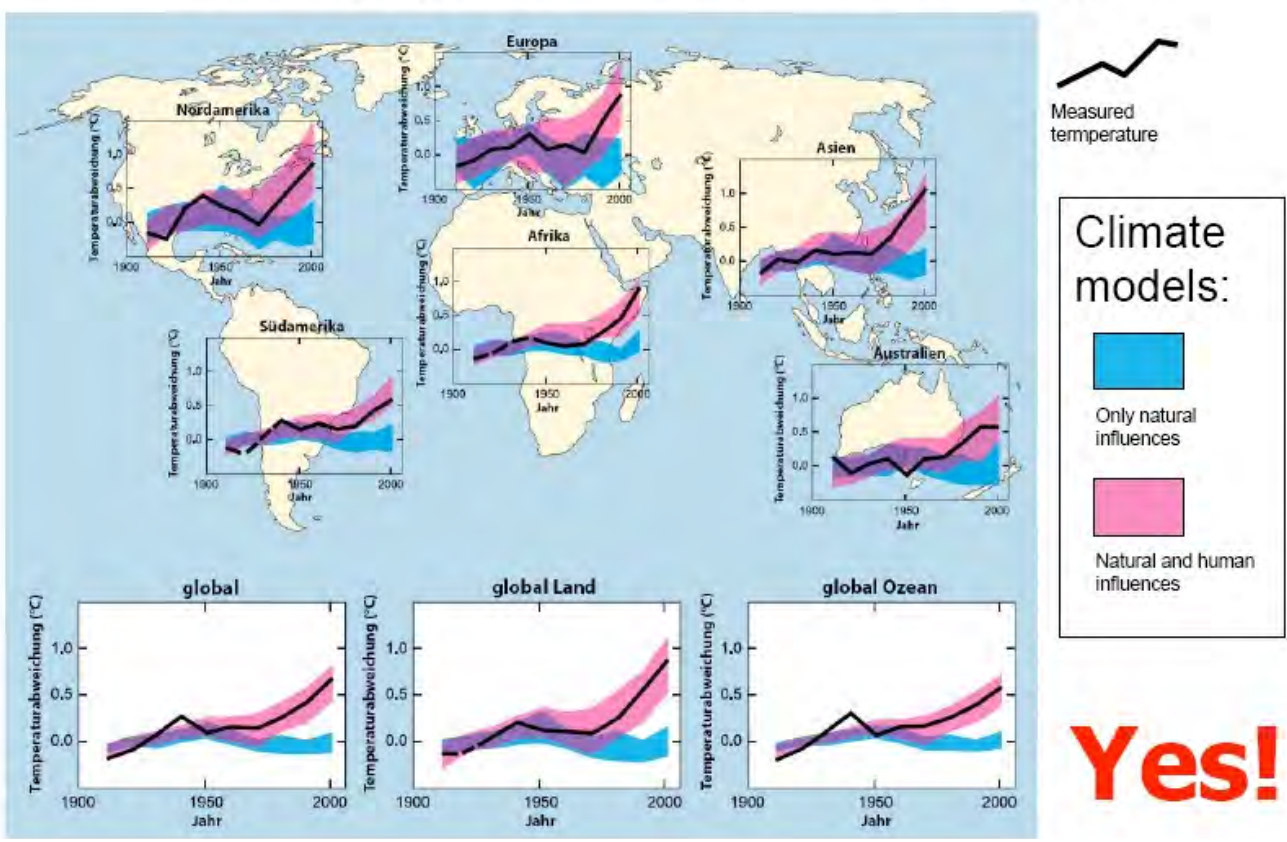

Figure 1.2. Measured and modelled temperature change from long-term average (Fischlin, 2007).

\subsubsection{Evidence of climate change}

Observed impacts are the basis for climate change problem identification and understanding. They allow doing simulations in order to predict expected impacts. Climate and environment monitoring is the best way to detect and study impacts; its improvement is thus a real challenge in order to better identify, understand and predict climate change consequences. Some impacts appear progressively according to trends and can be taken into account as they go along. But many consequences result from extreme events (such as storms, floods, droughts etc) thus crisis management has to be implemented when the event has just occurred.

Evidence for climatic change is taken from a variety of sources that can be used to reconstruct past climates. Reasonably complete global records of surface temperature are available beginning from the mid-late 19th century. For earlier periods, most of the evidence is indirect - climatic changes are inferred from changes in proxies, indicators that reflect climate, such as vegetation, ice cores, dendrochronology, sea level change, and glacial geology.

The instrumental temperature record from surface stations was supplemented by radiosonde balloons, extensive atmospheric monitoring by the mid-20th century, and, from the 1970s on, with global satellite data as well. The $18 \mathrm{O} / 16 \mathrm{O}$ ratio 
in calcite and ice core samples used to deduce ocean temperature in the distant past is an example of a temperature proxy method, as are other climate metrics noted in subsequent categories.

The projected effects for the environment and for human life are numerous and varied. The main effect is an increasing global average temperature. This causes a variety of secondary effects, namely, changes in patterns of precipitation, rising sea levels, altered patterns of agriculture, increased extreme weather events, the expansion of the range of tropical diseases, the opening of new trade routes.

Potential effects include sea level rise of 110 to $770 \mathrm{~mm}$ between 1990 and 2100 , impacts to agriculture, possible slowing of the thermohaline circulation, reductions in the ozone layer, increased intensity and frequency of extreme weather events, acidification of ocean $\mathrm{pH}$ and the spread of different diseases such as malaria and dengue fever.

A summary of probable effects and recent understanding can be found in the report made for the IPCC Third Assessment Report by Working Group II. The 2007 contribution of Working Group II detailing the impacts of global warming for the IPCC Fourth Assessment Report has been summarized for policymakers.

Climate change in the recent past may be detected by corresponding changes in settlement and agricultural patterns. Archaeological evidence, oral history and historical documents can offer insights into past changes in the climate. Climate change effects have been linked to the collapse of various civilizations.

Glaciers are considered among the most sensitive indicators of climate change. Their size is determined by a mass balance between snow input and melt output. As temperatures warm, glaciers retreat unless snow precipitation increases to make up for the additional melt; the converse is also true.

Figure 1.3. United Nations Intergovernmental Panel on Climate Change $4^{\text {th }}$ assessment report 2007.

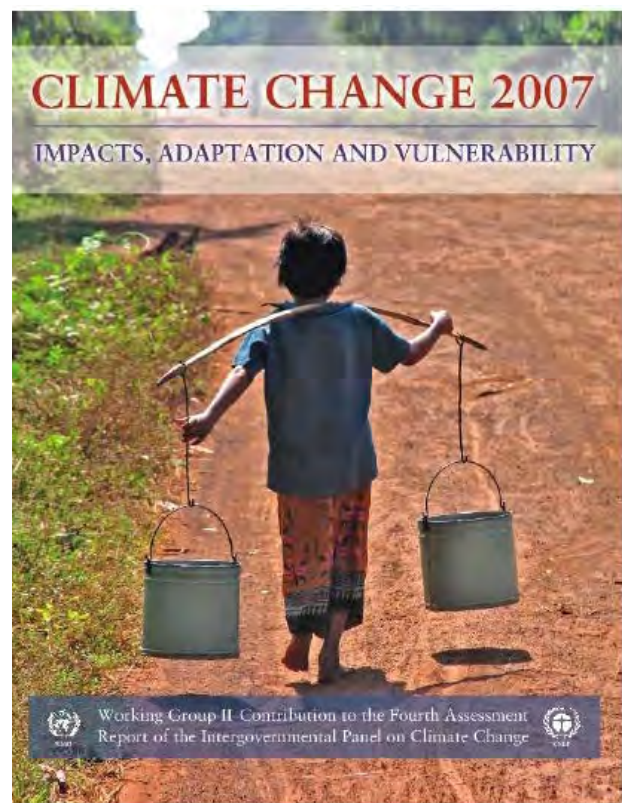


Glaciers grow and shrink due both to natural variability and external forcings. Variability in temperature, precipitation and hydrology can strongly determine the evolution of a glacier in a particular season. Therefore, one must average over a decadal or longer time-scale and/or over a many individual glaciers to smooth out the local short-term variability and obtain a glacier history that is related to climate.

A world glacier inventory has been compiled since the 1970s, initially based mainly on aerial photographs and maps but now relying more on satellites. This compilation tracks more than 100,000 glaciers covering a total area of approximately $240,000 \mathrm{~km}^{2}$, and preliminary estimates indicate that the remaining ice cover is around 445,000 $\mathrm{km}^{2}$. The World Glacier Monitoring Service collects data annually on glacier retreat and glacier mass balance From this data, glaciers worldwide have been found to be shrinking significantly, with strong glacier retreats in the 1940s, stable or growing conditions during the 1920s and 1970s and again retreating from the mid 1980 s to present.

The most significant climate processes since the middle to late Pliocene (approximately 3 million years ago) are the glacial and interglacial cycles. The present interglacial period (the Holocene) has lasted about 11,700 years. Shaped by orbital variations, responses such as the rise and fall of continental ice sheets and significant sea-level changes helped create the climate. Other changes, including Heinrich events, Dansgaard-Oeschger events and the Younger Dryas, however, illustrate how glacial variations may also influence climate without the orbital forcing.

Glaciers leave behind moraines that contain a wealth of material-including organic matter, quartz, and potassium that may be dated-recording the periods in which a glacier advanced and retreated. Similarly, by tephrochronological techniques, the lack of glacier cover can be identified by the presence of soil or volcanic tephra horizons whose date of deposit may also be ascertained.

The decline in Arctic sea ice, both in extent and thickness, over the last several decades is further evidence for rapid climate change. Sea ice is frozen seawater that floats on the ocean surface. It covers millions of square miles in the polar regions, varying with the seasons. In the Arctic, some sea ice remains year after year, whereas almost all Southern Ocean or Antarctic sea ice melts away and reforms annually. Satellite observations show that Arctic sea ice is now declining at a rate of 11.5 percent per decade, relative to the 1979 to 2000 average.

A change in the type, distribution and coverage of vegetation may occur given a change in the climate. Some changes in climate may result in increased precipitation and warmth, resulting in improved plant growth and the subsequent sequestration of airborne CO2. A gradual increase in warmth in a region will lead to earlier flowering and fruiting times, driving a change in the timing of life cycles of dependent organisms. Conversely, cold will cause plant bio-cycles to lag. Larger, faster or more radical changes, however, may result in vegetation stress, rapid plant loss and desertification in certain circumstances. An example of this occurred during the Carboniferous Rainforest Collapse (CRC), an extinction event 300 million years ago. At this time vast rainforests covered the equatorial region of Europe and America. Climate change devastated these tropical rainforests, 
abruptly fragmenting the habitat into isolated 'islands' and causing the extinction of many plant and animal species.

Satellite data available in recent decades indicates that global terrestrial net primary production increased by 6\% from 1982 to 1999 , with the largest portion of that increase in tropical ecosystems, then decreased by $1 \%$ from 2000 to 2009 .

Palynology is the study of contemporary and fossil palynomorphs, including pollen analysis. Palynology is used to infer the geographical distribution of plant species, which vary under different climate conditions. Different groups of plants have pollen with distinctive shapes and surface textures, and since the outer surface of pollen is composed of a very resilient material, they resist decay. Changes in the type of pollen found in different layers of sediment in lakes, bogs, or river deltas indicate changes in plant communities. These changes are often a sign of a changing climate. As an example, palynological studies have been used to track changing vegetation patterns throughout the Quaternary glaciations and especially since the last glacial maximum.

Past precipitation can be estimated in the modern era with the global network of precipitation gauges. Surface coverage over oceans and remote areas is relatively sparse, but, reducing reliance on interpolation, satellite data has been available since the 1970s. Quantification of climatological variation of precipitation in prior centuries and epochs is less complete but approximated using proxies such as marine sediments, ice cores, cave stalagmites, and tree rings.

Climatological temperatures substantially affect precipitation. For instance, during the Last Glacial Maximum of 18,000 years ago, thermal-driven evaporation from the oceans onto continental landmasses was low, causing large areas of extreme desert, including polar deserts (cold but with low rates of precipitation). In contrast, the world's climate was wetter than today near the start of the warm Atlantic Period of 8000 years ago.

Estimated global land precipitation increased by approximately $2 \%$ over the course of the 20th century, though the calculated trend varies if different time endpoints are chosen, complicated by ENSO and other oscillations, including greater global land precipitation in the 1950s and 1970s than the later 1980s and 1990s despite the positive trend over the century overall. Similar slight overall increase in global river runoff and in average soil moisture has been perceived.

Dendroclimatology is the analysis of tree ring growth patterns to determine past climate variations. Wide and thick rings indicate a fertile, well-watered growing period, whilst thin, narrow rings indicate a time of lower rainfall and less-than-ideal growing conditions.

Analysis of ice in a core drilled from an ice sheet such as the Antarctic ice sheet, can be used to show a link between temperature and global sea level variations. The air trapped in bubbles in the ice can also reveal the $\mathrm{CO} 2$ variations of the atmosphere from the distant past, well before modern environmental influences. The study of these ice cores has been a significant indicator of the changes in $\mathrm{CO} 2$ over many millennia, and continues to provide valuable information about the differences between ancient and modern atmospheric conditions. 


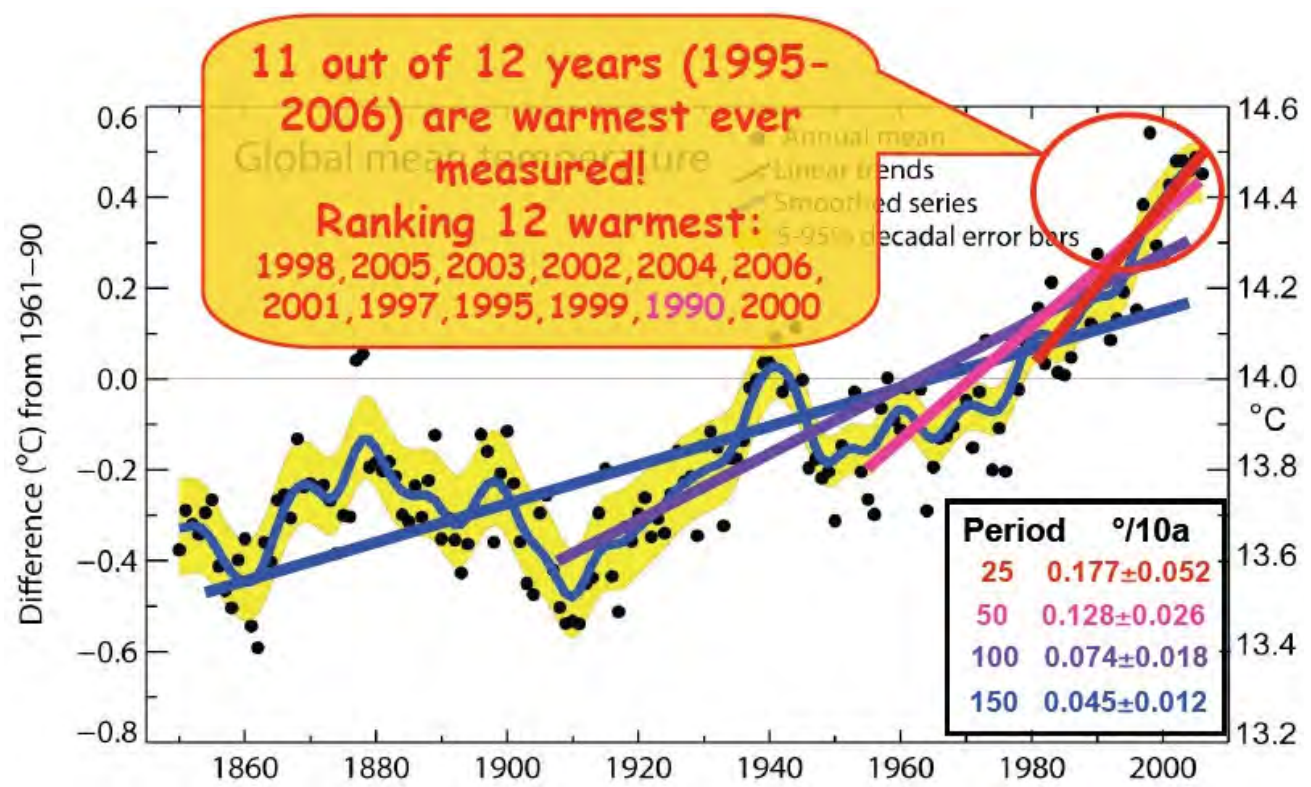

Figure 1.4. Global temperatures measured as difference from average (IPCC, 2007; Fischlin, 2007)

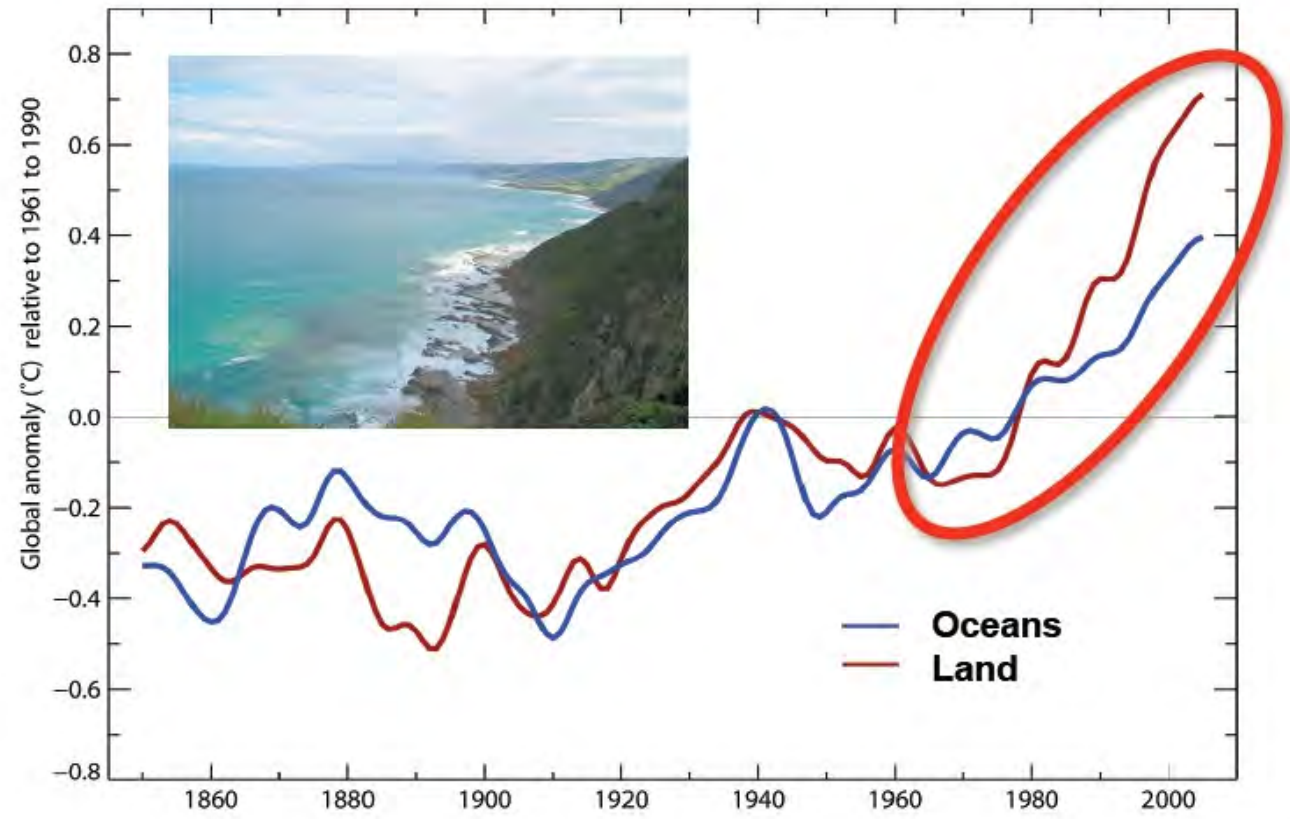

Figure 1.5. Global land and ocean temperatures measured as difference from average (IPCC, 2007; Fischlin, 2007 
Remains of beetles are common in freshwater and land sediments. Different species of beetles tend to be found under different climatic conditions. Given the extensive lineage of beetles whose genetic makeup has not altered significantly over the millennia, knowledge of the present climatic range of the different species, and the age of the sediments in which remains are found, past climatic conditions may be inferred.

Similarly, the historical abundance of various fish species has been found to have a substantial relationship with observed climatic conditions. Changes in the primary productivity of autotrophs in the oceans can affect marine food webs.

Global sea level change for much of the last century has generally been estimated using tide gauge measurements collated over long periods of time to give a long-term average. More recently, altimeter measurements - in combination with accurately determined satellite orbits - have provided an improved measurement of global sea level change. To measure sea levels prior to instrumental measurements, scientists have dated coral reefs that grow near the surface of the ocean, coastal sediments, marine terraces, ooids in limestones, and nearshore archaeological remains. The predominant dating methods used are uranium series and radiocarbon, with cosmogenic radionuclides being sometimes used to date terraces that have experienced relative sea level fall.

\subsection{Climate Change in Coastal Areas}

Sea surface temperature (SST) is rising globally due to the absorption of extra heat energy from the Earth's surface. Global observations of the heat content of the oceans show significant annual and decimal variances in long-term increases.

Global Medium Sea Level (MSL) is rising. This is due to two factors: (1) the thermal expansion of seawater caused by the increase in SST; And (2) the application of water to the ocean by the melting of land ice. However, spatial variability is not uniform due to regional ocean variations, such as warming. Therefore, some regions will experience more SLR than the mean rise.

Global MSL is important and the main factor determining coastal impact is local or relative sea level 1. Unlike the global mean SLR, the RSLR is responsible for regional changes in sea level and delta (Savitsky et al., 2009) for vertical movements of land relative to ocean surface. RSLR raises mean and marginal sea levels.

Climate change can increase both the height of extreme waves and the intensity of storms. In particular, tropical storms may be more intense but less common.

Finally, the carbon content of the world's oceans appears to have increased. This is due to the absorption of carbon dioxide released into the atmosphere by the burning of fossil fuels. This has led to a drop in the $\mathrm{pH}$ of the surface ocean, which could continue into the future. 


\subsubsection{Physical Impacts of Climate Change on the Coastal Zone}

The potential impact of these physical changes in the coastal region is described by Nichols et al. (2007a). A range of effects is evident and are discussed below. While some impacts may apply to some coastal types, different coastal types will respond differently to the effects of climate change. So they have to be looked at separately. Climate change impacts apply to all beaches first and then to specific beaches.

\subsubsection{General Impacts}

The most common and practical model of this process is presented by Baron (1962) and is shown in Figure 1.6. The 'Bernie Rule' suggests that coastal depression has increased by 50 to 200 times relative sea level. Sediment is removed from the shoreline to maintain an equilibrium profile in front of the SLR. It is deposited on the shoreline, causing the nearest coastal zone to rise at an altitude similar to that of sea level rise. As sea level rises, the coastal profile is formed by shifting to the land and upland, removing sediments from the shore and depositing them in the adjacent coastal zone. Therefore, the volume of the eroded and deposited material is the same.

However, the Burney rule greatly simplifies coastal behavior, and in reality, processes other than profile alignment with the SLR will affect the shape and location of the coastal profile, so a full 2009).Strict coastal protection will prevent natural freshwater habitat migration with SLR

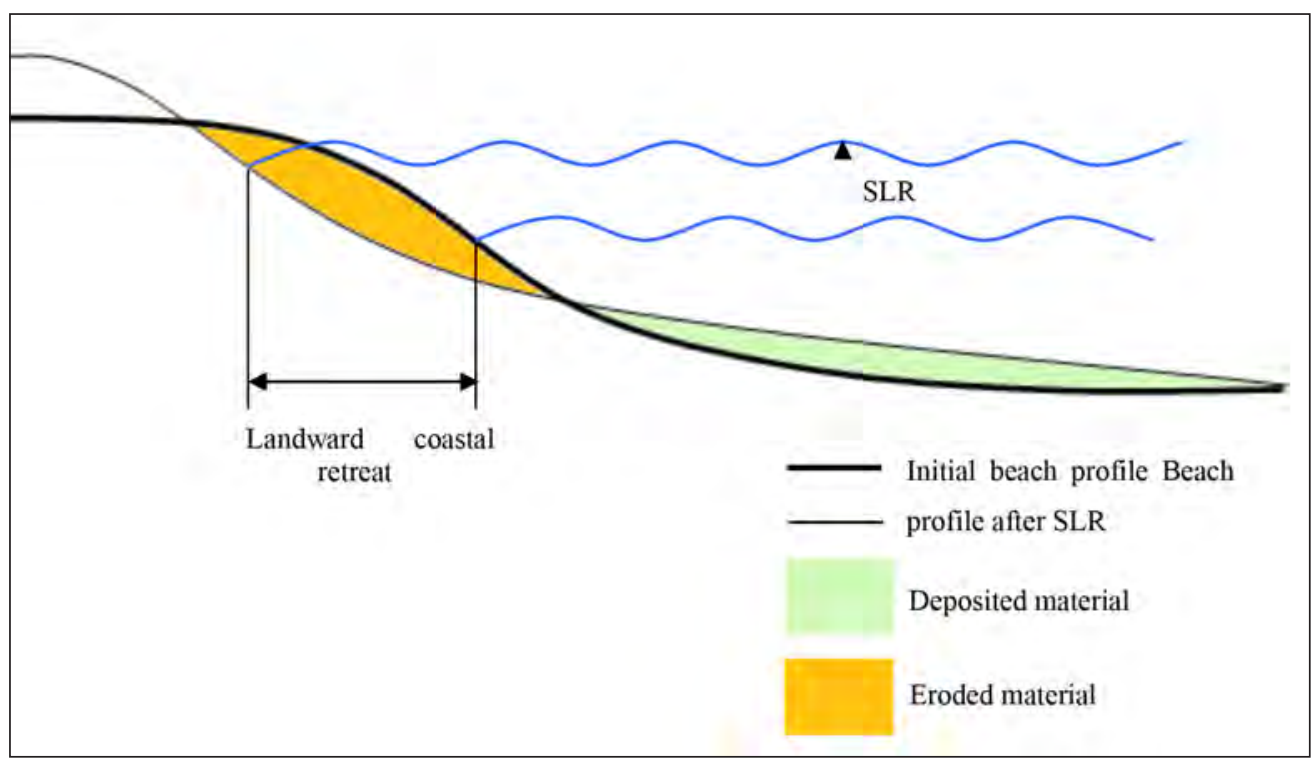

Figure 1.6: Simple model of land-coastal retreat under SLR (based on Burney rule).

Source: Adapted from French, 2001 
'Beach squeezing' is a broader consequence of coastal retreat that affects areas between the rising sea and high security. Coastal habitats are expected to migrate inland as sea levels rise. However, in the face of tight security, these habitats are unable to migrate to land and are effectively squeezed between the rising sea and the ever-increasing security. This causes the area in front of the defence to narrow significantly and can cause drastic reductions in the areal extent of saltmarshes and other habitats typically found in the intertidal zone. This phenomenon is shown in Figure 1.7.

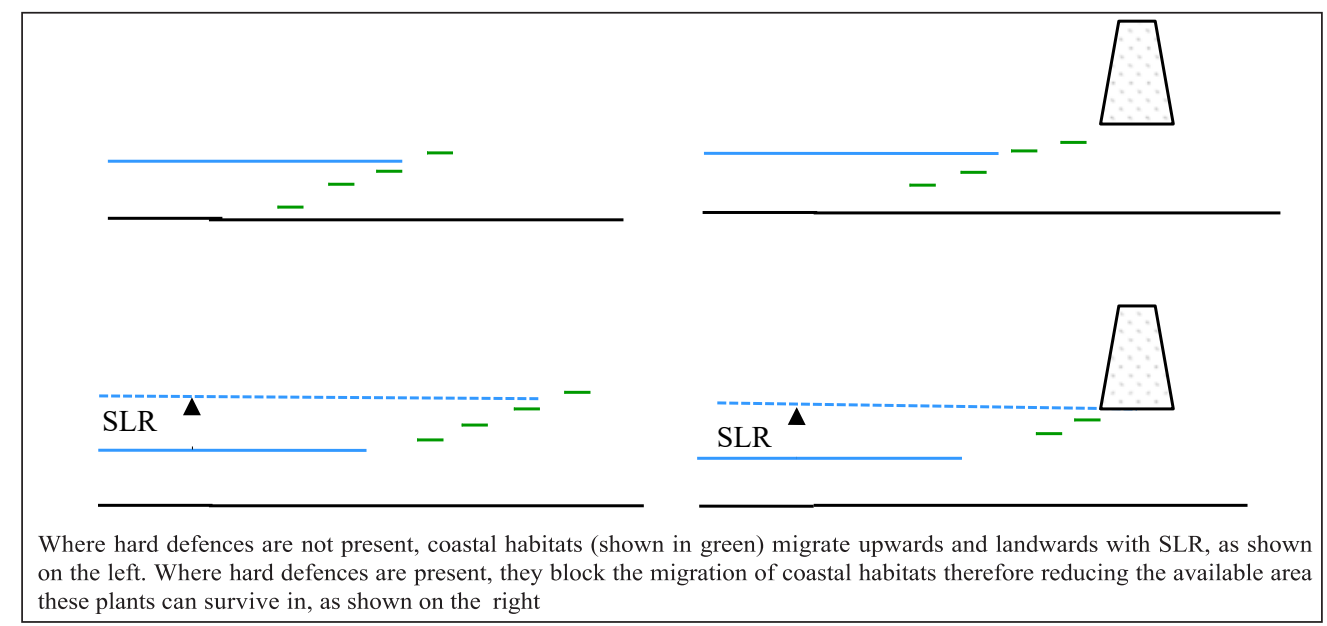

Figure 1.7: The process of coastal squeeze

Adverse effects on one part of the coastal system may erode or submerge other parts of the coast. For example, in many places, sandy barriers reduce wavelengths in island bays. Erosion, and especially the removal of barrier islands, can cause wavelengths to increase in neighboring bays. This then increases the rate of erosion along the coast.

The SLR will increase the likelihood and depth of flooding. This can be illustrated by using the The 'flood frequency probability curve' shown in Figure 1.8. Increased flood risk with high storm water levels potentially causing more damage, threats to drinking water supply and risk to life.

The frequent occurrence of extreme water levels will be exacerbated by the deterioration of natural coastal systems such as wetlands and mountains that currently serve as natural coastal defenses. Many coastal communities rely on these natural defenses in extreme cases. SLRs and the possibility of frequent storms increase the risk of flooding, even in protected areas

Areas with artificial coastal defenses are still vulnerable to extreme events when the water level exceeds the defenses or fails - this is called residual risk. This will happen more and more as the sea level rises. In addition, severe storms can damage existing coastal defenses and other infrastructure (Nichols et al., 2007a). Therefore, it is expected that the coastal flood situation will increase with the Sri Lanka Air Force if there is no adaptation to deal successfully with these changes.. 


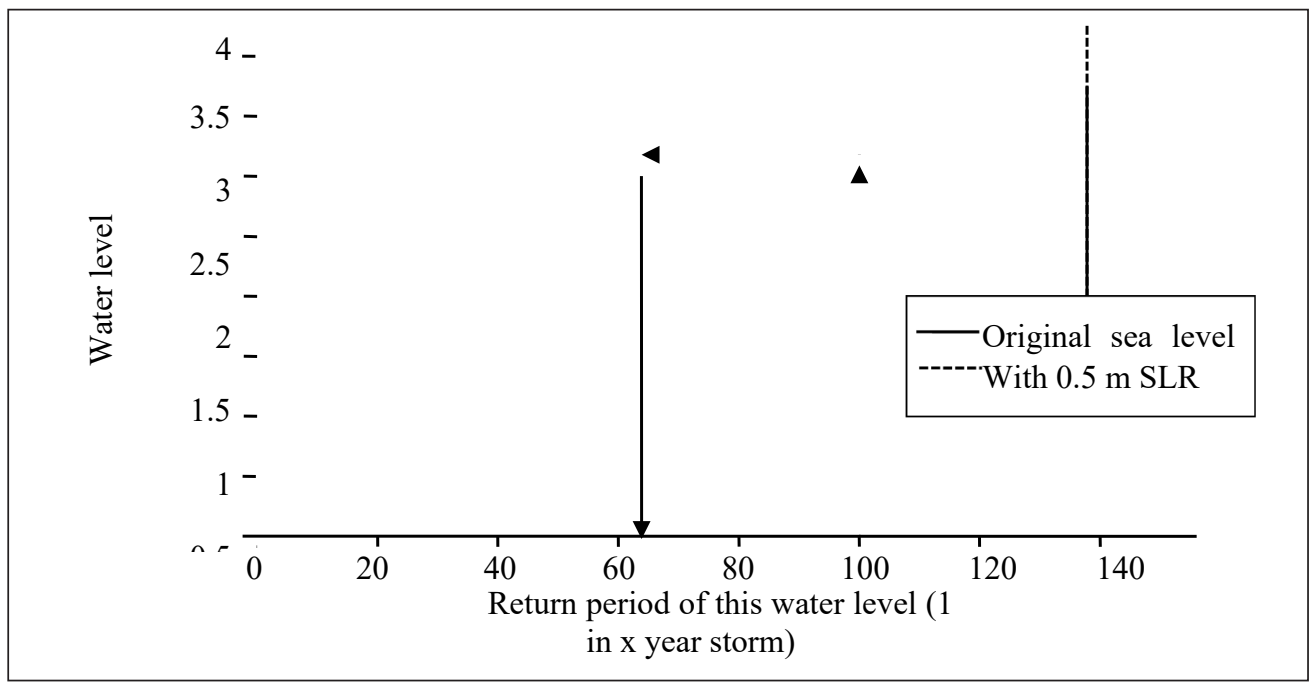

Figure 1.8: SLR raises extreme water levels and increases the probability of flooding without adaptation

Beaches, rocky beaches and Cliffed beaches are uneven, loose material such as sand, shingles or pebbles. They occur at the interface between land and sea. These landslides often occur in areas affected by wave activity. Rocky beaches range from rocky rocks such as granite and basalt to relatively mildly erosive material (Finkel, 2004). Loping Beach is made up of erosion processes or alternatively upliftment. Slopes occur in various forms and are eroded by definition. However, regardless of the episodic waterfall, the rate of retreat varies greatly as the gentle slopes recede by $1-2 \mathrm{~m}$ per year.

The effects of climate change and SLR beaches, rocky beaches and slopes are as follows. These effects are in addition to those affecting all coastal species. Slope regression will increase due to SLR and climatic factors. Depending on the material from which they are made, there is a different risk of slope erosion. It is relatively resistant to rock erosion and the gentle slopes will recede more rapidly in the future.

Increased rainfall and rising groundwater levels can also increase slope failure. The gentle slope can be episodic and can be very tiring.

Tourist preferences may change due to the indirect and indirect effects of climate change

Climate change can have a major impact on the coastal tourism industry, which is heavily dependent on the sun, sea and sand. For example, hot air and sea temperatures can make previously unattractive destinations more attractive to the tourism industry and make existing resorts 'too hot' for tourists. In addition, changes made by the SLR and its counter-coastal erosion adversely affect the value of an area for tourism. 
Large rivers form deltas, where large amounts of sediment flow into the sea. A delta is formed by the deposition of sediment from the river and the subsequent remodeling of coastal processes such as waves, currents and tides. The Delta is home to an estimated 500 million people worldwide.

In addition to sinking, there are human impacts on the Delta's ability to cope with climate change. Sediment starvation due to dams, alteration of tidal flow patterns, changes in flood and flood control and changes in surface flooding. Decreased sedimentation supply increases the risk of erosion, permanent flooding, and frequent flooding in these areas.Today, deltaic wetland losses are largely caused by human development, for example, by direct zoo destruction and rapid changes in the natural delta environment. As well as causing direct destruction, such changes will reduce the Delta's adaptability to adapt climate change.

In addition to the direct wetland damage caused by human development, the SLR and the increase in tropical storm intensity are exacerbating the current wetland loss rate. The SLR Deltic poses a particularly serious threat to the environment, along with the adverse interactions of other climates and human pressures.

\subsubsection{Estuaries and Lagoons}

An estuary is a river bank that opens into the sea at the end of a tidal wave. They are usually subjected to tidal movements and a mixture of fresh and salt water (Bird, 2005). These environments are generally protected from wind and wave activity. However, coastal lagoons are shallow, coastal, salt water, sandbanks, compressed or less frequently separated from the sea by rocks (JNCC, 2010).

SLR will trigger inland migration of coastal habitats and inundation of lowlying areas

SLR usually results in high water levels and salinity in estuary systems. This means that existing plant and animal communities will be displaced by freshwater. If these communities are not fast enough to move their natural systems without interfering with their migration, sea levels will continue to rise.

Coastal landing speed with SLR and the level of permanent land subsidence of coastal land depend on both the SLR rate and the slope of the coastal land. As shown in Figure 1.9, shallow coastal slopes cause further retreat along the coast. Since estuaries and lagoons generally have shallow shores, coastal landings are important only for relatively small sea level rise.

\section{Climate change may alter coastal water quality}

Water temperature and the concentration of dissolved carbon dioxide caused by climate change can encourage harmful algae breeding. Changes in freshwater inputs will further affect water quality: increasing promotes flushing and vice versa. 


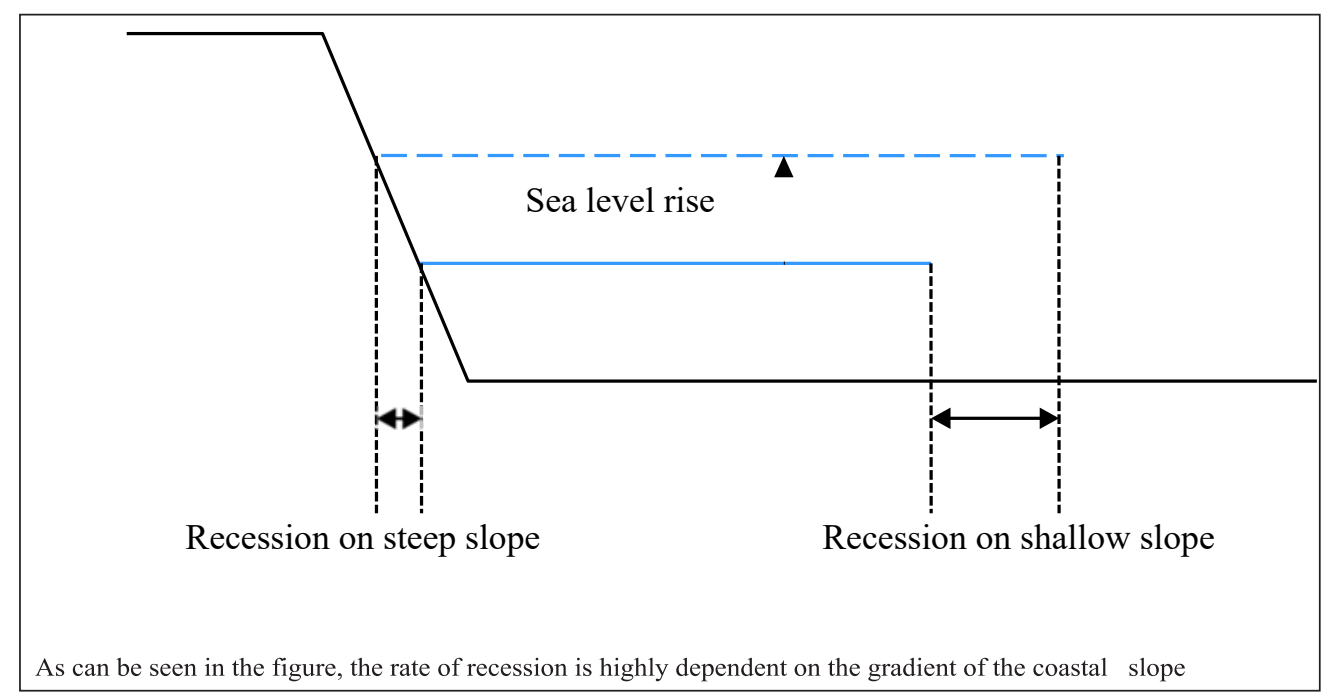

Figure 1.9: Shoreline recession caused by SLR

A projected increase in the intensity of tropical cyclones and coastal storms is associated with coastal sedimentation, organic matter inputs important for plant and animal growth, plant and animal populations, and salinity and oxygen levels.

\subsubsection{Coral Reefs}

The coral reef is almost entirely covered with tropical cancers and dragons (Shepherd, 2005). Coral reefs are a collection of hard, rock-like marine life. The reef component of the coral is limited by the requirements of the coral. This includes clear freshwater with a temperature between 15 and $30 \mathrm{oC}$ and is fresh sedimentary, very fresh or highly salty (Shepherd, 2005). Waves act as reefs, providing effective wave energy dissipation (France, 2001).

Rising sea surface temperatures increase coral bleaching and mortality rates Corals have a range of living temperatures. As the ambient temperature rises, the coral becomes stressed and can 'bleach'. Coral bleaching is the loss of living colorful algae of coral organisms. This is problematic because corals rely on these algae to develop nutrition and energy and eventually survive. Coral bleaching occurs naturally to some extent due to seasonal fluctuations in water temperature. However, prolonged warming due to global warming could threaten the longterm survival of corals.

Although some organisms have the ability to adapt to high temperatures, there is evidence that this is limited to corals. As a result, an increase in SST may lead to more frequent and large-scale bleaching and coral death in the future.

Ocean acidification will affect coral growth rates 
As the concentration of carbon dioxide increases, the $\mathrm{pH}$ of seawater decreases, reducing the rate at which marine life can form rocks by producing hard, outer skeletons. With the frequency of coral bleaching, the reef has the ability to disperse, increasing the wave energy across the reef flats and increasing the potential for coastal erosion as a result.

The intensification of tropical storms caused by climate change can have devastating effects on inhabitants of rocks, other parts of the marine ecosystem and lowland islands. More intense tropical storms can break coral reefs, and if the storm is strong enough, it can destroy most of the corals on a reef. Considering all the above effects, coral reefs are under severe threat due to climate change and other tensions.

\subsubsection{Saltmarsh, mangroves and seagrass}

Saltmarsh, mangroves and seabed are intermediate and shallow subtropical habitats that provide shelter for moderate 'wave' energy environments.

Saltmarsh is a salty tidal wave covered with grass-like vegetation. They most often occur in temperate and high latitude estuaries and open beaches. They are protected from extreme wave activity by extreme inter-apartment and barrier complexes (Allen \& Pi, 1992).

Mangroves are woody trees or shrubs that grow naturally in tropical and subtropical beaches and in tributaries or estuaries.

Sea urchins are flowering, underwater plants that are abundant in the ocean or estuary. Most beaches are rooted in fine or sandy sediments in shallow water (Merlin, 2005).

Saltmarsh, mangroves and beaches perform important coastal functions, setting sediment traps, stabilizing erosion, wave energy and many fish, bird and insect habitats. However, these coastal wetlands are highly sensitive to climate change and SLR, so their location is closely related to sea level (Nichols et al., 2007a).

Freshwater and freshwater / salt water transitional wetlands will have a more significant impact

The SLR will increase the immersion time in salt marshes during the tidal cycle. Climate change can also cause changes in the number and severity of extreme coastal events. These effects will be most severe in wetlands located in freshwater and freshwater / saltwater transition areas.

Rapid SLR may submerge in salt marshes and mangroves

If the sediment supply is sufficient, the swamps and mangroves can move rapidly with the Sri Lanka Air Force. However, if the sediment retrieval capacity is insufficient, the sediment accumulation exceeds SLR. The response largely depends on the sediment budget. The threshold at which this occurs varies widely and largely depends on the changes caused by erosion and sedimentation. Interstate habitats in areas with high tidal ranges and high sediment inputs are at least at risk from SLR. 
Many beaches today appear to be shrinking due to human influence. Climate change is expected to accelerate changes in environmental conditions such as salinity, temperature, sea level, atmospheric carbon dioxide, storm activity, and ultraviolet radiation intensity in coastal waters. The survival of coastal wetlands depends on the availability of sediments and the possibility of land migration. In many wetlands, sediment is readily available and land migration is prohibited.

\subsubsection{Socio-economic Impacts of SLR}

SLR New or new causes of saltwater intrusion into surface water and coastal aquifers, saltwater infiltration into estuaries and coastal river systems, widespread coastal flooding, rising sea levels, increased tidal and storm landings, and acceleration. Coastal erosion (Nichols et al., 2007a). These consequences are expected to be extremely negative and particularly severe in the delta and small islands.

Climate change and climate variability are also expected to affect agriculture. Largely through declining soil and water quality (Nichols and Kline, 2005). It will also affect coastal forests and estuary forests and fisheries to some extent.

Increasing the concentration of carbon dioxide in the atmosphere will give an advantage to the plant growth rate, but increasing the temperature can shorten the growing cycle. The high frequency of extreme climatic events has a positive effect on crop yields.

\subsubsection{Summary}

The effects of climate change are many and varied, but from a human point of view the five most important effects of climate change in the coastal region are: (1) increased likelihood of coastal flooding and flooding; (2) coastal erosion; (3) rising water tables; (4) Leakage of salt water into surface and groundwater and (5) Biological effects (Clean et al., 2006).

A change in the coastal zone. Instead, the guidebook focuses on floods, inundation and erosion, which are the main impacts of the Sri Lanka Broadcasting Corporation, with adverse socio-economic impacts on climate change and adaptive technologies being well developed, and lessons learned in media such as this guide. Rising water tables, salt water invasion, and methods of dealing successfully with biological influences are less developed and are not discussed in this guide. Adaptive technologies to these influences require more work.

\subsection{Adaptation Technologies and Practices}

In this chapter, we present 13 adaptive technologies for coastal erosion and flood response. Under each technology, we describe (1) the technical advantages and disadvantages; (2) institutional and organizational needs; (3) cost and finan- 
cial requirements; (4) barriers and opportunities for implementation; And (5) a relevant case study. Further sources are provided in Appendix II.

It should be noted that an adaptive adaptation strategy may consist of adaptive technologies. Table 1.1 shows the complementary steps and the competing steps to assist in identifying possible portfolios. It seems that a wide range of combinations is possible.

Table 1.1 Complementary and competing adaptation technologies

\begin{tabular}{|c|c|c|c|c|c|c|c|c|c|c|c|}
\hline & 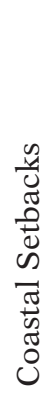 & 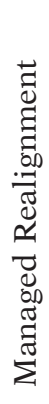 & 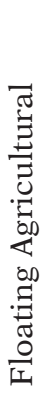 & 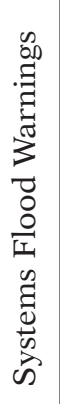 & 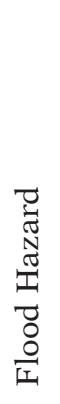 & 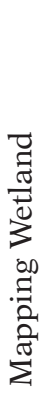 & 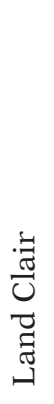 & 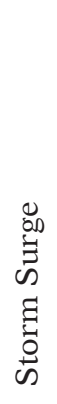 & 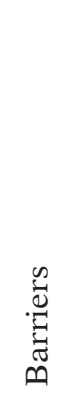 & 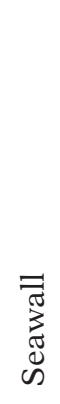 & 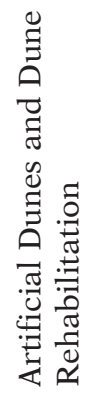 \\
\hline Beach Nourishment & & a & & & & $\mathrm{b}$ & & & & & \\
\hline $\begin{array}{l}\text { Artificial Dunes \& Dune } \\
\text { Rehabilitation }\end{array}$ & & a & & & & $\mathrm{b}$ & & & & & \\
\hline Seawalls & & a & & & & & c & & & & \\
\hline Sea Dikes & & a & & & & & c & & & & \\
\hline Storm Surge Barriers & & & & & & & & & & & \\
\hline Land Claim & & & & & & & & & & & \\
\hline Flood Proofing & & & & & & & & & & & \\
\hline Wetland restoration & & & & & & & & & & & \\
\hline Flood Hazard Mapping & & & & & & & & & \multicolumn{3}{|c|}{ Complementary } \\
\hline Flood Warnings & & & & & & & & & \multicolumn{3}{|c|}{ Compety } \\
\hline $\begin{array}{l}\text { Floating Agricultural } \\
\text { Systems }\end{array}$ & & & & & & & & & & & \\
\hline Managed Realignment & & & & & & & & & & & \\
\hline
\end{tabular}

a Complementary when these features are realigned landward of their present location. $\mathrm{b}$ Wetlands and sandy beaches are rarely coincident.

c When used to protect claimed land.

The level of experience and knowledge in using these 13 adaptive technologies varies around the world. To a large extent, the experience and knowledge of coastal 
adaptation in developed countries is more advanced. The current level of experience in adaptive technologies is summarized in Table 1.2 for developed and developing

Table 1.2 Current degree of experience in the application of adaptation technologies

\begin{tabular}{|c|c|c|c|c|c|c|c|}
\hline \multirow{2}{*}{ Technology } & \multicolumn{3}{|c|}{$\begin{array}{l}\text { Developed } \\
\text { country }\end{array}$} & \multicolumn{3}{|c|}{$\begin{array}{l}\text { Developing } \\
\text { country }\end{array}$} & \multirow{2}{*}{ Comments } \\
\hline & Low & Med & High & Low & Med & High & \\
\hline Beach nourishment & & & $\square$ & & $\square$ & & Rapid growth in application \\
\hline $\begin{array}{l}\text { Artificial dunes \& } \\
\text { dune rehabilitation }\end{array}$ & & & $\square$ & $\square$ & & & \\
\hline Seawalls & & & $\square$ & & & $\square$ & $\begin{array}{l}\text { Developing country approaches } \\
\text { are often ad-hoc }\end{array}$ \\
\hline Sea dikes & & & $\square$ & & & $\square$ & $\begin{array}{l}\text { East Asian countries have a } \\
\text { long legacy of dike construction }\end{array}$ \\
\hline Surge barriers & & $\square$ & & $\square$ & & & $\begin{array}{l}\text { A more specialised technology } \\
\text { which is likely to see more } \\
\text { widespread application }\end{array}$ \\
\hline Closure dams & & & $\square$ & & & $\square$ & \\
\hline Land claim & & & $\square$ & & & $\square$ & $\begin{array}{l}\text { Most common in areas of high } \\
\text { population density }\end{array}$ \\
\hline Flood-proofing & & $\square$ & & & $\square$ & & Growing application worldwide \\
\hline Wetland restoration & & & $\square$ & $\square$ & & & \\
\hline $\begin{array}{l}\text { Floating agricultural } \\
\text { systems }\end{array}$ & $\square$ & & & & & $\square$ & $\begin{array}{l}\text { Application only occurs in a few } \\
\text { delta environments (e.g. } \\
\text { Bangladesh) }\end{array}$ \\
\hline $\begin{array}{l}\text { Flood hazard } \\
\text { mapping }\end{array}$ & & & $\square$ & & & $\square$ & Rapid growth in application \\
\hline Flood warnings & & & $\square$ & & & $\square$ & Rapid growth in application \\
\hline Managed realignment & & & $\square$ & $\square$ & & & $\begin{array}{l}\text { Applied in areas of historic land } \\
\text { claim - mainly in NW Europe } \\
\text { and USA to date }\end{array}$ \\
\hline Coastal setbacks & & & $\square$ & & & 口 & Rapid growth in application \\
\hline
\end{tabular}

\subsubsection{Protection Approaches}

Coast Guard, in its broadest use, is intended to minimize or eliminate damage to the coast and backwaters caused by floods, waves and erosion using barriers to 
eliminate hydraulic effects (Krause, 2005). Society's desire to build infrastructure close to the coast and utilize the coast and its resources has generally led to a preference for a safer option (Cooper \& Harlow, 1998).

Safety includes protection against flooding, tidal surges, the impact of waves on infrastructure, coastal erosion, salt intrusion, and loss of natural resources. Steps are available in a variety of 'hard' and 'soft' structural solutions. They can be applied individually or in combination (IPCC CZMS, 1990) depending on the specific terms of the website. The following are strict and gentle safety measures.

\section{Hard Defences}

Strict security is the traditional approach to coastal security. Uses structures that provide a barrier between land and sea and resist the force of tidal waves and waves (France, 2001). Examples of high security include sea walls, seagulls, exposures, armor units, and breakwaters. Ically historically, they have been given strict protection because they are provided with tactical protection and are trusted by the protected population. Over time, however, these structures take advantage of the climate that protects them and have little to do with physical erosion. Instead, the problem immediately shifts from beach to beach (Pilarsik, $1990 \mathrm{~b}$ ) or adjacent coast (Nichols et al., 2007b). Therefore, the use of strict security should anticipate these issues and be prepared to respond to the consequences (e.g. Leaf et al., 1998; Defra, 2006).

Perhaps the main problem with tight security is that once they are built, they are installed during the beach location. While this is advantageous, at least initially, with regard to stopping coastal erosion, coastal location fixation is problematic because the coast is naturally dynamic and responds to factors such as sea level rise and wave climate.

Structures can be a barrier to recreational use on the beach and can be costly to build and maintain (USACE, 2002) These costs and benefits should be considered when considering applications of these adaptive technologies.

Raising awareness of the negative and negative side effects of hard structures on erosion and sedimentation patterns has led to increased recognition of the benefits of 'soft' protection and adaptive strategies for retreats and accommodation (Clean et al., 2006). Alternatively, strict security (sections 1.3.1 to 1.3.3) can be combined with soft defenses such as beach nutrition. Utilizing this approach, nutrition will maintain beach levels and tight security will continue to protect the coastline from extreme events.

\section{Soft Defences}

Adaptations to natural processes include strong protection against natural forces, such as wave energy and soft engineering techniques. Soft defenses are largely stimulated in response to the negative effects of hard defenses. They also represent a significant shift in approach to adopting a more holistic and proactive approach, from transition reactions to coastal hazards (Dean, 2002; Hanson et 
al., 2002; Williams \& Micallef, 2009). Examples of soft defence include beach nourishment (Section 1.3.1) and dune building (Section 1.3.2).

By taking gentle engineering steps we can avoid many of the negative consequences of strict security. This approach is especially appealing to beaches that are exposed to the sea. In addition, gentle protection helps maintain the natural landscape and habitat along the coast. There is also the potential to maximize the benefits of a scheme by working with natural processes, minimizing environmental impacts and creating environmental opportunities (Chadwick et al., 2004).

However, a key point to consider when taking soft engineering approaches is that these solutions require continuous and systematic monitoring, maintenance, and engineering; This requires the strong intervention of engineers, designers, architects and others (Edge et al., 2003). Therefore, these additional costs and feasibility requirements should be considered when selecting an option.

\section{Summary}

Extensive measures have been taken for soft protection, and both of these technologies will continue to be operational in the future. Strict protection is especially important to protect coastal urban areas from flooding. Sedimentary beaches with beaches are more prone to mild protection. In many cases, soft and tight security combinations can often occur.

\subsubsection{Beach Nourishment}

\section{Definition}

Coastal nutrition is an adaptive technology used primarily in response to coastal erosion, but the benefits of flood mitigation can also occur. Nutrition is also known as beach recharging, beach refilling, refilling, re-feeding and beach feeding.

\section{Description}

The addition of coastal material rebuilds and maintains coastal widths to provide storm protection. This approach is mainly used on sandy beaches but the term can also mean feeding with shingles or cobble. However, the goal should be to ensure that the nutrients are consistent with the existing naturel (or local) coastal material (Reve et al., 2004). Simultaneous feeding is often used to create artificial dew.

The advantage of beach nutrition lies in the dispersal of wave energy. When waves break along a beach, they lose their strength. Different shore profile shapes and series interact with different wavelengths. Therefore, the cross-sectional shape of a beach affects the ability to receive wave energy. The 'scattering' coastline, which disperses significant wave energy, is wide and shallow, and the 'reflective' coastline that reflects the incoming wave energy beach is narrow and narrow, gaining little wave energy. The rationale behind beach nutrition is to turn an ero- 
sive, reflective shoreline into a wider, more diffuse beach, which increases wave energy (France, 2001).

While helping to dissipate incoming wave energy, coastal nutrition addresses a sediment shortage: the root cause of erosion. This can be achieved by introducing a large amount of coastal fluid into the coastal sediment budget from an external sedimentary source known as a loan termination. The term 'sedimentary budget' is used to describe the careful balance between incoming and outgoing sediments. Like a bank account. Introducing a large amount of coastal material into the coastal system causes a nutrient sediment shortage - the cause of erosion. On the other hand, this leads to the formation of the coastline.

Several feeding methods can be used, including excavation, truck or conveyor belt positioning. The sand can be deposited as an extension of the beach width. Or can be taken ashore under the action of normal waves - this is the current practice in the Netherlands (Vankoningsweld et al., 2008). Location as an underwater reservoir helps to encourage the dissipation of wave energy and therefore reduces its impact on the coast (Dean, 2002).

The supply of nutrients by coastal excavations is largely due to the removal of coastal communities and the acquisition of large quantities of material from areas that do not reasonably interfere with coastal transport (Governor, 2002). During

Figure 1.10. Data illustrating beach volume at Bournemouth Beach, UK

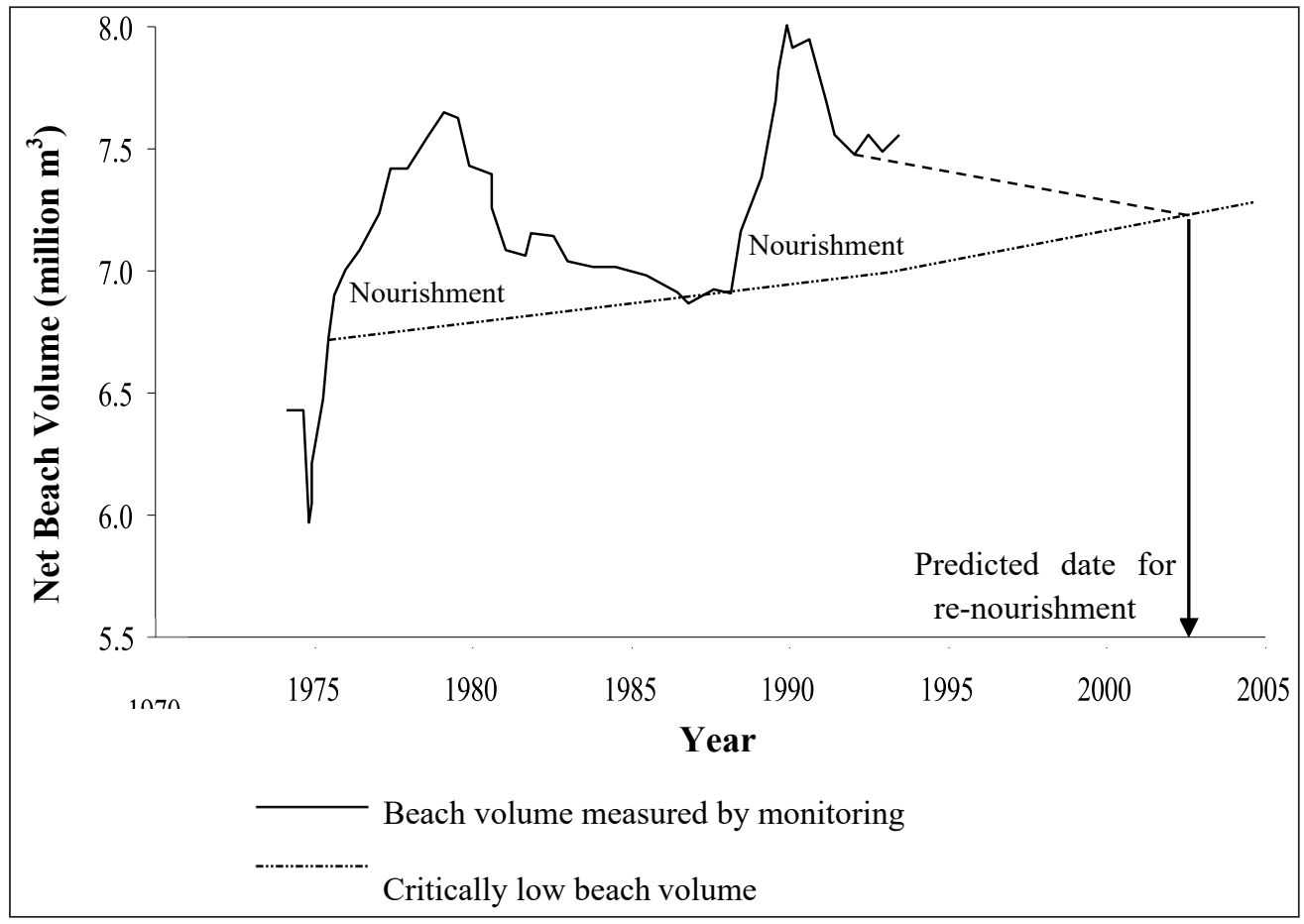

Source: Adapted by Harlow and Cooper (1996) 
excavations, a significant amount of sediment is removed from the beach. This mixture is called 'slum' and due to its liquid properties it allows it to be carried ashore by floating or submerged pipeline or 'rainbow method' (see Figure 1.11).

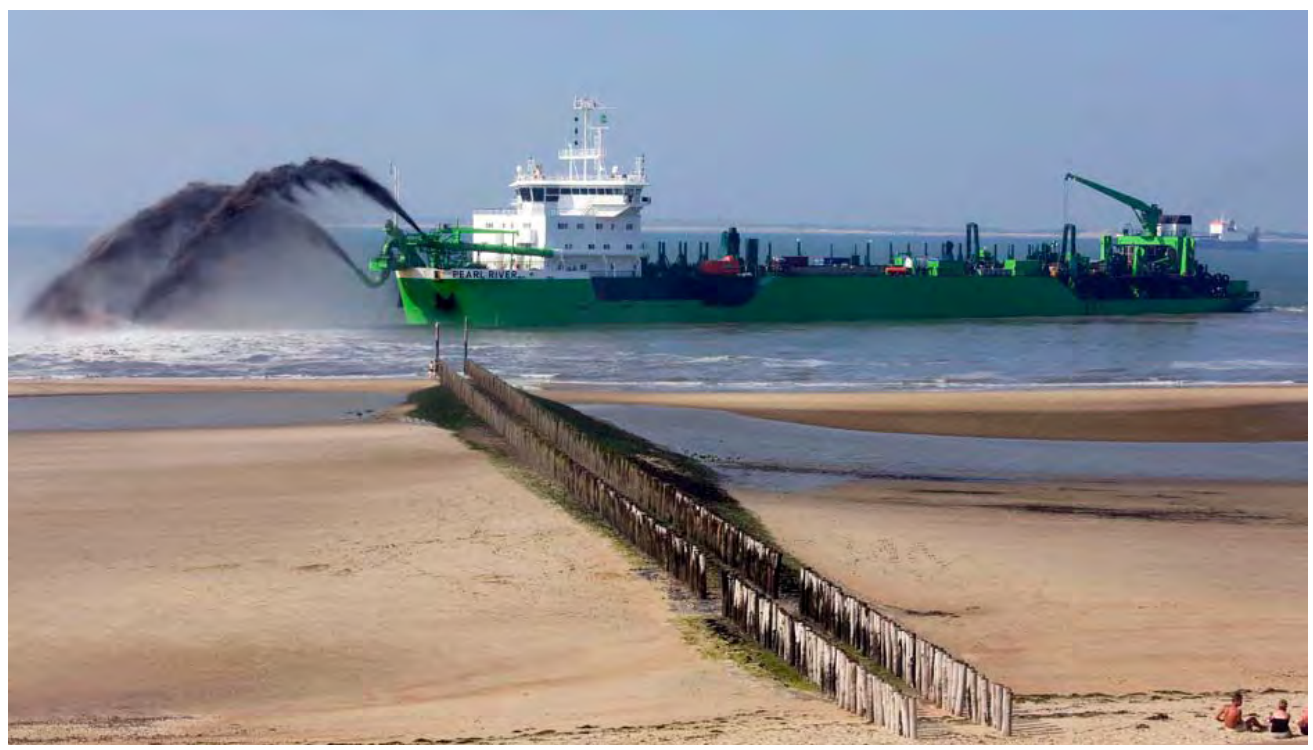

Figure 1.11. The rainbow method of transferring nutrients to the shore Slurry is discharged via a jet at the bow of the ship once it has been sailed as close to the shore as possible

An alternative to offshore mining is the removal of coastal sediments from land-based sources. Sediments are transported to the destination by truck. This way only a small percentage of the food is consumed and the approach is more suitable for small scale operations due to the more labor intensive mode of transport (Dean, 2002).

Once the sediment is transported to the target shore, it must be properly deposited. If offshore excavation sites are used, the sediment can be disposed of as an underwater reservoir. However, the nutrients are more abundantly brought to the sedimentary shores. Once on shore, the sediments can be rearranged to form a flat beach. If necessary, bulldozers or other methods can be used to create artificial hills on the coastal land area (see Section 1.3.1).

\section{Advantages of Beach Nourishment}

The nutritional benefits, if done well, are many. Most importantly, minimizing the adverse effects of coastal erosion is the provision of additional sediments that satisfy coastal erosion forces. Coastal erosion will continue, but the wider and deeper coastline will provide a buffer to protect coastal infrastructure and other assets from coastal erosion and storm damage. Coastal Nutrition is a reversible flexible coastal management solution. This is very useful as it allows a wide range of coast management options to be passed on to the next generation. 
The material collected under the action of waves, tides and winds is known as long-distance drift. Longshore drift is caused by waves that do not reach the beach. However, when the waves go back to sea, the motion is always perpendicular to the shore. As shown in Figure 1.12, this gradually initiates a sedimentary motion. Prolonged coastal drift will have a positive effect on adjacent areas where coastal nutrition is not directly fed as a result of sediment redistribution. It has a wide range of benefits for all coastal cells, including slope and slope erosion.

\section{Figure 1.12. Schematic illustration of longshore drift}

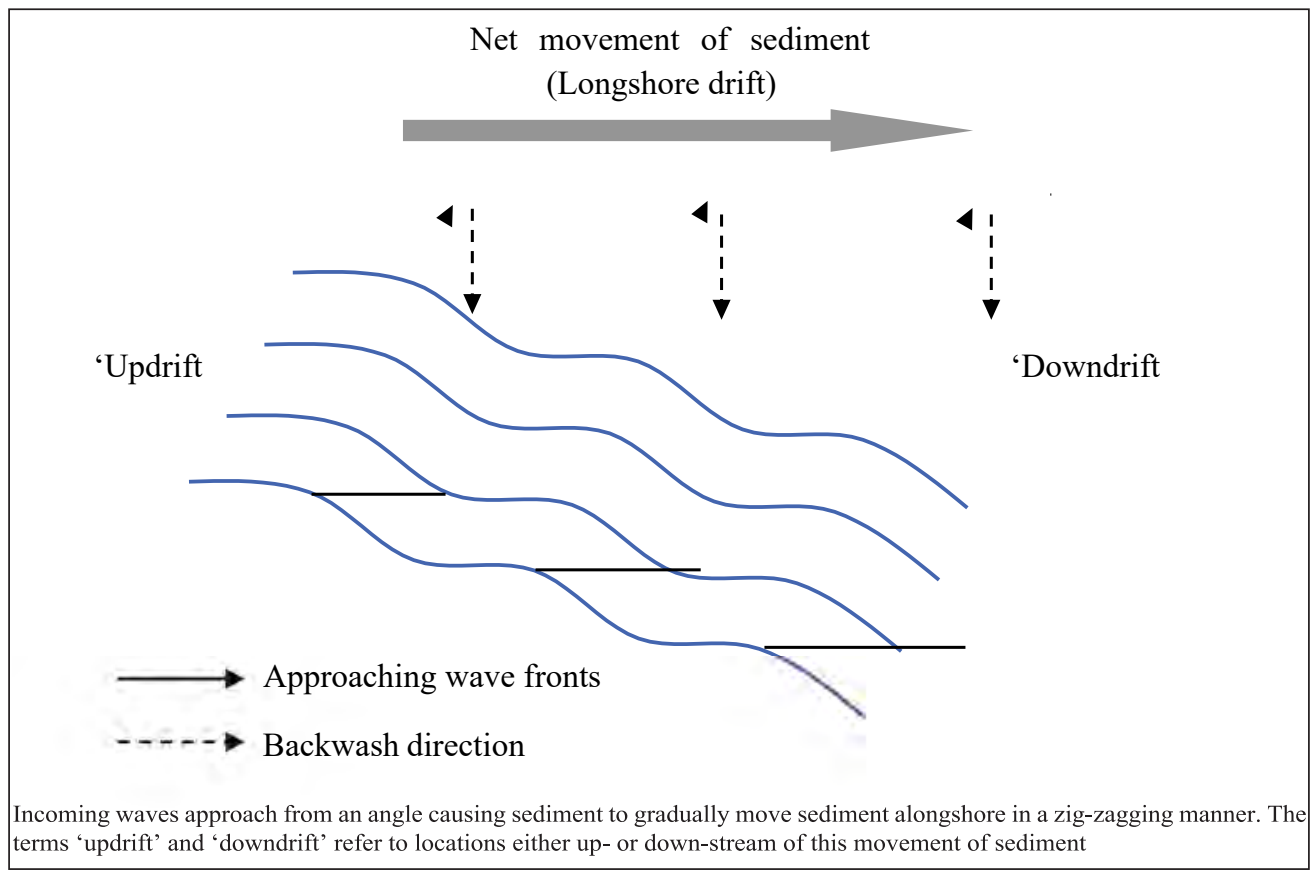

Source: Adapted from French, 2001

Coastal feed can meet strict security measures such as a sea wall (see Section 1.3.1.3), which can continue to be used as a final defensive ring. Having a wide sandy beach in front of such structures greatly reduces the wave energy that reaches them. While providing more capacity to cope with coastal erosion and flooding, the accumulation of sediments close to the native shoreline helps to retain the natural landscape of the coast. These schemes are also aesthetically pleasing in the natural sense of nutrition projects.

As mentioned in Section 1.2, the coastal tourism industry is largely dependent on the 'sun, sea and sand'. As a result, beach nutrition has the potential to promote entertainment and tourism through beach expansion (Nichols et al., 2007b). This will help to enhance or attract more tourists from the previous tourism industry and thereby encourage development. 
Coastal nutrition can provide environmental benefits. Proposals have been made to provide improved nesting sites for sea turtles, taking into account the needs of these creatures (President, 2002). This, in turn, helps to promote 'eco-tourism' with development benefits.

\section{Disadvantages of beach nutrition}

As already mentioned, nutrition is not a permanent solution to coastal erosion. The effectiveness of a scheme requires occasional re-feeding or 'top up' to maintain productivity. This requires regular reinvestment but can be considered as a maintenance cost associated with hard engineering structures.

As with any form of coastal protection, coastal areas feel more protected by minimizing the risk of flooding and erosion. To some extent this is appropriate. However, the coastline regardless of safety measures region will be prone to severe coastal flooding and erosion and will be exposed to natural disasters with longterm benefits. If not carefully regulated, safety measures can promote the development of ignorance in these vulnerable areas.

Coastal sediment deposition can have a number of environmental impacts, including the direct burial of seabirds and organisms, the amount of lethal or harmful water disturbances, the clouds caused by sedimentary rise, and the altered sediment composition that affects species. Living in the area (Dean, 2002). As a result, projects should be designed with an understanding of the potential adverse effects on the environment.

If the filling is not properly designed, the placement of the filling on the beach can interfere with the beach and interfere with marine habitats such as bird and sea turtle nests. This is especially true if the sand grain size / composition does not match the native coastal material (IOC, 2009).

Coastal nutrition is expected to grow in the future and there may be a greater demand for high quality sediments as a result. The limited utility of large contractors and the increasing demand for nutrition projects have already led to increased costs for nutrition projects in the Netherlands (Hylan et al., 2010). This upward trend could be seen elsewhere in the future.

\section{Costs and Financial Requirements}

Lynham et al. (2010) conducted extensive research on the unit cost of coastal nutrition. Excavation sites have been shown to vary from US \$3-15 / m3 (at 2009 price levels) on average (Linham et al., 2010). Transportation distance seems to be the most important criterion for determining feeding costs.

Payment to contractors is usually based on sediment volume. This usually requires the completion of coastal views and underwater and post-nutrition surveys. The current monitoring cost should be calculated when considering the total cost of nutrition. Oversight costs can vary with domestic labor costs and can vary (Mason, pers. comm.). 


\section{Box 1.1. Factors Affecting Nutrition Unit Costs}

- Project size and resulting economies of scale

- Distance between dredge and target sites

- Number of journeys required between dredge site and nourishment area

- Seabed shape at the borrow site - determinant of the dredger size which can be used and therefore affects the number of journeys that must be made

- Rechargematerial-coarsermaterialcausesgreater equipment wearandtear which is likely to be passed on to customers by contractors

- Estimated material losses

- Availability (and size) of dredgers

- Degree of site exposure - determines type of dredger to be used and may also shorten working hours when a site is subjected to energetic winds and waves

- Tidal range - large tidal ranges provide time constraints on when dredgers are able approach close enough to shore to deposit material. This is turn can affect the time required to complete a project

- Third party requirements

Source: CIRIA, 1996; Linham et. al., 2010

\section{Institutional and Organizational Requirements}

Significant beach nutrition usually requires extensive engineering studies and specialized knowledge and equipment. This may include dredgers and pipelines that must be rented from a specialized contractor. However, it is also possible to conduct feeding on a small scale. Coastal sediments can be transferred from land-based sources or deposits to erosion areas by truck. Due to the small scale nature of this approach and the availability of readily available equipment, feeding by trucks may be more practical at the local level. Once feeding is done, continuous coastal monitoring is needed to assess nutritional success and determine when re-feeding is needed.

\section{Barriers to Implementation}

Coastal nutrition requires the identification of a sedimentary source close to the feeding point. This ensures that costs are kept at a reasonable level. Sediment availability is highly variable worldwide and suitable sources are not readily available. Sedimentation problems can occur as demand increases due to increased coastal nutrition worldwide. This problem has already been experienced in the context of small islands where sand travels long distances for nutrition projects.

Rental of Coastal Nutrition requires highly specialized equipment and knowledge, including dredgers and pipelines. Hilan et al. (2010) Note the limited number of large contractors available. Local site features will also affect the type and size of the drawer, which may further limit the availability of the drawer. 
Educating the public on how coastal nutrition schemes work can also be a hindrance. This is especially true when depositing sediment in coastal food or underwater. Using these methods, the benefits of nutrition will not be immediately apparent, and if the public is not made aware of how these schemes work, they may doubt the nutritional benefits and oppose such projects.

\section{Opportunities for Implementation}

Coastal nutrition can serve as a cost-cutting option for port and channel maintenance. The use of excavation material may also lead to a shortage of sediment suitable for the coast. However, care should be taken when using drilling rigs as port excavations may contain high levels of contaminants.

\section{Case Study: Bournemouth Beach, Poole Bay, UK}

As shown in Figure 1.13, this nutrition helps to maintain a wide sandy coastline which is important for the tourism economy of the area. Provides the best practical case study of coastal nutrition with systematic and systematic monitoring of nutritional activities.

It was decided to get nutrition in this place after the 1960s damage to the sea walls and tight defenses such as guerrillas. These stringent safety measures have had limited success in retaining coastal waters (Harlow \& Cooper, 1996). The nutrition was chosen to solve these problems and was largely due to the golden,

Figure 1.13. Bournemouth Beach, Poole Bay, UK

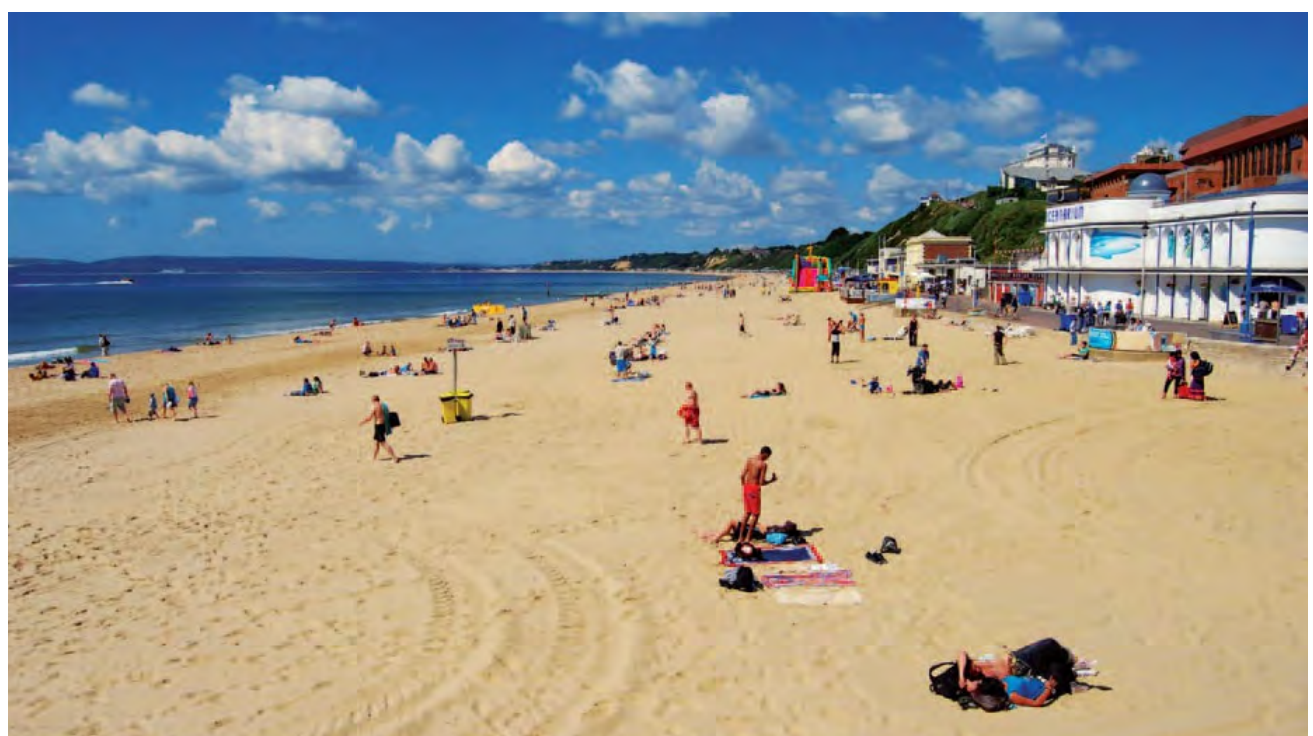

Source: Courtesy of Robert Courtman, Wikimedia Commons 
sandy coastline that was considered beneficial to the tourism economy of the area (Cooper \& Harlow, 1998).

Feeding costs can be reduced by using sand dug from ports and channels. If this can be achieved in developing countries, nutrition will be more robust. In India, for example, nutrition is generally expensive enough to be used as a coastal erosion protection tool. However, in some areas, when sediment is excavated from shipping lanes and harbors, it has been shown that the cost of feed is sufficiently reduced to allow for its application (Rao et al., 2009).

In order to prevent damage to coastal infrastructure, as happened in 1987, the approach to nutrition was changed by adopting BIS3. Future nutrition is designed to be localized, not just frequently, using low sedimentation volumes (Linham, 2008). In order to prevent damage to coastal infrastructure, as happened in 1987, Adherence to BIS3 changed the approach to nutrition. Future feeding is designed to localize rather frequently using lower sedimentation volumes (see Table 1.3). Each project focused on a specific part of the coast rather than feeding the entire system.

Table 1.3 Poole Bay beach nourishments 2005 - 2009

\begin{tabular}{|c|c|c|c|}
\hline $\begin{array}{c}\text { Improvement } \\
\text { Seheme }\end{array}$ & Year & $\begin{array}{c}\text { Volume of beach fill } \\
\text { added }\left(\mathrm{m}^{3}\right)\end{array}$ & Material Source \\
\hline BIS4.1 & $2005 / 06$ & 600,000 & Harbour dredging \\
\hline BIS4.2 & $2006 / 07$ & 898,000 & Offshore dredging area \\
\hline BIS4.3 & 2008 & 70,000 & Offshore dredging area \\
\hline BIS4.4 & 2009 & 70,000 & Offshore dredging area \\
\hline BIS4.5 & 2010 & TBC & TBC \\
\hline
\end{tabular}

Beach fill volumes added to specific beach sections in Poole Bay from 2005 to 2009

Beach surveillance has been an important part of Bournemouth's nutrition since the first feeding activities on Site 2 The new 'small and often' nutritional approach means that monitoring is more important now than ever before.

Adding beach profile information has a number of advantages. It allows the calculation of net beach volume and current erosion rate, then estimates of dates for future replenishment. This allows you to plan for future fundraising. Monitoring also shows when nutrition is needed, before unacceptable damage to coastal defense and infrastructure occurs. Ensures maintaining a stable beach volume for facilities. Finally, future projects can be improved by analyzing the erosion rate in the post-feeding period. For example, by adjusting the fill volume to minimize rapid post-fill erosion.

\subsubsection{Artificial Sand Dunes and Dune Rehabilitation}

\section{Definition}

Reasonably occurring sand dunes are wind-formed sand deposits that represent a sedimentary deposit in the region. Average high tide (France, 2001). Artifi- 
cial mountains are engineering structures designed to mimic the functionality of natural mountains.

Large-scale rehabilitation is the process by which natural or man-made debris becomes more vulnerable, less active, or less active in order to reap the greatest coastal protection benefits. Artificial landfill construction and landfill rehabilitation are technologies aimed at minimizing coastal erosion and flooding in adjacent coastal lowlands.

\section{Description}

Mountain range runs naturally along many undeveloped, sandy beaches. A typical example is shown in Figure 1.14. Where they are, their coastal defense role is twofold:

1 They represent a barrier between the sea and land, in a similar way to a seawall

2 Dunes are 'dynamic', i.e. the dune/beach system interacts a great deal and is constantly undergoing small adjustments in response to changes in wind and wave climate or sea level. As such, dunes are able to supply sediment to the beach when it is needed in times of erosion, or store it when it is not (French, 2001).

Clearly natural sand dunes are an effective defence against coastal floods and erosion. However, there is a problem with that wide sandy beach - the environment where most of the sand dunes occur - which is very conducive to develop-

Figure 1.14. Coastal sand dunes at Aberffraw, Anglesey, UK

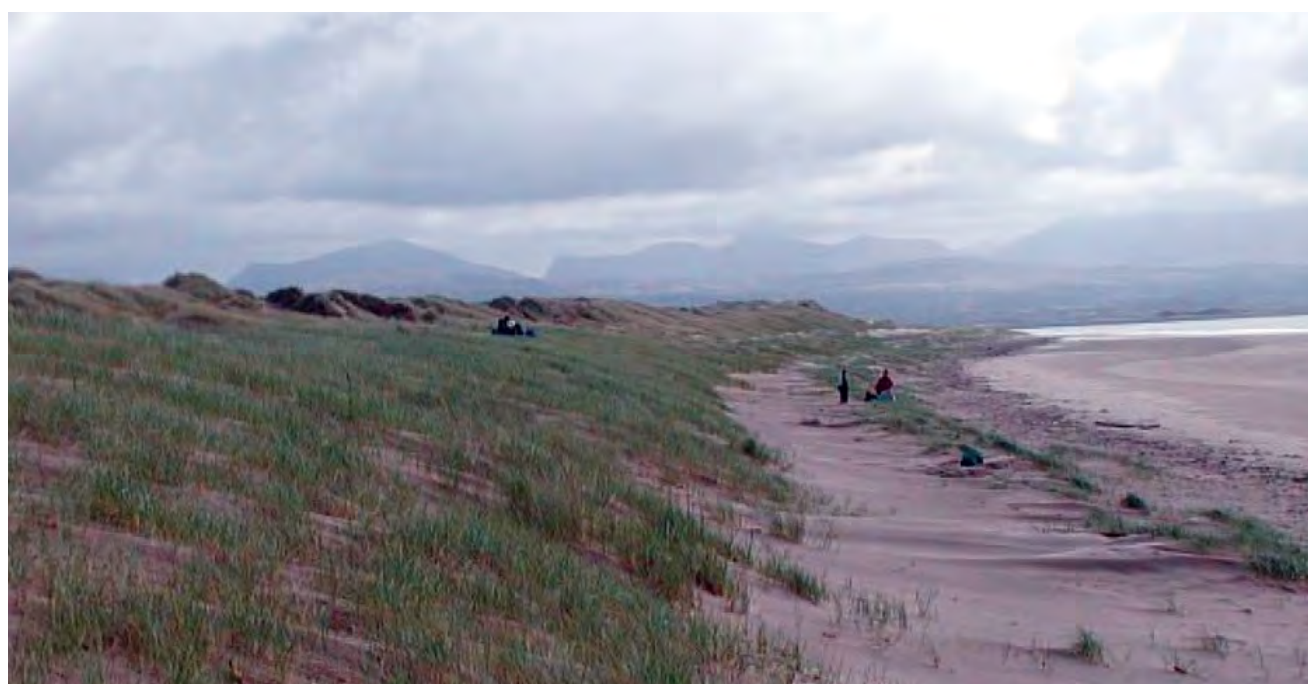

Source: Courtesy of David Rayner, Wikimedia Commons 
ment. So the natural sand dunes are deteriorating. SLR And sand dunes are at risk of storm erosion due to the more robust wave climate.

However, the importance of mountains for coastal protection has now been recognized, and the creation of artificial mountains and the rehabilitation of existing ones are potential technologies for adapting to coastal climate change.

Its simplest, artificial dew construction involves the localization of sediments from dredging sources on the beach. This is done after bulldozers or other methods are used to reset the deposits to the hills. As a by-product, beach feeding is often done because sand is readily available (see Section 1.3.1).

There are a number of ways to recycle garbage. One such method is to build sandbank fences for an existing storm trap and to help stabilize any hollow sand surface.

\section{Returns of Artificial Sand Dunes and Dune Rehabilitation}

The importance of sandy beaches in wavelength dissipation is already set out in Section 1.3.1. However, sandy beaches are frequent. Tides react to ever-changing tidal climates and sea levels. Therefore the volume of sand on the beach is constantly fluctuating. During low-lying coastal periods, the coastline can be eroded, and sand dunes are particularly valuable as a sedimentary reservoir that can be accessed to satisfy erosive forces. This compensates for the sand removed from the shore and helps to maintain a wide sandy beach that continuously dissipates incoming wave energy. This process is shown in Figure 1.15. The volume of a

Fig 1.15 A simple illustration of storm erosion caused by storm surges

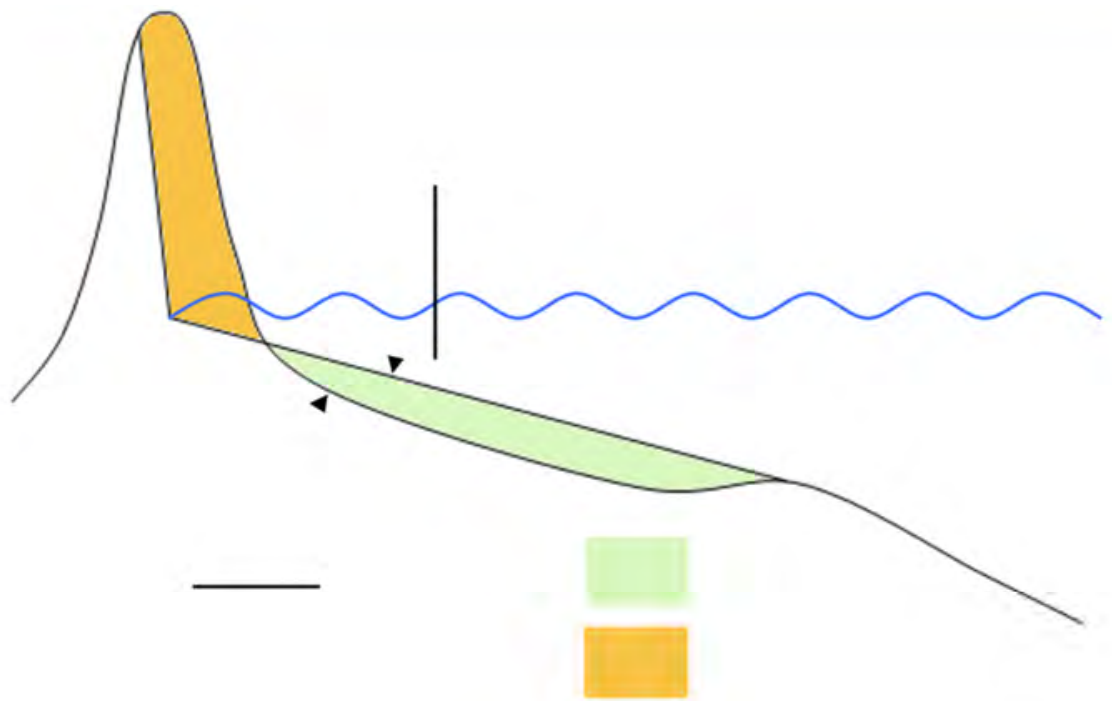

Source: Adapted from Charlier \& De Meyer (1998) Ref: Charlier R.H. and De Meyer, C.P. (1998) Coastal Erosion: Response and Management, Volume 70. Berlin: Springer Verlag 
wave can only be calculated from the Wellinga (1983) equation, which requires knowledge of wave height, high water level, and sedimentation rate.

The mountains can provide high protection against coastal flooding and erosion. As the mountains provide physical and tactile protection, they will even serve to encourage sustainable development in the coastal region.

Garbage dumps are a natural feature and if the construction / commissioning of artificial hills is completed in a sympathetic manner, they will not necessarily spoil the local landscape. Many sandy beaches may have had naturally occurring sand dunes before coastal development; So starting with artificial peaks can give the site a natural look

\section{Difficulties of Artificial Sand Dunes and Dune Rehabilitation}

Although a natural feature of many sandy beaches, the mountains also represent a barrier to access to the coast. In many cases, mountains have been removed as a result of development, and communities have become accustomed to accessing the sea directly to shores and scenery. If these factors are affected, there may be local opposition to mountaineering.

Land loss is another matter; The mountain has a reasonable footprint. This will further increase the scope for adequate adaptation of the Sri Lanka Broadcasting Corporation to prevent coastal compression. The use of land with development potential for waste generation and rehabilitation could be controversial unless the full benefits are explained. Alternatively, sand dunes may be built on a beach that is important for tourism and recreation, thereby restricting public use.

\section{Corporate and Institutional Needs}

Fences can be applied to stabilize bare sand and encourage dew growth using local, naturally occurring materials such as twigs and reeds (Nordstrom \& Arens, 1998).

\section{Box 1.2: Factors affecting dew construction unit cost}

- Whether dredged material is required for dune construction/restoration or whether fences or vegetation can be used to promote sand accumulation

- Availability and proximity of appropriate construction material from onshore or offshore sites

- Dredgertype, sizeandavailability

- Requirement to fence newly constructed dunes to prevent erosion

- Requirement for planting new dunes with vegetation

- Frequency with which the dune needs to be artificially replenished or whether the structure naturally accumulates sand

- Project size and resulting economies of scale 
Therefore, there is very little need to provide or guide external materials for measurements. Fencing can prevent erosion caused by human encroachment.

Once enough material is available to create mountains, another task that can meet the limited technical requirements is to create debris through naturally occurring processes or through artificial placement, movement and rearrangement. The use of bulldozers or other earth-moving equipment is sufficient to carry out temporary operations to repair or repair slopes. The sediment can be bulldozed from the tops of the mountains and placed in low lying areas (Nordstrom \& Arens, 1998).

\section{Barriers to Implementation}

If dew builds up in an area primarily used for residential or tourism and local landowners may be concerned about maintaining sea views. In these cases, the new mountain can be kept relatively low and linear, but this affects the level of protection it provides. Opposition can be kept to a minimum if the full coastal defense benefits of the mountains are communicated.

Opposition may also arise from the need to acquire land on the slopes. The large width of the ocean side can reduce coastal space and bring mountain peaks to human settlements such as houses on the land side.

Sand dunes are a dynamic form of coastal protection that responds to coastal processes such as coastal and windy climates. For example, during the summer months, sediments accumulate during the sedimentary period and sediments stored in the mountains during winter storms can come ashore to erode. Most communities are only familiar with static protections that do not respond to local conditions. The way dirt reacts to hurricanes can cause communities to oppose their use in different ways, especially in communities where coastal stabilization has been a long-term goal (Nordstrom et al., 2000).

\subsubsection{Seawalls}

\section{Definition}

The coastline is a structure with a primary function to prevent further erosion. They are built parallel to the coast and provide protection against landslides (UNFCCC, 1999). Although their primary function is to reduce erosion, they have a secondary function as coastal flood protection.

The physical appearance of these structures is highly variable; Sea walls can be vertical or sloping and are made of a variety of materials. They can also be called revelations.

\section{Description}

Beaches are the most widespread beaches in the world and are found in many temporary beaches in developing countries. Although these principles can be applied to more temporary structures, here we emphasize the best training guide. 
Figure 1.16: Variation in design type of seawalls

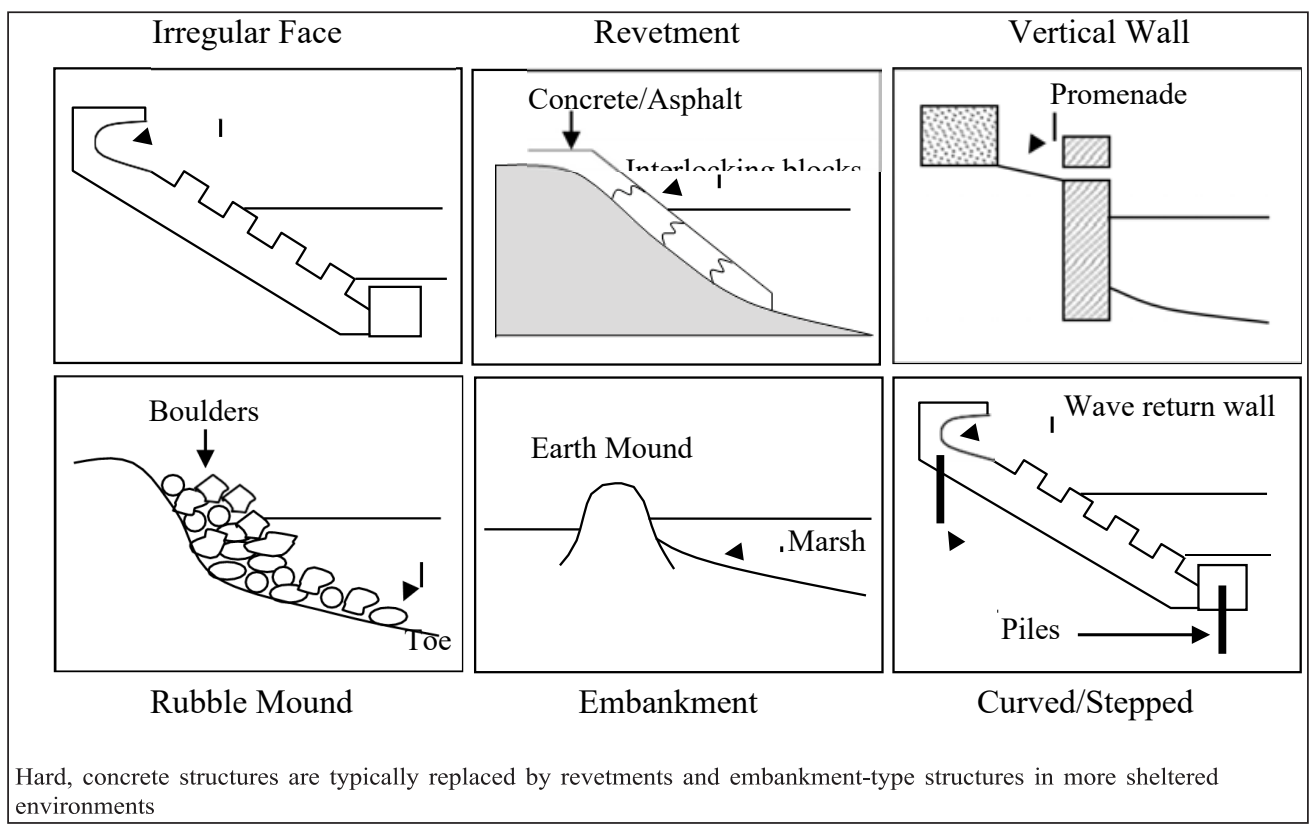

Source: Adapted from French, 2001

Sea walls form a line of interpretation between sea and land. They are often used in areas where further damage from coastal erosion is possible, e.g. When roads and buildings are about to fall into the sea. However, they no longer prevent coastal erosion and do not deal with the causes of erosion (French, 2001).

Some typical sea patterns are shown in Figure 1.16. Sea walls are generally well-designed, flexible structures that are generally expensive to construct and require proper design and construction supervision (UNFCCC, 1999).

The shape of the sea face is important in diverting incoming wave energy; Smooth surface aces reflect wave energy, while irregular surface aces scatter the direction of wave reflection (France, 2001). The waves are likely to affect the structure with high forces and carry the sand away and to the shore (Compuis, 2000). Sea walls are often built as a last resort and many are subjected to continuous intense wave tension.

Sea walls generally have a deep foundation for stability. Also, to avoid ground pressure on the ground side of the structure, 'dead' or earth anchors can be buried in the ground and attached to the wall (Dean \& Dalrymple, 2002).

\section{Advantages of Seawalls}

The main advantage of a sea wall is that it provides high protection against coastal flooding and erosion. A well-maintained and properly designed seawall 
will bridge the sea-land boundary to ensure further erosion - this is useful if the beach is home to important infrastructure or other important buildings.

Coastal flood protection against land and sea borders as well as seawater. Properly covered, it will withstand a great deal of adverse conditions. In the past, the design height of many sea walls was based on the highest known flood level (van der Meer, 1998).

There is a high demand for the region; Reducing space requirements for coastal protection reduces the overall cost of construction. The greater protection provided by the construction of the seawall maintains climatic values and can promote investment and development in the area (Nichols et al., 2007b). Moreover, if properly designed, the beach is highly valued for convenience - in many countries the beach includes a promenade and a promenade that enhances the tourism industry.

Another advantage of sea walls in terms of adaptation to climate change is that these structures can be gradually improved by increasing the height of the structure in response to the Sri Lanka Railways. However, it is important that the improvement of the sea wall does not harm the integrity of the structure. Improving security leaves a 'construction junction' between the new section and the existing seawall. Improvements should be accounted for this weakened part and it should be properly strengthened.

If they are adequately maintained, sea walls are a structure that can last a long time. The seawall at Galveston, Texas, was built in 1903 and provides coastal flood and erosion protection to this day (Dean \& Dalrymple, 2002).

\section{Disadvantages of Seawalls}

The sea wall is subjected to a significant load due to the wave effect. This load increases with the depth of water in front of the structure. Sea walls are designed to dissipate or reflect incoming wave energy and, accordingly, must be designed to be stable under extreme wave loads. The impact of the SLR, the increase in wavelength and the increase in storms caused by climate change must all be taken into account. The spots at the base of the sea wall are a special problem with vertical sea wall designs. This phenomenon is due to the process shown in Figure 1.17. The incoming waves affect the structure and the water shoots upwards. A similar process takes place in the seawall, but in this case the base of the structure is scaled (see Figure 1.21).

The inclusion of slopes and irregular surfaces in the design of the structure can reduce the problems of wave reflection and plague to some extent. Sloping waves encourage breakdown and therefore dissipate energy, while irregular surface aces scatter in the direction of wave reflection (France, 2001). Pilarsik (1990a) recommends used. Slop of 1:3 maximum sea slopes to minimize scarring caused by wave reflection.

In the absence of a beach, natural coastal erosion will provide sedimentary sediments along the coast, known as long-distance drift (see Figure 1.12). Howe- 
Figure 1.17: Schematic cross-section illustrating seawall scour

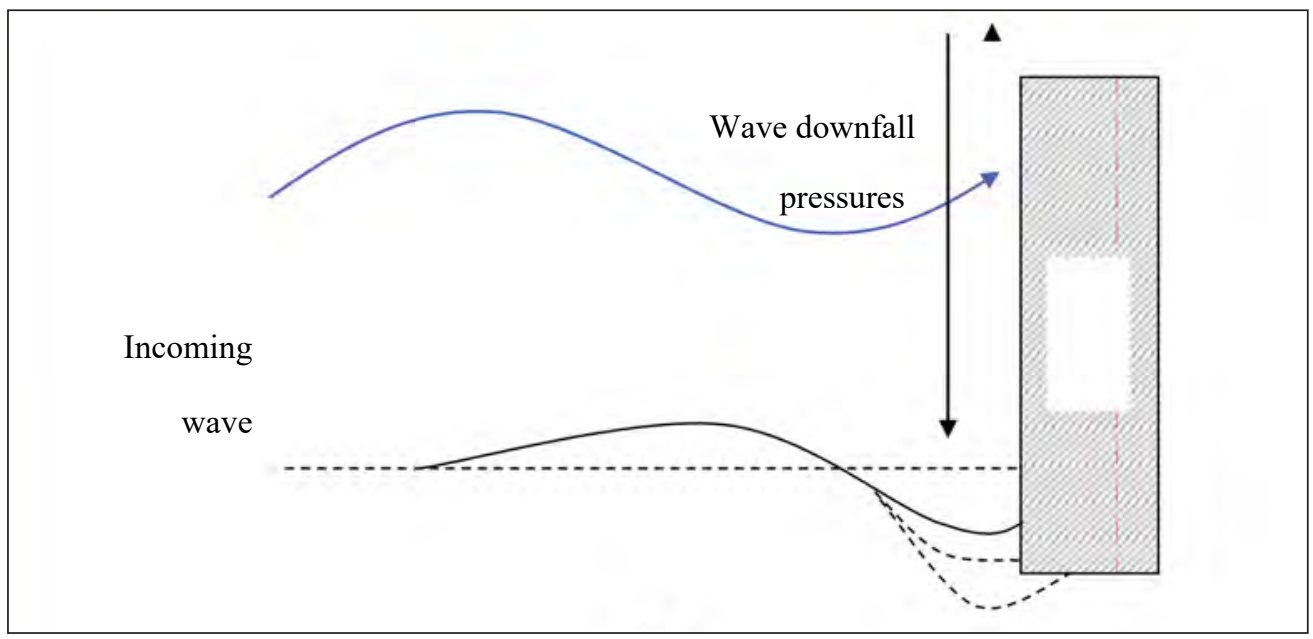

Source: Adapted from French, 2001

ver, once a sea wall is built, the coastline is protected from erosion and sedimentation is cut off.

This causes sedimentary starvation in coastal areas in the direction of long coast drift.

Although safe beaches at the end of the coast prevent erosion, the coastline remains free to respond to natural conditions. This means that unprotected areas adjacent to the wall can be accessed internally. It shows a step towards the coast (France, 2001). As a result of natural processes, the end of the seawall recession is usually more erosive (see Figure 1.18). This flanking effect can cause undermining and instability of the wall in extreme cases.

Because sea walls are a static protection, they can also interfere with natural processes, such as habitat migration, caused by changes in sea level. In response to the Sri Lanka Railways, the coast interferes with the natural internal migration of coastal systems, thus causing coastal compression (discussed in Section 1.2). This process reduces the land area of interstitial habitats such as sandy beaches and salt marshes.

Along the estuary, the seawall also changes the tidal area. With the same volume of water flowing into the estuary, the water level will rise after the sea wall is built. On the other hand, this will affect the vegetation distribution and increase the tidal range to a higher level of protection (French, 2001).

Another potential problem is overtopping. This occurs when water levels exceed the height of the seawall, resulting in water flow into areas behind the structure. Overtopping is not a continuous process but usually occurs when individual high waves attack the seawall, causing a temporary increase in water level which exceeds the structure height (Goda, 2000). If the structure is too low, excessive overtopping can remove considerable amounts of soil or sand from behind the 
Figure 1.18: A seawall as viewed from above, showing typical end effects associated with the structure

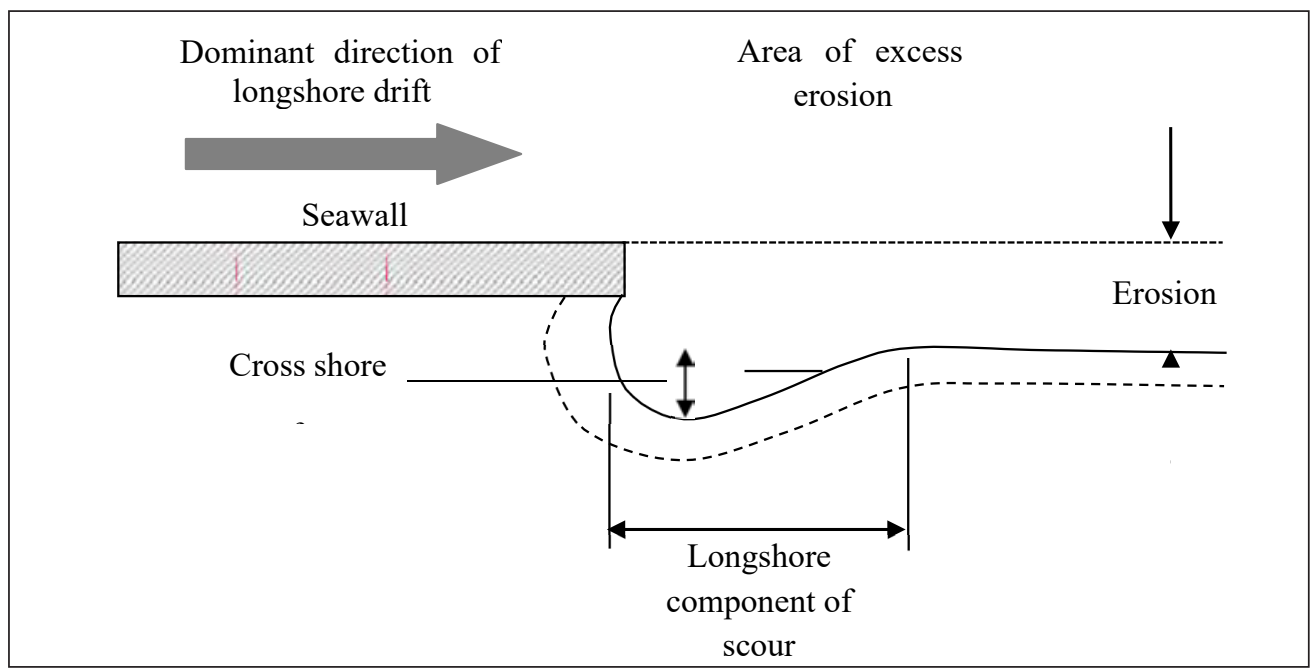

Source: Adapted from McDougal et al., 1987

wall, thus weakening it. Further, overtopping water saturates and weakens the soil, increasing pressures from the landward side, which can cause the foot of the structure to 'kick out' and collapse (Dean \& Dalrymple, 2002). Overtopping will become increasingly problematic with SLR, increased wave heights and increased storminess.

As mentioned in the advantages section, seawalls increase security by reducing the risk of flooding and erosion. However, the coastal zone remains a high risk location not least due to the presence of residual risk. To combat unwise development of the coastal zone, future developments need to be carefully planned.

Additionally, by encouraging development, hard defences necessitate continued investment in maintenance and upgrades, effectively limiting future coastal management options. Although authorities may not have a responsibility to continue providing protection, the removal of defences is likely to be both costly and politically controversial (Nicholls et al., 2007b).

Seawalls also reduce beach access for handicapped people and for emergency services. This can be problematic if the beach fronting such structures is to be used for recreation. The appearance of seawalls can be aesthetically displeasing which can further negatively affect beaches dependent upon a tourist economy.

\section{Costs and Financial Requirements}

A study by Linham et al. (2010) indicates that the unit cost of constructing 1 $\mathrm{km}$ of vertical seawall is in the range of US $\$ 0.4$ to 27.5 million. The study found seawall costs for around ten countries. Most were developed country examples, 
although a number of newly developed and developing countries, such as Egypt, Singapore and South Africa were also found. Problems arise in the reporting of unit costs for vertical seawalls as the effect of height on unit costs is rarely considered. As such, these costs are likely to relate to seawalls of various heights; this explains some of the significant variation in costs between projects.

Some of the best unit cost information is given by the English Environment Agency (2007), for unit costs relevant to the UK. This source gives an average construction cost for seawalls of US $\$ 2.65$ million (at 2009 price levels). This cost includes direct construction costs, direct overheads, costs of associated construction works, minor associated work, temporary works, compensation events and delay costs. This does not include Value Added Tax (VAT) or external costs such as consultants, land and compensation payments. Variation in costs between projects is a result of numerous factors, detailed in Box 1.3.

\section{Box 1.3: Factors affecting the unit cost of sea wall construction}

- Design height is a major factor affecting costs per unit length of seawall. Height affects the volume of materials required for construction and the build time

- Anticipated wave loadings will affect how resilient the structure needs to be; deeper waters and exposed coasts cause higher wave loadings which will mean the structure needs to be more robust, thus higher costs

- Single or multi stage construction; costs are lower for single stage (Nicholls \& Leatherman, 1995)

- Selected seawall design and the standard of protection desired. Certain design features will increase costs and more robust seawalls will be more costly

- Construction materials (e.g. rubble blocks, pre-cast concrete elements, metal, soil, etc.)

- Proximity to and availability of raw construction materials

- Availability and cost of human resources including expertise

Maintenance costs are another significant and ongoing expense when a hard defence is selected. These costs are ongoing for the life of the structure and are therefore likely to result in significant levels of investment through a project's lifetime. Continued investment in maintenance is highly recommended to ensure defences continue to provide design levels of protection (Linham et al., 2010).

It has been noted that construction and maintenance costs are likely to increase into the future in response to SLR (Burgess \& Townend, 2004; Townend \& Burgess, 2004). This is caused by increases in water depth in front of the structure which, in turn cause increased wave heights and wave loadings on the structure.

Maintenance costs are also likely to be higher when seawalls are poorly designed or constructed of inappropriate materials. In many cases, design can be of secondary importance to the availability of raw materials, especially in locations where appropriate construction materials are scare. This was found to be the case 
in a study of shoreline protection in rural Fiji by Mimura and Nunn (1998). Their study highlights the problem that inappropriate design often leads to unfavourable effects, such as wave reflection and toe scour. In the absence of improper design, it is not unusual for designs from one location to be blindly copied at another. Such an approach is likely to result in exaggerated socio-economic and environmental costs (UNFCCC, 1999). The provision of even, basic design guidance would improve project performance in many cases.

\section{Institutional and Organisational Requirements}

Seawall construction is possible on a community scale. There are many examples of ad-hoc construction to protect individual properties and communities. However, ad-hoc seawalls are likely to give much less consideration to the water levels, wave heights and wave loadings during an extreme event. This is largely because these events are hard to foresee without a well-developed science and technology base. For example, traditional seawall construction methods in Fiji involved poking sticks into the ground to create a fence, behind which logs, sand and refuse would be piled to pose a barrier to the sea. This type of traditional construction has shown to have low effectiveness against significant events, however, and in many cases, these defences are washed away during extreme events (Mimura \& Nunn, 1998). A degree of technical guidance would be of benefit in the design and construction of effective seawalls. This would improve their effectiveness during extreme events and would also help to reduce adverse impacts on adjacent coastlines.

Although it is clearly possible to construct ad-hoc, or traditional, low technology seawalls at a community level, these structures have been shown to afford lower levels of protection against

extreme events than designs with a solid science and technology base. They have also been known to exacerbate existing problems.

At present, the advice given in developing countries for modern seawall construction appears to be informal, if given at all. If effective design and construction is to occur, local communities must be given at least basic design guidance. This may come from government or voluntary organisations.

Seawall maintenance is likely to be possible at a community level when given appropriate training. This may include educating maintenance engineers on the likely failure mechanisms, how often to survey the structure, what to look for and how to identify weaknesses in the design. If major weaknesses are found, it may be necessary to employ a professional organisation to repair the structure in the most effective manner.

\section{Barriers to Implementation}

One of the main barriers to the implementation of a well designed seawall is cost. The design of an effective seawall requires good quality, long-term environmental data such as wave heights and extreme sea levels. 
This is frequently unavailable in developing countries and can be costly to collect. Secondly, because seawalls are frequently exposed to high wave loadings, their design must be highly robust, requiring good design, significant quantities of raw materials and potentially complicated construction methods. In locations of high energy waves, additional cost must be expended on protective measures such as rip-rap6 to protect the structure's toe.

A study in Fiji (Mimura \& Nun, 1998) on the Pacific island found that beach construction was very expensive, even when local currency was used in conjunction with other government-supplied materials. The construction of the seawall in Fiji took the time of the villagers and required considerable time and money to provide food and beverage services for the workers.

Experience in building sea walls, materials, labor and specialized machinery may also be an obstacle to the implementation of this technology.

\section{Opportunities for Implementation}

Sea wall construction is one of the few options available when high value lands cannot be protected in other ways. This approach provides a high level of protection for valuable coastal areas, but the long-term sustainability of access must also be taken into account.

Less technologically advanced designs can be implemented at the local level by utilizing local knowledge and technical skills. This requires less investment and less the need for the intervention of large organizations such as the national or sub-national government or non-governmental organizations (NGOs). Although it can be implemented temporarily, the technical guidance of specialized expert organizations is appropriate to ensure an adequate level of security.

The positioning of inland sea walls after a managed recess reduces the disruption to coastal zone processes and creates a protection zone to protect coastal flooding and erosion (French, 2001). The sea wall therefore acts as the final defensive ring. The use of sea walls in conjunction with beach nutrition can provide solutions to the negative effects of beach construction, such as coastal erosion and low erosion.

Following the lack of success of the measures described in Table 1.4, local authorities began further work in 2006 to prevent erosion. The main feature of this scheme was a $1 \mathrm{~km}$ long sea wall. And designed to interconnect and dissipate wave energy on impact. The top of the seawall is $4 \mathrm{~m}$ higher than the MSL (Chagari Group, 2006) and the blocks are designed to withstand the impact of numerically modeled waves (HiTech, 2006).

The beach is linked with other coastal engineering initiatives to provide a more effective solution to the coastal erosion problems in the area. Further beach feeding was carried out and additional rock cover was also placed on the beach. The seawall is covered with a $10 \mathrm{~m}$ wide layer of concrete (Hitech, 2006). This provides a promenade that can be used for recreational activities in the area. The finished structure is shown in Figure 1.19. 
Table 1.4: History of Erosion Control Measures, Bar Beach, Nigeria

\begin{tabular}{|c|c|}
\hline Period & Measures Applied \\
\hline 1958 & Construction of a groyne at the foot of eastern breakwater to avoid undermining \\
\hline 1958-60 & $\begin{array}{l}\text { Dumping of dredged sediment from the harbour channel for dispersal along the beach } \\
\text { bywaves }\end{array}$ \\
\hline $1960-68$ & $\begin{array}{l}\text { Permanent pumping station built on eastern breakwater supplying an average } 0.66 \text { million } \\
\mathrm{m}^{3} \text { of sediment from the channel to the beach }\end{array}$ \\
\hline 1964 & Shore-parallel timber groyne constructed $26 \mathrm{~m}$ from the shoreline \\
\hline 1969-74 & Artificial sand replenishment \\
\hline 1974-75 & 3 million $\mathrm{m}^{3}$ sand dumped and spread on beach \\
\hline 1981 & 2 million $\mathrm{m}^{3}$ sand dumped and spread on beach \\
\hline 1985-86 & 3 million $\mathrm{m}^{3}$ sand dumped on beach \\
\hline 1990-91 & $\begin{array}{l}5 \text { million } \mathrm{m}^{3} \text { sand dumped on beach (all the sand deposited from } 1985-86 \text { had been washed away } \\
\text { in most places) }\end{array}$ \\
\hline 1995-97 & 6 million $\mathrm{m}^{3}$ sand dumped on beach ( 2 million $\mathrm{m}^{3}$ per year $)$ \\
\hline 1998 & Groyne constructed \\
\hline 1999 & 2 million $\mathrm{m}^{3}$ sand dumped and spread on beach using dredger \\
\hline 2002-03 & Dredging of more than 2 million $\mathrm{m}^{3}$ of sand \\
\hline
\end{tabular}

Source: Sunday \& John, 2006

In July 2007, Bar Beach was devastated by severe storms and the structure was protected from flooding and erosion. However, unprotected areas were still severely affected by the storms. Therefore, the extension of the sea wall for another 500 meters is currently being considered.

\subsubsection{Sea Dikes}

\section{Definition}

The primary function of guinea pigs is to protect lowland coastal areas from flooding under extreme conditions (Pilarsik, 1998a). Dyke is not meant to protect unprotected shores in front of or adjacent to the structure. 
Figure 1.19: Bar Beach seawall, Victoria Island, Lagos, Nigeria

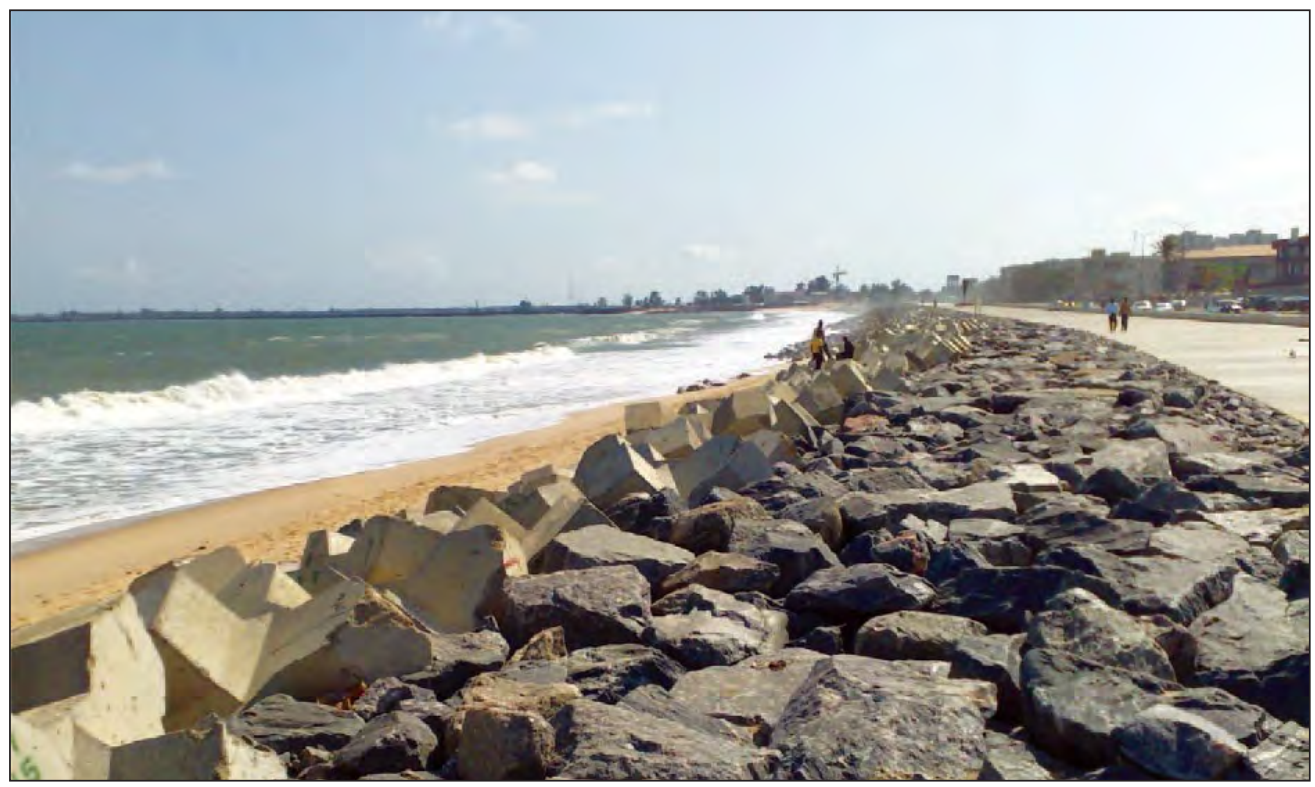

Source: Courtesy of B. Winder

\section{Description}

Dyke is widely used to protect low-lying areas to prevent flooding. Therefore, they are widely used in countries such as Vietnam, Bangladesh, Thailand, the Netherlands and the United States. Figure 1.20 shows a typical dyke cross section. It is mainly a land structure consisting of a sand core, a waterproof outer protective layer, finger protection and a drainage channel. These structures are designed to resist wave action and prevent or minimize rolling.

Dykes have been widely used for flood protection in the Netherlands for hundreds of years. So the Dutch have extensive experience in their creations. As a result, many countries use Dutch designs in dyke construction.

\section{Advantages of Sea Dikes}

Dyke provides high protection against flooding in low-lying coastal areas. When the value of coastal lands decreases, they often result in cheaper security (Brampton, 2002).

Compared to vertical structures, the seabed at the dyke slope dissipates more wave energy and reduces the weight of the structure. This is achieved because the seabed is forced to break when the water is shallow. Wave breakdown causes energy to dissipate, and the process causes the waves to lose a significant portion of their energy. Because the waves have lost energy, they are less likely to have 
Figure 1.20 : Archetypal sea dike cross section

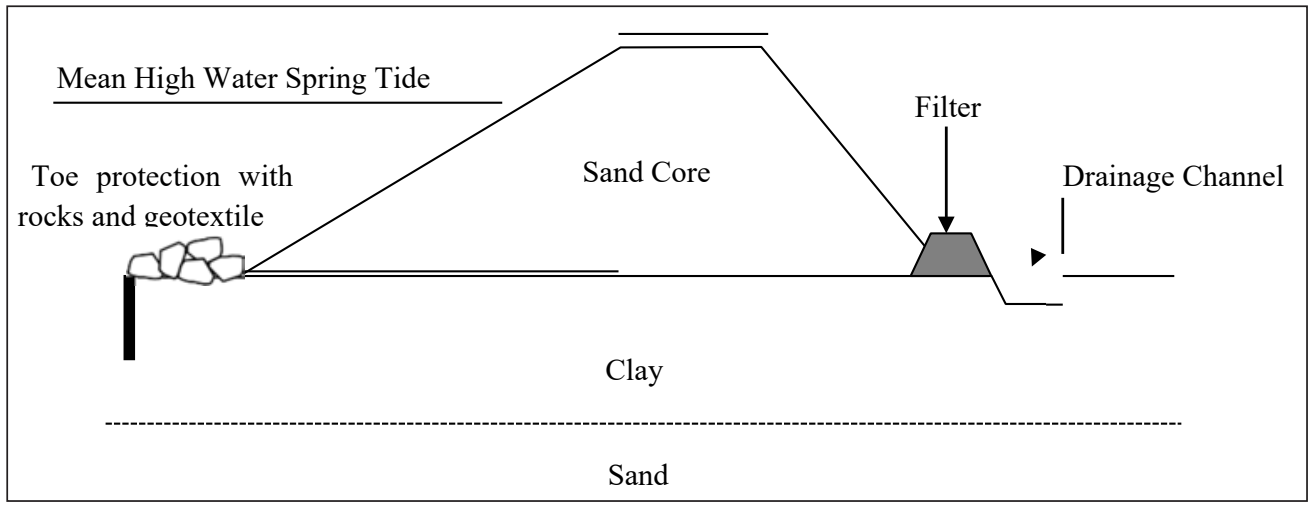

negative effects, such as coastal erosion. Reducing wavelength also reduces the likelihood of catastrophic failure or damage in extreme cases.

\section{Disadvantages of Sea Dikes}

Dykes require high volumes to withstand the high water pressure on beach faces (Berendz, 2003). As a substitute, they use a large amount of building materials, including sand, clay and asphalt, which can be expensive.

Another disadvantage of applying a dyke is that the dyke has a large footprint due to the application of shallow slopes to facilitate the dissipation of wave energy; That is, a significant amount of land is required for their construction. This can increase the cost of construction of coastal land value.

Raising the dyke in response to the SLR will increase the land area required for dyke construction if slope standards are maintained (see Figure 1.22). Beach lengthening can avoid this problem but it significantly increases the cost.

Figure 1.21: Toe scour on sloping structures

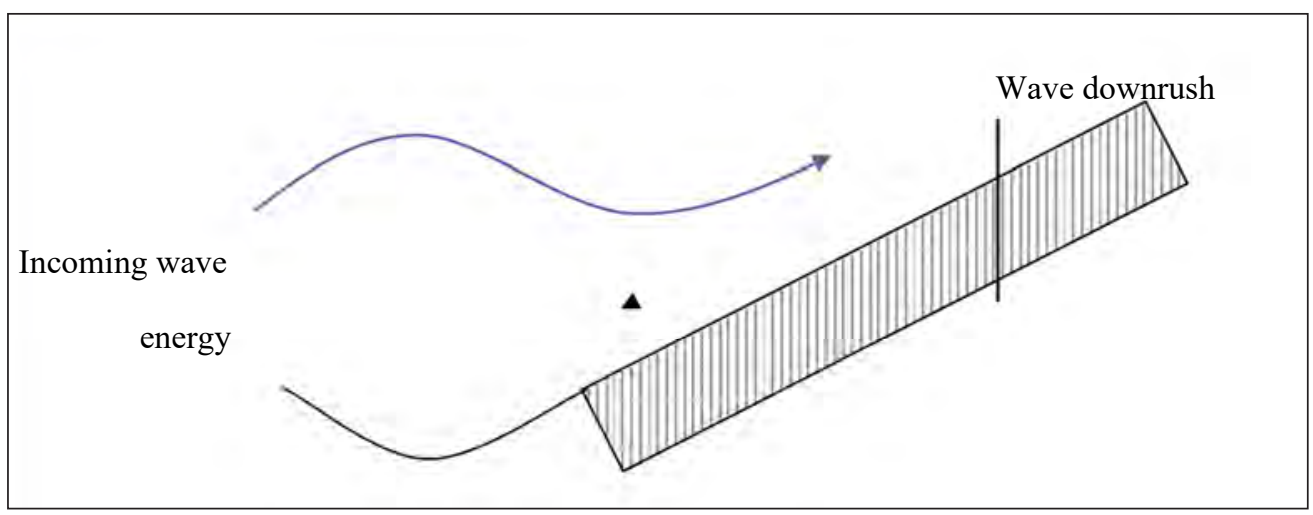


Figure 1.22: Land area requirements for sea dikes

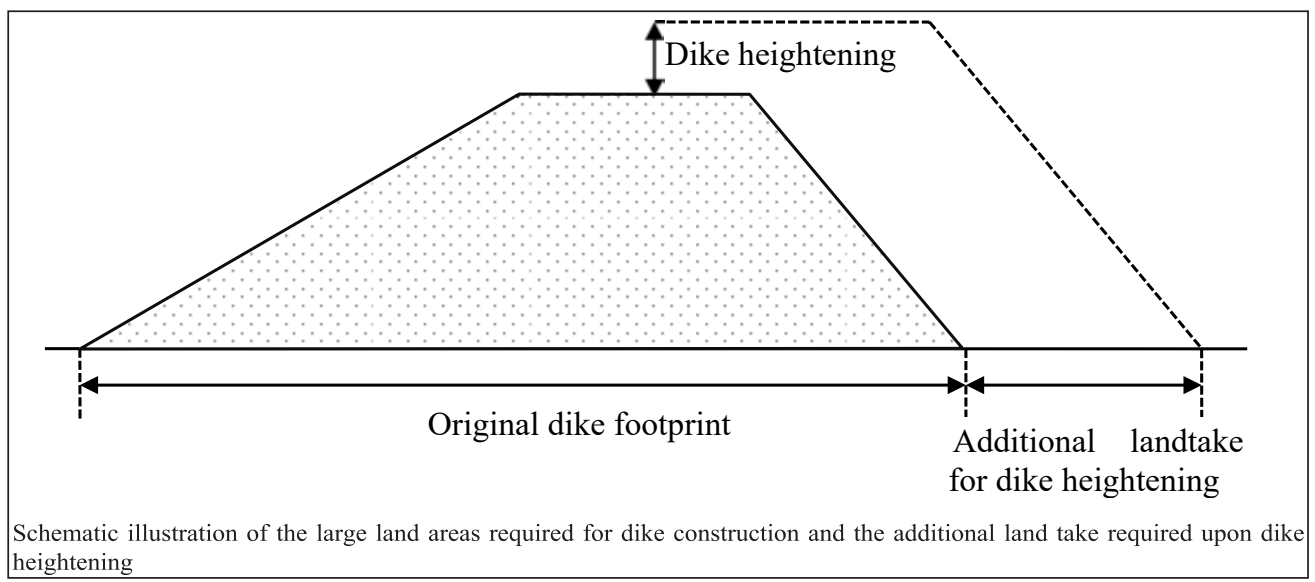

Like all tight security, the Dykes can create a false sense of security on the ground. Strict security construction firmly fixes the location along the coast. This can be detrimental as the coast is a naturally dynamic system. Coastal location adjustment can prevent natural coastal processes such as responding to changes in sea level, beach / dew interaction, and sediment input from coastal erosion (France, 2001). The cessation of these processes not only affects the immediate environment, but also the impact of tapping elsewhere on the coast, as the coastal system shares sediments in a coastal cell.

Beach enincing measures can be particularly aesthetically pleasing, especially in areas where natural beaches depend on a valuable tourism economy (IOC, 2009).

\section{Costs and Financial Requirements}

The best cost information for Guinea Gold is provided by Hilan et al. (2010) Review of Vietnam, the Netherlands and New Orleans. Millions of U.S. people present information as to the cost of raising a dyke per linear kilometer.

Cost in Vietnam to make dyke, al. (2010) are sometimes more relevant than developing countries. In Vietnam, dyke construction costs have been shown to vary from $\$ 0.9$ million to $\$ 1.6$ million per kilometer - significantly less than construction in the Netherlands or New Orlean (Hillen et al., 2010). The cost varied due to different costs of materials, land use and internal / external protection of the dyke slope. When comparing completed projects in Vietnam, it was observed that labor costs are highly variable even within the country.

The cost of building the dyke will be shown by Hilan et al. (2010) Significant difference between rural and urban areas. This is the situation around the world. Cost affects a number of other factors described in Box 1.4. 


\section{Box 1.4: Factors affecting the unit cost of sea dyke construction}

- Land availability and cost. As shown in Figure 4.13, dike construction needs significant land input. Accurate cost studies often draw a distinction between rural and urban construction costs to reflect differential land values

- Selected dike design and in-built margin for safety. This can affect the volume of the structure and the requiredmaterials

- Anticipated wave loadings; higher wave loadings require more robust and expensive structures. Wave loading is affected by wave breaker types, cleanness of the breaking wave, seabed shape and individual storm characteristics such as storm duration, wind strength and storm orientation in relation to the structure

- Single or multi stage construction; aggregate costs are lower for single stage construction (Nicholls \& Leatherman, 1995)

- Proximity to and availability of raw construction materials

- Availability and cost of human resources including expertise

These expenses are presented in 2009 USD. This cost variability is largely due to the fact that dyke maintenance in the Netherlands is well organized and given high priority, but in many other places maintenance programs are less rigorous. To some extent, local factors such as labor and material costs and various types of dyke / coastal protection measures will also affect costs (Hillen, pers comm.).

\section{Institutional and Organizational Requirements}

Construction of seaports can be done on a local scale (Section 1.3.1.2). However, the efficiency of the structure can be significantly improved by an enhanced science and technology base through the intervention of large organizations.

The temporary construction of the Coast Guard will pay less attention to water levels, wave height and wave loads in the event of an extreme event. This is largely due to the fact that these events are difficult to predict without well-developed knowledge. Therefore, temporary protection usually provides a lower level of protection.

Dykes designed and built by local communities are likely to use local materials and traditional methods. Although the only option available, this should not be the most effective approach. Providing design and construction guidelines for even the smallest details such as recommended slopes and material may improve the effectiveness of security structures.

Depending on global location (Linham et al., 2010) and additional annual maintenance costs, Dyke can cost anywhere from $\$ 1$ million to $\$ 7.6$ million per kilometer. Therefore, external funding is required before a successful dyke construction project can proceed.

If implementation at the community level continues, it is imperative that the broader security implications for the coastal zone be ignored. It is easy to focus on 
local benefits and ignore the big picture when implementing projects at the local level. As noted under the disadvantages of dykes, some effects of dyke construction can be felt at a considerable distance from the active site. Local level dyke activation may require less attention to minimize these effects.

Extreme care must be taken if the implementation of temporary, coastal communities is to proceed. Because dykes are often designed to protect large areas of low-lying areas, catastrophic failure due to poor planning can be associated with a significant threat to the lives of a significant number of people.

\section{Barriers to Implementation}

One obstacle to activating a large space for sea ducks. This factor is especially important in areas where coastal value plays an important role in determining adaptive technologies. The availability of materials, labor, and specialized machinery to build dykes may also be a barrier to the implementation of this technology.

The cost of implementing an effective dyke system can sometimes prove to be a barrier. This is especially true in areas of high wave energy that require additional protective elements such as rip-wrap (IOC, 2009).

The most effective dikes are those that are designed with good quality, longterm environmental data in mind, such as wavelength and extreme sea level information. Obtaining long-term datasets is one of the major barriers to building a dynamic dyke that leads to local conditions. The cost of collecting such data can be costly. However, by calculation for these local conditions, dyke design is generally more efficient. The additional cost of data collection and unique design can be a barrier to implementation in some situations.

\section{Case Study: Nam Dinh Province, Vietnam}

Vietnam is located in the tropical monsoon region of Southeast Asia and is prone to hurricanes. A large portion of Vietnam's population is concentrated in the lowland river flood plains, deltas and coastal borders. This population is mainly involved in agriculture and fisheries (Mai, 2004).

Namdin Province is part of the Red River Delta in northern Vietnam. This area is lowland and has a coastline of about $70 \mathrm{~km}, 95 \%$ of which is protected by dykes (May, 2004). As shown in Figure 1.23, most of this coastline is protected on both sides. This will help limit freshwater flooding in the event of a breach (Mai, 2008).

Nam Din's coastline is prone to severe erosion and storms. Therefore, the dyke system has two main functions: (1) flood protection and (2) freshwater protection from erosion (May, 2004). It is important to prevent these processes as erosion reduces agricultural land, flooding and overcoming safety poses a risk to human life, and agricultural produc reduces productivity leading to saltwater intrusion. Furthermore, the risk of floods constantly discourages farmers from using new technology or investing in other sources of income (Mai, 2004). 
Ducks in the Nam Din region have high altitudes that can cause high tides, storms and waves. They also have an extra margin for protection. However, funding problems and a lack of equipment have contributed to Dyke's construction, with structures weakening and collapsing as a result (Mai, 2004). The typical dyke cross section for the name din is shown in Figure 1.24. These structures usually have local sand and clay surface soils and reveal natural rock, artificial blocks or clay layers. The use of local clay is problematic as the material is thin and easily seawater (Mai, 2004).

Built to withstand loads with a repetition of 1 in 20 years, Dyke in Nama Din has a lower design standard in reality. Dyke failures can be expected to occur almost annually (Mai et al., 2008). Lack of information such as budget constraints, sea levels and water levels and wave heights, and lack of appropriate planning methods are largely responsible for the predicted design standards (Mai et al., 2008).

In response to these problems, the Vietnamese government has launched a large sea dyke program

With two important functions:

1 Research on safety standards, border conditions and find optimal solutions for maritime security throughout the country

Design and construction of new dykes in locations that have not previously existed or have been breached. This includes strengthening existing ducks based on the findings of Task 1

Figure 1.23: Schematic illustration of the double dike system utilised in Nam Dinh Province, Vietnam

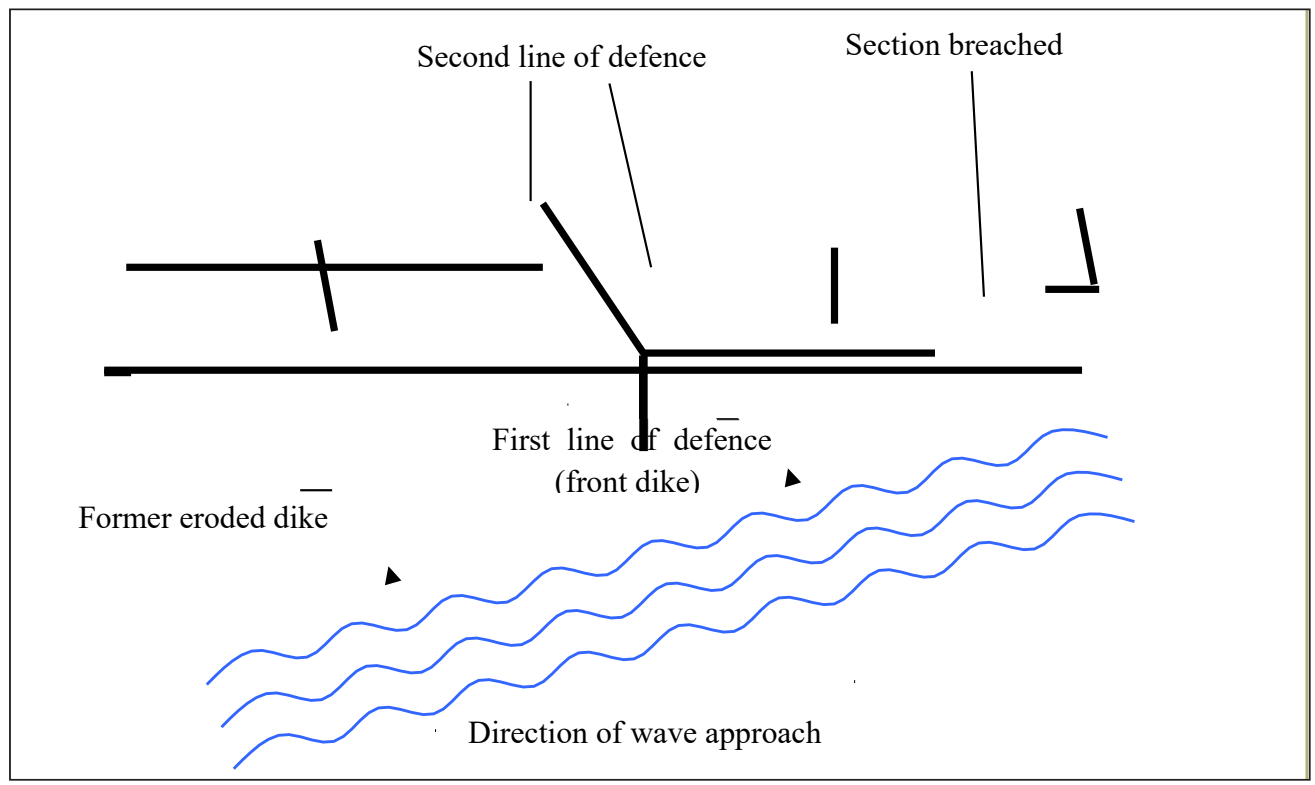

Source: Adapted from Mai, 2004 
Figure 1.24: Representative cross-section of sea dikes in Nam Dinh Province, Vietnam

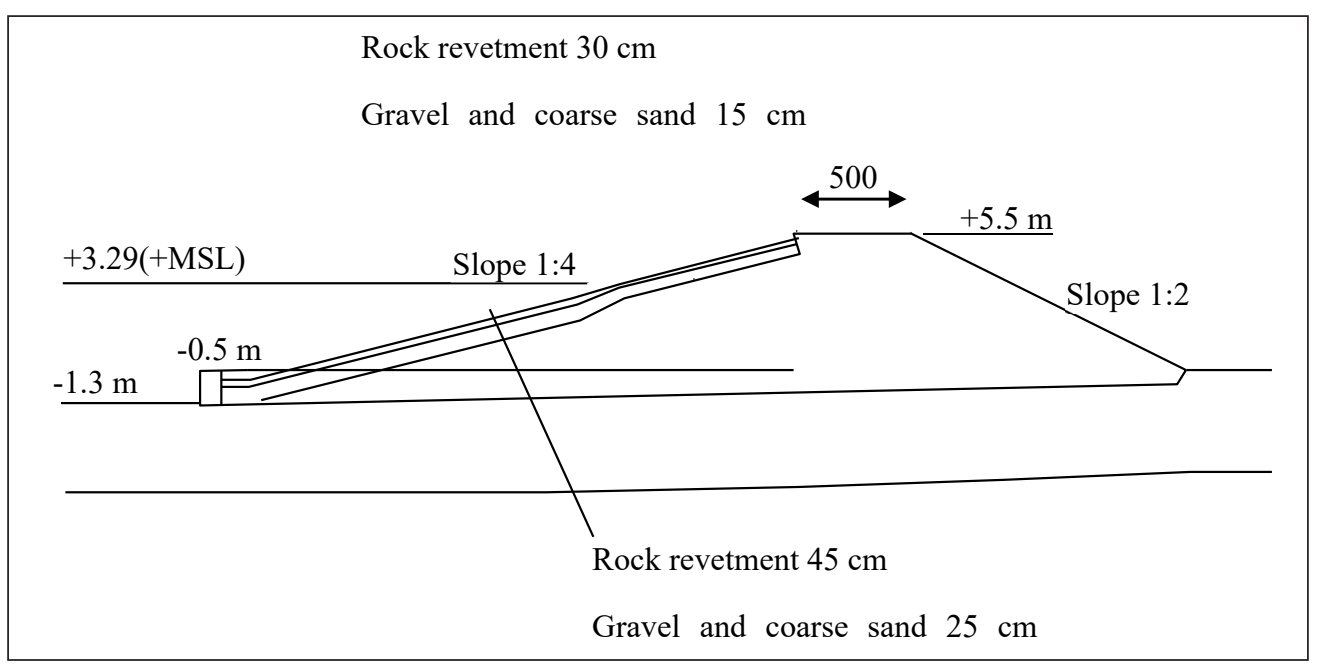

Source: Mai, 2008

Nam Din's case highlights some important points to keep in mind when implementing coastal adaptation measures:

1. It is important to select an appropriate coastal management approach. Given the high shoreline erosion rates around Nam Dinh and the limited funds available for construction of hard defences, it may be worth considering accommodation and retreat options over the long term

2. It is vitally important to design adaptation measures with local conditions in mind. The design of an effective coastal structure will require information on boundary conditions such as water levels and wave climate.

3. The ability to fund coastal protection measures is of paramount importance. In Vietnam, budget constraints led to weakened coastal structures which offer a false sense of security. Construction of sub-standard defences may encourage development in highly risky locations

4. Continued investment in maintenance measures is essential to repair damage caused by extreme events

\subsubsection{Storm Surge Barriers and Closure Dams}

\section{Definition}

Coastal flood mitigation is a rigidly engineered structure for storm surge barriers and closure dams. Their secondary role is to shorten the defensive length behind the barrier. This reduces the risk of security failure and reduces the cost of 
providing additional security. Surge barriers are movable or stationary barriers or gates that are closed when a high water level is predicted to prevent flooding. Closing dams are a permanent structure that closes permanently at the mouth of a river or estuary. Water is drained for these and fixed barriers, or pumped over the barrier (IOC, 2009).

\section{Description}

Hurricane barriers and closure dams are large-scale coastal protection projects that can protect against occasional storms (tidal inlets, rivers, and estuaries) (UNFCCC, 1999). They provide a physical barrier to prevent storm surges. This helps to keep the high water level low minimizes coastal flooding. Both of these solutions are often implemented with narrow tide inputs where the length of the structure does not need to be so large and the protection behind the barrier can be reduced in height or length. An example of the construction of a closure dam in Bangladesh is shown in Figure 1.25.

Storm surge barriers most commonly consist of a physical, movable barrier across the mouth of a tidal inlet or estuary. While there are no known examples in the developing world, a number of projects have been completed in developed countries, mainly in Europe. For example, the Thames Barrier, London, the Maeslantkering Barrier, Rotterdam and the St. Petersburg Flood Protection Barrier,

Figure 1.25: Closure dam under construction at Jamuna river, Bangladesh

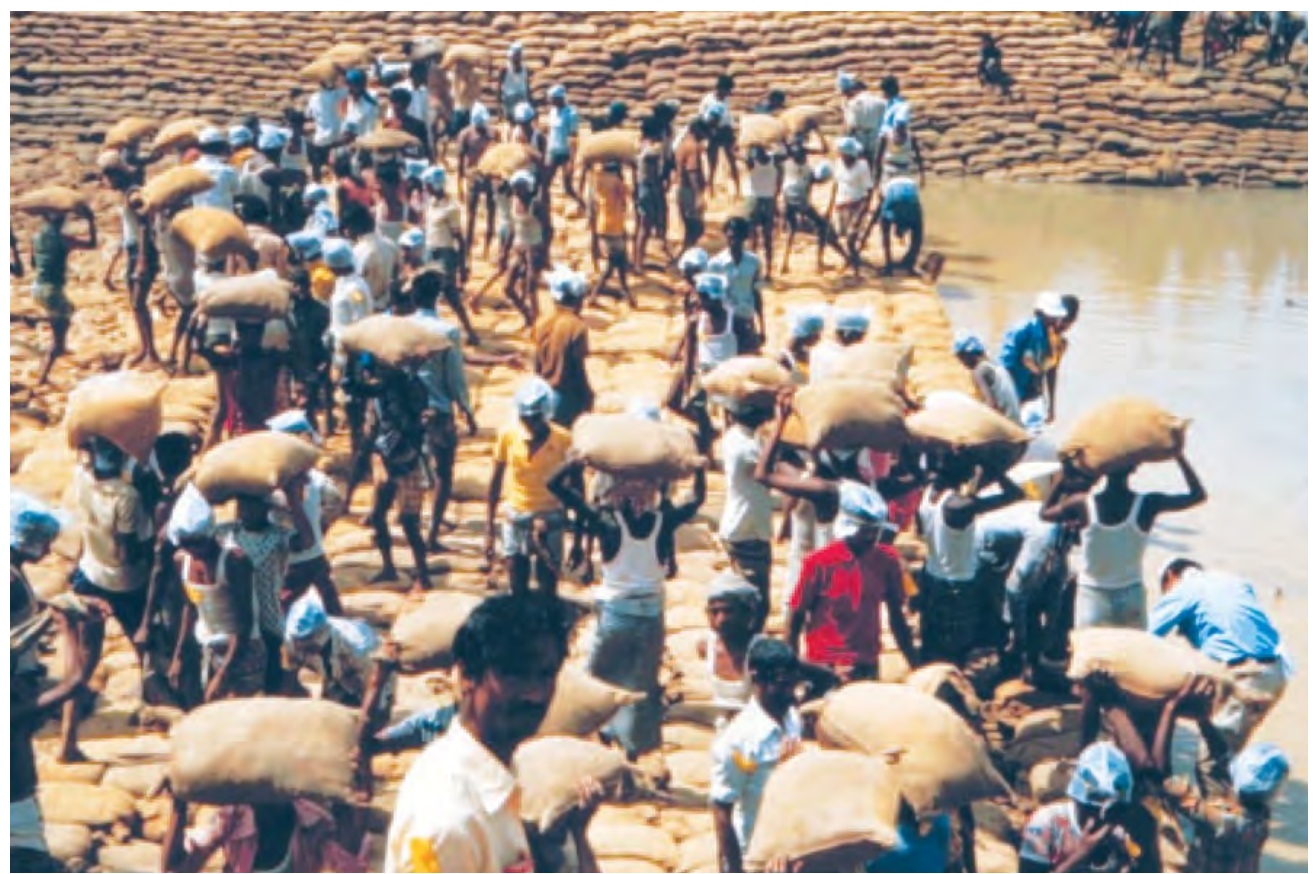

Source: Courtesy of K. Pilarczyk 
while the MOSE project in Venice is scheduled for completion in 2012. Although each of these projects has roughly the same objective, the design of these structures varies significantly.

Fixed barriers and closure dams are a lower technology option which may be more appropriate in developing countries. These are non-movable barriers across tidal inlets or estuaries. They constructed through gradual or sudden closure of an inlet. Gradual closure can be accomplished through land-based construction which gradually narrows the inlet, or by water-based construction which builds a barrier up, layer by layer, from the seabed. Alternatively, sudden closure blocks an inlet in a single operation, using pre-installed gates or by the placement of a caisson7.

Examples of completed closure dams include the Feni closure dam in Bangladesh, constructed mainly to provide a freshwater reservoir for irrigation purposes, several projects in Korea to close tidal basins, mainly for land claim (van Houweninge \& de Graauw, 1982) and the Afsluitdijk, in the Netherlands, which separates what is now Lake IJsselmeer from the North Sea.

Movable barriers will require the simultaneous implementation of a storm surge monitoring and forecasting system (an adaptation option in its own right and discussed in Section 1.3.1.5). This will allow the barrier to be moved into position before a storm surge arrives. Because closure dams are fixed structures, they do not require these systems.

While there are clear differences between storm surge barriers and closure dams, the coastal defence purpose of the structures is the same; to prevent extreme water levels penetrating an estuary. The method, by which this is achieved, is illustrated in Figure 1.26.

Surge barriers and closure dams can be easily integrated into a larger, overall flood prevention systems. For example, barriers may be present alongside additional flood prevention works such as dikes and flood warning systems (Sections 1.3.1.4).

\section{Advantages of Storm Surge Barriers and Closure Dams}

Storm surge barriers and closure dams provide a high degree of protection against coastal flooding by preventing storm surges from entering low-lying estuarine areas. Although permanently closing off the estuary mouth using a closure dam, would achieve the same outcome, the use of a movable barrier allows waterways to remain open during normal conditions. This can be beneficial to trade if the estuary also acts as a trading port and is also valuable for estuarine species reliant on brackish water8 conditions.

The two technologies effectively reduce the height of extreme water levels in the area behind the barrier, if closed in a timely fashion. Doing so may allow the strength of existing defences behind the barrier to be reduced (Hillen et al., 2010). This will reduce both construction and maintenance costs for defences on the landward side of these structures. 
Figure 1.26: Methodical illustration of storm barriers and barrier dams to prevent coastal flooding

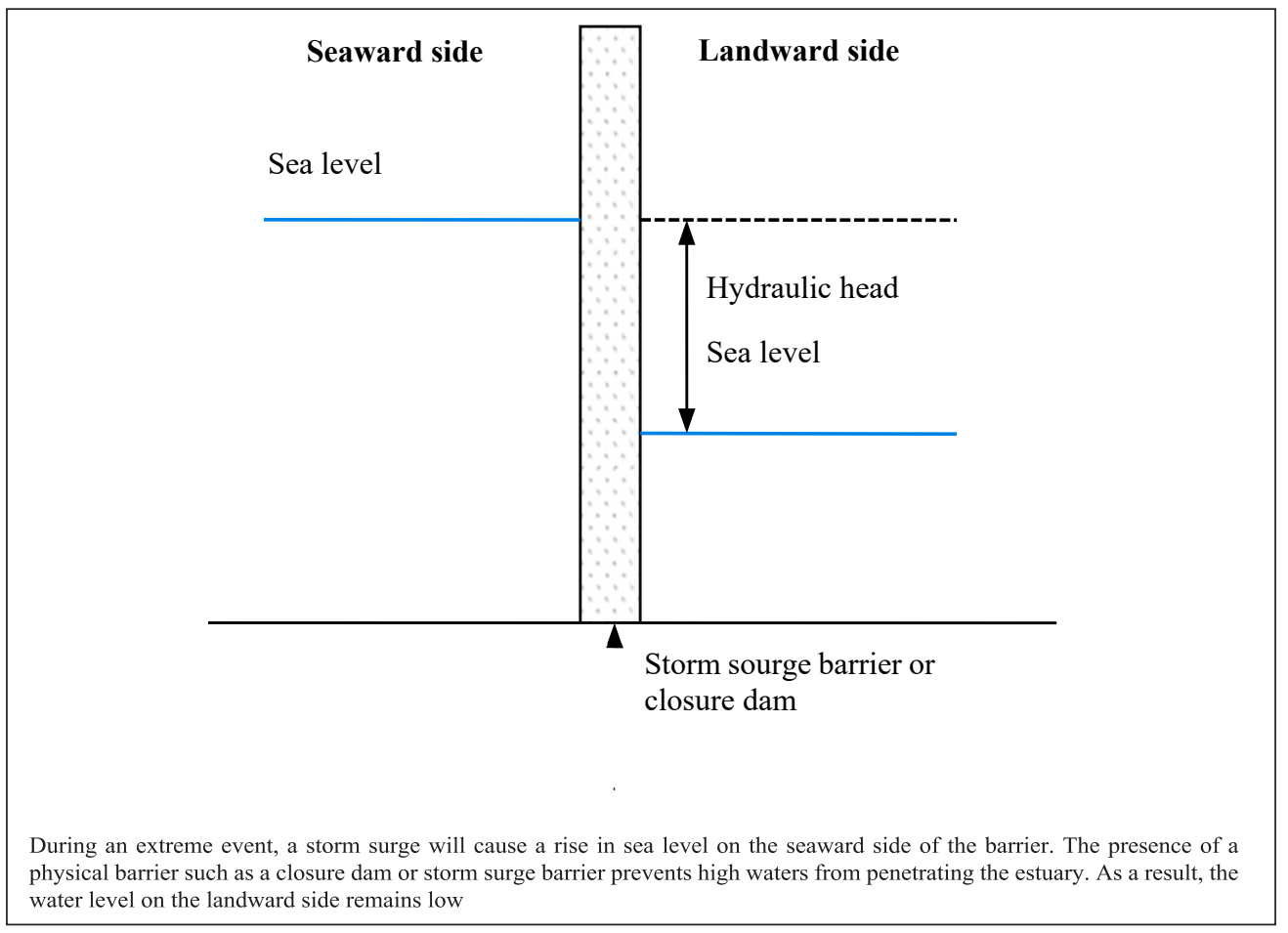

By reducing the height of extreme water levels inside of the barrier, the length of a coastal flood defence system may also be shortened (Hillen et al., 2010). This too, would have the effect of reducing maintenance and construction costs of defences on the landward side of the barrier.

More than one barrier may be constructed to close off narrow inlets into a tidal system, such as a lagoon. This is the case in Venice under the MOSE project where three barriers are under construction to close three of the lagoon's narrow tidal inlets. Through the construction of multiple barriers, the scheme offers the additional benefit of enhancing the lagoon's natural capacity to clean itself. This is achieved by independently opening and closing selected barriers, depending on wind direction. By closing barriers it enhances the ability of the wind to drive water out of the lagoon, therefore increasing the turnover of water, dispersing pollutants.

Closure dams can provide additional benefits by forming a permanent barrier between freshwater and the sea. For example, in Bangladesh, the Feni closure dam was constructed primarily to provide a reservoir of freshwater for irrigation purposes. Closure dams may also be used in conjunction with land claim (see Section 1.3.1.6) and may even be used for the production of tidal energy (van Houweninge \& de Graauw, 1982). 


\section{Disadvantages of Storm Surge Barriers and Closure Dams}

One of the key disadvantages of the storm surge barrier is the high capital and maintenance costs.

Significant investment is required to construct these structures and to continually maintain them. In addition, movable barriers also require simultaneous investment in flood warning systems which provides information on when to close the barrier. This cost is avoided through the use of a closure dam, which also has lower capital and maintenance costs.

A potential disadvantage of both climbing barriers and closing dams is that flooding can occur on the landward side of the barrier when river levels are high, and in movable barriers, if safety is closed for extended periods of time. Landslides occur as a result of water seeping into the landward side of the barrier. This should not be a problem, as closed dams are designed to successfully withstand

Table 1.5: Overview of storm barriers, types and costs

\begin{tabular}{|c|c|c|c|}
\hline $\begin{array}{l}\text { Barrier and } \\
\text { Location }\end{array}$ & Barrier Type & Hydraulic Head (m) & $\begin{array}{l}\text { Construction Costs } \\
\text { (2009 price level) } \\
\text { (US\$ mil.) }\end{array}$ \\
\hline $\begin{array}{l}\text { Ems } \\
\text { Germany }\end{array}$ & Sector gates & 3.8 & 519 \\
\hline $\begin{array}{l}\text { Thames Barrier, London, } \\
\text { UK }\end{array}$ & Sector gates & 7.2 & 2043 \\
\hline $\begin{array}{l}\text { IHNC Barrier, } \\
\text { New Orleans, USA }\end{array}$ & Sector gates & 4 & 730 \\
\hline $\begin{array}{l}\text { Seabrook Barrier, } \\
\text { New Orleans, USA }\end{array}$ & $\begin{array}{l}\text { Vertical lifting gates/ } \\
\text { sectorgates }\end{array}$ & 4 & 162 \\
\hline $\begin{array}{l}\text { Hartel Barrier, Hartel } \\
\text { Channel, NL }\end{array}$ & Vertical lifting gates & 5.5 & 202 \\
\hline $\begin{array}{ll}\text { Eastern } & \text { Scheldt } \\
\text { Barrier,NL } & \end{array}$ & Vertical lifting gates & 5 & 5670 \\
\hline $\begin{array}{l}\text { Maeslantkering } \\
\text { Rotterdam, NL }\end{array}$ & Floating sector gate & 5 & 925 \\
\hline $\begin{array}{l}\text { MOSE Project, } \\
\text { Venice, IT }\end{array}$ & Flap gates & 3 & 6596 \\
\hline $\begin{array}{l}\text { Ramspol, } \\
\text { Near IJssellake, NL }\end{array}$ & Bellow barrier & 4.4 & 186 \\
\hline
\end{tabular}

Source: Hillen et al., 2010 
extreme river discharges and studies have been conducted to determine the maximum closure duration with respect to movable barriers.

Both surge barriers and closure dams have the capacity to change the chemical, physical and biological properties of estuarine systems by altering the inflow and outflow of water from the estuary. This may include alterations to water salinity, temperature, suspended matter, nutrients which all have the potential to affect local communities of organisms (Elgershuizen, 1981). These changes will be more important in a closing dam because a barrier is permanent. These effects can be minimized by applying movables rather than fixed doors (IOC, 2009).

\section{Table 1.6: Costs of completed closure dams in Bangladesh}

\begin{tabular}{|c|c|c|c|c|}
\hline Project & $\begin{array}{c}\text { Year } \\
\text { Completed }\end{array}$ & $\begin{array}{l}\text { Barrier width } \\
\mathrm{x} \text { depth }(\mathrm{m})\end{array}$ & Construction Materials & $\begin{array}{l}\text { Cost (2009 } \\
\text { value })^{1}\end{array}$ \\
\hline Feni River & 1985 & $\begin{array}{l}1200 \mathrm{~m} \text { width } \\
\text { Unknown depth }\end{array}$ & $\begin{array}{l}\text { Clay filled sacks } \\
\text { Bamboo } \\
\text { Reed rolls Steel } \\
\text { beams Bricks \& } \\
\text { blocks }\end{array}$ & US\$38 million \\
\hline $\begin{array}{l}\text { Chaka Maya } \\
\text { Khal }\end{array}$ & 1979 & $210 \times 5.5$ & $\begin{array}{ll}\text { Bamboo } & \text { Palm } \\
\text { leaves } & \text { Reed } \\
\text { bundles } & \\
\text { Timber } & \text { piles } \\
\text { Jute } & \end{array}$ & US\$1.3 million \\
\hline Amtali Khal & 1982 & $130 \times 8$ & $\begin{array}{l}\text { Reed bundles } \\
\text { Golpata leaves } \\
\text { Clay filled sacks } \\
\text { Timber piles }\end{array}$ & $\mathrm{Tk}^{2} 16$ million \\
\hline
\end{tabular}

1 Due to the absence of historic exchange rate data, it has not been possible to convert costs to a common currency.

2 Bangladesh Taka-the currency of Bangladesh.

Source: DHV Haskoning, 2007

As shown in both Tables 1.5 and 1.6, the cost of construction of the embankment barrier and closure dams is highly variable and may affect the factors listed in Box 1.5 with the project cost.

\section{Institutional and Organisational Requirements}

Significant engineering studies are required to design and install these structures for the effective operation of storm surges (IOC, 2009). Barrier design is technically challenging and almost impossible at the community level. In addition, as seen under the Cost and Financial Needs section, rising barriers can be very expensive and funding can be scarce at the local level. Therefore, technical assistance can be obtained from coastal engineering consultants or other experienced organizations, as well as from outside organizations such as NGOs or local authorities and enterprises that benefit from the structure. 


\section{Box 1.5: Factors affecting storm surge barrier and dam construction unit cost}

- Typeofbarrier

- Localsoilcharacteristics

- Desired height of the barrier

- Required hydraulic head for the structure

- Anticipated wave loadings; higher wave loadings require more robust and expensive structures

- Single or multi stage construction; costs are lower for single stage construction (Nicholls \& Leatherman, 1995)

- Proximity to and availability of raw construction materials

- Availability and cost of human resources including expertise

In addition to the hardware, effective forecast and warning systems are required when implementing a movable storm surge barrier. This may require significant institutional capacity (IOC, 2009). Implementation of a flood warning system requires some or all of the following tasks to be conducted: system design, management and forecasting of floods, operation, detection of storms and warning dissemination (Sene, 2008).

Closure dams and non-movable barriers are lower technology alternatives to movable surge barriers. A number of such projects have been successfully constructed in countries such as Bangladesh and Korea. To make these projects more feasible at a local level, construction methods may employ local materials and labour, although guidance from experienced contractors would also prove beneficial (e.g. DHV Haskoning, 2007).

\section{Barriers to Implementation}

The high cost of surge barrier construction (shown in Table 1.5) and the requirement for specialist knowledge in the design and implementation phases may prove a barrier to implementation of storm surge barriers.

Additionally, surge barriers and closure dams are not suitable for all locations. They are most appropriate in locations where a narrow river mouth or inlet can be closed. Alternatively, they are appropriate where the length behind the barrier that would otherwise require defending can be substantially reduced; in the case of a short defensive length, it may be more effective to upgrade defences than to construct a barrier.

Although barrier construction across narrow channels is cheaper, it is apparent that surge barriers can be implemented where narrow inlets are absent, provided sufficient funds for construction are available and the political will exists. For example, the St. Petersburg Flood Protection Barrier employs two movable 
storm surge barriers within a man-made $25.4 \mathrm{~km}$ long barrier, across the mouth of the Neva Bay on the Gulf of Finland.

\section{Opportunities for Implementation}

Opportunities for the implementation of storm surge barriers are numerous. The MOSE project in Venice, Italy, has demonstrated the capacity for surge barriers to offer co-benefits alongside flood protection. For example, opening and closing specific barriers depending on the wind direction can facilitate dispersion of pollutants thus helping to improve coastal water quality. This is beneficial for both recreation and tourism.

Storm surge barriers can also provide additional services such as recreation, amenity and water supply when appropriately designed. The Marina Barrage in Singapore was completed in 2008 and provides an excellent example of the additional benefits which can be gained from a well designed surge barrier. As well as providing protection against coastal flooding, construction of the barrier has also provided a large reservoir which will help meet water demand in one of the island's most urbanised catchments (Moh \& Su, 2009). By eliminating tidal influence inside the reservoir the area is now an ideal venue for recreational activities such as boating, windsurfing and water skiing (Moh \& Su, 2009). By integrating an art gallery and retail outlets into the barrier design, the defence is also now a significant tourist attraction.

Storm surge barrier projects have also been seen to act as a catalyst for development of newly protected areas. This was observed following construction of the Thames Barrier, when London's derelict docklands were regenerated with new transport links, homes, businesses and the important financial district around Canary Wharf (Nicholls, 2006).

In future there could even be opportunities to integrate storm surge barrier or closure barrier design with the production of renewable hydroelectricity. This will provide long-term, sustainable energy as well as security of energy supply for local communities.

\section{Case Study: Chaka Maya Closure Dam, Bangladesh}

Chaka Maya is located in the southwestern district of Patuakhali in Bangladesh. During 1978-79, a dam was built across the Andarmanik River overflow. The following project information is obtained from DHV Haskoning (2007).

The channel through which the dam is built is 210 meters wide and the average depth is less than 5.5 megavol. Conventional methods could not be used because of the size and depth of the channel. The dam was constructed using traditional Dutch methods on the recommendation of an experienced international coastal engineering consultant. This method is easily accessible, using local material and manual labor, barrier from the seabed, layer by layer, layer by channel.

The closure dam will be constructed in four phases. First, a large bottom safety mattress, measuring $17 \times 45 \mathrm{~m}$, was installed on the channel bed. Their goal 
was to prevent excessive water currents and turbulent erosion. The mattresses are made of bamboo, reeds and palm leaves and are tied with jute ropes. They are ballasted from clay-filled bags and sunk into the channel bed, then anchored with ropes.

Next, 5500 clay-filled bags were used, prioritizing policy offerings to the minimum water level. Prioritizing policy offerings, more secure mattresses were ballasted using soil-filled bags. Third, a large watertight chamber is built and filled with clay-filled bags, giving priority to policy offerings. The purpose of this activity is to stop the flow of water. The chamber was called Cofferdam and consisted of three chambers.

The 8-meter-wide, waterproof chamber was filled to the brim with design dimensions and levels to complete the closure dam. Statistically modeled for a storm return period of 1 in 20 years, this soil-filled dam is designed with sufficient cross-section and logo height to withstand the associated water levels and wave climate.

The final cost of the project in 1979 was US $\$ 500,000$ and required 180,000 man-days to complete. This labor was sourced from local communities. When adjusted for inflation, the cost of this project is approximately US $\$ 1.3$ million at the 2009 price level.

\subsubsection{Land Claim}

\section{Definition}

The main purpose of land ownership is not erosion or storm mitigation. The purpose of land ownership is to create new lands in areas where the former high tide has receded.

Land ownership can be achieved by encircling or filling in or near coastal areas (Bird, 2005). Several alternative terms can be used when referring to land ownership; This can include land reclamation, landfill filling and line moving forward.

\section{Description}

This is a more aggressive coastal defense system and can more accurately be referred to as 'attack' or 'line forward' under the methods of land claim shown in Figure 1.27. Land ownership is usually done to acquire land for agricultural or development purposes (French, 1997). The cost is justified by the fact that land values are very high in coastal cities such as Singapore and Hong Kong. In recent years, large tracts of land in Dubai have been acquired for residential, leisure and

Coastal land ownership is often used in estates or deltas due to the large number of affordable, flat lands available for industrial development such as harbors and access to both land and sea (French, 1997). In areas such as the Delta, which has a positive sedimentation budget, land ownership often facilitates steady ex- 
pansion (e.g., Li et al., 2004), but this is likely to decrease further by the 21 st century due to sedimentation supply failures (e.g. Siwitsky et al. Others, 2009). However, engineering land ownership such as the Isle of Palms in Dubai will continue and the implications of the SLR should still be considered.

Land ownership usually takes place in the highlands of the inter-regional region. This is because high altitude interacts with lower inter-habitats, reducing wave energy and requiring less material to build up the claimed land relative to sea level. High altitudes are also selected as they do not have to be as high as the safety rings required to prevent overtaking. Finally, if required for agriculture, the upper intertidal zone presents more mature soil and is more suitable for farming than the lowland (French, 1997).

Although these projects require more engineering and investment, low altitude intermediate and subtropical areas can be used for land ownership. In order to claim low altitude areas, these areas need to be severely protected from flooding or significantly elevated through sedimentary deposits. The latter can be achieved in a similar way to sediment deposition during coastal feeding (see Section 1.3.1.1). Ambitious land ownership projects have been implemented in both Singapore and Hong Kong, where interstates and tidal flats have been filled by raising the altitude for development.

The use of hard defences to claim low-lying land, as shown in Figure 1.27, can be detrimental because these structures cause erosion and scour of the shoreline. Hard defences also prevent habitat adjustment in response to changing factors such as SLR (French, 1997). Other negative impacts associated with hard defences can be found in Sections 1.3.1.3 to 1.3.1.5.

Any kind of land ownership causes water to displace during a natural tidal cycle. This is illustrated by Figure 1.28. Due to this displacement, the incoming tide has a small area to submerge. This causes the water depth to increase, which means that the inter-regional areas are flooded - this has the potential to have negative biological consequences and increase the range of the upstairs (French, 1997).

By replacing a large amount of water, land ownership can change the basic erosion / prevalence characteristics of the estuary. Erosion / accretion characteristics of the estuary are closely related to the magnitude of the incoming and outgoing tides. When floods dominate, estates naturally accumulate sediments, i.e. when the outflow tide is larger than the size. However, by displacing water on the rising tide, land ownership can shift to estuary dominance, thereby increasing coastal sediment transport, erosion, and depth (Fredericks et al., 1992). If the volume of land ownership is sufficient, there may be problems with the erosion of the previous permanent estuary.

The construction of tight security rings prevents interactions between the sea and the mountains. If coastal deposits of sand dunes, mudflats or salt marshes are located behind these defenses, they will be prevented from contributing to the local sedimentary budget. This can be problematic because these sedimentary deposits are required during erosion. Without them, future sedimentation shortages and consequent erosion problems are likely (French, 1997). 
Figure 1.27: The main methods of land claim

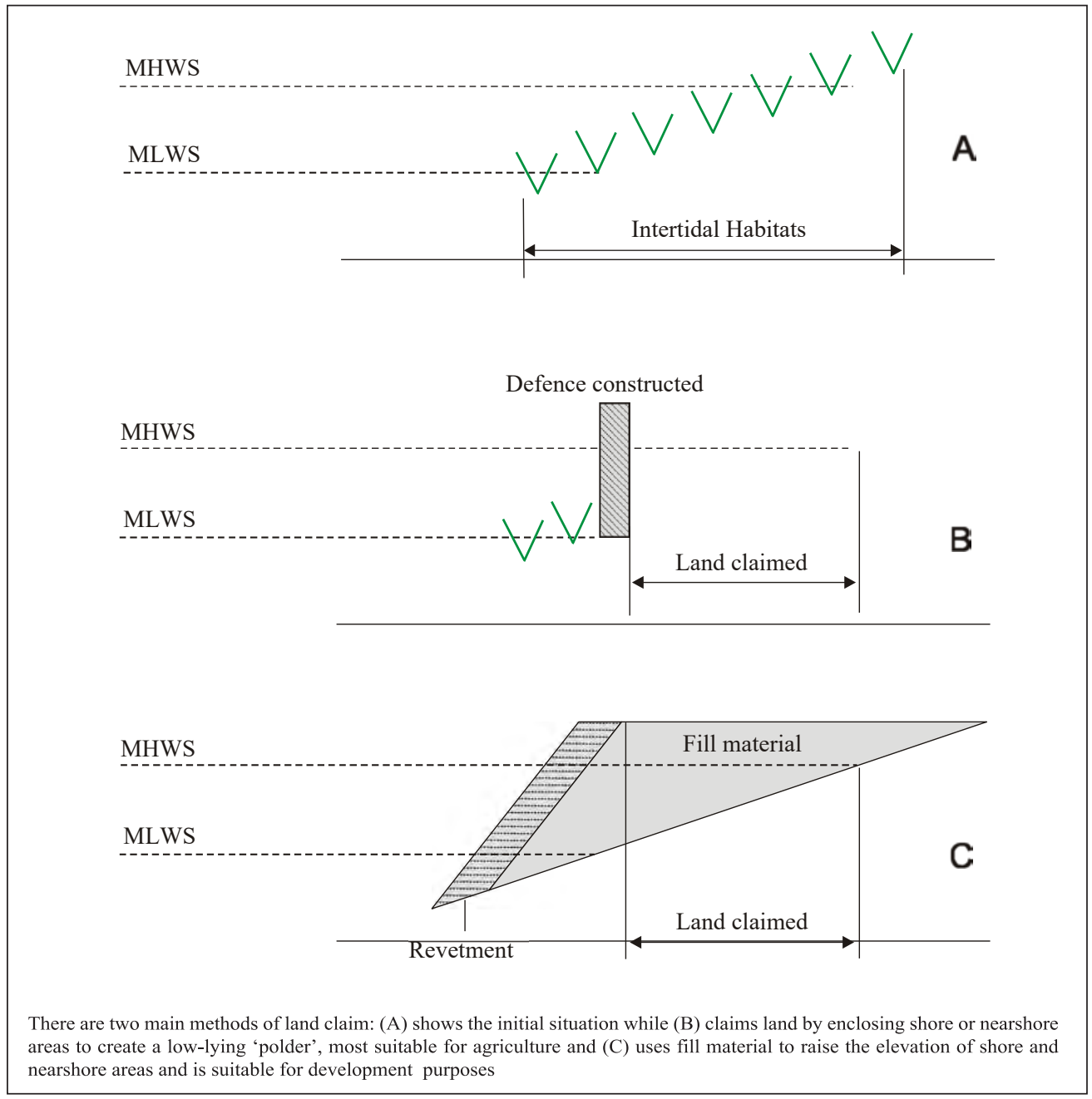

Land ownership can introduce pollution to coastal areas and acidification of coastal waters. This can be problematic when the claimed land is important for use in agriculture or for coastal water fishing. Contaminants can be introduced using sediments dug for land elevation - Caused by the application of hazardous chemicals from coastal industries, ships, or upstream sources. Acidity, on the other hand, is related to the bacterial activation of estrogen sediments that form sulfuric acid when exposed to air (Anderson, 1991).

If land ownership can be obtained by raising the elevation of previously submerged land, the cost of fillers may be the main factor determining project cost. On the other hand, these costs will be affected by the availability of suitable material, the proximity to the construction site and the characteristics of the filling site 
Fig 1.28 Water displaced due to land ownership during Natural Tidal Cycle

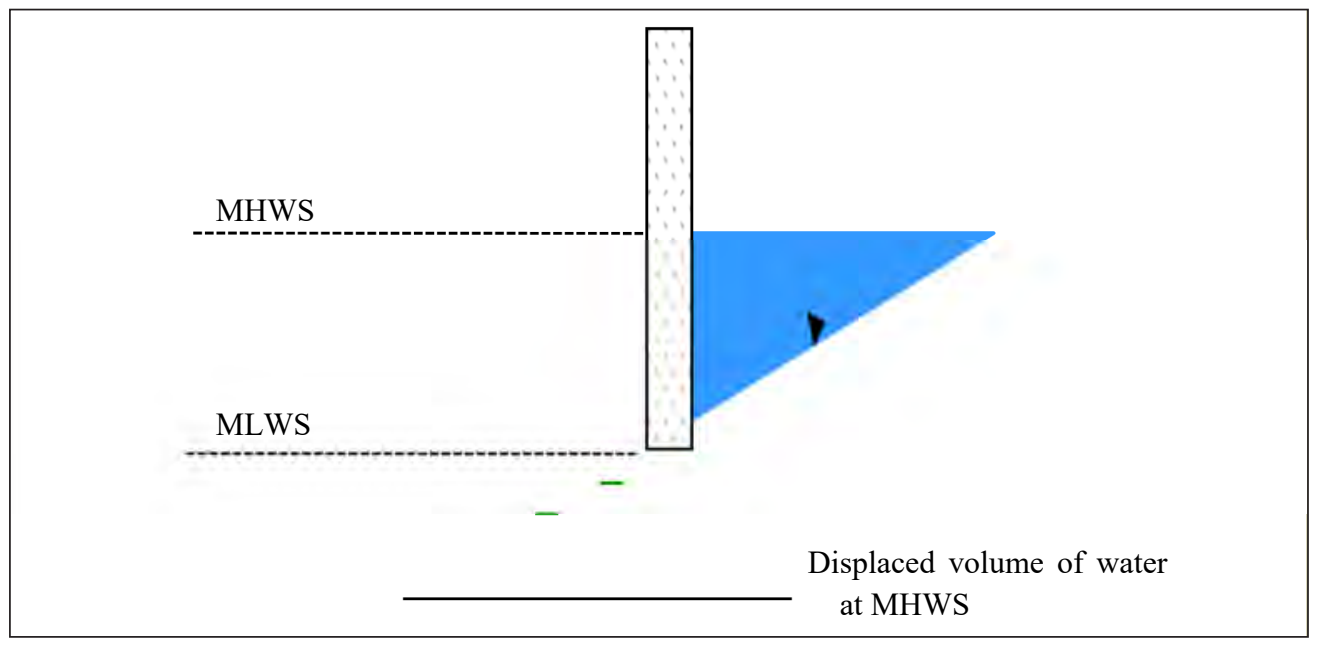

\section{Box 1.6: Factors affecting the cost of land reclamation projects}

- Chosen method of reclaim (enclosing previously intertidal areas using hard defences or raising the elevation of previouslysubmerged land)

- Availability and proximity of fill material from onshore or offshore sites

- Number, type, size and availability of dredgers

- Requirement for hard protection measures to defend reclaimed land from coastal flooding and erosion

- Project size and resulting economies of scale

- Estimated material losses

- this affects the type of excavation equipment that can be used. The cost of fillers is likely to increase in the future due to increased demand and increased restrictions on excavation.

\section{Institutional and Organisational Requirements}

The organizational and organizational needs of land ownership projects depend on the scale and purpose of the project. Small-scale land ownership for agricultural use is more likely to be achieved at the community level than for large-scale islands enlargement and creation, as is the case in Singapore or Dubai. These large-scale projects require the involvement of large organizations and large funds.

Due to the low energy wave climate and reduced filler requirements, land ownership at high inter-margins is easier to accomplish at the local level. Signifi- 
cant security measures are required for land ownership at greater water depths and a significant amount of filler material is required.

Small-scale land ownership projects have been carried out for centuries, and therefore the technical requirements of these schemes seem minimal. Projects Historic projects consisted of dyke constructions to clear the sea and then drainage measures were followed. Land Historic land ownership, however, has led to significant unpredictable environmental issues. These issues are discussed under the disadvantages of land ownership. Therefore, although land ownership can be done at the local level, its impact should be kept in mind and the benefits weighed against the benefits. If a project goes ahead, the involvement of organizations with a good scientific and technical basis will help minimize the negative impact.

\section{Barriers to Implementation}

Land reclamation in these areas can lead to the loss of ecologically important interconnected habitats and the impact of milking, such as changing flood / flood dominance. As a result, environmental opposition to land ownership may increase. In the EU, compensation is required for lost habitat; This is likely to spread to other countries throughout the 21 st century.

As mentioned in the disadvantage section, the adverse effects of land ownership are now better understood than in the past. Our knowledge of these impacts may reduce the acquisition of land ownership projects based on the principle of precaution.

\section{Case Study: Singapore}

Singapore, a small island nation in the South China Sea, has been involved in a number of large-scale land ownership projects since the 1960s. By 1991, reclaimed land was estimated to be $10 \%$ of the country's land area (Glazer \& Walsh, 1991). The extent of land reclaimed with planned future projects is shown in Figure 1.29 .

Land ownership is part of the island's history since the land was established in 1819. Early land ownership projects used the material in the surrounding hills to raise the elevation of floodplains. Lands, especially through mangrove swamps, were acquired through drainage (Glaser \& Walsh, 1991).

Singapore has been growing rapidly since the country declared independence in 1963. This led to increased demand for land for industry, transportation, infrastructure, commerce and housing (Glazer \& Walsh, 1991). Major land ownership projects are considered as a viable way to create additional land. The scale of land reclamation from autonomy can be understood as a response to rapid economic growth and an increase in related building activities (Glaser \& Walsh, 1991).

More recently, land ownership projects have stopped using the material in the mountains of the island. The majority now carry beach sand from countries such as Indonesia and Malaysia. This material will be imported by the filling contractors (Eisma, 2006). 
Figure 1.29: Past and Future Land Title Works in Singapore

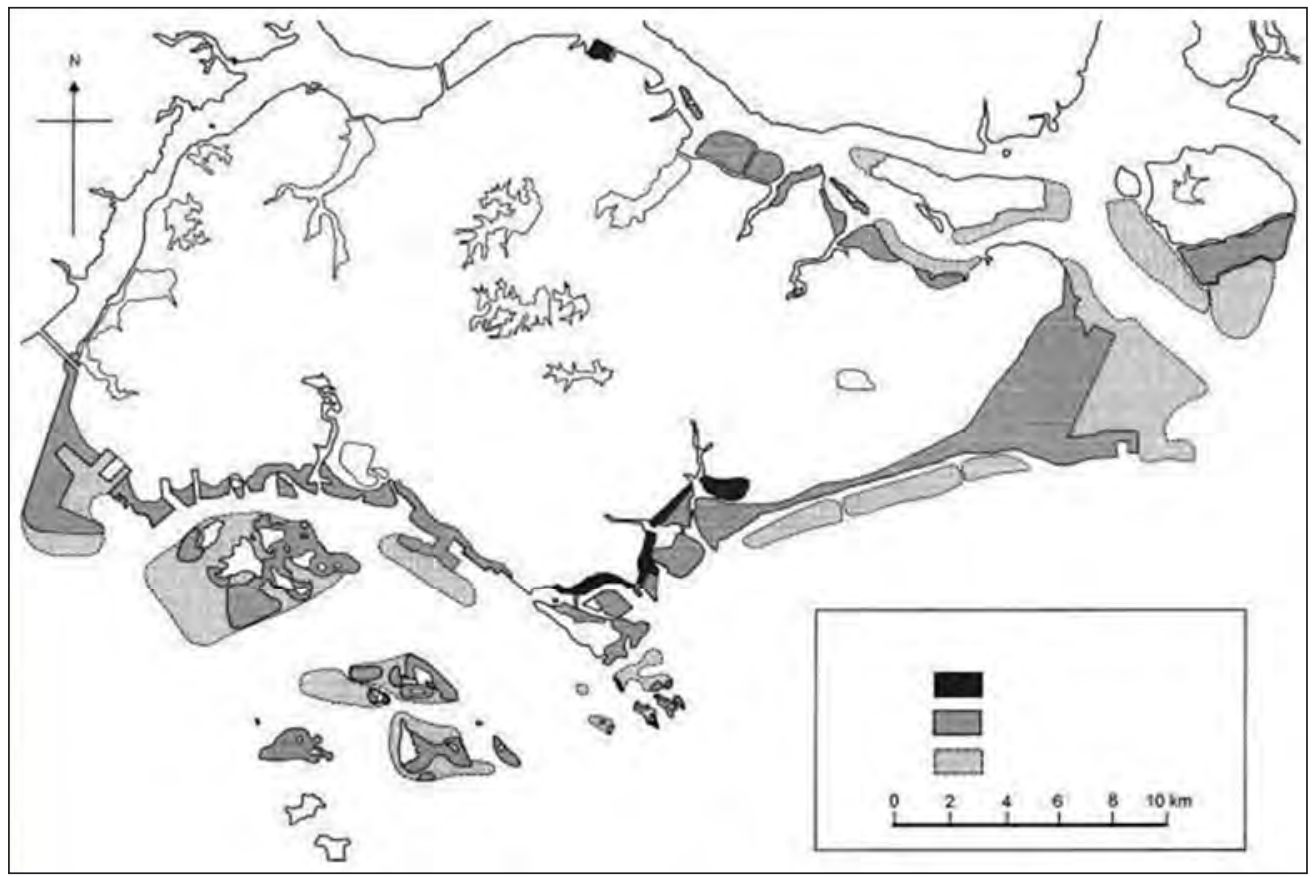

Source: Schwartz, 2005

One recent land ownership project designed to meet the demand for industrial land is the Jurong Industrial Estate Construction Project. The project will be located at a distance of $1 \mathrm{~km}$ from the sea (Eisma, 2006). Many offshore areas have also been reclaimed for the expanding petrochemical industry (Glaser \& Walsh, 1991).

In 1984, the Singapore government approved a landfill proposal. Upon completion of the project, $8.75 \mathrm{~km}$ of shallow coastline and wetlands will be reclaimed, primarily for residential construction (Omar, 2007). The project also involved clearing swamps and bays to encourage / initiate land reclamation processes (Glazer \& Walsh, 1991). An estimated 76 million acres of soil were needed for reclamation; Half of it was to be obtained from the development sites of the Housing Development Board and the other half was imported (Omar, 2007). Development was halted due to economic problems but has now been restored.

Several approaches have been adopted to protect reclaimed land. The landfill on the east and north coasts is protected by a series of streams that act as mainland areas. Beaches are among the main attractions and can be used for recreational purposes (Wong and Pask, 2008). Elsewhere, beaches or revelations are often used as safety measures. This is more common in areas where recreational value is low.

Coastal flood hazards have contributed to the design of land ownership projects in Singapore by enforcing landfill levels $+3 \mathrm{~m}$ above the MSL on the south 
coast and $3 \mathrm{~m}$ above the MSL on the north coast. This allows the coast to be protected from flooding. Increasing the minimum landfill height by $1.0 \mathrm{~m}$ is likely to calculate the SLR with climate change in the future (Linham et al., 2010). Existing landfills may also be raised as part of the redevelopment cycle.

\subsection{Accommodation Approaches}

Accommodation access is the continuation and use of vulnerable areas by increasing the community's ability to cope with the consequences of extreme events. This approach should be implemented in advance as it requires advanced planning and recognition that some coastal values may change (IPCC CZMS, 1990).

The adaptive technologies discussed in this chapter can be subdivided into one of two subsets: (1) technologies with physical modifications that allow for increased flooding and erosion; And information systems that enhance our awareness and awareness of coastal risks and enable the coastal population to respond appropriately to minimize the impact of these events. Both of these approaches allow coastal populations to continue to live in high-risk areas. In these guidelines, flood prevention, floating agricultural systems and wetland rehabilitation represent the first approach, while flood hazard mapping and flood warnings are the second approach.

\subsubsection{Flood-Proofing}

\section{Definition}

The primary purpose of flood mitigation is to minimize or prevent the impact on coastal flood structures. This includes other measures such as raising structures above the flood, creating structures that are more resistant to flood damage and using building materials and preventing flood water from entering the flood zone.

\section{Description}

Flood control measures are widely used in the United States, where two types of flood protection are widely identified: wet and dry. Wet flood prevention reduces flood damage in three ways; (1) allowing floodwaters to easily enter and exit a structure to minimize structural damage; (2) use of flood-resistant material; And (3) raising important utilities. Dry flood prevention, on the other hand, is the submergence of a building up to the desired flood height or significant flooding (FEMA, 2008).

A structure that is resistant to dry flooding will be submerged above the expected flood level and will prevent floodwaters from entering first. Waterproofing coatings, sealing walls with a protective film or masonry or concrete layer, mounting water shields on openings and appropriate drainage preventive measures (FEMA, 2007) are required to make the structure waterproof. A typical example of dry flood prevention is shown in Figure 1.31. 


\section{Figure 1.30: Basic wet flood-proofing measures for a residential structure}

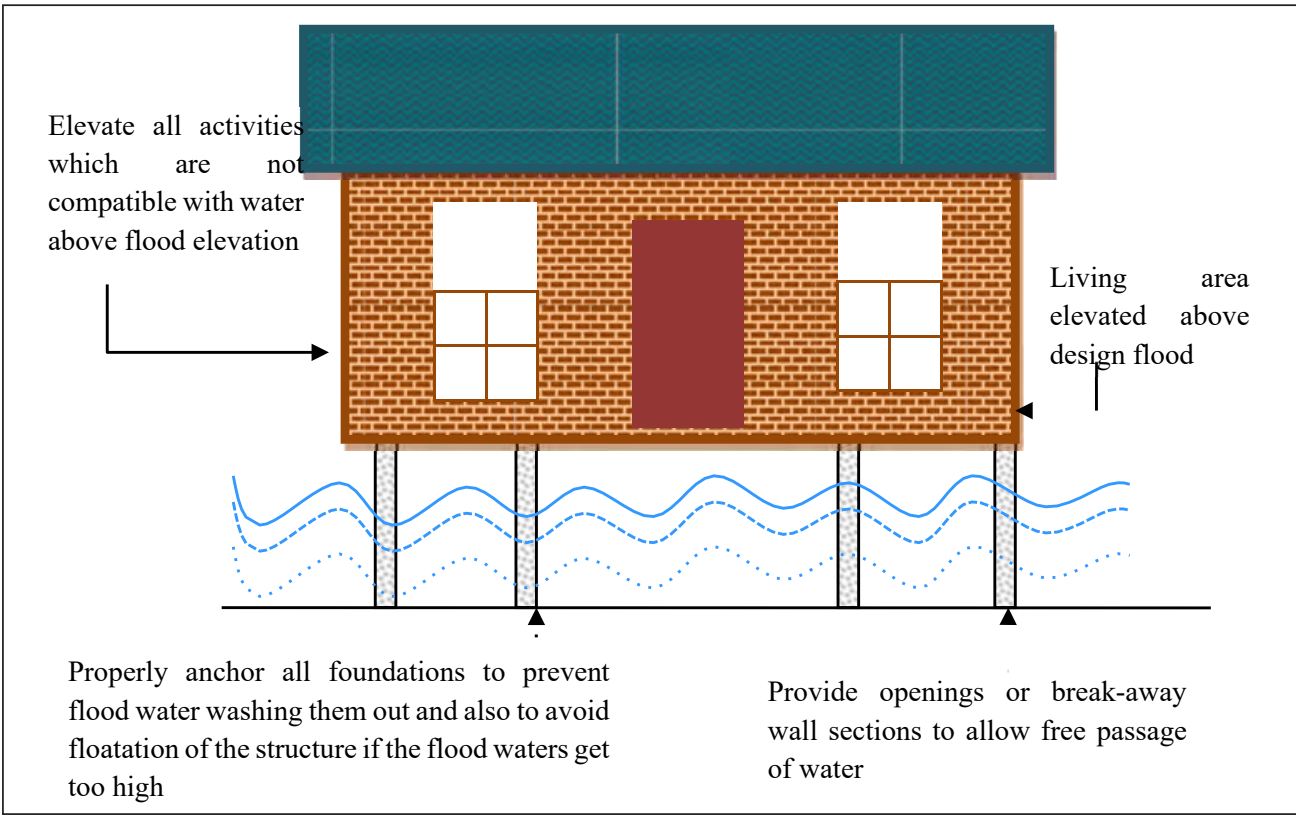

Figure 1.31: Basic dry flood-proofing measures for a residential structure

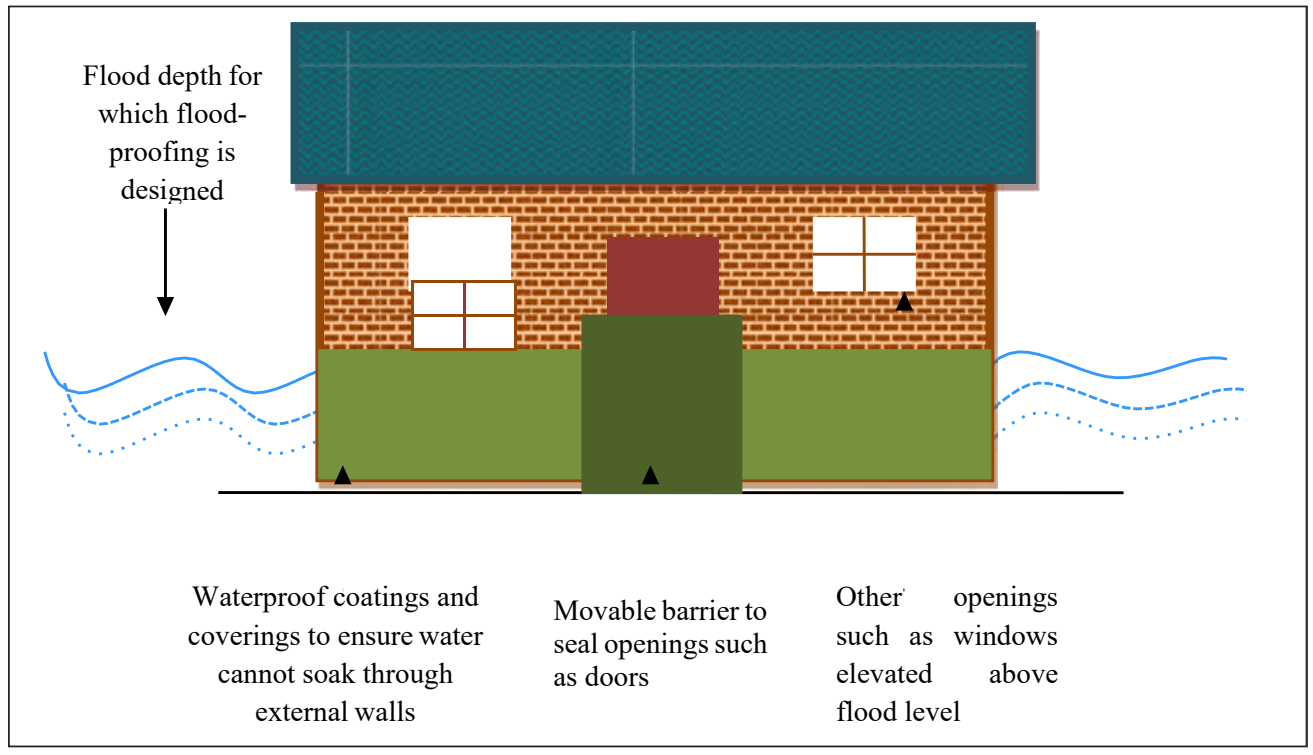

Flood prevention can be applied to residential and non-residential buildings and the principles of flood mitigation design can be applied to other important 
infrastructure such as electrical substations and sewage treatment. Undoubtedly, the decision to choose wet or dry flood prevention should be influenced by the protection of the structure and compliance with flood water.

\section{Advantages of Flood-proofing}

A major advantage of flood prevention is that it avoids the need to lift, demolish, or relocate structures, and as a result is often a cheaper approach to mitigating flood risk (Powell \& Wrangler, 2009). Extensive flood protection measures such as seawater and dyke systems can be more affordable than construction (FEMA, 2007).

Wet flood mitigation measures are useful because they allow the internal and external water pressures to be equal to 9 in a flood. Therefore the weight of the walls and floors is reduced (FEMA, 2007). This means that the risk of structural failure during floods is low.

\section{Disadvantages of Flood-proofing}

Flood mitigation measures require flood risk mapping studies and flood warning systems to communicate flood risk to the public (see Sections 1.3.2. for more information). This will allow flood mitigation measures to be properly implemented and give residents time to evacuate flood-affected buildings in the event of an emergency. It also allows residents to close barriers in a timely manner to prevent dry flooding. While flood hazard maps and flood warnings can be beneficial, they are an additional cost to implement in flood mitigation measures.

Shelter should also be provided for the evacuees as the residents of the flood-affected houses can no longer live during the floods. These facilities may be required for some time after a flood event, as the structure cannot be inhabited for a short period of time after wet flood prevention.

Flood prevention measures are most effective in shallow floodplains. Minimal use of flood mitigation measures to minimize damage caused by high-velocity flood currents and wave activity (FEMA, 2007). In the event of a flood larger than the design specification, its effect seems to be that there is no protection at all (FEMA, 2001).

Another disadvantage is that the flood shield is not aesthetically pleasing in preventing dry flooding (FEMA, 2007). Shields for doors and windows are often placed so that they can be closed quickly when needed. However, this does not mean that the move is permanent. Continued maintenance of flood mitigation measures is also required to ensure adequate protection (FEMA, 2007).

When wet flood prevention measures are implemented, flood water still enters the structure. Therefore, significant post-flood cleaning is required to remove contaminants, such as sediment, sludge, or chemicals (FEMA, 2007). The choice of material used in these structures allows for faster cleaning of flood-free structures. 
In preventing dry flooding, if the design weight is exceeded, walls can collapse, floor clamps and even houses can float. This has the potential to do more harm than good if the house is flooded (FEMA, 2009).

\section{Costs and Financial Requirements}

In the absence of cost information from developing countries, cost estimates are provided for a number of U.S. flood prevention measures. The United States is one country where flood mitigation measures are widely applied.

In the United States, the cost of raising a structure above the depth of a flood can be between $\$ 29$ and $\$ 96$ per square foot of housing (FEMA, 2009). The cost range is due to the type of construction and foundation and the required elevation.

Wet flood prevention measures include wall openings for flood entry and exit, installation of pumps, rearrangement or repositioning of utility systems, and removal of large equipment and cover surfaces to facilitate post-flood cleaning. . According to FEMA (2009), Considering the ground level flood prevention to a depth of approximately 2.4 meters, the cost of wet flood prevention in the United States can be between US $\$ 2.20$ and US $\$ 17.00$ per square foot.

Due to the unwillingness to take flood prevention measures on a single basis, it may be necessary to inspect the properties in the hazardous zone to ensure that the flood prevention measures have been implemented and to an acceptable standard.

Local communities can be funded to promote flood prevention projects. This can increase the attendance of poor communities and help protect those at risk rather than those who can take such action. If flood insurance is regionally impor-

Table 1.7: Gross cost of dry flood prevention measures in the United States

\begin{tabular}{|l|l|l|}
\hline \multicolumn{1}{|c|}{ Component } & \multicolumn{1}{c|}{ Cost } & \multicolumn{1}{c|}{ Per } \\
\hline Sprayed on cement & $\$ 55.10$ & Linear metre of wall covered \\
\hline Waterproof membrane & $\$ 18.70$ & Linear metre of wall covered \\
\hline Asphalt & $\$ 39.36$ & Linear metre of wall covered \\
\hline Drainage line around perimeter of house & $\$ 101.68$ & Linear metre \\
\hline Plumbing check valve & $\$ 1060$ & Each \\
\hline Sump and sump pump & $\$ 1710$ & Lump sum \\
\hline Metal flood shield & $\$ 1230$ & Linear metre of shield surface \\
\hline Wood flood shield & $\$ 383.76$ & Linear metre of shield surface \\
\hline
\end{tabular}

Source: FEMA, 2019. Cost in US dollars. 
tant, a similar return can be obtained. Reduction of premiums for flood resistant properties will encourage flood prevention.

Communities need to map out some form of flood hazard before proceeding with flood mitigation measures (see Section 1.3.2.1). This will let those who decide which buildings are needed and at what depth to prevent flooding. It can also help plan flood prevention measures appropriately.

\section{Opportunities for Implementation}

Implementing flood mitigation has a key opportunity in allowing the development of the flood mitigation zone to move forward despite clear limitations. When there is a high demand for coastal land, flood mitigation measures provide an opportunity to utilize this land. This is contrary to policies such as building retreats that prevent coastal development (see Section 1.3.2.1).

\section{Case Study: The National Flood Insurance Programme, USA}

Developing countries do not have a well-documented flood prevention program. Therefore, the long-established National Flood Insurance Program (NFIP) is used in the United States. NFIP provides federally certified flood insurance to communities that agree to regulate development on mapped floodplains. If communities play their role in ensuring that future floodplain development meets certain criteria, FEMA (Federal Emergency Management Association) will provide flood insurance for community property.

The NFIP wants all new non-residential developments in a flood prone area to be either flood-proof or flood-resistant. Residential buildings should be elevated above the initial flood elevation. The flood mitigation measures described in Figure 1.30 and Figure 1.31 are taken from FEMA Publications in accordance with NFIP.

For the purpose of regulating new construction, NFIP defines flood prevention as a measure included in the building plan:

- Walls are watertight

- Structural components can resist hydrostatic and hydrodynamic10 loads, as well as buoyancy effects

- Utilities are protected from flood damage

Under these regulations, a registered professional engineer or architect is required to prepare building plans and ensure flood prevention measures (FEMA, 1998). The minimum requirement for flood prevention under the NFIP is flood protection for up to 1 in 100 years.

According to the NFIP, buildings in the flood-prone zone should be anchored appropriately to stabilize the structure against flood forces. This means ensuring adequate protection against hydrostatic and hydroelectric forces and the erosion and plague that can cover the foundation (FEMA, 1998). 
Normal construction procedures may be sufficient in shallow floodplains. In the event of a deep flood, additional anchors, such as bolts, may be needed to attach the foundation to the foundation, prioritizing policy offerings. This is recommended in three cases (FEMA, 1998):

- Where the flood flows faster than approx. $1.5 \mathrm{~m} / \mathrm{s}$

- In coastal areas subject to waves and high winds

- In manufactured or mobile homes

Under the NFIP, all parts of flood-resistant buildings shall be made of flood-resistant materials. 'Flood resistant material' includes building products that have the ability to come into direct and long-term contact with flood water without significant damage. A list of recommended materials under NFIP is given in Table 1.8.

The NFIP in the United States is a long-established national program to encourage flood protection in flood-prone areas. It will provide a useful template for application in developing countries. For example, the NFIP is regulated by FEMA, a national organization with extensive knowledge of coastal flood mitigation and mitigation This provides the advantage of having a dedicated, efficient organization that can provide advice and guidance. Establishing such organizations in developing countries would be very beneficial. In addition, many of the design

\section{Table 1.8: NFIP recommended flood-resistant materials}

\begin{tabular}{|l|}
\hline Concrete, concrete blocks or glazed bricks \\
\hline Clay, concrete or ceramic tiles \\
\hline Galvanised or stainless steel nails, hurricane clips and connectors (when subject to saltwater) \\
\hline Indoor-outdoor carpeting with synthetic backing (do not fasten down) \\
\hline Vinyl, terrazzo, rubber or vinyl floor covering with waterproof adhesives \\
\hline Metal doors and window frames \\
\hline Polyester-epoxy paint \\
\hline Stone, slate or cast stone (with waterproof mortar) \\
\hline Mastic, silicone or polyurethane formed-in-place flooring \\
\hline Pressure treated or naturally decay resistant lumber and marine grade plywood \\
\hline Water-resistant glue \\
\hline
\end{tabular}

Source: FEMA, 1998 
guidelines used in the NFIP also apply to developing countries. For example, 1 in 100 years of use of flood plains and exposure to dangerous flood currents. The case study also highlights the need to develop capacity in developing countries to train architects and engineers in building flood-resistant structures.

\subsubsection{Wetland Restoration}

\section{Definition}

The primary objective of wetland reconstruction may be threefold. These projects can reduce coastal flooding and erosion and provide new habitat and environmental benefits.

'Wetland' refers to the shallow waters and intertidal habitats that occur in various parts of the world. Wetland restoration is the restoration of pre-existing wetland functions from weaker to less active or overall functional imbalance.

Although similar to managed rehabilitation (Section 1.3.1.2), wetland reconstruction may identify the current state of the coastline differently than land reclamation.

\section{Description}

Wetland habitats are important because they play an important role in coastal flood and erosion management. They generate waves and tidal energy (Brampton, 1992) act as a sediment trap for matter. Root cover of wetland plants also helps stabilize coastal sediments, thereby reducing erosion (USACE, 1989). Wetland Rehabilitation restores these beneficial functions for coastal flood and erosion protection benefits.

Methods have been devised to reintroduce coastal wetlands to pre-existing and non-existent areas, but conditions will allow. The diversity of wetland types means that there are a number of ways to restore wetlands. The methodology adopted depends on the habitat being rehabilitated.

Salt mash is being widely replaced through management recovery schemes (see Section 1.3.1.2) However, this includes the current defensive ring retreat. Saltmarsh can be re-established while maintaining the current coastal conditions by vegetative transplants from healthy wetlands. Transplanting varieties are often plants, leafy stems or seedlings grown in pots; Sowing seeds on eroded sites is not effective (USACE, 1989). The height of the site should be increased by using the appropriate filler material to restore the salt marsh.

\section{Barriers to Implementation}

One of the most significant barriers to the use of wetlands as a measure to combat coastal flooding and erosion is a lack of public awareness of the flood and erosion protection benefits offered by these ecosystems. Unless the public is educated on the benefits that wetlands provide, the link between coastal flood and erosion protection and wetland restoration is likely to be unclear. This will hinder 


\section{Box 1.7: Factors Affecting the Cost of Wetland Reconstruction}

- Type of wetland to be restored, expertise availability, and consequent chances of success

- Degree of wetland degradation and consequent restoration requirements

- Intended degree of restoration (for example, it may not be possible to restore all the ecosystem functions of a wetland if it is located in a highly industrialised/urbanised environment and the plannedrestoration measures maybe lessambitious)

- Land costs if land purchase is required to convert to wetlands

- Labour costs

- Transportation distance between seedling source and planting site

- Seedling mortality rate between collection and planting

- Cost of raising specific species in nurseries before transplantation because they cannot be directly planted on mud flats due to strong wind and wave forces

- Scale of post-implementationmonitoring operations

Source: Adapted from Tri et al., 1998

the uptake of these projects as communities press for more tangible, hard defence options, for which the protective benefits are more widely understood.

Another barrier to successful implementation is an incomplete understanding of the ability of a degraded wetland to recover, and of the success rates of wetland creation. We still do not fully understand the needs of wetland plants and animals. As such, uncertainty also surrounds the effectiveness of wetland restoration activities and whether the full range of ecosystem functions will be restored during wetland repair. Monitoring of completed schemes will enhance our understanding of wetland restoration.

The adoption of wetland restoration and (re)creation as a response to coastal flooding and erosion requires a sustainability-focussed and anticipatory coastal management plan. The establishment of wetlands which provide full coastal flood and erosion protection takes time, and the approach does not offer immediate benefits. As such, wetland recreation may not be practicable where coastal management is reactive and focussed on hard defences.

A desire to improve wetland habitats also needs to exist before the strategy can go ahead. This may involve raising public awareness of the benefits of wetland restoration and (re)creation.

Wetlands only exist under specific conditions and it is not always clear if habitat restoration will be achievable or successful, especially when coastal managers have limited predictive capabilities for shoreline change (NRC, 1994). Although studies have shown that it is possible to create wetlands in areas where they did not previously exist (Platong, 1998), sites with the potential for wetland restoration or creation should be identified on a case-by-case basis.

Identifying individuals and organisations qualified to undertake wetland restoration and recreation work can also prove a barrier to implementation. The 
qualifications and know-how of the implementing organisations directly influence the effective application of scientific knowledge and engineering capabilities and ultimately, project performance (NRC, 1994). To address problems associated with limitations in knowledge and capabilities, it is advisable to seek direct involvement or guidance by experienced and qualified organisations.

\section{Opportunities for Implementation}

One of the biggest opportunities that exists to aid implementation of wetland restoration programmes is a growing concern regarding wetland loss and the associated loss of ecosystem functions such as habitat provision, food production and water quality improvement. The implementation of wetland restoration projects not only compensates for wetlands lost through development and natural processes but also provides the additional benefits of coastal flood and erosion protection. This option also helps reduce wetlands losses as a result of climate change.

Wetland creation can bring about various economic, social, and environmental benefits to local communities. For example, it has the capacity to improve the productivity of coastal waters for fishing. Given the importance of the fishing sector in many coastal communities in developing countries, this is likely to be highly beneficial. Such an effect may increase incomes of local communities and contribute toward local sustainable development. Other goods and services provided by wetlands, such as the provision of wood and fibres could also prove highly beneficial to local communities, especially in developing countries. Wetland recreation can also create opportunities for eco-tourism and increase recreational opportunities. Creation of wetlands, especially in or in close proximity to urban areas can even serve to increase awareness of the important functions performed by these habitats.

Because wetland restoration meets multiple management objectives - such as habitat protection, public access to environmental and recreational resources and hazard mitigation - and is less expensive and more aesthetically pleasing than some engineering solutions, the approach is likely to find broader public support in the future (Moser, 2000).

There is also the opportunity to implement wetland restoration or creation together with hard defences such as dikes or seawalls. In such a case, the presence of wetlands on the seaward side of the defence leads to lower maintenance costs over the lifetime of the structure (Tri et al., 1998).

\subsubsection{Floating Agricultural Systems}

\section{Definition}

Floating agriculture is a method of utilizing areas that have been submerged for a long time in food production. The technology is primarily aimed at adapting to more frequent or prolonged floods. 


\section{Description}

Floating agriculture can be used in areas where agricultural land is submerged for long periods; the approach is reasonably widespread in Bangladesh where agricultural land is inundated for extended periods during the monsoon season (APEIS \& RIPSO, 2004). The practice is similar to hydroponic agriculture whereby plants can be grown on the water on a floating bed of water hyacinth, algae or other plant residues (Saha, 2010).

A typical example of floating agriculture in Bangladesh involves a floating layer of water hyacinth, straw or rice stubble to which is added upper layers of small and quick-rotting waterworts which make for good manure (APEIS \& RIPSO, 2004). The structure of the floating raft is strengthened with bamboo, while bamboo poles are used to fix it in position to avoid damage caused by wave action or drifting (Saha, 2010). This floating raft can then be transferred to any submerged location for agricultural purposes (APEIS \& RIPSO, 2004). An example of a floating agricultural system is shown in Figure 1.32.

\section{Figure 1.32: Floating agriculture at Lake Inle, Burma}

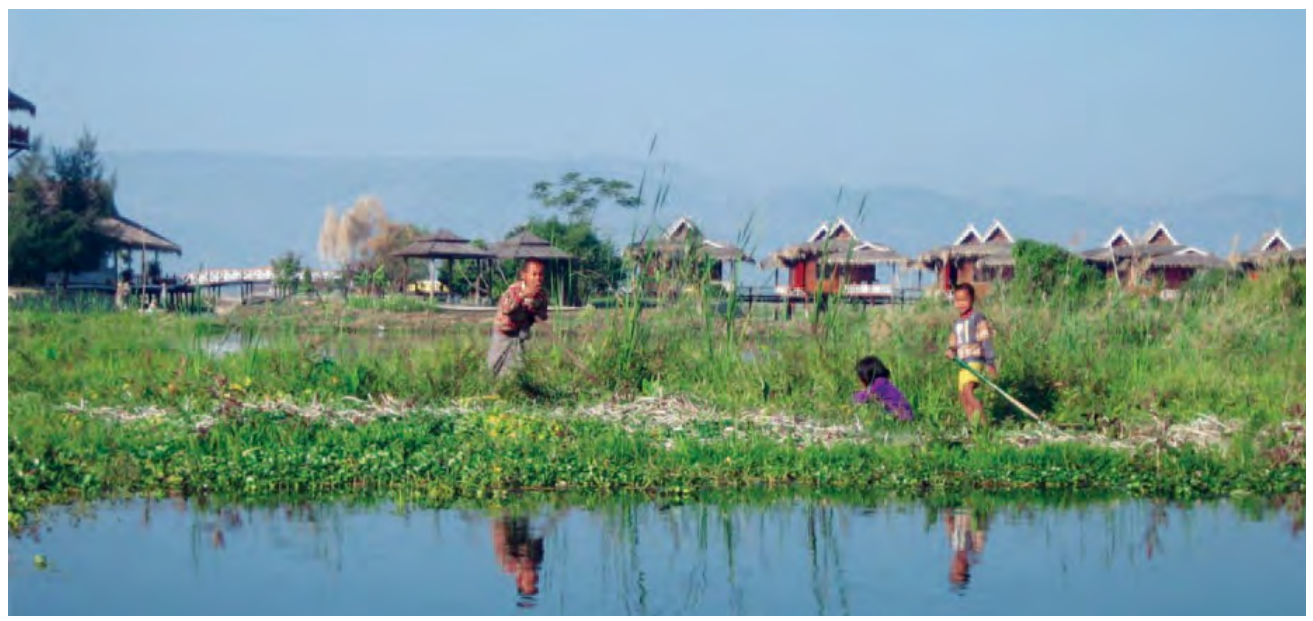

Source: Courtesy of Wikimedia Commons

\section{Advantages of Floating Agricultural Systems}

The practice helps mitigate land loss through flooding, by allowing cultivation of these areas to continue. In this way, the total cultivatable area can be increased and communities can become more self sufficient. In addition to this, the area under floating cultivation is up to 10 times more productive than traditionally farmed land (Haq et al., 2004) and no additional chemical fertilisers or manure is required. When the crops have been harvested and floating rafts are no longer required, they can be used as organic fertilisers in the fields or incorporated into 
the following years floating beds as a fertiliser (AEPIS \& RIPSO, 2004; Saha, 2010).

The approach uses water hyacinth, a highly invasive weed with prolific growth rates, in a highly beneficial way. By harvesting water hyacinth, areas covered by the weed are cleared, with the beneficial side-effect of reducing breeding grounds for mosquitoes and improving conditions for open-water fishing (Saha, 2010). By cultivating crops in water, it is also possible to simultaneously harvest fish populations which reside in the beds (APEIS \& RIPSO, 2004).

The practice of floating agriculture also helps supplement the income of local communities and contributes to alleviation of poverty (Saha, 2010). It also provides greater food security by increasing the land output and supporting capacity for poor and landless people (Irfanullah et al. 2007). People practicing floatingbed cultivation are enjoying a better life economically, than those in other flood-affected areas who have not yet adopted this practice (Saha, 2010).

Because the system is fairly labour intensive, it also has the capacity to provide employment opportunities within communities (Haq et al., 2004). As both men and women can carry out the floating agriculture practices, it can also lead to improvements in gender equity.

\section{Disadvantages of Floating Agricultural Systems}

While this technology works well in some areas today, it is unclear how it may be affected by SLR and increases in salinity, which are likely to occur under scenarios of climate change. Additionally, while the technique is applicable in several mega-deltas such as the Ganges-Brahmaputra, the success of a more general application of this approach seems unlikely and we recommend caution in applying this approach more widely.

The methods used in floating agriculture have the drawback of encouraging insect and rodent infestation. This may cause health problems and damage to crops (Saha, 2010).

The technology can also cause conflict within the community if common property areas are dedicated to the practice. Such an approach may lead to politically more powerful individuals attempting to acquire these areas for their own gains (Islam \& Atkins, 2007)

Although this technology provides the advantage of maintaining food production, it may be difficult to transport produce to market because the area remains waterlogged most of the time (APEIS \& RIPSO, 2004).

In stark contrast to high security, the Wetlands Sri Lanka Air Force has the ability to adapt 'autonomously', allowing the increased accumulation of sediments to rapidly maintain wetland elevation with changes in sea level (Nichols \& Kline, 2005). The supplied wetlands are not subject to coastal compression and are not fast enough to maintain SLR speeds, wetlands have the potential to adapt to SLRs without further investment. 
Coastal wetlands provide a number of important ecosystem services, including water quality and climate regulation, which are valuable accumulators for sediment, pollutants, carbon and nutrients, and are essential breeding grounds for a variety of birds, fish, oysters and mammals. They are a sustainable source of wood, fuel and fiber (White et al., 2010).

The disadvantages of this radical proposal are small. Restoring natural ecosystem services, including flood and erosion protection benefits, far outweighs the disadvantages.

One possible disadvantage is the need for space, often in places with high development potential. This should be well measured relative to the range of benefits earned.

Wetland regeneration will also require special expertise, especially in areas where wetland replanting should be encouraged by planting wetlands. There is no doubt that some wetland habitats are more difficult to recreate than others.

\subsection{Prioritisation of Technologies and Practices}

Risk factors for the impact of climate change should be analyzed and prioritized after identifying potential adaptive technologies. This occurs during the coastal adaptation planning and planning phase (see Section 1.3.1). This requires a decision-making framework to compare and choose between possible options. This is necessary because there is a need to evaluate all the costs, benefits and physical and environmental impacts associated with coastal adaptation options throughout the lifetime of the scheme (Pierce \& Turner, 1992; MAFF, 2001). This is because several coastal adaptation schemes have a purely local and short-term impact. So they can't really be considered 'alone'.

Three decision-making frameworks are widely used today, all of which are recommended for use in the National Adaptation Program (NAPA) under appropriate circumstances (UNFCCC, 2002):

- Cost-Benefit Analysis (CBA): An assessment of all the costs and benefits of alternative options (e.g. Penning-Rowsell et al., 2003; DCLG, 2009).

- Cost-Effectiveness Analysis (CEA): An assessment of the costs of alternative options which all achieve the same objective. The costs need not be restricted to purely financial ones (e.g. DCLG, 2009).

- Multi-Criteria Analysis (MCA): Comparative assessment of options, taking account of several criteria simultaneously. Mainly used to assess impacts that can not be readily quantified in monetary terms (e.g. NI Direct, 2007).

Economic assessments such as the CBA and the CEA seek to convert all costs and benefits into financial terms. This helps to achieve the objectives of optimizing the use of public funds, sustainability, accountability and quality assurance (MAFF, 1999). However, some effects are not economically viable and others do 
not carry the full weight of economic analysis (MAFF, 1999). Therefore, the CBA and the Central Environmental Authority have a tendency to influence the MCA approach, but economic criteria predominate.

For the CBA, the cost of a scheme includes design, construction, maintenance and supervision costs. A key component of the benefits is the reduction of damage caused by coastal floods or erosion. However, the CBA will fight to include untouchable figures such as the loss of life and long-term health costs from flood or erosion victims (Sene, 2008). In coastal management, factors such as the impact on the downstream sedimentary budget are very important, and financial conditions may not adequately express its importance. Practically financially valuing all the costs and benefits of alternatives is by no means realistic. As a result, many cost-benefit analytics analyzes include additional items that may not be valued or economically viable (DCLG, 2009). This approach is standard in the United Kingdom and the United States.

The CEA can be used where the overall goal is agreed, but the best means of achieving this goal is uncertain. For example, when there is a legal need to obtain a return or an alternative is justified by the general evaluation process, intervention is required to continue to grant it. Option (DEFRA, 2009). Essentially, the CEA is used to estimate the least costly method to achieve a given objective (DCLG, 2009). This approach is set out in the security standards law of Germany and the Netherlands.

An MCA is a decision-making framework that uses a tool called a performance model. Each line of the performance model describes an option and each column describes the functionality of the options against each of the criteria. Individual performance ratings are often numerical but can be expressed as 'bullet points' or color coding (DCLG, 2009). Using this approach, the various financial and non-financial advantages and disadvantages can be directly compared according to their importance.

The MCA economic case is not considered in as much detail as the CBA and the CEA. Therefore, although the approach can be integrated with economic analysis, it is more subjective in terms of decision-making (Sene, 2008). The advantage of the MCA is that the indicator measurement does not have to be done financially, so it leads to significant environmental and social impacts that are not easily monetized.

MCA techniques can be used to identify the preferred single option, to rank the options, then shortlist a limited number of options for a detailed evaluation, or to distinguish the acceptable from the unacceptable capabilities (DCLG, 2009). The purpose is to determine the functionality of a number of options in relation to a set of criteria that are considered relevant when selecting a community between different approaches.

Table 1.9 outlines some of the criteria that may be important in determining the most acceptable adaptive option for dealing successfully with coastal flooding or erosion. The weighting assigned to these different criteria varies between applications as determined by the relevant parties. 
Requirements for knowledge and specialization related to each adaptation option are already outlined in section 1.3. In addition, the pros and cons are also presented. The MCA provides a practical framework for assessing widely varying factors in relation to the local environment and needs. The combination of the three decision-making frameworks outlined here will provide support that will allow us to identify the most viable solutions to successfully deal with the effects of climate change in the coastal region of the three approaches outlined, the CBA has the ability to manipulate and prioritize options. Using this method, it is not even necessary to measure potential alternatives against each other. Its limitation is that both cost and benefit must be stated financially and the main objective is economic efficiency. In contrast, MCA only allows optional ranking options. However, it is more capable of evaluating cases where more criteria are considered relevant and cannot be financially quantified and assessed. Finally, CEA is a system that falls somewhat between the CBA and MCA approaches. Its main use is to incur costs for different options that achieve the same objective. Similar to the MCA, the CEA approach can handle cases with different objectives or criteria (UNFCCC, 2002).

For more information, users are advised to refer to Appendix D, UNFCCC (2002), to discuss these methods in the context of NAPA. Examples of coastal zone projects covered under NAPA are given in UNFCCC (2008).

\subsection{Climate change mitigation}

Climate change mitigation is action to reduce the effects of global warming. Most often, climate change mitigation involves scenarios for the reduction of concentrations of greenhouse gases by reducing their sources or by increasing their sinks. In contrast, adaptation to climate change involves acting to tolerate the effects of global warming.

The UN defines mitigation in the context of climate change, as a human intervention to reduce the sources or enhance the sinks of greenhouse gases. Examples include using fossil fuels more efficiently for industrial processes or electricity generation, switching to renewable energy (solar energy or wind power), improving the insulation of buildings, and expanding forests and other "sinks" to remove greater amounts of carbon dioxide from the atmosphere. Some assert that also non-renewable sources of energy such as nuclear power should be seen as a way of reducing carbon emissions. The International Atomic Energy Agency advocates this approach.

Scientific consensus on global warming, together with the precautionary principle and the fear of abrupt climate change is leading to increased effort to develop new technologies and sciences and carefully manage others in an attempt to mitigate global warming. Most means of mitigation appear effective only for preventing further warming, not at reversing existing warming. The Stern Review identifies several ways of mitigating climate change. These include reducing demand for emissions-intensive goods and services, increasing efficiency gains, in- 
Table 1.9: Potentially important criteria for determining effectiveness of coastal flood and erosion adaptation

\begin{tabular}{|c|}
\hline Criteria \\
\hline Total scheme cost \\
\hline Value of flood/erosion avoidance benefits \\
\hline Effect on local economy \\
\hline Implications for down-drift sediment supply \\
\hline Impact on intertidal habitats \\
\hline Effects on tourism \\
\hline Functional effectiveness \\
\hline Durability/Maintenance requirements \\
\hline Sustainability \\
\hline Ease of construction \\
\hline Flexibility in the face of climate change \\
\hline Impacts on coastal flora/fauna \\
\hline Degree of specialist knowledge/equipment required \\
\hline Access to the shoreline \\
\hline Social acceptability \\
\hline Space requirements \\
\hline Equity \\
\hline Information and capacity requirements \\
\hline
\end{tabular}

creasing use and development of low-carbon technologies, and reducing fossil fuel emissions.

The energy policy of the European Union has set a target of limiting the global temperature rise to $2{ }^{\circ} \mathrm{C}$ compared to preindustrial levels, of which $0.8^{\circ} \mathrm{C}$ has already taken place and another $0.5-0.7^{\circ} \mathrm{C}$ is already committed. The $2{ }^{\circ} \mathrm{C}$ rise is typically associated in climate models with a carbon dioxide equivalent concentration of 400-500 ppm by volume; the current (April 2011) level of carbon dioxi- 
de alone is $393 \mathrm{ppm}$ by volume, and rising at $1-3 \mathrm{ppm}$ annually. Hence, to avoid a very likely breach of the $2{ }^{\circ} \mathrm{C}$ target, $\mathrm{CO} 2$ levels would have to be stabilised very soon. This is generally regarded as unlikely, based on current programs in place to date. The importance of change is illustrated by the fact that world economic energy efficiency is presently improving at only half the rate of world economic growth.

\subsubsection{Greenhouse gas concentrations and stabilization}

One of the issues often discussed in relation to climate change mitigation is the stabilization of greenhouse gas concentrations in the atmosphere. The United Nations Framework Convention on Climate Change (UNFCCC) has the ultimate objective of preventing "dangerous" anthropogenic (i.e., human) interference of the climate system. As is stated in Article 2 of the Convention, this requires that greenhouse gas (GHG) concentrations are stabilized in the atmosphere at a level where ecosystems can adapt naturally to climate change, food production is not threatened, and economic development can proceed in a sustainable fashion.

A distinction needs to be made between stabilizing GHG emissions and GHG concentrations. The two are not the same. The most important GHG emitted by human activities is carbon dioxide. Stabilizing emissions of $\mathrm{CO} 2$ at current levels would not lead to stabilization in the atmospheric concentration of $\mathrm{CO} 2$. In fact, stabilizing emissions at current levels would result in the atmospheric concentration of $\mathrm{CO} 2$ continuing to rise over the 21 st century and beyond.

The reason for this is that human activities are adding $\mathrm{CO} 2$ to the atmosphere far faster than natural processes can remove it (see carbon dioxide in Earth's atmosphere for a more complete explanation). This is analogous to a flow of water into a bathtub. So long as the tap runs water (analogous to the emission of carbon dioxide) into the tub faster than water escapes through the plughole (the natural removal of carbon dioxide from the atmosphere), then the level of water in the tub (analogous to the concentration of carbon dioxide in the atmosphere) will continue to rise.

Stabilizing the atmospheric concentration of the other greenhouse gases humans emit also depends on how fast their emissions are added to the atmosphere, and how fast the GHGs are removed. $\mathrm{CO} 2$ is not the only GHG relevant to mitigation and governments have acted to regulate the emissions of other GHGs emitted by human activities (anthropogenic GHGs). The emissions caps agreed to by most developed countries under the Kyoto Protocol regulate the emissions of almost all the anthropogenic GHGs. These gases are $\mathrm{CO} 2$, methane, nitrous oxide, the hydrofluorocarbons (abbreviated HFCs), perfluorocarbons (PFCs), and sulfur hexafluoride.

Stabilizing the atmospheric concentrations of the different anthropogenic GHGs requires an understanding of their different physical properties. Stabilization depends both on how quickl GHGs are added to the atmosphere and how fast they are removed. The rate of removal is measured by the atmospheric lifetime of 
the GHG in question Methane has a relatively short atmospheric lifetime of about 12 years, while nitrous oxide's lifetime is about 110 years. For methane, a reduction of about $30 \%$ below current emission levels would lead to a stabilization in its atmospheric concentration, while for nitrous oxide, an emissions reduction of more than $50 \%$ would be required.

Another physical property of the anthropogenic GHGs relevant to mitigation is the different abilities of the gases to trap heat (in the form of infrared radiation). Some gases are more effective at trapping heat than others, e.g. sulfur hexafluoride is 22,200 times more effective a GHG than $\mathrm{CO} 2$ on a per-kilogram basis. A measure for this physical property is the global warming potential (GWP), and is used in the Kyoto Protocol.

\subsubsection{Methods and means}

At the core of most proposals is the reduction of greenhouse gas emissions through reducing energy waste and switching to cleaner energy sources. Frequently discussed energy conservation methods include increasing the fuel efficiency of vehicles (often through hybrid, plug-in hybrid, and electric cars and improving conventional automobiles), individual-lifestyle changes and changing business practices. Newly developed technologies and currently available technologies including renewable energy (such as solar power, tidal and ocean energy, geothermal power, and wind power) and more controversially nuclear power and the use of carbon sinks, carbon credits, and taxation are aimed more precisely at countering continued greenhouse gas emissions. The ever-increasing global population and the planned growth of national GDPs based on current technologies are counter-productive to most of these proposals.

Climate change concerns and the need to reduce carbon emissions are driving increasing growth in the renewable energy industries. Some 85 countries now have targets for their own renewable energy futures, and have enacted wide-ranging public policies to promote renewables. Low- carbon renewable energy replaces conventional fossil fuels in three main areas: power generation, hot water/ space heating, and transport fuels. Scientists have advanced a plan to power $100 \%$ of the world's energy with wind, hydroelectric, and solar power by the year 2030.

In terms of power generation, renewable energy currently provides 18 percent of total electricity worldwide and this percentage is growing each year. Renewable power generators are spread across many countries, and wind power alone already provides a significant share of electricity in some areas: for example, 14 percent in the U.S. state of Iowa, 40 percent in the northern German state of Schleswig-Holstein, and 20 percent in Denmark. Some countries get most of their power from renewables, including Iceland (100 percent), Brazil (85 percent), Austria (62 percent), New Zealand (65 percent), and Sweden (54 percent).

Solar water heating makes an important and growing contribution in many countries, most notably in China, which now has 70 percent of the global total 
(180 GWth). Worldwide, total installed solar water heating systems meet a portion of the water heating needs of over 70 million households. The use of biomass for heating continues to grow as well. In Sweden, national use of biomass energy has surpassed that of oil. Direct geothermal heating is also growing rapidly.

Renewable biofuels for transportation, such as ethanol fuel and biodiesel, have contributed to a significant decline in oil consumption in the United States since 2006. The 93 billion liters of biofuels produced worldwide in 2009 displaced the equivalent of an estimated 68 billion liters of gasoline, equal to about 5 percent of world gasoline production.

\subsubsection{Nuclear power}

Nuclear power currently produces $13-14 \%$ of the world's electricity. Since about 2001 the term nuclear renaissance has been used to refer to a possible nuclear power industry revival, driven by rising fossil fuel prices and new concerns about meeting greenhouse gas emission limits. At the same time, various barriers to a nuclear renaissance have been identified. These barriers include unfavourable economics compared to other sources of energy and slowness in addressing climate change.

New reactors under construction in Finland and France, which were meant to lead a nuclear renaissance, have been delayed and are running over-budget. China has 20 new reactors under construction, and there are also a considerable number of new reactors being built in South Korea, India, and Russia. At least 100 older and smaller reactors will "most probably be closed over the next 10-15 years".

Nuclear power brings with it important waste disposal, safety, and security risks which are unique among low-carbon energy sources. Public attitudes towards nuclear power remain ambiguous in many developed countries, with significant anti-nuclear opposition even when majority opinion is in favour. However some Nuclear reactor 'waste' byproducts are of high

value and used in many radiopharmaceuticals, for example, Yttrium-90 and Technetium 99m have a wide and valuable use in Oncology and diagnostic medicine.

\subsubsection{Carbon intensity of fossil fuels}

Most mitigation proposals imply an eventual reduction in global fossil fuel production. Also are proposed direct quotas on global fossil fuel production.

Natural gas combustion produces less greenhouses gases per energy unit gained than oil which in turn produces less than coal, principally because coal has a larger ratio of carbon to hydrogen. The combustion of natural gas emits almost 30 percent less carbon dioxide than oil, and just under 45 percent less carbon dioxide than coal. In addition, there are also other environmental benefits. 
A study performed by the Environmental Protection Agency and the Gas Research Institute in 1997 sought to discover whether the reduction in carbon dioxide emissions from increased natural gas (predominantly methane) use would be offset by a possible increased level of methane emissions from sources such as leaks and emissions. The study concluded that the reduction in emissions from increased natural gas use strongly outweighs the detrimental effects of increased methane emissions. Thus the increased use of natural gas in the place of other, dirtier fossil fuels can serve to lessen the emission of greenhouse gases in the United States.

\subsubsection{Carbon capture and storage}

Carbon capture and storage (CCS) is a method to mitigate climate change by capturing carbon dioxide (CO2) from large point sources such as power plants and subsequently storing it away safely instead of releasing it into the atmosphere. The Intergovernmental Panel on Climate Change says CCS could contribute between $10 \%$ and $55 \%$ of the cumulative worldwide carbon mitigation effort over the next 90 years. The International Energy Agency says CCS is "the most important single new technology for $\mathrm{CO} 2$ savings" in power generation and industry. Though it requires up to $40 \%$ more energy to run a CCS coal power plant than a regular coal plant, CCS could potentially capture about $90 \%$ of all the carbon emitted by the plant. Norway, which first began storing $\mathrm{CO} 2$, has cut its emissions by almost a million tons a year, or about 3\% of the country's 1990 levels. As of late 2011 , the total CO2 storage capacity of all 14 projects in operation or under construction is over 33 million tonnes a year. This is broadly equivalent to preventing the emissions from more than six million cars from entering the atmosphere each year.

\subsubsection{Energy efficiency and conservation}

Efficient energy use, sometimes simply called "energy efficiency", is the goal of efforts to reduce the amount of energy required to provide products and services. For example, insulating a home allows a building to use less heating and cooling energy to achieve and maintain a comfortable temperature. Installing fluorescent lights or natural skylights reduces the amount of energy required to attain the same level of illumination compared to using traditional incandescent light bulbs. Compact fluorescent lights use two-thirds less energy and may last 6 to 10 times longer than incandescent lights.

Energy efficiency has proved to be a cost-effective strategy for building economies without necessarily growing energy consumption. For example, the state of California began implementing energy-efficiency measures in the mid-1970s, including building code and appliance standards with strict efficiency requirements. During the following years, California's energy consumption has remained approximately flat on a per capita basis while national U.S. consumption doubled. 
As part of its strategy, California implemented a "loading order" for new energy resources that puts energy efficiency first, renewable electricity supplies second, and new fossil-fired power plants last.

Energy conservation is broader than energy efficiency in that it encompasses using less energy to achieve a lesser energy service, for example through behavioural change, as well as encompassing energy efficiency. Examples of conservation without efficiency improvements would be heating a room less in winter, driving less, or working in a less brightly lit room. As with other definitions, the boundary between efficient energy use and energy conservation can be fuzzy, but both are important in environmental and economic terms. This is especially the case when actions are directed at the saving of fossil fuels.

Reducing energy use is seen as a key solution to the problem of reducing greenhouse gas emissions. According to the International Energy Agency, improved energy efficiency in buildings, industrial processes and transportation could reduce the world's energy needs in 2050 by one third, and help control global emissions of greenhouse gases.

\subsubsection{Transport}

Modern energy efficient technologies, such as plug-in hybrid electric vehicles, and development of new technologies, such as hydrogen cars, may reduce the consumption of petroleum and emissions of carbon dioxide. A shift from air transport and truck transport to electric rail transport would reduce emissions significantly.

Increased use of biofuels (such as ethanol fuel and biodiesel that can be used in today's diesel and gasoline engines) could also reduce emissions if produced environmentally efficiently, especially in conjunction with regular hybrids and plug-in hybrids. For electric vehicles, the reduction of carbon emissions will improve further if the way the required electricity is generated is low- carbon (from renewable energy sources).

Effective urban planning to reduce sprawl would decrease Vehicle Miles Travelled (VMT), lowering emissions from transportation. Increased use of public transport can also reduce greenhouse gas emissions per passenger kilometer.

\subsubsection{Urban planning}

Urban planning also has an effect on energy use. Between 1982 and 1997, the amount of land consumed for urban development in the United States increased by 47 percent while the nation's population grew by only 17 percent. Inefficient land use development practices have increased infrastructure costs as well as the amount of energy needed for transportation, community services, and buildings.

At the same time, a growing number of citizens and government officials have begun advocating a smarter approach to land use planning. These smart growth 
practices include compact community development, multiple transportation choices, mixed land uses, and practices to conserve green space. These programs offer environmental, economic, and quality-of-life benefits; and they also serve to reduce energy usage and greenhouse gas emissions.

Approaches such as New Urbanism and Transit-oriented development seek to reduce distances travelled, especially by private vehicles, encourage public transit and make walking and cycling more attractive options. This is achieved through medium-density, mixed-use planning and the concentration of housing within walking distance of town centres and transport nodes.

Smarter growth land use policies have both a direct and indirect effect on energy consuming behaviour. For example, transportation energy usage, the number one user of petroleum fuels, could be significantly reduced through more compact and mixed use land development patterns, which in turn could be served by a greater variety of non-automotive based transportation choices.

\subsubsection{Building design}

Emissions from housing are substantial and government-supported energy efficiency programmes can make a difference.

For institutions of higher learning in the United States, greenhouse gas emissions depend primarily on total area of buildings and secondarily on climate. If climate is not taken into account, annual greenhouse gas emissions due to energy consumed on campuses plus purchased electricity can be estimated with the formula, $\mathrm{E}=\mathrm{aSb}$, where $\mathrm{a}=0.0241$ metric tonnes of $\mathrm{CO}_{2}$ equivalent/square meter and $\mathrm{b}=1.1354$.

New buildings can be constructed using passive solar building design, low-energy building, or zero-energy building techniques, using renewable heat sources. Existing buildings can be made

more efficient through the use of insulation, high-efficiency appliances (particularly hot water heaters and furnaces), double- or triple-glazed gas-filled windows, external window shades, and building orientation and location. Renewable heat sources such as shallow geothermal and passive solar energy reduce the amount of greenhouse gasses emitted. In addition to designing buildings which are more energy efficient to heat, it is possible to design buildings that are more energy efficient to cool by using lighter-coloured, more reflective materials in the development of urban areas (e.g. by painting roofs white) and planting trees. This saves energy because it cools buildings and reduces the urban heat island effect thus reducing the use of air conditioning.

\subsubsection{Eliminating waste methane}

Methane is a significantly more powerful greenhouse gas than carbon dioxide. Burning one molecule of methane generates one molecule of carbon dioxide. Ac- 
cordingly, burning methane which would otherwise be released into the atmosphere (such as at oil wells, landfills, coal mines, waste treatment plants, etc.) provides a net greenhouse gas emissions benefit. However, reducing the amount of waste methane produced in the first place has an even greater beneficial impact, as might other approaches to productive use of otherwise-wasted methane.

\subsubsection{Negative carbon dioxide emissions}

A carbon sink is a natural or artificial reservoir that accumulates and stores some carbon- containing chemical compound for an indefinite period, such as a growing forest. A negative carbon dioxide emission on the other hand is a permanent removal of carbon dioxide out of the atmosphere, such as directly capturing carbon dioxide in the atmosphere and storing it in geologic formations underground.

Creating negative carbon dioxide emissions literally removes carbon from the atmosphere. Examples are direct air capture, biochar, bio-energy with carbon capture and storage and enhanced weathering technologies. These processes are sometimes considered as variations of sinks or mitigation and sometimes as geoengineering. In combination with other mitigation measures, sinks in combination with negative carbon emissions are considered crucial for meeting the 350 ppm target, and even the less conservative 450 ppm target.

\subsubsection{Geoengineering}

Geoengineering is seen by some as an alternative to mitigation and adaptation, but by others as an entirely separate response to climate change. In a literature assessment, Barker et al. (2007) described geoengineering as a type of mitigation policy. IPCC (2007) concluded that geoengineering options, such as ocean fertilization to remove $\mathrm{CO}_{2}$ from the atmosphere, remained largely unproven. It was judged that reliable cost estimates for geoengineering had not yet been published.

Chapter 28 of the National Academy of Sciences report Policy Implications of Greenhouse Warming: Mitigation, Adaptation, and the Science Base (1992) defined geoengineering as "options that would involve large-scale engineering of our environment in order to combat or counteract the effects of changes in atmospheric chemistry." They evaluated a range of options to try to give preliminary answers to two questions: can these options work and could they be carried out with a reasonable cost. They also sought to encourage discussion of a third question

- what adverse side effects might there be. The following types of option were examined: reforestation, increasing ocean absorption of carbon dioxide (carbon sequestration) and screening out some sunlight. NAS also argued "Engineered countermeasures need to be evaluated but should not be implemented without broad understanding of the direct effects and the potential side effects, the ethical 
issues, and the risks.". In July 2011 a report by the United States Government Accountability Office on geoengineering found that "climate engineering technologies do not now offer a viable response to global climate change."

Carbon dioxide removal has been proposed as a method of reducing the amount of radiative forcing. A variety of means of artificially capturing and storing carbon, as well as of enhancing natural sequestration processes, are being explored. The main natural process is photosynthesis by plants and single-celled organisms (see biosequestration). Artificial processes vary, and concerns have been expressed about the long-term effects of some of these processes.

It is notable that the availability of cheap energy and appropriate sites for geological storage of carbon may make carbon dioxide air capture viable commercially. It is, however, generally expected that carbon dioxide air capture may be uneconomic when compared to carbon capture and storage from major sources - in particular, fossil fuel powered power stations, refineries, etc. In such cases, costs of energy produced will grow significantly. However, captured $\mathrm{CO}_{2}$ can be used to force more crude oil out of oil fields, as Statoil and Shell have made plans to do. $\mathrm{CO}_{2}$ can also be used in commercial greenhouses, giving an opportunity to kick-start the technology. Some attempts have been made to use algae to capture smokestack emissions, notably the GreenFuel Technologies Corporation, who have now shut down operations.

The main purpose of solar radiation management seek to reflect sunlight and thus reduce global warming. The ability of stratospheric sulfate aerosols to create a global dimming effect has made them a possible candidate for use in geoengineering projects.

\subsubsection{Societal controls}

Another method being examined is to make carbon a new currency by introducing tradeable "Personal Carbon Credits". The idea being it will encourage and motivate individuals to reduce their 'carbon footprint' by the way they live. Each citizen will receive a free annual quota of carbon that they can use to travel, buy food, and go about their business. It has been suggested that by using this concept it could actually solve two problems; pollution and poverty, old age pensioners will actually be better off because they fly less often, so they can cash in their quota at the end of the year to pay heating bills etc.

\subsubsection{Population}

Various organizations promote population control as a mean for mitigating global warming. Proposed measures include improving access to family planning and reproductive health care and information, reducing natalistic politics, public education about the consequences of continued population growth, and improving access of women to education and economic opportunities. 
Population control efforts are impeded by there being somewhat of a taboo in some countries against considering any such efforts. Also, various religions discourage or prohibit some or all forms of birth control. Population size has a different per capita effect on global warming in different countries, since the per capita production of anthropogenic greenhouse gases varies greatly by country.

\subsubsection{Governmental action}

Many countries, both developing and developed, are aiming to use cleaner technologies (World Bank, 2010, p. 192). Use of these technologies aids mitigation and could result in substantial reductions in $\mathrm{CO} 2$ emissions. Policies include targets for emissions reductions, increased use of renewable energy, and increased energy efficiency. It is often argued that the results of climate change are more damaging in poor nations, where infrastructures are weak and few social services exist. The Commitment to Development Index is one attempt to analyze rich country policies taken to reduce their disproportionate use of the global commons. Countries do well if their greenhouse gas emissions are falling, if their gas taxes are high, if they do not subsidize the fishing industry, if they have a low fossil fuel rate per capita, and if they control imports of illegally cut tropical timber.

The main current international agreement on combating climate change is the Kyoto Protocol, which came into force on 16 February 2005. The Kyoto Protocol is an amendment to the United Nations Framework Convention on Climate Change (UNFCCC). Countries that have ratified this protocol have committed to reduce their emissions of carbon dioxide and five other greenhouse gases, or engage in emissions trading if they maintain or increase emissions of these gases.

The first phase of the Kyoto Protocol expires in 2012. The United Nations Climate Change Conference in Copenhagen in December 2009 was the next in an annual series of UN meetings that followed the 1992 Earth Summit in Rio. In 1997 the talks led to the Kyoto Protocol, Copenhagen was considered the world's chance to agree a successor to Kyoto that would bring about meaningful carbon cuts.

\subsubsection{Subsidies}

A program of subsidization balanced against expected flood costs could pay for conversion to $100 \%$ renewable power by 2030 . The proponents of such a plan expect the cost to generate and transmit power in 2020 will be less than 4 cents per kilowatt hour (in 2007 dollars) for wind, about 4 cents for wave and hydroelectric, from 4 to 7 cents for geothermal, and 8 cents per kwh for solar, fossil, and nuclear power.

\subsubsection{Carbon emissions trading}

With the creation of a market for trading carbon dioxide emissions within the Kyoto Protocol, it is likely that London financial markets will be the centre for this 
potentially highly lucrative business; the New York and Chicago stock markets may have a lower trade volume than expected as long as the US maintains its rejection of the Kyoto. However, emissions trading may delay the phase-out of fossil fuels.

The European Union Emission Trading Scheme (EU ETS) is the largest multi-national, greenhouse gas emissions trading scheme in the world. It commenced operation on 1 January 2005, and all 25 member states of the European Union participate in the scheme which has created a new market in carbon dioxide allowances estimated at 35 billion Euros (US $\$ 43$ billion) per year. The Chicago Climate Exchange was the first (voluntary) emissions market, and is soon to be followed by Asia's first market (Asia Carbon Exchange). A total of 107 million metric tonnes of carbon dioxide equivalent have been exchanged through projects in 2004, a 38\% increase relative to 2003 (78 Mt CO2e).

Twenty three multinational corporations have come together in the G8 Climate Change Roundtable, a business group formed at the January 2005 World Economic Forum. The group includes Ford, Toyota, British Airways and BP. On 9 June 2005 the Group published a statement stating that there was a need to act on climate change and claiming that market-based solutions can help. It called on governments to establish "clear, transparent, and consistent price signals" through "creation of a long-term policy framework" that would include all major producers of greenhouse gases.

\subsubsection{Emissions tax}

An emissions tax on greenhouse gas emissions requires individual emitters to pay a fee, charge or tax for every tonne of greenhouse gas released into the atmosphere. Most environmentally related taxes with implications for greenhouse gas emissions in OECD countries are levied on energy products and motor vehicles, rather than on $\mathrm{CO} 2$ emissions directly.

Emission taxes can be both cost effective and environmentally effective. Difficulties with emission taxes include their potential unpopularity, and the fact that they cannot guarantee a particular level of emissions reduction. Emissions or energy taxes also often fall disproportionately on lower income classes. In developing countries, institutions may be insufficiently developed for the collection of emissions fees from a wide variety of sources.

\subsubsection{Implementation}

Implementation puts into effect climate change mitigation strategies and targets. These can be targets set by international bodies or voluntary action by individuals or institutions. This is the most important, expensive and least appealing aspect of environmental governance. Implementation requires funding sources but is often beset by disputes over who should provide funds and under what conditions. Lack of funding can be a barrier to successful strategies as there are no formal arrangements to finance climate change development and implementa- 
tion. Funding is often provided by nations, groups of nations and increasingly NGO and private sources. These funds are often channelled through the Global Environmental Facility (GEF). This is an environmental funding mechanism in the World Bank which is designed to deal with global environmental issues. The GEF was originally designed to tackle four main areas: biological diversity, climate change, international waters and ozone layer depletion, to which land degradation and persistent organic pollutant were added. The GEF funds projects that are agreed to achieve global environmental benefits that are endorsed by governments and screened by one of the GEF's implementing agencies.

There are numerous issues which result in a current perceived lack of implementation. It has been suggested that the main barriers to implementation are, Uncertainty, Fragmentation, Institutional void, Short time horizon of policies and politicians and Missing motives and willingness to start adapting. The relationships between many climatic processes can cause large levels of uncertainty as they are not fully understood and can be a barrier to implementation. When information on climate change is held between the large numbers of actors involved it can be highly dispersed, context specific or difficult to access causing fragmentation to be a barrier. Institutional void is the lack of commonly accepted rules and norms for policy processes to take place, calling into question the legitimacy and efficacy of policy processes. The Short time horizon of policies and politicians often means that climate change policies are not implemented in political action to prevent or postpone decisions being made. Missing motives and willingness to start adapting is a large barrier as it prevents any implementation.

Despite a perceived lack of occurrence, evidence of implementation is emerging internationally. Some examples of this are the initiation of NAPA's and of joint implementation. Many developing nations have made National Adaptation Programs of Action (NAPAs) which are frameworks to prioritize adaption needs. The implementation of many of these is supported by GEF agencies. Many developed countries are implementing 'first generation' institutional adaption plans particularly at the state and local government scale. There has also been a push towards joint implementation between countries by the UNFCC as this has been suggested as a cost effective way for objectives to be achieved.

\section{References}

ABPMER (Associated British Ports Marine Environmental Research) (2010a) Abbotts Hall (Stage 2). Southampton: ABPMER. Available from: http:/tiny.cc/ 59f7o.

ABPMER (Associated British Ports Marine Environmental Research) (2010b) The Online Managed Realignment Guide: Details for Abbotts Hall Stage 2. Southampton: ABPMER. Available from: www.abpmer.net/omreg/index.php?option $=$ com_ wrapper\&Itemid $=57$.

ADRC (Asian Disaster Reduction Centre) (2005) Total Disaster Risk Management - Good Practices 2005. Kobe: ADRC. Available from: http://tiny.cc/2cis5. 
AFPM (Adviescommissie Primaire Waterkeringen) (2006) Tussensprint naar 2015 - advies over de financiering van primaire waterkeringen voor de bescherming van Nederland tegen overstromingen (in Dutch).

Ahas, R. 1998. Climate change impact on seasonal cycles in nature: spatial and temporal variability of the phenological time-series in Estonia. In: Climate change studies in Estonia. Eds. Kallaste, T., Kuldna, P. Stockholm Environmental Institute Tallinn Centre. Tallinn. pp 21-26.

Alongi, D.M. (2002) Present state and future of the world's mangrove forests. Environmental Conservation, 29 (3), 331-349. Anderson, I. (1991) Land reclamation poisons coastal waters. New Scientist, 1797, p 11.

APEIS and RIPSO (2004) Floating Agriculture in the flood-pr one or submerged areas in Bangladesh (Southern regions of Bangladesh). Bangladesh: APEIS and RIPSO. Available from: http://enviroscope.iges.or.jp/contents/APEIS/RISPO/inventory/ db/pdf/0146.pdf.

Awosika, L., Dublin-Green, C.O. and Folorunsho, R. (2002) Bar Beach Victoria Island Erosion Problem: A Critical Assessment as at October 30th 2002 and Need for Urgent Mitigating Measures. Lagos: Nigerian Institute for Oceanography and Marine Research. Available from: www.oceandocs.org/bitstream/1834/540/1/AssWA_BB2002.pdf.

Bermingham, S., Ferretti, J., King, L, Kinninment, D., Ryan, C., Tidmarsh, C., Totterdell, R., Yates, G., Flintoff, I., Owen, A. and Digby, B. (2000) Changing Environments. Oxford: Heinemann Educational Publishers.

Bijlsma, L., Ehler, C.N., Klein, R.J.T., Kulshrestha, S.M., McLean, R.F., Mimura, N., Nicholls, R.J., Nurse, L.A., Péres Nieto, H., Stakhiv, E.Z., Turner, R.K. and Warrick, R.A. (1996) Coastal zones and small islands in Watson, R.T., Zinyowera, M.C. and Moss, R.H. (eds.). Climate Change 1995 - Impacts, Adaptations and Mitigation of Climate Change: Scientific-Technical Analyses. Contribution of Working Group II to the Second Assessment Report of the Intergovernmental Panel on Climate Change. Cambridge: Cambridge University Press.

Bindoff, N.L., J. Willebrand, V. Artale, A, Cazenave, J. Gregory, S. Gulev, K. Hanawa, C. Le Quéré, S. Levitus, Y. Nojiri, C.K. Shum, L.D. Talley and A. Unnikrishnan (2007) Observations: Oceanic Climate Change and Sea Level in Solomon, S., D. Qin,

Boumans, R.M.J. and Day, J.W. (1993) High precision measurements of sediment elevation in shaloow coastal areas using a sedimentation-erosion table. Estuaries, 16 (2), 375-380.

Brampton, A. (2002) ICE Design and Practice Guides: Coastal Defence. London: Thomas Telford.

Brampton, A.H. (1992) Engineering significance of British saltmarshes in Allen, J.R.L. and Pye, K. (eds.). Saltmarshes: Morphodynamics, conservation and engineering significance. Cambridge: Cambridge University Press, 115-122.

Brøgger, C. and Jakobsen, P. (2008) Beach nourishment combined with SIC vertical drain in Malaysia in McKee Smith, J. (ed.). Coastal Engineering 2008, 
Hamburg, 31 Aug - 5 Sept, 2008. Singapore: World Scientific Publishing, 4725-4737.

Bruun, P. (1962) Sea level rise as a cause of shore erosion. Proceedings of the American Society of Civil Engineers, Journal of Waterways and Harbors Division, 88, 117-130.

Burgess, K. and Townend, I. (2004) The impact of climate change upon coastal defence structures. 39th DEFRA Flood and Coastal Management Conference, University of York, UK, 29 June-1 July, 2004.

Burgess, K., Jay, H. and Nicholls, R.J. (2007) Drivers of coastal erosion in Thorne, C.R., Evans, E.P. and Penning-Rowsell,

Bush, D.M., Neal, W.J., Longo, N.J., Lindeman, K.C., Pilkey, D.F., Esteves, L.S., Congleton, J.D. and Pilkey, O.H (2004) Living with Florida's Atlantic Beaches: Coastal Hazards from Amelia Island to Key West. USA: Duke University Press.

Cambers, G. (1998) Planning for Coastline Change: Coastal Development Setback Guidelines in Antigua and Barbuda. Paris: UNESCO. Available from: http:// tiny.cc/j5va7.

Chadwick, A., Morfett, J. and Borthwick, M. (2004) Hydraulics in Civil and Environmental Engineering, 4th ed. London: Spon Press.

Chagoury Group (2006) Bar Beach- Shore Protection. Lagos: The Chagoury Group. Available from: www.chagouryconstruction. com/barbeach.html.

Cicin-Sain, B. and Knecht, R. (1998) Integrated Coastal and Ocean Management Concepts and Practices. Washington DC: Island Press.

Coastal Carolina University (2010) Oceans in Motion: Waves and Tides. Carolina: Kingfish. Available from: http://kingfish. coastal.edu/biology/sgilman/770Oceansinmotion.htm.

Coastal Research (2010) Glossary. Utrecht: Utrecht University. Available from: www.coastalresearch.nl/glossary/5/view.

ComCoast (2006) Innovative flood management solutions and spatial development - A wider approach in coastal management. Delft (the Netherlands): Rijkswaterstaat.

Cooper, N.J. and Harlow, D.A. (1998) Beach replenishment: implications for sources and longevity from results of the Bournemouth schemes in Hooke, J. (ed.). Coastal Defence and Earth Science Conservation. London: Geological Society of London, 162-177.

CZMU (Coastal Zone Management Unit of Barbados) (2005) Guidelines for the assessment of planning applications. Barbados: CZMU. Available from: http:// www.coastal.gov.bb/UserFiles/File/GUIDELINES_for_the_ASSESSMENT_ OF_PLANNING_APPLICATIONS.doc.

CZMU (Coastal Zone Management Unit of Barbados) (2010) What are the Coastal Setbacks? Barbados: CZMU. Available from: www.coastal.gov.bb/info.cfm?category $=2 \&$ catinfo $=9$. 
Daniel, E.B. and Abkowitz, M.D. (2005) Improving the Design and Implementation of Beach Setbacks in Caribbean Small Islands. URISA Journal, 17 (1), 53-65.

Dawson R.J., Dickson, M., Nicholls, R. J., Hall, J., Walkden, M., Stansby, P.K., Mokrech, M., Richards, J., Zhou, J., Milligan, J., Jordan, A., Pearson, S., Rees, J., Bates, P.D., Koukoulas, S. and Watkinson, A. (2009) Integrated analysis of risks of coastal flooding and cliff erosion under scenarios of long term change. Climatic Change, 95, 249-288.

DCLG (Dept. for Communities and Local Government) (2009) Multi-Criteria Analysis: A Manual. London: DCLG. Available from: www.communities.gov. uk/documents/corporate/pdf/1132618.pdf.

de Lacerda, L.D. (2002) Mangrove Ecosystems: Function and Management. Berlin: Springer.

de Quelerij, L. and van Hijum, E. (1990) Maintenance and monitoring of water retaining structures in Pilarczyk, K.W. (ed.). Coastal Protection. Rotterdam: A.A. Balkema, 369-401.

Dean, R.G. (2002) Beach Nourishment Theory and Practice. Singapore: World Scientific Publishing.

Dean, R.G. and Dalrymple, R.A. (2002) Coastal Processes with Engineering Applications. Cambridge: Cambridge University Press.

DEFRA (Dept. for Environment, Food and Rural Affairs) (2006) Shoreline Management Plan Guidance. Volume 1: Aims and Requirements. London: DEFRA.

DFID (Department for International Development) (2004) Disaster Risk Reduction: A Development Concern. Norwich: University of East Anglia. Available from: www.sheltercentre.org/sites/default/files/DFID_DisasterRiskReductionADevelopmentConcern. pdf.

Drenkhan, R., and Hanso, M. (2006). Alterations of Scots pine needle characteristics after severe weather conditions in south-eastern Estonia. Aktuelt fra skogforskningen (Oslo), 1: 69-74. E.C. (eds.). Future Flooding and Coastal Erosion Risks. London: Thomas Telford, 267-279.

Etverk, I. 2003. 20th Century in Estonian Forests. Estonian Society of Foresters. ISBN 9985-78-653-X. Fischlin,

Fischlin, (2007|). Climate Change Impacts on Terrestrial Ecosystems. Presentation, RMK, Sagadi 18

Hanso, M., Drenkhan, R. (2007). Retrospective analysis of Lophodermium seditiosum epidemics in Estonia. Acta Silvatica \& Lignaria Hungarica. Special Edition, 31-45.

Hanso, M., Drenkhan, R. (2008). First observations of Mycosphaerella pini in Estonia. Plant Pathology, 57 (6), 1177. Doi: 10.1111/j.1365-3059.2008.01912.x

Hanso, M., Drenkhan, R. (2009). Diplodia pinea is a new pathogen on Austrian pine (Pinus nigra) in Estonia. Plant Pathology, 58 (4), 797. Doi: 10.1111/j.1365-3059.2009.02082.x.

IPCC, 
Jaagus, J., Ahas, R., Aasa, A. (2002). Eesti asub kliimamuutuste keskel. Eesti Loodus 11: 6-13. Kiviste, A., (1998). Estimation of Estonian forest growth change on 1951-1994 on the basis of forest inventory data. In: Climate change studies in Estonia. Eds. Kallaste, T., Kuldna, P. Stockholm Environmental Institute Tallinn Centre. Tallinn. pp 191- 196.

Jaagus, J., Tarand, A. (1998). Precipitation. Periodical fluctuation and seasonal shift. In: Country case study on climate change impacts and adaptation assessments in the Republic of Estonia. Eds. Tarand, A., and Kallaste, T. Stockholm Environmental Institute Tallinn Centre. Tallinn ISBN: 9985-9114-3-1. pp 2122.

Kallis, A., (2003). Photosynthetically active radiation (PAR). In Handbook of Estonian Solar radiation climate. Ed Tooming, H. Eesti meteoroloogia ja Hüdroloogiainstituut. Tallinn. pp 153- 158.

Kõlli, R., Lemetti, I. (1999). Eesti muldade lühiiseloomustus. 1. Normaalsed mineraalmullad. Eesti Põllumajandusülikool. Tartu.

Kull, A., Meitern, H. (1998). Changes in wind climate. In: Country case study on climate change impacts and adaptation assessments in the Republic of Estonia. Eds. Tarand, A., and Kallaste, T. Stockholm Environmental Institute Tallinn Centre. Tallinn ISBN: 9985-9114-3-1. pp 23-24.

Kuusk, J., Kuusk, A., Lang, M., Kallis, A. (2009). Hyperspectral reflectance of boreo-nemoral forests in a dry and normal summer. accepted for publication in International Journal of Remote Sensing.

Lang, M., Jürjo, M., Adermann, V., and Korjus, H. (2006). Integrated approach for quantitative assessment of illegal forest fellings in Estonia. Baltic Forestry, 12(1), 103-109.

M. Manning, Z. Chen, M. Marquis, K.B. Averyt, M. Tignor and H.L. Miller (eds.). Climate Change (2007), The Physical Science Basis. Contribution of Working Group I to the Fourth Assessment Report of the Intergovernmental Panel on Climate Change. Cambridge: Cambridge University Press.

Nilson, A., (1998). The paradigm of forestry in changing climate and adaptation to the changes. In: Climate change studies in Estonia. Eds. Kallaste, T., Kuldna, P. Stockholm Environmental Institute Tallinn Centre. Tallinn. pp 181-190.

Oja, T. (1998). Possible changes on nutrient fluxes and availability in Estonian forests. Country case study on climate change impacts and adaptation assessments in the Republic of Estonia. Eds. Tarand, A., and Kallaste, T. Stockholm Environmental Institute Tallinn Centre. Tallinn ISBN: 9985-9114-3-1. pp 5760.

Pärt, E:, Adermann, V., Lepiku, P., (2008). Yearbook Forest 2007. Metsakaitse- ja Metsauuenduskeskus. pp 217. Available online http://www.metsad.ee/eng/ main_e.html.

Russak, V. (2003). Kiirgusbilansi komponentide pikaajalised muutused (Long term trends in the components of radiation budget). In Handbook of Estonian Solar radiation climate. Ed Tooming, H. Eesti meteoroloogia ja Hüdroloogiainstituut. Tallinn. pp 123-133. 
Tarand, A., Eensaar, A. (1998). Air temperature. In: Country case study on climate change impacts and adaptation assessments in the Republic of Estonia. Eds. Tarand, A., and Kallaste, T. Stockholm Environmental Institute Tallinn Centre. Tallinn ISBN: 9985-9114-3-1. pp 17-21.

Valk, U., (2005). Eesti rabad. Ökoliigilis-metsanduslik uurimus. Eesti Põllumajandusülikool. OÜ Halo Kirjastus. 314pp.

Vallner, L, (1998). Assessment of the climate change impact on groundwater. In: Country case study on climate change impacts and adaptation assessments in the Republic of Estonia. Eds. Tarand, A., and Kallaste, T. Stockholm Environmental Institute Tallinn Centre. Tallinn ISBN: 9985-9114-3-1. pp 83-85.

Voolma, K. (2008). Kliimamuutuste ja inimtegevuse mõju metsakahjustustele (Impact of climate change and anthropogenic factors on forest damages). Luua Metsanduskool. Artiklid ja uurimused. 7: 41-48. ISSN 1406-8842. 


\title{
Chapter 2 \\ Carbon economics: technology, process and planning
}

\author{
Noelia Cruz Pérez, Jesica Rodríguez Martín \\ \& JuAn CARLos SANTAMarTa
}

SUMARY: 2.1 Introduction. 2.1.1 Impacts of Climate Change on the Planet. 2.1.2 Carbon cycle 2.1.3 Anthropogenic climate change.-2.2 Definition of carbon economics. 2.2.1 Europe and maritime transport. 2.2.2 Measures for the reduction of greenhouse gases.-2.3 Renewable energy. 2.3.1 Energy demand. 2.3.2 Transition to renewable energy in ports.2.4 Environmental impact associated with the production and extraction of coal.- -2.5 Carbon footprint. 2.5.1 Hydric footprint.-References

\subsection{Introduction}

"The present decade has been marked by a retreat from social concerns. Scientists bring to our attention urgent but complex problems bearing on our very survival: a warming globe, threats to the Earth's ozone layer, deserts consuming agricultural land. We respond by demanding more details, and by assigning the problems to institutions ill-equipped to cope with them. Environmental degradation, first seen as mainly a problem of the rich nations and a side effect of industrial wealth, has become a survival issue for developing nations. It is part of the downward spiral of linked ecological and economic decline in which many of the poorest nations are trapped. Despite official hope expressed on all sides, no trends identifiable today, no programmes or policies, offer any real hope of narrowing the growing gap between rich and poor nations. And as part of our "development", we have amassed weapons arsenals capable of diverting the paths that evolution has followed for millions of years and of creating a planet our ancestors would not recognize.»

The Brundtland Report: "Our Common Future” (Keeble, 1988)

What do we mean by climate change?

What are the main global organizations that are taking the lead in communicating information on climate change? 
- Greenhouse gases

- Climate change

- Global temperature

The production of a good, the provision of a service or the performance of an activity requires a certain amount of energy. However, energy production emits greenhouse gases (GHGs) into the atmosphere which are affecting the planet's climate. In this sense, in order to limit the increase in global temperature to below $2^{\circ} \mathrm{C}$, agreed by 195 countries at the Paris Climate Conference (COP21), it is necessary to know the carbon footprint of any economic activity in a country, whether agricultural, industrial or in the service sector, and specifically the source of carbon dioxide generation on which to act to reduce, eliminate or offset the carbon footprint.

United Nations defines climate change as "... a change in climate which is attributed directly or indirectly to human activity that alters the composition of the global atmosphere in addition to natural climate variability observed over comparable periods" (ONU, 1992). On the other hand, climate change is directly related to the emission of greenhouse gases (GHGs), generated in the energy production process. Greenhouse gases are the gaseous components of the atmosphere (natural and anthropogenic) which absorb and emit radiation at specific wavelengths within the spectrum of infrared radiation emitted by the Earth's surface and the atmosphere. This characteristic of GHGs to absorb and emit infrared radiation makes them responsible for being the main cause of global warming. In this sense, the three main gases (Table 2.1) contributing to the greenhouse effect in the Earth are the carbon dioxide $\left(\mathrm{CO}_{2}\right)$, methane $\left(\mathrm{CH}_{4}\right)$ and nitrous oxide $\left(\mathrm{N}_{2} \mathrm{O}\right)$. Therefore, due to the importance of greenhouse gas emissions in climate change, reducing and/or eliminating $\mathrm{CO}_{2}$ emissions can also minimize the risks of future disasters for humanity (Xu, Yao, \& Lu, 2014).

Table 2.1. Sources and concentrations of major greenhouse gases

\begin{tabular}{|c|c|c|c|c|}
\hline Gas & Source & Lifetime (years) & $\begin{array}{c}\text { Contribution to } \\
\text { warming (\%) }\end{array}$ & $\begin{array}{c}\text { Concentration year } \\
2017 \text { (ppm) }\end{array}$ \\
\hline $\mathrm{CO}_{2}$ & $\begin{array}{l}\text { Fossil fuels, deforestation, soil } \\
\text { destruction }\end{array}$ & 500 & $78,00 \%$ & 405,5 \\
\hline $\mathrm{CH}_{4}$ & Livestock, biomass, rice fields, mining & $7-10$ & $14,00 \%$ & 1859 \\
\hline $\mathrm{N}_{2} \mathrm{O}$ & Fossil fuels, crops, deforestation & $140-190$ & $8,00 \%$ & 329,9 \\
\hline
\end{tabular}

Source: OMM, 2018

Observations of climate, which began in the mid-19th century, together with paleoclimatic reconstructions, which provide records going back centuries or millions of years, provide a global view of observed variability and changes in the planet's climate. The global average surface temperature has been rising steadily since the late nineteenth century and each of the last three decades has been warmer than any other decade on record, with the 2000s being the warmest decade on record (IPCC, 2014). The changes observed in the climate have led the states to include climate change in their agendas. In 1992, the first international commitment to address global warming took place with the creation of the United 
Nations Framework Convention on Climate Change (UNFCCC). Three years later, and with its origin in the aforementioned Convention, the international agreement on climate change called the Kyoto Protocol (1995) is concluded. The purpose of this protocol was to commit participating countries to stabilize greenhouse gas emissions, whereas the Convention only encouraged them to do so (Chrysanthis, 1991). However, it is in the Paris Agreement of 2015 that it is agreed to keep the global temperature increase in this century below $2^{\circ} \mathrm{C}$ with respect to pre-industrial levels and to try not to exceed $1.5^{\circ} \mathrm{C}$ (UNFCCC, 2016). Table 2.2 specifies in more detail the different international agreements that have been concluded, with climate change as the main theme. ${ }^{1}$

Table 2.2. Chronology of climate negotiations

\begin{tabular}{|cc|}
\hline \multicolumn{2}{|c|}{ International Climate Conventions } \\
First World Climate Conference & 1979 \\
The Intergovernmental Panel on Climate Change (IPCC) is & 1988 \\
established & \\
Creation of the United Nations Framework Convention on Climate & 1992 \\
Change (UNFCCC) & 1997 \\
$\quad$ Kyoto Protocol & 2001 \\
Marrakech Agreements & 2005 \\
Nairobi Work Programme & 2007 \\
Bali Road Map & 2009 \\
Copenhagen Accord & 2010 \\
Cancun Agreements & 2011 \\
Durban Platform & 2012 \\
Doha Amendment to the Kyoto Protocol & 2015 \\
\hline
\end{tabular}

Source: United Nations ${ }^{1}$

The countries that emit the most carbon dioxide into the atmosphere are in the northern hemisphere (mainly China and the USA), as they are the most industrialised countries and have the highest energy consumption, while the lowest amounts emitted correspond to the countries on the African continent, with lower levels of development.

Today, there are several international organizations whose main mission is to study climate variations and their effects on the earth's surface, the oceans and living beings:

- World Meteorological Organization (WMO): It is a specialized agency of the United Nations dedicated to international cooperation and coordination on the state and behaviour of the Earth's atmosphere

1 https://www.un.org/sustainabledevelopment/ 
- Intergovernmental Panel on climate Change (IPCC): It publishes neutral reports which determine the state of knowledge on climate change. The IPCC numbers 195 member countries and it was created by the United Nations Environment Programme (UN Environment)

- United Nations Framework Convention on Climate Change (UNFCCC): Created in 1994, the Convention established that there was a climate concern that needed to be addressed, indicated a specific goal in this regard and led the responsibility to lead this awareness of climate change in developed countries

\subsubsection{Impacts of Climate Change on the Planet}

The impacts of climate change can be defined as the effects on livelihoods, health, ecosystems, the economy and society resulting from the interaction of variations in climate and the vulnerability of systems exposed to them (IPCC, 2014), as detailed below:

- Impacts on livelihoods (agriculture and livestock): Decreased rainfall and increased temperature lead to the emergence of agricultural pests, displacement of crops from one area of the planet to another, decreased yields due to high temperatures and/or adverse weather events (e.g. heavy rains), variability in water resource availability with consequent risk of water stress to plants, etc.

- Impacts on health: the effects on health can be of a direct type, such as a heat stroke produced by an abnormal increase in temperatures, or of an indirect type, such as respiratory diseases caused by air quality.

- Impacts on ecosystems: climate change generates physiological and demographic changes that modify the functioning of ecosystems. Among the impacts that are occurring in the habitats we can find the following: alteration of bird migration, defoliation of trees, displacement of plant species, acceleration of the duration of the larval stages of insects and acidification of the oceans and consequent destruction of corals, among others.

- Impacts on the economy: The effects of climate change on ecosystems translate into economic losses for the global whole. Both losses due to decreases in agriculture and losses due to destruction caused by adverse weather events (increasingly frequent), alteration of traditional tourist seasons, increased frequency and duration of forest fires, etc.

\subsubsection{Carbon cycle}

The flow of carbon, mainly in the form of carbon dioxide around the planet, is called the carbon cycle (Figure 2.1). There are two types of processes in the carbon cycle, there being a rapid cycle and a slow one. In the rapid carbon cycle, plants take 
carbon dioxide from the atmosphere and use it for photosynthesis. The slow carbon cycle begins with rain, which washes away atmospheric carbon and generates a series of chemical processes in the rocks called weathering. In the process of weathering, the rock decomposes, and calcium, magnesium, potassium and sodium ions are released, which end up in the sea and in living marine organisms. Once these organisms die, they are transformed into sediments that give rise to new rocks.

Figure 2.1. Carbon cycle2

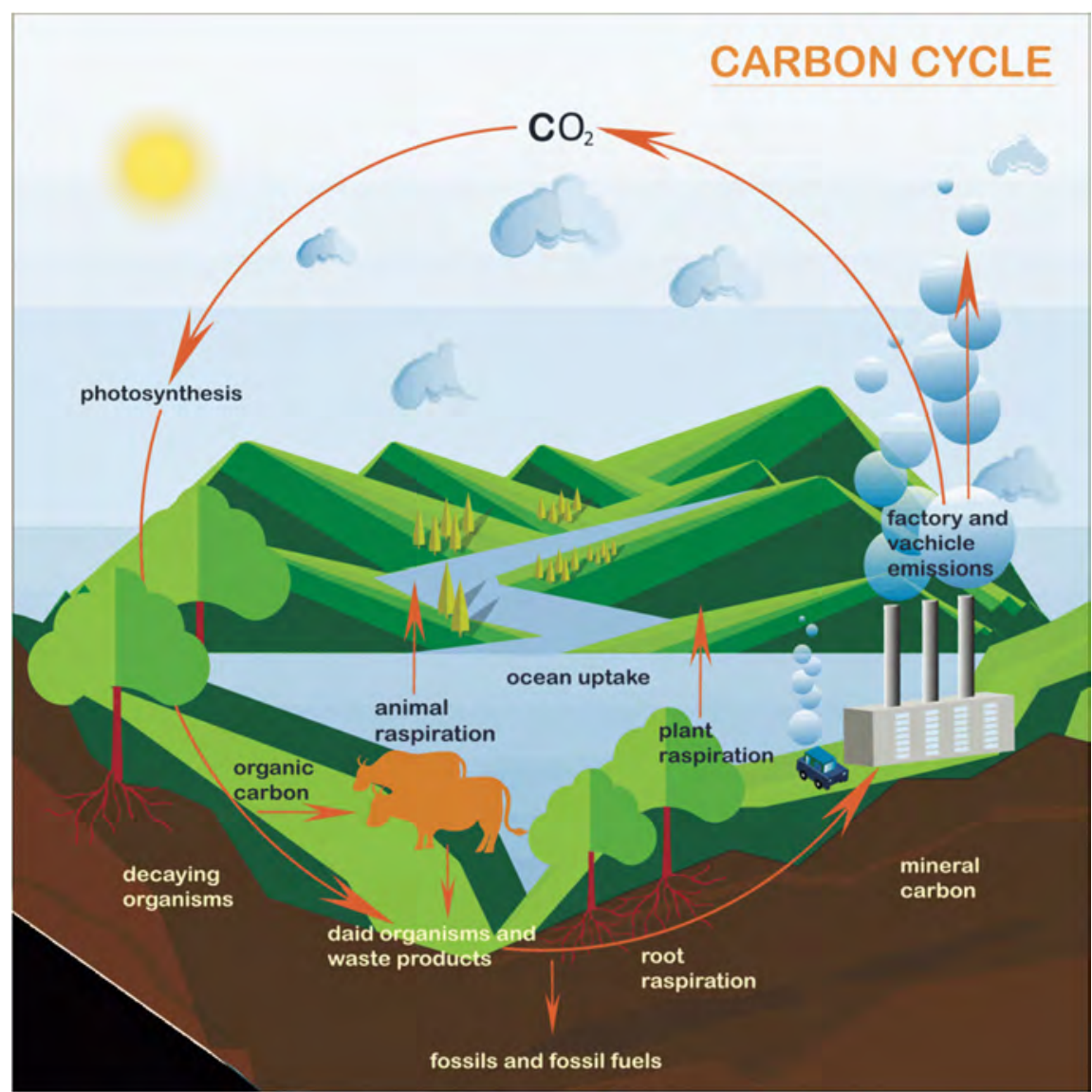

In the carbon cycle we can also distinguish between two key concepts: source and sink. Sinks are any activity or mechanism that absorbs a greenhouse gas. For example, plants behave as sinks when they absorb $\mathrm{CO}_{2}$. Water bodies are also sinks, because as we mentioned before, carbon, which is the result of weathering, dissolves and precipitates as calcium carbonate. The sources are the processes or activities that release greenhouse gases into the atmosphere (e.g. industrial activities, livestock, etc.).

\footnotetext{
${ }^{2}$ Source: https://www.alevelgeography.com/carbon-cycle/
} 


\subsubsection{Anthropogenic climate change}

It is about all the effects and consequences of human actions in the natural environment. The human being has always used the natural environment for his own benefit. The resources of the environment have always been available to meet the needs of mankind.

It is since the Industrial Revolution that the use of these resources has increased. In order to carry out industrial activity and supply the needs of a growing population, the consumption of fossil fuels grew rapidly.

There are several human activities causing climate change, which are listed below:

- Deforestation: It consists of the elimination of forests by slashing or burning, in order to make the area available for various purposes, such as agriculture, livestock farming, construction, etc. and to obtain wood for use in the timber industry.

- Fossil fuel burning: The fuels that are burned are responsible for major environmental problems, such as the accumulation of greenhouse gases, acidification, air pollution, water pollution, etc. Currently, the burning of oil and coal are the most harmful as they contribute a very high percentage of greenhouse gases to the atmosphere.

- Use of land for urban, industrial or agricultural purposes: One of the biggest problems today is rapid population growth. In developed countries, due to the powerful economic development, most of the landscape has been transformed. Agriculture, livestock, forestry, industry and construction have drastically reduced soil quality.

Some consequences of climate change that can be seen today are:

- Decreased rainfall

- Alterations in terrestrial ecosystems with risk of increased pests

- Increased desertification due to loss of soil properties

- Reduction of animal and plant species richness

- Increase in pests and emergence of new forest diseases

- Decrease in drinking water

- Increased intensity, frequency and magnitude of fires

- Increased air pollution

In addition to the information contained in this unit, it should be noted that climate change will generate economic costs that cannot yet be accurately estimated. In fact, the latest agreements to confront climate change propose the creation of a Green $\mathrm{Fund}^{3}$, in order to be able to assume the costs that climate change will entail at an international level.

\footnotetext{
${ }^{3}$ Website: https://www.greenclimate.fund/
} 


\subsection{Definition of Carbon Economics}

The concept of a low-carbon economy was first mentioned in the United Kingdom's Energy White Paper in 2003 (Great Britain Department of Trade and Industry, 2003) and has since gained increasing importance, with countries such as Germany and Japan setting up national systems to reduce their carbon-related emissions. Scientists around the world have recognized that emissions related to the traditional energy production system have led to serious climate consequences. Therefore, a low-carbon economy is presented as one of the main solutions to curb the climate crisis we are experiencing.

How is defined a low-carbon economy?

Which are the main air emissions from the maritime transport?

- Low-carbon economy

- Case of maritime transport in Europe

- Mitigation

The European emissions market initiative ${ }^{4}$ has set a goal of reducing EU emissions by $43 \%$, taking 2005 as a reference year.

Figure 2.2. Total Emissions in $2018=\mathbf{6 , 6 7 7}$

Million Metric Tons of $\mathrm{CO} 2$ equivalent

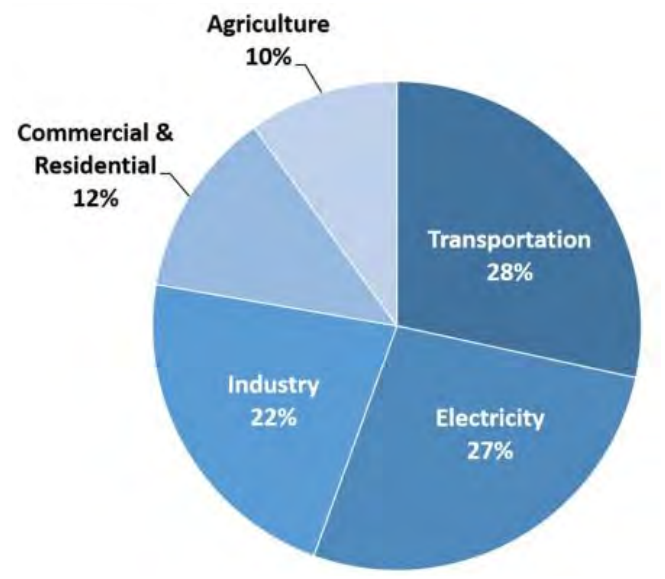

The five sectors that contributed most to greenhouse gas emissions in 2018, at the global level, were transport (28\%), electricity generation $(27 \%)$, industry (22\%), residential, commercial and institutional sector (12\%) and agriculture $(10 \%)$ (Figure 2). Within the transport sector, the port system constitutes an essential element of social and economic life, which has made it possible to guarantee the mobility of citizens, to satisfy to a great extent the needs of passenger trans-

\footnotetext{
${ }^{4}$ https://ec.europa.eu/clima/policies/ets_en
} 
port and to provide the fishing, commercial and industrial sectors with the installations and infrastructures essential for carrying out the tasks of economic exchange and goods traffic. On the other hand, the great development of tourism has led to the appearance of ports and maritime facilities of a sporting or recreational nature, linked to leisure and quality tourism, which have a great impact on the economic model of the municipalities where they are located and on the territory.

The operations in the port that have the greatest impact on the environment are those carried out at the gas oil dispensing stations and the repairs and maintenance of the ships in the dry dock. The products handled in these operations such as petrol, fuel and its derivatives, dirty water, detergents, paints, glue, resin, protectors and used oils have potential negative effects on the marine environment. Dredging activities also cause significant changes in the physical and chemical conditions of the environment closest to the marina (Valdor et al., 2019). Other actions with impacts on the environment are the losses suffered by ships during navigation (Davenport \& Davenport, 2006), the management of solid waste, the discharge of used oils or bilge water and the alteration of the sea floor due to anchoring or mooring, the movement of propellers. However, the pressure depends on the density of the boats and the length of the boat, whether the boat is motor or sail, and the number of crew members. Finally, it also depends on the mode of operation. For example, the pressure of marinas differs from that of cargo ports because the latter have associated logistics and industrial services that do not exist in marinas.

Low-carbon economy is defined by eight mains aspects (Xue, 2013): Low-carbon production; Low-carbon energy; Low-carbon technology; Low-carbon transportation; Low-carbon consumption and lifestyle; Low-carbon housing and building; Low-carbon farming and Low-carbon city. The European Union has launched the EU Emissions Trading System (EU ETS) in 2005 as the cornerstone of its strategy for cutting emissions of carbon dioxide $\left(\mathrm{CO}_{2}\right)$, which has become the largest carbon market today. With this programme, the European Union has achieved various objectives: placing climate change as a priority on the agenda of European companies, assigning a value to the carbon emissions emitted and promoting investment in clean energy that does not have an economic penalty associated with its use (Climate Action - European Commission, 2015). The operation of the EU ETS is that companies and firms included in the system can make emissions up to a limit set by the European Union. Therefore, within that limit, companies can buy or receive allowances, trading them if they wish.

The Marine Environment Protection Committee (MEPC) addresses environmental issues under IMO's remit. This includes the control and prevention of ship-source pollution covered by the MARPOL treaty, including oil, chemicals carried in bulk, sewage, garbage and emissions from ships, including air pollutants and greenhouse gas emissions. The main air emissions from the maritime transport sector are: sulfur dioxide $\left(\mathrm{SO}_{2}\right)$; nitrogen oxides $\left(\mathrm{NO}_{\mathrm{x}}\right)$; volatile organic compounds (VOCs); particulate matter (PM) and carbon dioxide $\left(\mathrm{CO}_{2}\right)$ (Miola, Marra, \& Ciuffo, 2011): 
- Sulphur dioxide (SO2): it is a colourless gas with a characteristic irritating odour. Combustion of fuels for heating and power generation produces an environmental pollution with sulphur dioxide (Vale, 2012).

- Nitrogen oxides (NOx): $\mathrm{NO}_{2}$ and other $\mathrm{NO}_{\mathrm{x}}$ encounters water, oxygen and other chemicals in the atmosphere to form acid rain. Acid rain harms sensitive ecosystems such as lakes and forests.

- Volatile organic compounds (VOCs): it is a group formed by organic chemical compounds with significant vapour pressure values (Fellow, 2000).

- Particulate matter (PM): particulate matter may have a natural origin or an anthropogenic origin. Its anthropogenic origin lies in the combustion of fossil fuels and biofuels.

- Carbon dioxide (CO2): it is an important greenhouse gas that contributes to trapping heat in our atmosphere. However, a gradual increase in $\mathrm{CO}_{2}$ concentrations in the Earth's atmosphere is helping to drive global warming, threatening to disrupt our planet's climate as average global temperatures gradually rise.

In January 2020, a limit has been set by the European Union for the maximum sulphur content of marine fuels and has been reduced to $0.5 \%$. The Commissioner for Transport in the EU has signed (Virginijus, 2020): "Maritime transport is a global business, and reducing its emissions requires global solutions. The entry into force of the global sulphur cap is an important milestone for the entire maritime sector; it will contribute to further reduce emissions of harmful air pollutants, directly benefiting cities and communities around the globe, including important ones on our Southern European shores." These statements are corroborated by the consumption of fossil fuels by transport at the European level (Figure 2.3). ${ }^{5}$

Figure 2.3. Consumption by fuel type and sector

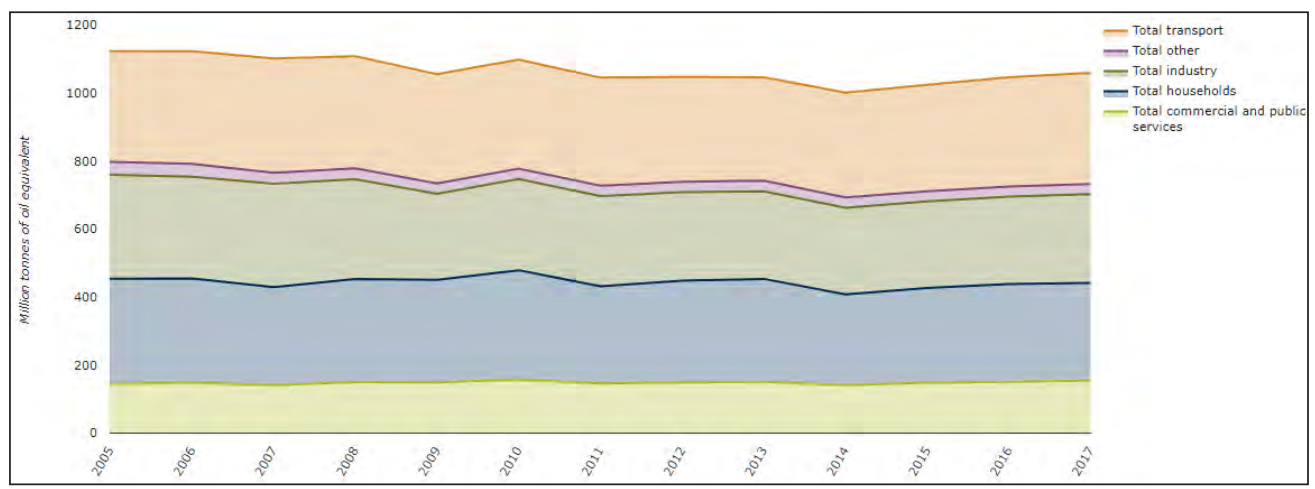

Source: European Union $^{5}$

${ }^{5}$ https://www.eea.europa.eu/data-and-maps/indicators/final-energy-consumption-by-sector-10/ assessment 


\subsubsection{Europe and maritime transport}

The European Union historically has had an important connection with the sea, as its trade relations with the rest of the world have depended heavily on its seaports. European Directive 2019/883 states that “... The Union's maritime policy aims to ensure a high level of safety and environmental protection" (EU, 2019). If at first consideration was given only to the development of a maritime sector ports focused mainly on trade, this concept has evolved over the years and the knowledge acquired has made possible to see nowadays ports dedicated also to other matters. Hence, ports have been recently developed also for tourism related activities, and cruise ships and maritime passenger transport vessels dock dedicated areas were made available (Paiano et al., 2020). On the other hand, there are the leisure ports, which are those where the boats that dock have a recreational and leisure purpose. In this article, the authors intend to focus on the study of the leisure marinas, because due to their quantity and characteristics, they constitute their own segment within the maritime sector, which has been less studied than commercial ports.

The operations in the port that have the greatest impact on the environment are those conducted at the diesel fuel dispensing stations, and the repairs and maintenance of ships in the dry dock. The impact depends on the density of the ships on each route and the length of the boat, whether the boat is motor or sail, and the number of crew. It also depends on the mode of operation. For example, pressure from leisure marinas differs from that of freight ports because the latter have associated logistics and industrial services that are not available in marinas.

Recent studies carried out by the European Union have analysed which navies hold the Blue Flag in Europe. The results of this study can be seen in Figure 2.4.

\subsubsection{Measures for the reduction of greenhouse gases}

Climate change mitigation can be achieved through different measures such as the following:

- Use of renewable energies

- Prioritizing the use of electric vehicles

- Recycling and reuse

- Increasing carbon sinks

There are production sectors that are worth emphasising more, because a drastic reduction in emissions in these sectors would mean a significant reduction in emissions on a global scale. These sectors are as follows:

- Energy sector: as will be seen in unit 4, to produce electricity today, a large amount of coal is required, with the consequent negative impacts of this activity on the environment. Therefore, a greater effort is required at a global level to increase the use of renewable energies in the energy sector. 
Figure 2.4. Sport marinas with blue flags in the Mediterranean coast

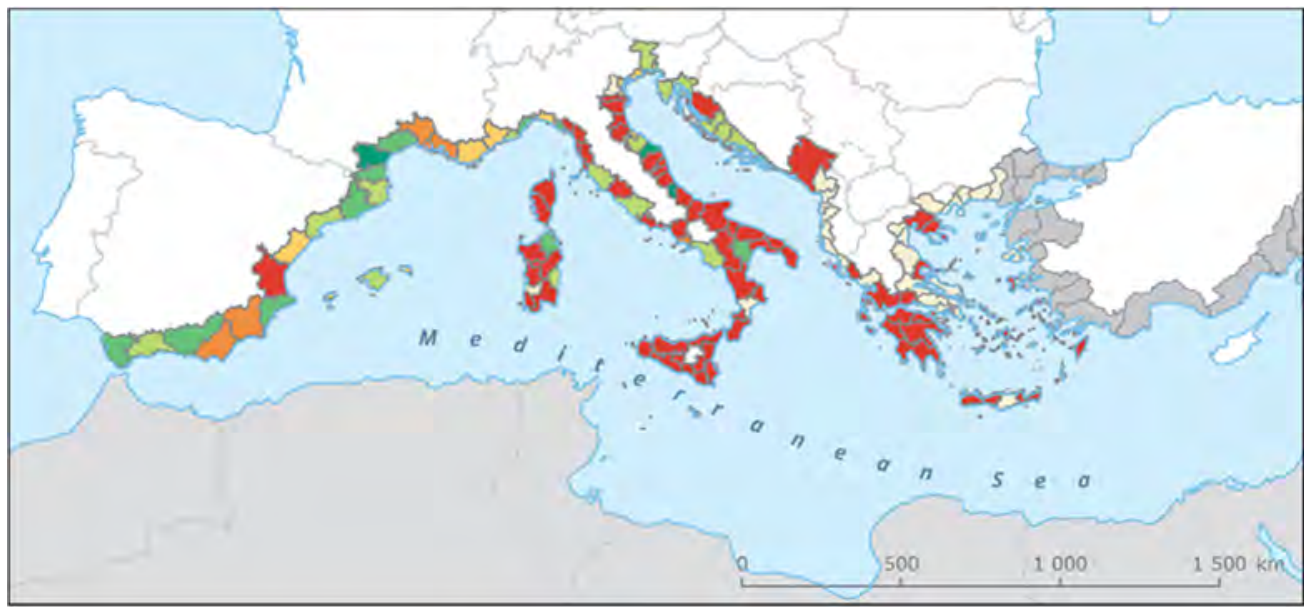

Share of marina port capacity with Blue Flags by Mediterranean coastal regions, 2015

Percentage
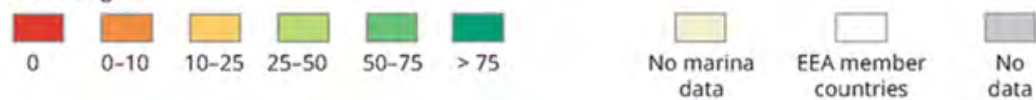

Source: European Union ${ }^{6}$

- Transport sector: the means of transport we use today involve a large consumption of fossil fuels. For this reason, in various sectors, attempts are being made to include renewable measures to improve the sustainability of land, sea and air communications.

- Industrial sector: Everything we consume today involves a previous industrial process. Therefore, as industry is such a powerful sector, these activities are increasingly required to be efficient in reducing emissions, recycling, heat and energy recovery to be reused in the production process, etc.

- Agricultural and livestock sector: With an effective management of crops, carbon sinks can be achieved, and through agriculture, degraded or disused soils can be recovered, and reforestation can also be practiced.

One of the major United Nations initiatives for climate change mitigation and reduction is Agenda 20307. This Agenda includes 17 objectives, of which the following are expressly related to Climate Change:

- SDG6: Clean Water and Sanitation

\footnotetext{
${ }^{6}$ Source: https://www.eea.europa.eu/data-and-maps/figures/share-of-marina-port-capacity

7 https://www.un.org/sustainabledevelopment/
} 
- SDG7: Affordable and clean energy

- SDG11: Sustainable Cities and Communities

- SDG13: Climate Action

These objectives are intended to be a global strategy when undertaking economic and development measures, to ensure a more sustainable and fairer world.

\subsection{Renewable Energy}

United Nations, in its Sustainable Development Goals (United Nations, 2018), includes energy as one of its priorities from two approaches: on the one hand, by requesting that people who do not have access to electricity have the option of accessing it. On the other hand, it requires countries that already have an energy supply network to make an urgent energy transition to renewable energy sources, since only $17.5 \%$ of the total energy consumed worldwide comes from clean energy. Developed countries should be the most involved in taking measures to mitigate climate change, as they are also the ones that generate the most greenhouse gas emissions. Moreover, in this way, a cascade effect can be achieved, whereby developing countries grow by taking ecological measures from the outset.

What are the main sources of renewable energy?

How can we start a transition to renewable energy?

- Clean energy

- Energy supply

- Energy transition

Renewable energies are clean and practically inexhaustible resources offered by nature; whose environmental impact is zero in the emission of greenhouse gases such as $\mathrm{CO}_{2}$. The various sources of renewable energy that are available in the planet are:

- Solar: the solar radiation can be collected by collectors attending to two different types of principles: the photoelectric effect and the photothermal effect. Photovoltaic energy transforms the rays of the sun into electricity through solar panels. Photothermal energy uses the heat of the sun by capturing it with solar collectors.

- Wind: is the most efficient renewable energy exploited by humans. The principle of wind energy is to run a wind turbine that produces electrical energy. The wind turbine is activated by the movement of the blades, which are themselves moved by the force of the wind.

- Water: hydroelectric plants are in riverbeds to take advantage of the force of the water, which moves the plant's turbines, generating electricity (Figure 2.5). The percentage of energy used worldwide and covered by hydroelectric power is $16 \%$ (World Bank, 2015). 


\section{Figure 2.5. Operating diagram of a hydropower plant}

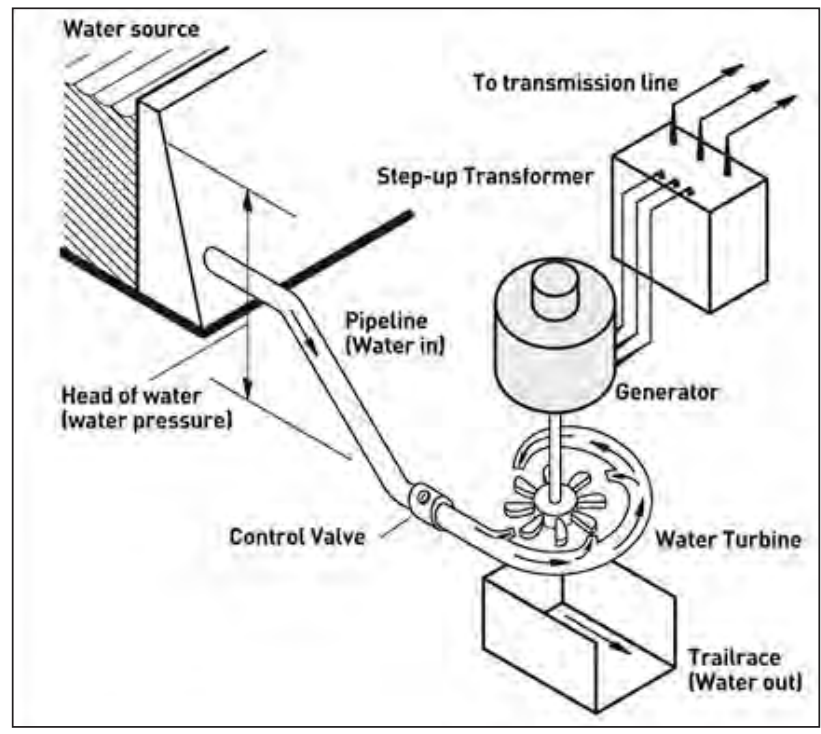

Source: http://www.veoliawater2energy.com/en/ references/micro-hydro-power-plants/

- Geothermics: geothermal energy is tied to the heat of the interior of the earth's surface and, if we consider the entire surface of the earth, the geothermal power that arrives from the interior is $4.2 \times 1012 \mathrm{~J}$ (IDAE, 2008). Geothermal energy can be of high enthalpy, when temperatures reached are above $150^{\circ} \mathrm{C}$, or of low enthalpy, when temperatures are below that temperature.

- Biomass: biomass is organic matter used as an energy source. These biomass resources can be generally grouped into agricultural and forestry resources. The organic matter in wastewater and sewage sludge is also considered biomass. The valuation of biomass can be achieved through four basic processes by which it can be transformed into heat and electricity: combustion, anaerobic digestion, gasification and pyrolysis. Biomass can result in biogas or biofuels.

- Tidal energy: it is a blue energy, since it exploits the energy coming from the tides to generate, through a system of alternators, electrical energy.

\subsubsection{Energy demand}

Europe plans to become a zero-emission economic powerhouse by 2050. This strategy, in line with the Paris Agreement ${ }^{8}$, aims to continue economic and industrial growth, without compromising the state of the environment. To achieve this

\footnotetext{
${ }^{8}$ https://ec.europa.eu/clima/policies/international/negotiations/paris_en
} 
goal, the European Union needs to reduce emissions from energy production, which currently account for $75 \%$ of the continent's total emissions.

In the last European Union progress report ${ }^{9}$, corresponding to the years 2015/2016, the following interesting data have been obtained, and they are quoted literally:

- "In its final energy consumption, the EU achieved a $16 \%$ share of renewable energy in 2014 and an estimated 16.4\% share in 2015.

- Most EU countries are well on track to reach their 2020 binding targets for renewable energy, but all countries will have to continue their efforts to meet these targets.

- The transport sector achieved a $6 \%$ share of renewable energy in 2015, so some EU countries will have to intensify their efforts to reach the $10 \%$ binding target for transport by 2020."

Since the Industrial Revolution until today, the energy demand of all countries has been covered in a similar way, with a system known as the energy demand curve. This curve (which has its peaks at the times of the day of greatest consumption, varies slightly between countries due to the customs and schedules of each of them) has been fed at its base with thermal energy. One of the main applications of thermal energy is the generation of electricity from heat. Heat is a form of energy that can be converted into electricity in many ways. The main ones are:

- Burning fossil fuels: this is the most common way, and not only fossil fuels but also organic waste (biomass) can be burned

- From nuclear reactions: uranium, when breaking its atoms and producing fission, gives off an enormous amount of energy

Thermal energy obtained from the burning of fossil fuels is the most common in almost all countries, especially in those where nuclear energy is banned or in disuse. However, thermal energy from fossil fuels is characterized as the least environmentally friendly source of energy. Thermal energy emits high emissions of greenhouse gases into the atmosphere. Figure 2.6 shows the main emissions from Large Combustion Plants (LCP) in Europe.

For instance, if we take the case of the United Kingdom, we can see how its energy demand curve is composed of a large percentage of conventional thermal energy (Figure 2.7).

Traditionally, renewable energies have behaved as a support for conventional thermal energy, occupying a very discreet and unrepresentative percentage of demand. The current trend is trying to be reversed, in fact, there are two leading energies such as solar and wind ${ }^{10}$, which are growing by leaps and bounds, and are trying to lead the field of solar energy.

\footnotetext{
${ }^{9}$ https://eur-lex.europa.eu/legal-content/EN/TXT/PDF/?uri=CELEX:52019DC0225\&qi$\mathrm{d}=1559033163855 \&$ from $=$ EN

${ }^{10}$ Miller \& Carriveau. 2019. Energy demand curve variables - An overview of individual and systemic effects. Sustainable Energy Technologies and Assessments, 35, 172-179
} 
Figure 2.6. GHG emissions from large combustion plants in Europe

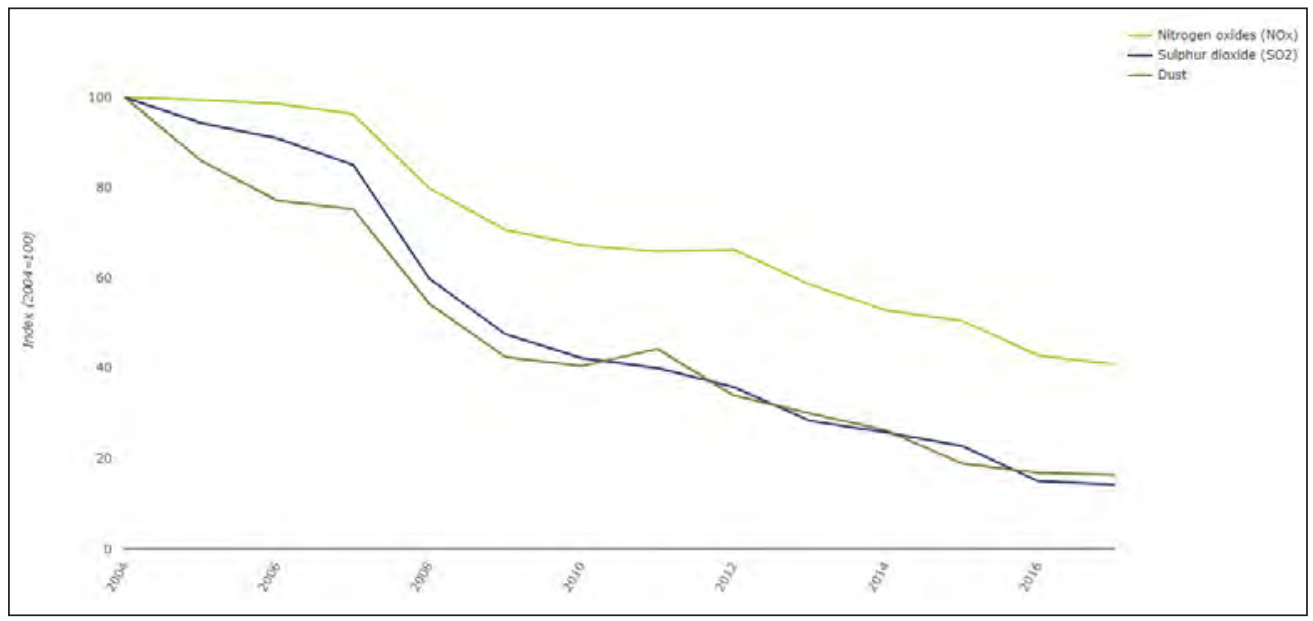

Source: European Union ${ }^{11}$

Figure 2.7. Electricity generation in the UK12

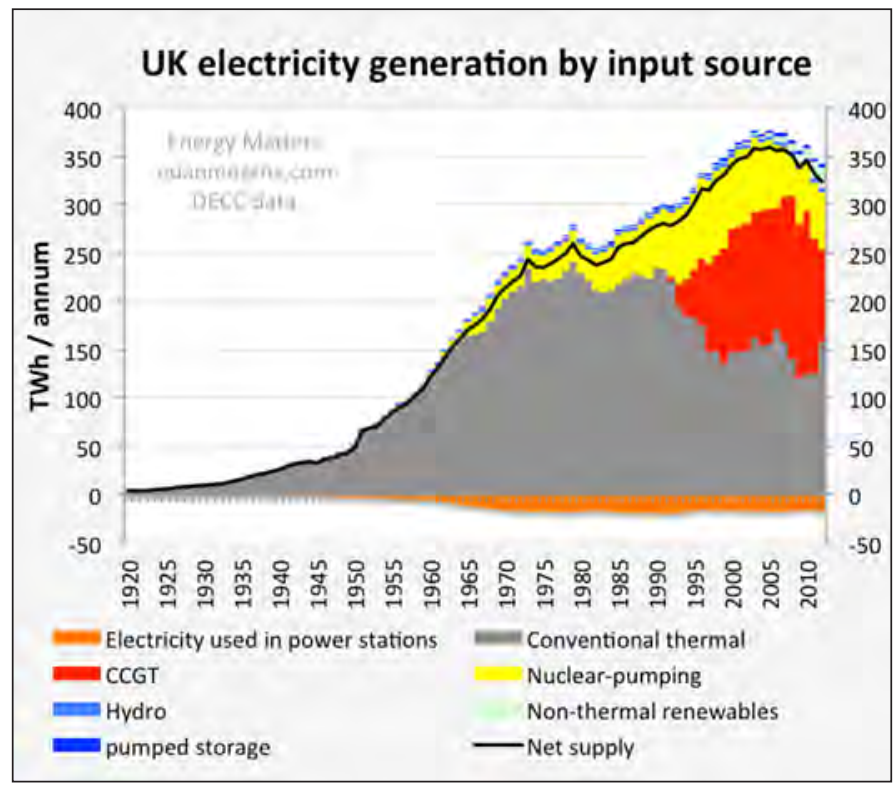

${ }^{11}$ https://www.eea.europa.eu/data-and-maps/indicators/emissions-of-air-pollutants-from-16/ assessment

${ }^{12} \mathrm{http} / / /$ euanmearns.com/uk-electricity-demand-gdp-and-energy-policy/ 
Traditionally, renewable energies have behaved as a support for conventional thermal energy, occupying a very discreet and unrepresentative percentage of demand. The current trend is trying to be reversed, in fact, there are two leading energies such as solar and wind ${ }^{13}$, which are growing by leaps and bounds, and are trying to lead the field of solar energy.

Another energy that so far has only been used in countries like Iceland, Nicaragua or the Philippines, which is geothermal energy, is trying to be increasingly integrated into the countries' renewable energy systems. Geothermal energy can be called either high-enthalpy or low-enthalpy. The countries mentioned are examples of countries with high enthalpy geothermal energy. However, taking into account that geothermal energy is constant and can be found from a depth of 100 metres below the earth's surface, it is consolidated as a magnificent source for heating homes and buildings. These uses have been in use for a long time in countries such as Sweden, Switzerland and Denmark.

A country's energy consumption is related to its GDP. Therefore, the most developed countries have the highest electricity consumption ${ }^{14}$. That is why it is necessary to focus on the great world powers, demanding them to increase their use of renewable energies, since they are the ones that emit the most and since they can serve as an example for the countries that are currently industrializing.

\subsubsection{Transition to renewable energy in ports}

There are a series of projects being implemented across Europe to reduce port-related emissions by using renewable energy to power ports. Some of these examples are as follows:

- Onshore Power Spply (OPS): The Onshore Power Supply (OPS) means a considerable decrease in the maritime sector, since when ports are berthed they depend entirely on fossil fuels, unless they are connected to the electricity grid of the city where they are anchored. There are successful cases in which the use of PAHOs has reduced a port's $\mathrm{CO}_{2}$ emissions by $10 \%$. It is therefore important to consider that, for the reduction of emissions to be more effective, the production of this electrical energy, which will replace fossil fuels, should come mainly from renewable energies. Otherwise, we would be transferring emissions from one process to another.

- Alternative fuels: Using alternative fuels such as Liquified Natural Gas (LNG) reduces the emission of $\mathrm{CO}_{2}$. Nevertheless, LNG produces methane, which is a greenhouse gas as well, but it is the cleanest fossil fuel right now.

${ }^{13}$ Miller \& Carriveau. 2019. Energy demand curve variables - An overview of individual and systemic effects. Sustainable Energy Technologies and Assessments, 35, 172-179

${ }^{14}$ Mujiyanto \& Tiess. 2013. Secure energy supply in 2025: Indonesia's need for an energy policy strategy. Energy policy, 61, 31-41 
Other measures that can be taken in the meantime to reduce emissions from European marinas are as follows:

a) Promote the use of public transport among marina workers and visitors, indicating on the marina's website the public service line between the marina and different locations on the island.

b) To carry out a supply plan that will make it possible to reduce the frequency of visits by suppliers.

c) Encourage the hiring of distributors with efficient transport fleets such as electric or low emission vehicles.

d) Contracting electricity that comes entirely from renewable sources.

e) Using solar panels to produce hot water for the marina.

f) Use of all possible renewable sources for other uses.

g) Transfer the results of the study to the marine workers so that they make a more conscious and efficient use of energy and resources.

\subsection{Environmental impact associated with the production and extraction of coal}

According to the ISO 14001:2015 standard, the concept of life cycle is defined as: "Consecutive and interrelated stages of a product (or service) system, from the acquisition of raw materials or their generation from natural resources to final disposal".

What are the main environmental impacts of mining activity on the environment?

What are the 4 main types of pollution produced by mining activity?

- Coal mining activity

- Coal mining impact on the environment

Coal is a fossil fuel, the result of a series of transformations on accumulated plant remains in swampy places or lagoons. Through diverse chemical actions and variations in pressure and temperature over long intervals of time, these plants are transformed into coal in a process called carbonization. There are four different types of carbon, due to the different types of plant from which they come. These are:

- Anthracite: is a hard coal, totally carbonized. With a pearly shine and black colour.

- Coal: it is a hard coal, totally carbonized. Glossy black colour.

- Lignite: it is a soft coal, so it has not suffered the complete carbonization process. 
- Peat: it is the most recent of the coals. It is soft, brown in colour and you can still see the remains of plants.

Coal has become the main source of energy; it can supply $29.6 \%$ of the world's energy requirements and $42 \%$ of the world's electricity requirements (Hasanuzzaman et al., 2018).

The coal mining industry involves four different types of pollution:

- Air pollution: The work of extracting coal, as well as the use of explosives in order to advance the drilling, favours air pollution in a mine. The main gases released in these activities are sulphur dioxide, nitrogen oxide and carbon dioxide.

Due to the characteristics and hardness of some materials that are crossed when the mine is executed, it is necessary to use explosives as a system of advance. The use of explosives depends on the type of terrain to be crossed. Therefore, if the rock to be excavated has a high resistance, it is advisable to excavate it by drilling and blasting (Santamarta, 2016).

Initially, the mines were built by hand and with animals used for the transport of tools and utensils. Afterwards, in areas with the presence of massive materials, it was necessary to use very rudimentary explosives, sometimes even manufactured by the operators of the mine themselves. As a complement to explosives, pneumatic hammers and even excavators are also used in drilling. The use of this machinery has obvious advantages in terms of productivity and comfort at work, nevertheless, it is precisely the utilisation of all such machinery that makes the impact of the mining process on the environment more severe.

\section{Figure 2.8. Landslides on slopes due to mining activity}

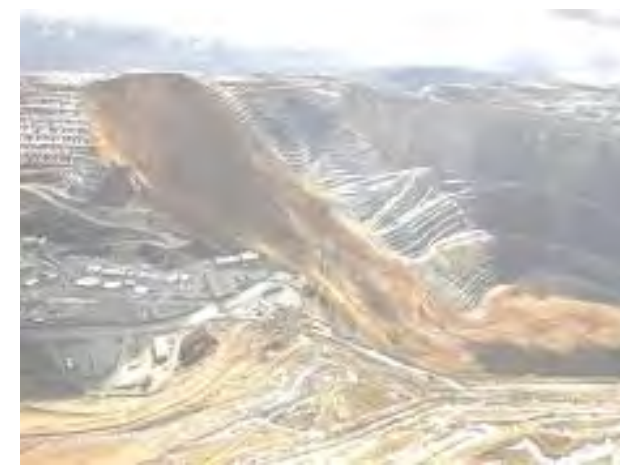

- Soil pollution: Coal mining activities generate a progressive loss of soil, due to changes in soil properties (e.g. a reduction in $\mathrm{pH}$ and electrical conductivity) turning it into a barren area over time. 
Other environmental consequences associated with coal mining activity include deforestation, loss of fertile soil, erosion and alteration of slope process dynamics (see Figure 2.8):

- Water pollution: there are two types of water pollution here. On the one hand, water used in extractive activities, that is, in production work, causing water used in industry to become contaminated after use and to change from drinking water to wastewater. On the other hand, the groundwater in the extraction area. With the rains, the above-mentioned pollutants are carried away, and part of these are infiltrated into the subsoil, causing the contamination of the groundwater (mainly acid contamination).

- Noise pollution: a mine at full capacity means the transfer of heavy machinery, generating noise non-stop. It is estimated that on a construction site, with work progressing during the day, it can have values of between 100 and $110 \mathrm{~dB}$ (Wang et al., 2014).

All these negative impacts of the mining activity are suffered in the first place by the workers of the sector, who usually present high percentages of lung cancer due to inhaled substances (Yang \& Chen, 2015). They also present high levels of stress associated with high noise levels in the workplace. Secondly, the damage is suffered by society in general, since the loss of fertile soil and water pollution are major damages that affect society collectively. The largest coal mines in the world are located in the United States, Russia, China and Australia. However, China is the largest producer and consumer of coal in the world.

Indeed, if we look at the trend proposed by the "World Energy Outlook 2019", we can see how global coal consumption is and will be led by Asian countries (Figure 2.9).

Figure 2.9. Forecasts of world coal consumption to 204015

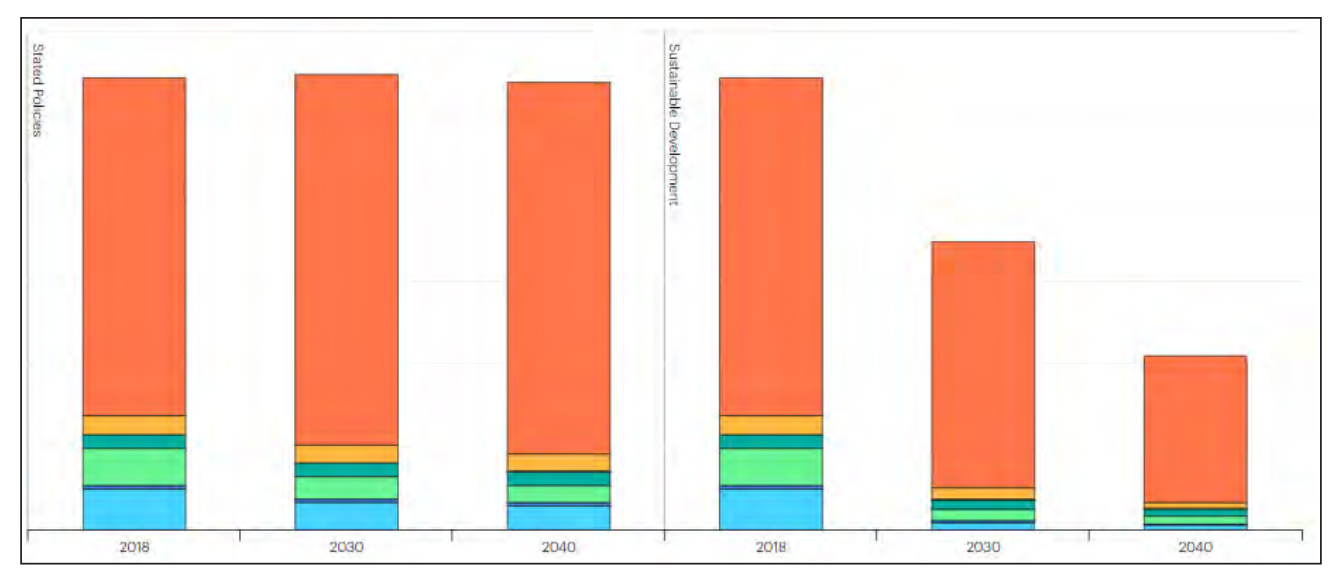

${ }^{15}$ https://www.iea.org/reports/world-energy-outlook-2019 


\subsection{Carbon footprint}

The carbon footprint accounts for all the greenhouse gases associated with the production of a product, the provision of a service or the performance of an activity, generated both directly and indirectly by the organisation (Blasco Hedo, 2014). Therefore, the carbon footprint makes it possible to measure the impact of a product, service or activity on the environment. In parallel to measuring, an implicit objective in the study of the carbon footprint is to provide recommendations to reduce or compensate emissions. And with the communication and implementation of these recommendations it is possible to act on the planet's climate.

How can we calculate the carbon footprint of an organization?

What is the hydric footprint?

- Carbon footprint

- Hydric footprint

- $\mathrm{CO}_{2}$ emissions inventory

- Scopes

Initiatives to communicate the carbon footprint to society have been undertaken in nearly every country in the world, either in the form of product labelling or in the form of an inventory of the $\mathrm{CO}_{2}$ emissions of companies and organisations. The carbon footprint is an indicator of the amount of greenhouse gases emitted into the atmosphere as a result of an activity. The accounting of these emissions is governed by various regulations at both international and national levels, and some countries have even devised their own system for calculating the carbon footprint. In this sense, a study promoted by the European Commission in 2010 found more than 140 different methodologies ${ }^{16}$.

The calculation of the carbon footprint can be addressed by following two basic methodological approaches. The first is the business-oriented method, which consists of collecting data on the direct and indirect consumption of materials and energy by an organization and translating it into equivalent $\mathrm{CO}_{2}$ emissions in order to have an inventory of emissions. The Green House Gas Protocol, developed by the Word Resources Institute and the Word Business Council for Sustainable Development, is the most widely used guide for companies, both large and small, to inventory their GHG emissions and thus calculate their carbon footprint. The importance of this protocol is that it has been the basis for many other methods and initiatives. The ISO 14064: 2006 standard (parts 1 and 3) is a second tool following the company's approach. Unlike the Green House Gas Protocol, the ISO standard is an international standard verification guide for companies to prepare and report on their greenhouse gas inventory. This standard is compatible with the Green House Gas Protocol. In addition to these tools, there are other tools that focus on the product. In the latter

${ }^{16}$ For example, France proposes the Bilan Carbone Method, England uses the PAS 2050 System and Germany has developed the PCF Projekt Project (CEPAL, 2008). 
case, the calculation consists of collecting all the information on material and energy consumption in each of the stages that a product goes through and translating it into $\mathrm{CO}_{2}$ emissions. Finally, the composite method of the accounting accounts or MC3 is a mixed approach, oriented both to the organization and to the product, in which the data are obtained from the accounting accounts of the organization.

\section{Figure 2.10. Carbon Footprint Scopes}

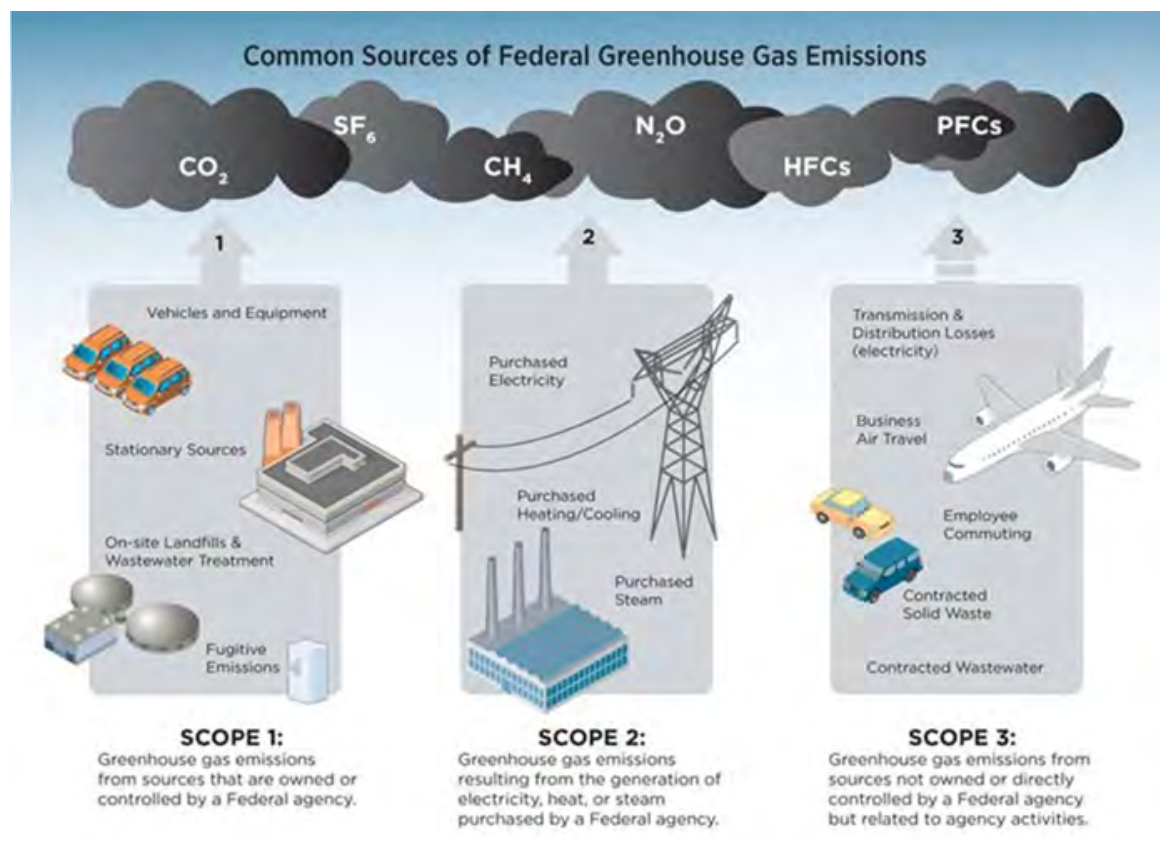

Source: EPA

Calculating the carbon footprint requires defining the limit of the company's inventory. Organizational and operational boundaries delimit the inventory. The ISO 14064 standard and the Corporate Accounting and Reporting Standard of the GHG Protocol allow a choice from two approaches to setting the organization's limits. The equity approach consists of accounting for emissions from shares, even if the company does not have control over its operations, and the control approach consists of accounting for emissions from operations over which the company has some control, either financial control or operational control. Under no circumstances should issues from operations in which the company has an ownership interest without control of the share be included. Note that the organizational boundaries depend primarily on the size and manner of operation of the company. On the other hand, the definition of operational limits requires determining the type of emissions to be included in the inventory, emissions that, in turn, are related to the scope of these emissions (see Figure 2.10). GHG emissions can be classified into three types. Direct or designated Scope 1 emissions are those 
that come from the fuels that the organization uses in its processes or in transportation, indirect or Scope 2 emissions are those related to the generation of electricity acquired by the organization and the so-called other indirect or Scope 3 emissions include everything that is not fuel, direct emissions of any type and electricity. Finally, the methodology used can be called complete if it includes the carbon footprint of capital goods, works and all fixed assets.

The emissions inventory requires the identification of the sources of gas emissions. Emission sources are classified into fixed and mobile sources. Among the fixed sources a distinction can be made between point sources derived from the generation of electrical energy and from industrial activities, area sources, which include the emissions inherent to certain activities and processes, and natural sources, which refer to the generation of emissions produced by volcanoes, oceans, ... The definition of mobile source includes all motor vehicles.

\section{Case Study - Company vehicle fleet}

The study will use the fuel consumption of an organisation's vehicle fleet. The company has a total of 20 vehicles. The frequency of passage of the vehicles is 30 minutes, in schedule of 07:00-24:00 h. The type of vehicles is known, the fuel used by all vehicles is diesel.

Calculation period: 2018

Operational limits: fossil fuel consumption of the vehicle fleet, electricity consumption in the offices, waste generation in the vehicle maintenance workshop.

The different scopes we comprise them thus:

Scope I: direct emissions are included as well as the diesel consumption of the vehicle fleet. Transport equipment using fossil fuels.

Scope II: Electrical consumption for heating the organisation's facilities, both in the offices and in the maintenance workshop.

Scope III: Production and management of waste in vehicle maintenance.

Methodology: ISO 14064-1.

Scope I calculations:

20 City Buses; 34 trips per day per vehicle; Distance covered per line $8 \mathrm{Km}$; 365 days worked/year.

Distance travelled $=20 \times 34 \times 8 \times 365=1.985 .600 \mathrm{Km}$

Total distance covered 1.985.600 Km. Diesel consumption $31.765 \mathrm{~L} / 100 \mathrm{Km}$.

$\mathrm{Kg} \mathrm{CO}_{2}=630.720 \mathrm{~L} \times 2.57 \mathrm{KgCO} 2 / \mathrm{L}=1.620 .950,4 \mathrm{KgCO}_{2}$

Emission factor $=2.57 \mathrm{Kg} \mathrm{CO}_{2} / \mathrm{L}^{17}$ 
Scope II calculations:

The electricity consumption is obtained from the bills of the electricity supply company.

$$
\begin{aligned}
& \mathrm{KgCO}_{2}=2.150 \mathrm{KW} \times 0.388 \mathrm{KgCO}_{2} / \mathrm{KW}=834.2 \mathrm{KgCO}_{2} \\
& \text { Emission factor }=0.388 \mathrm{Kg} \mathrm{CO}_{2} / \mathrm{KW}^{18}
\end{aligned}
$$

\section{Scope III calculations:}

The company has its own workshop where it carries out maintenance operations on the bus fleet. As a result of these operations, a number of waste products are generated. The amount of waste is obtained from the data provided by the authorised waste managers.

$$
\begin{aligned}
& \mathrm{Kg} \mathrm{CO}_{2}=20 \mathrm{TN} \times 0.2556 \mathrm{KgCO}_{2} / \mathrm{TN}=5.112 \mathrm{KgCO}_{2} \\
& \text { Emission factor }=0.2556 \mathrm{Kg} \mathrm{CO}_{2} / \mathrm{TN}
\end{aligned}
$$

If we intended to calculate the carbon footprint of a marina, we would have to take into account the following considerations: the scope of study of marinas covers the total area of the public port domain, including the water mirror surface and the land surface. The water surface area is defined by the number of berths and the average size of the boats operating. The land surface includes the surface of buildings and facilities. Buildings are those used for administrative activities, toilets and showers, restaurants such as bars, cafes and restaurants and hotels. The facilities include the road network and parking lots, the dry dock, maintenance and sanitation work, the transformer power station, the fuel station, the clean point, the drinking water supply facility, the surface drainage system and the electricity network.

There is no doubt that the scope of the activities is conditioned by the system of exploitation, in rent or ownership, of the places available in the port. Whatever the case, the main services offered by a marina are access to drinking water, electricity, petrol, mooring assistance, crane, waiting dock, maintenance service, weather information, towing, toilets, lockers, mechanics, nautical items, diving service, 24-hour surveillance, laundry, parking and catering. The issuing sources associated with operations of a fixed nature include facilities for administration, maintenance, toilet and shower activities, catering and hotels. In relation to administrative activities, the number of offices and persons working in each of them is counted; in the maintenance activities carried out, a distinction is made according to who carries them out, whether it is the port's own personnel, hired personnel or others. Whatever the case, the frequency with which these activities are carried out on average and the consumption of water and electricity used on average when these tasks take place are quantified. In restoration activities, the number of activities of each modality is quantified, distinguishing whether the power

18 https://www.epa.gov/energy/greenhouse-gases-equivalencies-calculator-calculations-and-references 
source is that of the port, the city, solar panels or others. The way the water is heated will require the port to have solar panels or natural gas or oil boilers. In the toilets and showers is included in the consumption of water, electricity or diesel oil total port. Finally, a boat can be the habitual residence or private recreational environment of its owner. However, they may also be used to carry out some professional activity as a recreational boat or for whale watching. Whatever the use, boats need energy and the way to get this energy can be a solar panel, a generator or by connecting to the port's electricity supply network.

Mobile sources include petrol or diesel vehicles and electric vehicles such as motorcycles, cars, vans and trucks used by navy personnel, visitors, suppliers and waste managers. In the case of vehicles used by navy personnel or visitors, the number of workers, the average number of visitors per day and the average return journey in kilometres of a working day per employee between their usual residence and the marina and the average return journey in kilometres per visitor to the marina have been taken into account. The marinas usually have regular suppliers. Depending on the number of suppliers that operate and the frequency of transport such as vans or trucks, the emissions of this group are counted, taking into account the average number of return kilometres between the marina and the last customer. In the event that the port has a clean point, the tank trucks are included among the mobile sources and their emissions are counted taking into account the percentage of navy ships that dump the waste at the clean point of the port, the frequency of truck collection and the distance in kilometres between the navy and the dump.

Measuring a product's carbon footprint creates benefits for organizations and businesses by identifying the sources of GHG emissions from a product, allowing better targets and more effective emission reduction policies to be defined. In addition, it allows to know the critical points for the reduction of emissions.

\subsubsection{Hydric footprint}

The water footprint can be calculated from the point of view of consumption or production. The water footprint as a producer or internal water footprint quantifies the volume of water used within the limits of the defined area in the production of goods. Likewise, the calculation of the water footprint can be focused on a consumer, a producer, a process, a product (IWMI, 2004) or a specific geographical area such as a country, region, watershed, or a specific economic sector (Hoekstra et al., 2011). A product water footprint assessment considers all stages of a product's life cycle, from raw material acquisition to final disposal, and an assessment of an organisation's water footprint takes a life cycle perspective based on all of its activities.

Whatever the case, both the direct and indirect use of water and the impacts resulting from its use are taken into account. Direct water or direct water consumption is defined as the amount of water required only in the production process or provision of a service. However, obtaining a product generally requires the input of several raw materials, intermediate products and a series of services in 
the different stages of the production process. On the other hand, the provision of a service requires work tools. Well, in the production of these intermediate inputs or means of work, water is also consumed that has not been considered in the final product or service provision. The water associated with these intermediate inputs is indirect water or indirect water consumption.

In both direct and indirect use, the origin of the water is distinguished (Figure 2.11). Green water corresponds to water from rainfall, which is not lost through runoff and is incorporated into the soil or vegetation (Falkenmark, 2003). This water is available for the free use of plants and constitutes the unique water support for rainfed crops, spontaneous vegetation and forests. This source of water is particularly important in crop production. In turn, blue water corresponds to the fraction of the hydrological cycle that is transformed into surface or underground runoff and is consumed by incorporation or evaporation in the process being evaluated. It feeds the flow of rivers and aquifer reserves, while it is susceptible to being naturally dammed in the form of lakes or artificially by means of the construction of reservoirs. Except for the desalination of seawater and other non-conventional water sources, domestic, industrial and irrigated cultivation are always supplied by blue water sources. Finally, grey water is a theoretical concept that refers to the pollution of the resource. It represents the volume of water needed to reduce the load of pollutants until it complies with current regulations on water quality. In view of the origin of the water, the water footprint contains a clear spatial and temporal component that must be considered in its evaluation.

Figure 2.11. Origin of the water for the calculation of the water footprint

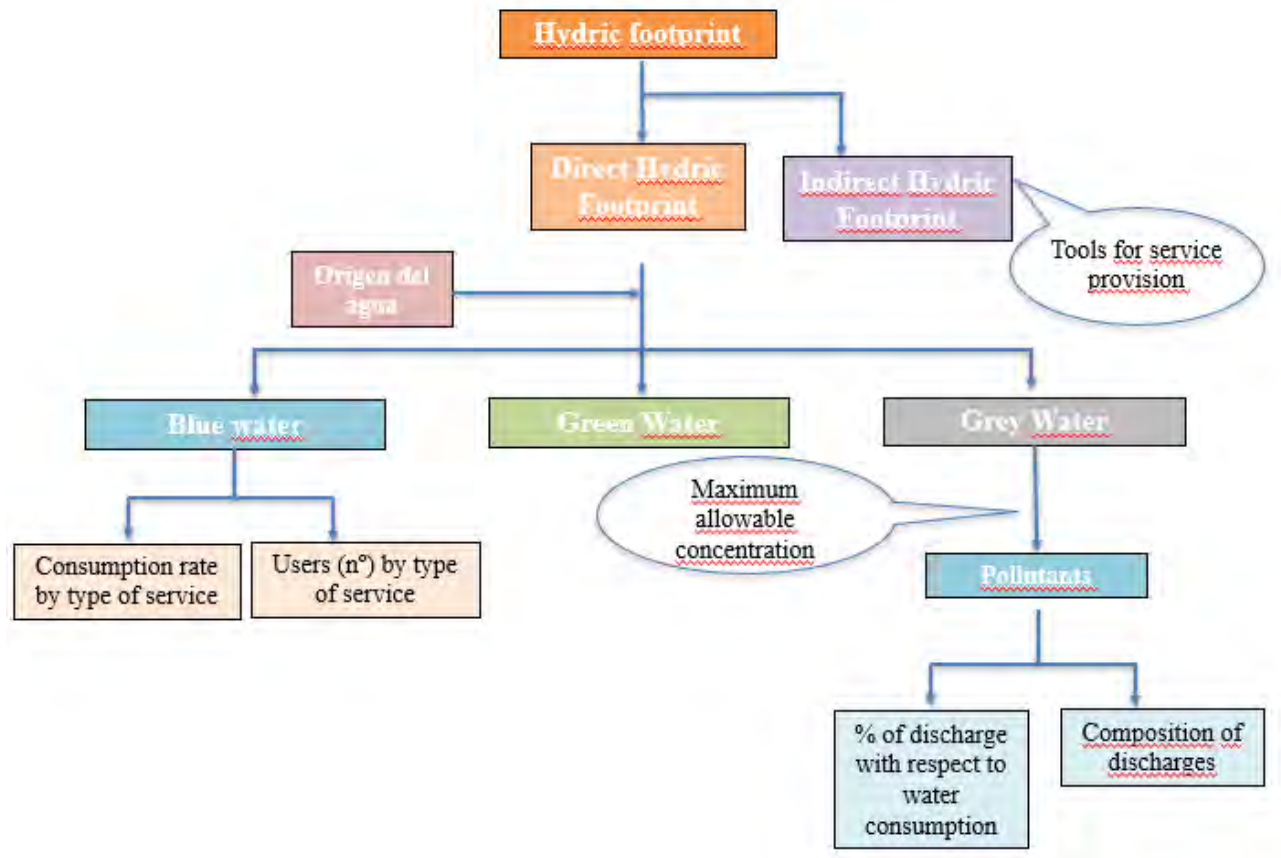




\section{References}

IPCC. (2014). Summary for policymakers. In Climate Change 2014: Synthesis Report. Contrubution of Working Groups I, II and III to the Fifth Assessment Report of the Intergovernmental Panel on Climate Change (Core Writi, Vol. 9781107025). https://doi.org/10.1017/CBO9781139177245.003

Keeble, B. R. (1988). The Brundtland Report: “Our Common Future." Medicine and War, 4(1), 17-25. https://doi.org/10.1080/07488008808408783

ONU. (1992). Convención marco de las naciones unidas sobre el cambio climático.

UNFCCC. (2016). 1/CP.21 Aprobación del Acuerdo de París. Unfccc, 01194, 40. Retrieved from http://unfccc.int/resource/docs/2015/cop21/spa/109s.pdf

Xu, J., Yao, L., \& Lu, Y. (2014). Climate Change Management Innovative Approaches Towards Low Carbon Economics. Retrieved from http://www.springer. com/series $/ 8740$

Chrysanthis, P. K. et al. (1991). Extracting concurrency from objects: A methodology. Proceedings of the ACM SIGMOD International Conference on Management of Data, 61702, 108-117. https://doi.org/10.1145/115790.115803

Climate Action - European Commission. (2015). Factsheet ECT. Climate Action, (July), 6. https://doi.org/10.2834/55480

Davenport, J. \& Davenport, J.L. (2006). The impact of tourism and personal leisure transport on coastal environments: a review. Estuarine, Coasgal and shelf Science, 67:280-292. DOI:10.1016/j.ecss.2005.11.026.

Fellow, L. B. (2000). Volatile Organic Compounds. (May 2011), 13-14.

Great Britain Department of Trade and Industry. (2003). Our energy future - creating a low carbon economy. Energy White Paper. Retrieved from https://assets. publishing.service.gov.uk/government/uploads/system/uploads/attachment_ data/file/272061/5761.pdf

Miola, A., Marra, M., \& Ciuffo, B. (2011). Designing a climate change policy for the international maritime transport sector: Market-based measures and technological options for global and regional policy actions. Energy Policy, 39(9), 5490-5498. https://doi.org/10.1016/j.enpol.2011.05.013

Paiano, A., Crovella, T., \& Lagioia, G. (2020). Managing sustainable practices in cruise tourism: the assessment of carbon footprint and waste of water and beverage packaging. Tourism Management, 77(October 2019), 104016. https:// doi.org/10.1016/j.tourman.2019.104016

Valdor, P. F., Gómez, A. G., Juanes, J. A., Kerléguer, C., Steinberg, P., Tanner, E., ... Méndez, G. (2019). A global atlas of the environmental risk of marinas on water quality. Marine Pollution Bulletin, 149(April), 110661. https://doi.or$\mathrm{g} / 10.1016 / \mathrm{j}$.marpolbul.2019.110661

Vale, A. (2012). Sulphur dioxide. Medicine, 40(3), 158. https://doi.org/10.1016/j. mpmed.2011.12.009

Virginijus, F. (2020). Cleaner Air in 2020:0.5\% sulphur cap for ships enters into force worldwide. (December 2019), 1-2. 
IDAE. (2008). Manual de Geotermia. In 3C Tecnología_Glosas de innovación aplicadas a la pyme (Vol. 4). https://doi.org/10.17993/3ctecno.2015.v4n3e15.96-108

United Nations. (2018). Affordable and clean energy: 3 billion people.

World Bank. (2015). Electricity production from hydroelectric sources. Retrieved from https://data.worldbank.org/indicator/EG.ELC.HYRO.ZS

Xue, J. (2013). Chapter 1: Introduction to low-carbon economics. 3-17.

Hasanuzzaman, Bhar, C., \& Srivastava, V. (2018). Environmental capability: a Bradley-Terry model-based approach to examine the driving factors for sustainable coal-mining environment. Clean Technologies and Environmental Policy, 20(5), 995-1016. https://doi.org/10.1007/s10098-018-1525-3

Santamarta Cerezal, J. C. (2016). Tratado de Minería de Recursos Hídricos en Islas Volcánicas Oceánicas Tratado de Minería.

Wang, Wenfeng; Hao, Weidou; Bian, Zhengfu; Lei, Shaogang; Wang, Xuesong; Sang, Shuxun; Xu, S. (2014). Effect of coal mining activities on the environment of Tetraena mongolica in Wuhai, Inner Mongolia, China-A geochemical perspective. International Journal of Coal Geology, 132, 94-102.

Yang, H., \& Chen, Y. P. P. (2015). Data mining in lung cancer pathologic staging diagnosis: Correlation between clinical and pathology information. Expert Systems with Applications, 42(15-16), 6168-6176. https://doi.org/10.1016/j. eswa.2015.03.019

Blasco Hedo, E. (2014). Real Decreto 163/2014, de 14 de marzo, por el que se crea el registro de huella de carbono, compensación y proyectos de absorción de dióxido de carbono. (BOE núm. 77, de 29 de marzo de 2014). Actualidad Jurídica Ambiental, (34), 39-40.

CEPAL. (2008). Metodologías de cálculo de la huella de carbono y sus potenciales implicaciones para América Latina.

Falkenmark, M. (2003). Freshwater as shared between society and ecosystems: from divided approaches to integrated challenges. Philosophical Transaction of the Royal Society B Biological Sciences, 358 (1440):2037-2049. DOI: 10.1098/rstb.2003.1386.

Hoekstra A.Y., Chapagain A.K., Aldaya M.M. \& Mekonnen M.M. (2011). The Water Footprint Assessment Manual: Setting the Global Standard. Earthscan. London, UK, 203 pp.

IWMI (2004). Does international cereal trade save water? The impact of virtual water trade on global water use. Comprehensive Assessment Report 4. Colombo, Sri Lanka. Comprehensive Assessment Secretariat, 41 pp. 



\section{Chapter 3 \\ Waste Management in Marinas}

Christos Anastasiou

SUMARY: 3.1 Introduction. 3.1.1 Definition of Waste. 3.1.2 Categories of Waste. 3.1.2.1 Wastewater. 3.1.2.2 Solid Waste. 3.1.2.3 Hazardous Waste. 3.1.2.4 Stormwater. 3.1.3 Generation of Waste.-3.2 Regulatory Development. 3.2.1 Wastewater (sewage). 3.2.2 Solid Waste. 3.2.3 Hazardous Waste. 3.2.4 Ports and Marinas \& Coastal and Marine Waters.-3.3 Characterization of Waste. 3.3.1 Sewage. 3.3.2 Solid Waste. 3.3.3 Hazardous Waste.-3.4 Management of Waste (Collection, Treatment \& Final Disposal). 3.4.1 Source Reduction. 3.4.2 Treatment \& Final Disposal. 3.4.2.1 Wastewater. 3.4.2.2 Solid Waste. 3.4.2.3 Hazardous Waste.-3.5 Best Management Practices for Marinas. 3.5.1 Siting, Design, and Habitat. 3.5.2 Stormwater Management. 3.5.2.1 Stormwater Treatment BMPs. 3.5.3 Boat Maintenance Areas. 3.5.4 Petroleum Control \& Boat Cleaning-related chemicals. 3.5.5 Sewage Handling. 3.5.6 Solid Waste Management and Recycling._Bibliographical References.-Resources and Readings List._Assessment Questions

\subsection{Introduction}

Marinas are becoming an increasingly popular type of coastal set of facilities, especially in such destinations as countries of the Mediterranean Sea, where tourism tends to predominate as an industry. The structures and the activities that surround marinas, and recreational boating in general, alongside other coastal development, has been putting environmental pressure on the already fragile coastal environment of countries. These pressures that coastal environments have been receiving has added the need to protect waterways and coastal waters and land. Environmental impacts can be especially severe in cases when associated facilities are poorly sited, planned or when associated operations are poorly managed. Construction and operation of marinas can pose a significant threat to the health of aquatic habitats. Non-point sources of pollution being prime most in marinas, it creates an imperative for the consideration of good practices in the planning construction, but also in the operation of these facilities. 
The fact that marinas are situated adjacent to open bodies of water creates extra concerns since the natural buffering of pollutants entering aquatic systems is often lacking. There is a number of possible negative environmental impacts that may result from a variety of pollution sources of pollution associated with marinas, with the following being indicative examples:

- Poor flushing of waterways exacerbating low dissolved oxygen conditions;

- Pollutants associated with the use of boats;

- Pollutants associated with boat maintenance (either on land or on water);

- Stormwater that can dissolve and or otherwise transport pollutants that can be found on the impervious surfaces of marinas (parking lots, paved surfaces, rooftops of buildings, etc.); and

- Physical changes (and often destruction) of specific ecosystems (i.e. wetlands) or aquatic communities of fauna and flora (i.e. shellfish or other benthic communities) during the construction of marinas, ramps, and related facilities.

To properly tackle the stated issues, the discussion must start with the introduction of basic definitions and concepts, revolving around the types of waste and management approaches that are commonly used.

\subsubsection{Definition of Waste}

Almost all human activities generate waste since the beginning of time (Brunner and Rechberger, 2014). However, more so today, the production of wastes remains a major source of concern (Chandler et al, 1997). In recent times, the rate at which we generate waste, its increased quantity, as well as the associated and toxicity, have been rising to a degree that can pose serious threat to the environment. The interconnected increase in the volume and variety of wastes (Vergara and Tchobanoglous, 2012) dictate proper approaches in their management, a model that has changed from past years when wastes were of a simpler form and that considered a mere nuisance that needed to be disposed of. In past years, the population was smaller, the toxicity of waste was lower, and there was an "abundance" of land that was available for waste disposal. The carrying capacity of the environment was adequate to handle the, then, produced quantities and type of waste (Tchobanoglous et al, 1993). With a systematic urbanization that started in in the sixteenth century, and got intensified with the industrial revolution, the volume and composition of waste has witnessed a non-linear increase (Wilson, 2007). Materials such as metals and glass made their appearance in larger quantities and became a significant portion of municipal waste (Williams, 2005). The increase in the population size and population density resulted in the creation of open dumps, indiscriminate littering, hence creating conditions conducive to the breeding of vermin and the spread of disease (posing a significant threat to public health). Inappropriate waste handling practices have been associated with epide- 
mic outbreaks that claimed many lives (Tchobanoglous et al, 1993). Local administrations recognized these association between inappropriate waste management practices and threatened public health, and in the nineteenth century a more controlled disposal of waste was initiated, in an attempt to safeguard public health (Tchobanoglous et al, 1993).

Nowadays, developed countries are diligently handling the various threats posed to public and environmental health by waste generation. However, developing countries (characterized by an increasing rate of urbanization and development) are now facing similar issues faced by developed countries in the past (Wilson, 2007).

To properly manage waste, the very term must be defined in a way that will allow its proper management. Waste is the useless by product of human activities which physically contains the same substance that are available in the useful product (White et al, 1995). Wastes have also been defined as any product or material which is useless to the producer (Basu, 2009).

However, it is also accepted that a substance regarded as a waste to one individual, may be a resource to another. Therefore, a material can only be regarded as a waste when the owner labels it as such (Dijkema et al, 2000). Under the Waste Framework Directive 2008/98/EC, Art. 3(1), the European Union defines waste as "an object the holder discards, intends to discard or is required to discard." Despite this rather "subjective" definition of wastes, it is important to describe clearly, what constitutes a waste because the classification of a material as a waste forms the foundation for the regulations required to safeguard public health and the environment.

\subsubsection{Categories of Waste}

Waste materializes in different instances, and its characterization can be achieved in different ways. The classification of waste includes such forms as physical states or properties, reusability, biodegradability, source and the potential for environmental impacts (Demirbas, 2011; Dixon \& Jones, 2005; White et al., 1995). Waste can be classified broadly into liquid, solid and gaseous waste (White et al., 1995). Classifications of waste may vary within different countries.

Therefore, classification of wastes can be a difficult task to achieve. Considering the sources of waste, these may commonly include the following categories: domestic sector, commercial sector, ashes, waste from animal farming operations, biomedical sector (including hospitals), construction industry, manufacturing industries, sewerage, biodegradable and non-biodegradable wastes, and hazardous wastes. A more detailed classification of waste, that is most commonly used, is the following:

- Physical state

o Solid waste

o Liquid waste

o Gaseous waste (waste to the atmosphere) 


\section{- Source}

○ Household/Domestic waste

- Industrial waste or Agricultural waste

- Commercial waste

- Demolition and construction waste

- Wastewater sludges

$\circ$ Mining waste

$\circ$ (Waste from Boat Marinas)

While this is not one of the main sources of waste normally discussed in classification schemes, it is hereby included; this being the topic of this study guide.

The main types of waste that will be discussed under this classification category are the following:

- Wastewater (similar in character to municipal wastewater)

- Solid waste (similar in character to domestic and to commercial waste)

- Stormwater, and

- Hazardous waste (which may result from such activities as boat maintenance)

- Environmental impact

- Hazardous waste

○ Non-hazardous waste

\subsubsection{Wastewater}

Wastewater can be categorized into two broad categories, not entirely separable: domestic wastewaters and industrial wastewaters. In turn, industrial wastewaters can further be categorized based on the industrial source and hence the constituents that characterize it. For example, agricultural wastewaters are largely different from, for example, a chemical industry.

As it is rather difficult to encapsulate all of the types of wastewaters into a space of a few pages, the brief discussion that is included in this document concentrates on domestic/municipal wastewaters. Furthermore, it should be noted that wastewaters associated with Boat Marinas are expected to be such that will resemble domestic wastewaters (as opposed to industrial). Also, wastewaters that are of more industrial nature are discussed in the section that introduces Hazardous Waste, alongside with oils and boat maintenance effluents.

\subsubsection{Solid Waste}

The general term solid waste may be used to describe the materials that are no longer of value to humans, and are commonly categorized as municipal solid waste (MSW), domestic or as household waste. The regulatory definition of solid was- 
te highly inclusive and it incorporates hazardous and nonhazardous industrial waste, wastewater sludges, as well as garbage, rubbish, and trash. All of these wastes may be managed in a different manner or may be disposed in different facilities. Any definition used may serve as a starting point for appropriate management decisions (Pichtel, 2005). For our purposes, relating to Marinas, solid waste will be used to mean primarily municipal solid waste (i.e. domestic type and commercial type waste). Hazardous waste is discussed in a separate section, since these may entail such things as hazardous wastewaters (ensuing from such chemicals as cleaners, oils, paints, etc.) or discharges to the marine environment. Municipal solid waste (MSW) is generated within a community from several sources, and not simply by the individual consumer or a household. MSW's origin includes residential, commercial, institutional, industrial, and other municipal activities.

\subsubsection{Hazardous Waste}

Hazardous wastes are those that pose a greater risk to the environment and to public health (when compared to non-hazardous waste). Therefore, hazardous waste requires stricter control and special handling and disposal. This control regime can be seen in Articles 17 to 20 of Directive 2008/98/EC of the European Union. It provides such actions as specific labelling, record keeping, monitoring and control considering all steps that encompass waste production, disposal, or recovery. Mixing hazardous waste with other waste streams is prohibited so that impacts on the environment and human health are minimized.

When it comes to hazardous waste disposal and management, understanding the waste that an organization generates is imperative. Hazardous waste is heavily regulated, and it cannot be treated or handled in a manner similar to that for everyday waste.

When categorizing hazardous waste, the following four characteristics are prominent:

- ignitability,

- corrosivity,

- reactivity,

- toxicity,

These high-level categories each have their own characteristics that further help a generator of waste understand the type of material they are dealing with.

\section{Ignitability}

There are three types of ignitable forms:

- Liquids with a flash point-the lowest temperature at which fumes above waste ignite-of 60 degrees Celsius or 140 degrees Fahrenheit. Examples include alcohol, gasoline, and acetone. 
- Solids that spontaneously combust.

- Oxidizers and compressed gasses.

\section{Corrosivity}

Corrosive substances, such as hydrochloric, nitric, and sulfuric acid, have the ability to "burn" through containers, thus being susceptible to harmful leakages, if special handling is not exercised. A corrosive is a substance, of primarily liquid form, that has a $\mathrm{pH}$ of $\leq 2$ (acidic) or $\geq 12.5$ (alkaline). Corrosivity may also be defined by a material's ability to corrode steel. Examples of corrosive substances include battery acid, solvents, or and rust removers.

\section{Reactivity}

Reactive wastes can be very dangerous, primarily due to their unstable nature. The conditions and situations that allow us to identify all types of reactive materials are too many; however, the following guidelines can help in the classification of waste classified as reactive:

- Unstable (may experience violent change with no detonation)

- when combined with water, may cause explosion or violent reaction

- when mixed with water, toxic gasses are released

\section{Toxicity}

Poisonous materials are a threat to groundwater, and can have long term impacts on human health and natural habitats. There are more than 60 contaminants on the toxicity characteristics list, which can be identified through a test method called Toxicity Characteristic Leaching Procedure. The REACH (EC 1907/2006), through which substances and their intrinsic properties are identified aims at defining the toxicity of certain chemicals in the EU.

\subsubsection{Stormwater}

One definition of stormwater runoff is the water from rain and other forms of precipitation (or snow melt) that flows across the land. This water dissolves pollutants from surfaces (soil or hard pavements) and carries them into aquatic habitats such as wetlands or coastal waters, thus negatively impacting water quality and possibly harming aquatic life. Any type of human development and infrastructure increases stormwater runoff, and can change natural drainage as well as increase the concentration and the number of pollutants that find themselves in aquatic environments.

\subsubsection{Generation of Waste}

Marinas and boating operations include; structures and activities that are related to recreational or commercial boating. These include storage, fueling, clea- 
ning, and maintenance structures and operations that produce a variety of wastes that contain a large mix of possible pollutants. Further, associated facilities and operations (i.e. commercial and entertainment facilities such as restaurants, bars, cafeteria, etc. generate primarily domestic-type wastes). This results in a high probability for the marina environment to be contaminated by a variety of sources and pollutants, especially if inadequate management measures are in place.

The main types of wastes that often result from marina-related operations and activities can be classified as follows: 1) fuel and petroleum wastes (mainly originating from fueling operations, bilges, storage tanks, boat maintenance facilities and operations); 2) hazardous materials (for example solvents, anti-freeze, paints, detergents, etc. are used or result from boat maintenance activities); 3) sewage; and 4) solid wastes. The latter two can be generated especially when boats docking in marinas are use as live-in quarters. In that case, sewages and solid waste must be properly collected and treated in central marina facilities, or sent to regional treatment centers. Solid wastes are generated in marinas include, apart from municipal-type waste (including recyclable material such as plastic, paper, and glass), other "specialty" substances that are the result of boat maintenance (e.g. fiberglass, wood chips, metals, paints, etc.). If liquid and solid wastes are not appropriately managed, aesthetic and sanitary problems will ensue in the marina and its surroundings, on top of negative impacts on adjacent natural habitats.

\subsection{Regulatory Development}

Understanding the regulatory backdrop is of utmost importance in any introduction to the management of any type of waste. In the following sections, an overview of the regulatory framework that covers wastewaters, solid and hazardous waste, and the framework that pertains to the specific activities of ports and marinas as well as coastal waters is provided.

\subsubsection{Wastewater (sewage)}

Water supply and sanitation in the European Union (EU) is the responsibility of each member state, but in the 21st century union-wide policies have come into effect. Water resources are limited and supply and sanitation systems are under pressure from urbanization and climate change. The wastewater policy of the EU is primarily codified in the following directives:

- The Urban Waste Water Treatment Directive (91/271/EEC) of 21 May 1991 concerning discharges of municipal and some industrial waste waters - it concerns the collection, treatment and discharge of urban waste water and the treatment and discharge of waste water from certain industrial sectors. Its aim is to protect the environment from any adverse effects due to discharge of such waters. This Directive also allows the establishment of less 
sensitive coastal areas, for which primary treatment would be sufficient, if it can be shown that there is no adverse impact on the environment (Art. 6).

- The Water Framework Directive (2000/60/EC) of 23 October 2000 concerning water resources management. Under this Directive, member states have to identify all the river basins lying within their national territory and assign them to individual river basin districts. A competent authority had to be designated for each of the river basin districts. In addition, member states have to analyze the characteristics of each river basin and have to carry out an economic analysis of water use. A management plan must be produced for each river basin district. The measures provided for in the river basin management plan seek to:

o prevent deterioration, enhance and restore bodies of surface water, achieve good chemical and ecological status of such water and reduce pollution from discharges and emissions of hazardous substances;

o protect, enhance and restore all bodies of groundwater, prevent the pollution and deterioration of groundwater, and ensure a balance between abstraction and recharge of groundwater;

o preserve protected areas.

EU member states have enacted national legislation in accordance with the above-mentioned Directives.

\subsubsection{Solid Waste}

Directive 2008/98/EC of the European Parliament and of the Council of 19 November 2008 is also know as the Waste Framework Directive and it provides definitions and concepts pertinent to waste management (including recycling and recovery of such waste). The Waste Framework Directive sets the basic waste management principles and requires waste management to materialize in a manner that does not endanger human health nor harms the environment, does not pose a risk to water, air, soil, fauna and flora, does not impart noise or odors, and has no adverse effects on non-urban areas.

It also distinguishes between waste and useful by-products, while it introduces the "polluter pays principle" and the "extended producer responsibility". Further, the Waste Framework Directive establishes a waste management hierarchy that places the prevention of generation of waste as its top priority, whereas the final disposal of waste in landfills is listed as its least preferred option. Reuse, recycling and recovery are the intermediate steps (listed in the order of preference).

\subsubsection{Hazardous Waste}

In the EU, the classification into hazardous and non-hazardous waste is based on the system for the classification and labelling of dangerous substances and 
preparations, which ensures the application of similar principles over the whole life cycle of materials. The properties which render waste hazardous are laid down in Annex III of Directive 2008/98/EC and are further specified by the Decision 2000/532/EC establishing a List of Waste, as last amended by Commission Decision 2014/955/EU. Guidance on waste classification is also available.

\subsubsection{Ports and Marinas \& Coastal and Marine Waters}

The protection of coasts and marine waters faces complex and multi-facetted problems. The marine and coastal environment is under severe pressure from both land-based and ocean-based pollution sources.

EU legislation to protect the marine environment has been progressively implemented in many relevant areas: for instance, the regulation of fisheries through the Common Fisheries Policy (CFP) or the control of input of nutrients and chemicals into the water through the Water Framework Directive (WFD). But these pieces of legislation, although crucial complementary tools to the protection of marine waters, contribute to the protection of the sea only from specific pressures resulting in a fragmented and sectoral approach.

That is why the European Union has adopted two instruments, the $2002 \mathrm{EU}$ Recommendation on Integrated Coastal Zone Management and the 2008 Marine Strategy Framework Directive, which offer a comprehensive and integrated approach to the protection of all European coasts and marine waters.

The Marine Strategy Framework Directive (or Marine Directive) is the first encompassing piece of EU legislation specifically aimed at the protection of the marine environment and natural resources and creating a framework for the sustainable use of our marine waters. The Directive involves many implementation challenges, which are addressed through a Common Implementation Strategy between the Commission and the Member States and a regional approach to the implementation of its objectives.

The 2002 Recommendation on Integrated Coastal Zone Management defines the principles of sound coastal planning and management. The need for such a tool has come from the realization that despite increasing deterioration of the natural, socio-economic and cultural resources of our European coastal zones, coastal planning activities or development decisions still take place in a sectoral, fragmented, way leading to inefficient use of resources, conflicting claims on space and missed opportunities for more sustainable coastal development.

Also, the Bathing Waters Directive (76/160/EEC) of 1976, which was replaced by the Directive 2006/7/EC, is the first European bathing water legislation. Its main objectives are to safeguard public health and protect the aquatic environment in coastal and inland areas from pollution. Bathing waters can be coastal waters or inland waters (rivers, lakes). To be covered by the Directive, including its mandatory quality standards as well as its monitoring and information obligations, bathing must either be explicitly authorized, or not prohibited and traditionally practiced by a large number of people. Swimming pools and waters for 
therapeutic purposes are not covered. The period during which bathers can be expected depends largely on local bathing rules and weather conditions. A bathing season can also vary within a Member State. In the European Union it generally runs from the end of May until the end of September.

Also, at the international level, the International Convention for the Prevention of Pollution from Ships (MARPOL) is the main international convention aimed at the prevention of pollution from ships caused by operational or accidental causes. It was adopted at the International Maritime Organization (IMO) in 1973. The Protocol of 1978 was adopted in response to a number of tanker accidents in 1976-1977. The 1978 Protocol was absorbed into the parent Convention and the combined instrument entered into force in 1983. In 1997, a Protocol was adopted to amend the Convention and a new Annex VI was added, which came into force in May 2005. The technical requirements of MARPOL are included in six separate Annexes:

- Annex I-Regulations for the Prevention of Pollution by Oil

- Annex II-Regulations for the Control of Pollution by Noxious Liquid Substances in Bulk

- Annex III-Prevention of Pollution by Harmful Substances Carried in Sea in Packaged Form

- Annex IV-Prevention of Pollution by Sewage from Ships

- Annex V-Prevention of Pollution by Garbage from Ships

- Annex VI-Prevention of Air Pollution from Ships

The official site for MARPOL can be reached through the following URL: http://www.imo.org/en/About/Conventions/ListOfConventions/Pages/International-Convention-for-the-Prevention-of-Pollution-from-Ships-(MARPOL).aspx

\subsection{Characterization of Waste}

\subsubsection{Sewage}

Wastewater is a complex mixture of water and solids that may be dissolved, suspended or colloidal (i.ee suspended solids that do not readily settle). This mixture also contains a large number of microorganisms (primarily bacteria, that are capable of breaking down organic matter such as carbohydrates and proteins) thus causing the nature of wastewaters to change fast. Wastewater sources, and hence their contents, vary by much, and the fact that the highly variable active microbial content of wastewaters can make them a very dynamic type of waste. A most important trait of municipal wastewaters (i.e. wastewaters resulting from domestic sources and commercial activities - not to be confused with agricultural or industrial activities) is the fact wastewater are $99.9 \%$ water, and their solids content (suspended or dissolved) being only $0.1 \%$ by weight. Even though this is a 
very small percentage of substances present in water, their varied character and the nature of these substances can be quite challenging to deal with (collect, treat and dispose of) and, if left untreated, have the potential to seriously damage human health and the environment.

Wastewater is a very complex mixture of components that would be difficult to completely chemically define. Generally, wastewaters are comprised of organic and inorganic substances, but for municipal wastewaters, organic substances dominate this mixture. A variety of tests are used to characterize wastewaters; however, only the most important components and tests will be hereby introduced.

Municipal wastewaters contain different pollutants, the most common of which are the following:

\section{1) Oxygen-Demanding Substances}

Dissolved oxygen is fundamental to the sustainment of aquatic life and thus a key parameter in assessing water quality. Many pollutants (of organic, primarily, nature) tend to place a demand on the dissolved oxygen of a body of water; a trait known as biochemical oxygen demand (BOD). This trait is one of the main measures of the "strength" of a wastewater (i.e. its contents that can be readily decomposed by microorganisms), as well as a measure of the effectiveness of wastewater treatment plants. If wastewater (raw or treated) that is discharged in a natural body of water has a high organics content (or ammonia content), it will exert a higher demand for dissolved oxygen from the water (due to microbial decomposition of that material that will ensue) thus leaving less oxygen in the water body, hence a reduced ability to support aquatic life. Organic matter and ammonia are "oxygen-demanding" substances. These substances are used as sources of food by microorganisms (primarily bacteria). While bacteria feed on these organics, they consume oxygen (these bacteria are primarily aerobic). If those substances are found in abundance in water, it means that there will be more food available for microbes, hence causing an increase in microbial populations and resulting in an increased consumption of available dissolved oxygen in water. This may easily result in anoxic conditions prevailing in natural bodies of water.

\section{2) Pathogens}

Wastewaters contain a great deal of microorganisms, many of which are pathogenic. Untreated wastewaters may be responsible for such waterborne diseases as typhoid fever, cholera, and dysentery, all of which are a real threat to several developing countries today. Such diseases caused by pathogenic microorganisms can be contracted by coming into contact with infected surface or groundwaters, often contaminated with wastewaters that are the result of sewage, stormwater runoff, agricultural or industrial activities. Humans do not have to consume water to contract these diseases, but they only have to get in touch with contaminated waters through such activities as swimming or fishing. Proper wastewater and potable water 
treatment, alongside modern disinfection technologies (commonly achieved with such methods as chlorination), have managed to virtually eliminate such diseases in the EU.

\section{3) Nutrients}

Several nutrients are necessary to sustain life. Some of these are called macronutrients (i.e. needed in larger quantities by organisms), whereas others are called micronutrients (i.e. needed in smaller quantities by organisms). Carbon, nitrogen, phosphorus, potassium are the main macronutrients that are essential to plants or animals. Although they are present in certain quantity in natural waters, they are present in much higher quantities in wastewater (whether that wastewater is municipal, agricultural or industrial). If untreated wastewater is discharged in a body of water, there is a large influx of these nutrients, hence stimulating the rapid growth of plants (primarily algae). This process is called eutrophication, and it can have a negative impact on aquatic ecosystems, since its result may be the blocking of sunlight and the eventual formation of anoxic conditions in the body of water. Secondary (biological) wastewater treatment processes although able to remove carbon from wastewaters, they are not designed to remove nitrogen nor phosphorous. For nutrient removal to take place, tertiary (biological) treatment is necessary.

\section{4) Inorganic and Synthetic Organic Chemicals}

The category of inorganic and organic (synthetic) chemicals is one of the largest categories of substances that may be present in wastewaters, in either large or in smaller quantities. These substances do not have to be present in large quantities to cause significant harm to humans to aquatic systems, since they are often toxic to life or may cause other types of damage to organisms (e.g. mutations). There are several examples of families of such chemicals that may be present in wastewaters, such as detergents, pharmaceuticals, pesticides, herbicides, industrial chemicals, heavy metals, or synthetic oils. These chemicals are difficult to deal with since conventional wastewater treatment processes are not designed to remove them. One of the best avenues for avoiding associated harm is to prevent such chemicals from entering a body of water or a wastewater. This can be achieved, for example, if stormwater is prevented from picking up such chemicals from land (especially important for marinas).

As it may have been insinuated in the previous paragraphs, wastewaters can be a very complex mixture of substances. This complexity is reflected by the great number of wastewater treatment approaches and technologies that have been devised over the years. However, the most typical type of wastewater that we are dealing with in everyday life is what is known as municipal wastewater. Some of the typical constituents of municipal wastewater are provided in Table 1. The concentrations of common contaminants of municipal wastewater vary widely and 
they depend on the overall water consumption patterns or special activities that may be taking place in a community. The character of a wastewater dictates the approach that is taken for treatment. For instance, concerning municipal wastewaters, typical values for constituents listed above can be seen in Table 1. Municipal wastewaters may be further classified into greywater (wastewater that contains significantly lower concentrations of solids, BOD, and nutrients) and "blackwater" (the higher strength wastewater introduced in Table 3.1). Biological wastewater treatment is the most common method used for the treatment of municipal wastewater.

Table 3.1. Typical composition (some basic parameters) of untreated domestic wastewater

\begin{tabular}{|l|c|c|}
\hline \multicolumn{1}{|c|}{ Contaminants } & Unit & Typical Concentration \\
\hline Total Solids (TS) & $\mathrm{mg} / \mathrm{L}$ & 700 \\
\hline Total Dissolved Solids (TDS) & $\mathrm{mg} / \mathrm{L}$ & 500 \\
\hline Total Suspended Solids (SS) & $\mathrm{mg} / \mathrm{L}$ & 200 \\
\hline BOD $_{5}$ at $20^{\circ} \mathrm{C}$ & $\mathrm{mg} / \mathrm{L}$ & 220 \\
\hline Chemical oxygen demand (COD) & $\mathrm{mg} / \mathrm{L}$ & 450 \\
\hline Total Nitrogen & $\mathrm{mg} / \mathrm{L}$ & 40 \\
\hline Total Phosphorus & $\mathrm{mg} / \mathrm{L}$ & 10 \\
\hline Total coliform & $\mathrm{CFU} 100 / \mathrm{mL}$ & $10^{6}-10^{7}$ \\
\hline
\end{tabular}

Concerning wastewaters that are more commonly associated with sea vessels, the Inter-governmental Maritime Consultative Organization (IMCO) follows the definitions of greywater and blackwater, as they were introduced above. Specifically, greywaters are waste that results from washbasins, baths/showers, laundry-machines, cleaning of surfaces, whereas blackwaters are essentially what is known as sewage (i.e. water associated primarily with use of a toilet or waste from kitchen sinks). According to IMCO, the character of wastewater associated with sea vessels is provided in Table 3.2.

When planning Best Management Practices (BMPs) for managing the waste in marinas, the data presented in Table 2 may be a good reference to use as basic estimates of the quantities and the character of wastewaters commonly dealt with. Such data are an integral part in the design of wastewater handling facilities (e.g. the volume capacity of wastewater storage tanks) or subsequent treatment processes. It should be kept in mind; however, that on-land facilities in marinas (i.e. boat maintenance facilities, commercial enterprises or and entertainment facilities such as restaurants) also produce wastewater, and those are expected to be more in tune with more conventional municipal wastewater (except in the case of boat maintenance facilities, where wastewaters that have a more industrial character are expected). For the design of wastewater handling and treatment systems, qua- 
Table 3.2. Characteristics of wastewaters generated from sea vessels

\begin{tabular}{|c|c|c|}
\hline Category & Units & Quantity \\
\hline \multicolumn{3}{|l|}{ Blackwater } \\
\hline Average volume of conventional flush water & L / flush & 20 \\
\hline Daily average volume of sewage & $\mathrm{L} /$ person day & 140 \\
\hline Average $\mathrm{BOD}_{5}$ & $\mathrm{mg} / \mathrm{L}$ & 350 \\
\hline Average Suspended Solids & $\mathrm{mg} / \mathrm{L}$ & 350 \\
\hline \multicolumn{3}{|l|}{ Greywater } \\
\hline Daily average shower and washbasin wastewater & $\mathrm{L} /$ person day & 20 \\
\hline Daily average laundry wastewater & $\mathrm{L} /$ person day & 20 \\
\hline Daily average galley wastewater & $\mathrm{L} /$ person day & 80 \\
\hline Others & L / person day & 30 \\
\hline Daily average volume of sanitary wastewaters & $\mathrm{L} /$ person day & 150 \\
\hline Mean $\mathrm{BOD}_{5}$ & $\mathrm{mg} / \mathrm{L}$ & 150 \\
\hline Average Suspended Solids & $\mathrm{mg} / \mathrm{L}$ & 125 \\
\hline
\end{tabular}

lified engineers should be employed and wastewater characterization must precede any planning activities.

\subsubsection{Solid Waste}

Solid wastes that result from municipalities are as highly varied as wastewaters. Typical composition of municipal solid waste (MSW) includes a variety of durable goods (e.g., appliances), nondurable goods (newspapers, office paper), packaging, containers, food wastes, yard wastes, other organic or inorganic waste, etc. The precise source of MSW will dictate the quantity, the synthesis and the character of wastes (as this is exemplified in Table 3.3).

Yet another classification of MSW is provided through the categories of garbage and rubbish. Garbage is primarily comprised of food scraps, and they have the quality to decompose quickly (through microbial action), hence producing malodors, harmful liquids (leachate) and gases. Rubbish is solid waste that is not so readily decomposable (i.e. waste other than food-associated waste). Due to the lower humidity content of several wastes in the rubbish category, they tend to be more combustible. Table 3.4 provides the categories and physical composition of municipal solid waste. 
Table 3.3. Municipal Solid Waste by source

\begin{tabular}{|l|l|}
\hline \multicolumn{1}{|c|}{ MSW Source } & \multicolumn{1}{c|}{ Examples of material included } \\
\hline $\begin{array}{l}\text { Residential } \\
\text { (single- and multi-family homes) }\end{array}$ & $\begin{array}{l}\text { Food scraps, food packaging, cans, bottles, newspa- } \\
\text { pers, clothing, yard waste, old appliances }\end{array}$ \\
\hline $\begin{array}{l}\text { Commercial } \\
\text { (offices, retail companies, } \\
\text { restaurants) }\end{array}$ & $\begin{array}{l}\text { Office paper, corrugated boxes, food wastes, dispo- } \\
\text { sable tableware, paper napkins, yard waste }\end{array}$ \\
\hline $\begin{array}{l}\text { Institutional } \\
\text { (schools, hospitals) }\end{array}$ & $\begin{array}{l}\text { Office paper, corrugated boxes, cafeteria waste, res- } \\
\text { troom waste, classroom waste, yard waste }\end{array}$ \\
\hline $\begin{array}{l}\text { Industrial } \\
\text { (packaging and administrative) }\end{array}$ & Office paper, corrugated boxes, cafeteria waste \\
\hline Municipal & $\begin{array}{l}\text { Litter, street sweepings, some construction and de- } \\
\text { molition debris }\end{array}$ \\
\hline
\end{tabular}

\subsubsection{Hazardous Waste}

A waste is defined as hazardous if it is either 1) listed as hazardous by a regulatory agency; or 2) has hazardous characteristics. Hazardous waste can include wastes generated by nonspecific sources (e.g. spent halogenated solvents); wastes generated by specific sources (e.g., distillation bottoms from recycling paint solvents); acutely hazardous commercial chemical products and manufacturing chemical intermediates which may be hazardous under certain conditions; and toxic commercial chemical and manufacturing chemical intermediates which may be hazardous in certain circumstances.

There are several criteria that are used in determining the hazardous status of a solid waste. These include its ignitability (e.g. flash point less than $60^{\circ} \mathrm{C}$ ); its corrosivity (e.g. pH less than 2 or greater than 12.5); its reactivity (e.g., reacts violently with water, unstable under normal conditions, generates toxic fumes, etc.); and its toxicity (determined by the effect a substance has on an organism). Examples of hazardous wastes include paints (especially if they are solvent-based), varnishes, pesticides, herbicides, batteries of sorts, synthetic machine oils, petrochemicals and fuel, and cleaning chemicals. Solid (non-hazardous) waste that has been mixed with hazardous waste, and that retains the characteristics of the hazardous waste, is called mixed or contaminated waste, and it can also be categorized as hazardous. Typical contaminated wastes that are considered as hazardous may include spent engine oils, chlorinated solvents, spent engine coolant, waste paints, filters, etc.

Marinas (including recreational and commercial boat docking facilities or maintenance facilities) are a prime source for a variety of hazardous or contaminated solid waste. Hazardous wastes in marinas may result from a various sources or operations; a summary of which is provided in Table 3.5, alongside some common tips on how to avoid contamination of the surrounding environment. 
Table 3.4. Physical composition of municipal solid waste

\begin{tabular}{|c|c|c|}
\hline Chemical Class & General Composition & Specific Composition \\
\hline \multirow{15}{*}{ Organic } & Paper products & $\begin{array}{l}\text { Office paper, computer printout, news- } \\
\text { print, wrappings, corrugated cardboard }\end{array}$ \\
\hline & \multirow{8}{*}{ Plastics } & Polyethylene terephthalate \\
\hline & & High-density polyethylene \\
\hline & & Polyvinyl chloride \\
\hline & & Low-density polyethylene \\
\hline & & Polypropylene \\
\hline & & Polystyrene \\
\hline & & Multi-layer plastics \\
\hline & & Other plastics including aseptic packaging \\
\hline & Food & Food (putrescible) \\
\hline & \multirow{5}{*}{$\begin{array}{l}\text { Yard waste } \\
\text { Textiles / rubber }\end{array}$} & $\begin{array}{l}\text { Grass clippings, garden trimmings, leaves, } \\
\text { wood, branches }\end{array}$ \\
\hline & & Cloth, fabric \\
\hline & & Carpet \\
\hline & & Rubber \\
\hline & & Leather \\
\hline \multirow{9}{*}{ Inorganic } & \multirow{2}{*}{ Glass } & Clear \\
\hline & & Green, brown \\
\hline & \multirow{3}{*}{ Metals } & Ferrous \\
\hline & & Aluminum \\
\hline & & $\begin{array}{l}\text { Other non-ferrous (e.g. copper, zinc, chro- } \\
\text { mium) }\end{array}$ \\
\hline & \multirow{3}{*}{ Dirt } & Dirt \\
\hline & & Gravel, stones \\
\hline & & Ash \\
\hline & Bulky wastes & $\begin{array}{l}\text { Old furniture and appliances (refrigerators, } \\
\text { stoves, etc.) }\end{array}$ \\
\hline
\end{tabular}


Table 3.5. Sources and characteristics of hazardous waste in marinas

\begin{tabular}{|c|c|}
\hline $\begin{array}{l}\text { Operation / } \\
\text { Source }\end{array}$ & Description / Response procedure \\
\hline Stormwater Runoff & $\begin{array}{l}\text { Stormwater from roofs, surfaces, parking lots, and other paved } \\
\text { impervious surfaces has the ability to dissolve or carry away a } \\
\text { variety of substances that are considered hazardous (especially } \\
\text { such debris as paint scrapings, solvents, cleaning agents, heavy } \\
\text { metals, or engine oils). Direct flow of stormwater run-off into } \\
\text { adjacent natural bodies of water should be avoided. }\end{array}$ \\
\hline Wastewater & $\begin{array}{l}\text { Most wastewaters in marinas can be categorized as municipal } \\
\text { wastewater. However, any non-municipal wastewater genera- } \\
\text { ted by marinas are considered industrial waste water, since } \\
\text { they may contain several of the substances that are classified as } \\
\text { hazardous. Such wastewaters are expected to ensue from such } \\
\text { facilities as boat maintenance units. In most cases, it is prohibi- } \\
\text { ted to mix industrial wastewater with municipal wastewater, } \\
\text { and if such a practice is allowed, it can only be achieved after } \\
\text { receiving required permissions. Hazardous chemicals can dis- } \\
\text { rupt most biological wastewater treatment systems. }\end{array}$ \\
\hline $\begin{array}{l}\text { Material Storage and } \\
\text { Handling }\end{array}$ & $\begin{array}{l}\text { Many chemicals that are commonly used in marinas are hazar- } \\
\text { dous and have the capacity to seriously damage the environ- } \\
\text { ment. Spills should be avoided by following good practices in } \\
\text { the handling and disposal of such chemicals. Care should be } \\
\text { taken to avoid such material from mixing with stormwater and } \\
\text { carried away in adjacent bodies of water or sewage systems. }\end{array}$ \\
\hline $\begin{array}{l}\text { Fueling Operations / } \\
\text { Spills }\end{array}$ & $\begin{array}{l}\text { Marinas, and specifically its facilities that are more likely to } \\
\text { contain such chemicals (e.g. maintenance points or fueling sta- } \\
\text { tions) should be equipped with spill prevention technologies } \\
\text { (e.g. automatic shut-offs for pumps), or material that can help } \\
\text { contain an accidental spill (e.g. petroleum absorption pads). } \\
\text { Use of detergents for cleaning accidental spills should be avoi- } \\
\text { ded, since these can form byproducts that can pollute adjacent } \\
\text { natural waters. Instead, mechanical containment and absorp- } \\
\text { tion material are preferred. Such liquids as grease, oil, and fuel } \\
\text { spilled on land should be collected and disposed of in appro- } \\
\text { priate containers } \\
\text { Proper training, ample signs, and appropriate contingency } \\
\text { plans should be enforced. }\end{array}$ \\
\hline $\begin{array}{l}\text { Engine Maintenance } \\
\text { and Repair }\end{array}$ & $\begin{array}{l}\text { Boat maintenance and repair activities should be performed, } \\
\text { whenever possible, on land so as to minimize the accidental } \\
\text { discharge of hazardous chemicals on surface waters. Open boat } \\
\text { engines or parts should be properly stored on impervious surfa- } \\
\text { ces and their contact with stormwater should be avoided. }\end{array}$ \\
\hline
\end{tabular}




\begin{tabular}{|c|c|}
\hline $\begin{array}{l}\text { Bottom Paint } \\
\text { Removal / other } \\
\text { sanding activities } \\
\text { (e.g. topsides) }\end{array}$ & $\begin{array}{l}\text { Boat paints (especially those used in underwater parts of boats) } \\
\text { often contain metals that are toxic to living organisms. Remo- } \\
\text { ving such paints from the bottom of boats can harm the envi- } \\
\text { ronment due to the associate metals that are often involved (e.g. } \\
\text { copper). The activity or paint removal should be conducted in } \\
\text { impervious surfaces and waste produced should be appropria- } \\
\text { tely collected, stored, and properly disposed of. The discharge } \\
\text { of such paint residues to water or land is prohibited, as well as } \\
\text { its disposal in sewage collection systems. Sanding of bottom } \\
\text { paints also produces hazardous dust particles that should be } \\
\text { contained via vacuuming and properly disposed of. }\end{array}$ \\
\hline Spray Painting & $\begin{array}{l}\text { Wastes related to spray painting are often a major source of en- } \\
\text { vironmental pollution and should always be conducted in facili- } \\
\text { ties with impermeable floor surfaces and protected from wind } \\
\text { and rain. To reduce waste and emissions from these operations, } \\
\text { waste paint and solvents should be kept to a minimum while } \\
\text { proper storage of liquids will reduce the evaporation or volatili- } \\
\text { zation of dangerous chemicals. Low volatility solvents and low } \\
\text { VOC coatings should be used as much as possible. Brushing and } \\
\text { rolling should be used, if possible, instead of spraying. }\end{array}$ \\
\hline $\begin{array}{l}\text { Pressure \& Steam } \\
\text { Cleaning }\end{array}$ & $\begin{array}{l}\text { Pressure and steam cleaning, when used for the initial rinse-off } \\
\text { of a boat removed from the water, can generate industrial was- } \\
\text { tewater. Hence, pressure cleaning should be conducted in areas } \\
\text { that possess impervious floors (e.g. asphalt or concrete) and } \\
\text { with features that allow the collection of the wastewater that } \\
\text { will be created. The collected wastewaters should be directed to } \\
\text { wastewater treatment systems and not to available septic tanks } \\
\text { or on surface waters. If that is not possible, then wastewater } \\
\text { should be handled by licensed companies. }\end{array}$ \\
\hline
\end{tabular}

\subsection{Management of Waste (Collection, Treatment \& Final Disposal)}

Waste management is defined by the total number of operations entailed in the management of waste, and specifically the collection, transport, treatment, and final disposal of waste materials. Waste management systems differ from one another, based on a number of characteristics, for example the type of waste involved (e.g. liquid or solid waste). For instance, if we isolate the discussion on the processing (treatment) of municipal solid waste, we can see that several approaches may be utilized in its treatment, including recycling, composting, final disposal (e.g. landfilling), or incineration (i.e. waste-to-energy). No single approach is applied to the management of all waste streams. However, if we can back to the example of solid waste management, we will see that there is a preferred hierarchy in the approach we take, based on their environmental soundness of each approach. This hierarchy comprises of the following elements, in this order of preference: waste reduction, reuse; recycling (including composting for organic / compostable waste), energy recovery, and finally landfilling in sanitary landfills. 


\subsubsection{Source Reduction}

Reduction of waste is best achieved by taking measures not to create it in the first place. New products use lots of natural resources and energy - extraction operations, fabrication and transportation to the consumer. Reduction and reuse are the most effective ways to save natural resources, minimize environmental impact and reduce costs.

Some of the benefits of Reducing and Reusing include the following:

- Prevents pollution - reduces the manufacturing processes of new (raw) materials

- Saves energy

- Reduces greenhouse gas emissions that contribute to global climate change

- Helps maintain the principles of sustainability

- Reduces economic costs

- Reduces the amount of waste that will need to be processed or that will end up in landfills

Of-course, source reduction includes not only the reduction in the quantity of waste, but also a reduction of the polluting capability (or toxicity) of a waste. A simple example may be provided by how we may choose not to use garbage disposal units in our sinks, through which we do not necessarily reduce the amount of food scraps that we produce, but at the same time, if we use this technology, then we may end up increasing the organic load (BOD) of our wastewater.

Some ideas on how to reduce and reuse waste include the following:

- Buy used - no need for new products being created.

- Look for products that use less packaging (thus requiring the use of less raw material that also contribute to lower costs on top of less waste). This practice can also result in cost savings that are passed along to the consumer. Also, buying in bulk can help reduce packaging and cut down on costs.

- Buy reusable over disposable items. Look for items that can be reused, and especially avoid using disposable plastics (i.e. utensils and cups).

- Maintain and repair products so that they won't have to be thrown out and replaced as frequently.

- Borrow, rent or share items that are used infrequently, like tools or furniture.

\subsubsection{Treatment \& Final Disposal}

Many of the problems that may be associated with marina activities (alongside boat repairs or maintenance) can be avoided if we apply pollution prevention measures. For example, facilities reserved for specialized and possibly pollution- 
prone activities can be constructed. Such facilities should cater to only to a specific set of activities (e.g. activities related to boat maintenance) and special measures should be taken so that waste streams do not go uncontrolled (e.g. avoidance of stormwater seeping in or out of these facilities. Also, use of specialized machinery that prevents the escape of pollutants into the atmosphere can be employed. For instance, during sanding activities dangerous dust can be created. This dust can be collected through vacuum systems and subsequently disposed of properly. The drafting and implementation of appropriate spill prevention plans, or waste management plans can help identify and put in effect procedures that avoid the creation of waste, or reduce the risk of contamination of the environment form the uncontrolled discharge of waste. For spills of hazardous liquids (e.g. antifreeze fluids), sorbent materials can be used to contain their dispersion. Automatic shutoff in fuel pumps can prevent accidental fuel spills, as well as fuel tank vents can help avoid fuel overflows in boats. Solvents use in the cleaning of boats, during maintenance operations, can be recovered through the use of onsite distillation units, or by employing external services. Following appropriate procedures in the cleaning of boats or hard surfaces of buildings (limited to no use of chemical cleaning agents) can prevent related contamination of natural waters. Municipal wastewaters in marinas can practice the separation of greywater and blackwater streams and subsequently either onsite or offsite treatment systems can properly treat the waste. For the collection of wastewaters from boats, this can be achieved through the use of pumps. This wastewater collected can then be directed to the marina's wastewater treatment plant or transferred to the municipal wastewater treatment plant through properly designed sewerage systems. Solid waste should also be managed appropriately. The Marine Plastic Pollution Research and Control Act, as well as the International Agreement MARPOL Annex V, prohibits the uncontrolled disposal of solid wastes to any natural waters. The use of separate containers for different types of waste (e.g. glass, paper, plastic, etc.) can help with the more efficient enforcement of recycling programs that may be in place. Such practices can minimize the amount of waste that will end up in landfills, which is the least desirable approach in the management of solid waste.

There is a multitude of waste treatment methods, depending on the individual nature of the waste. Approaches for liquid wastes are very different from approaches for solid wastes or from approaches for air emissions. However, treatment methods can be broadly categorized by their overall approach/ philosophy; namely into physical methods, chemical methods, or biological methods.

\subsubsection{Wastewater}

\subsection{Physical, Chemical, and Biological Processes}

Basic wastewater treatment processes can be categorized into three broad groups; Physical, Biological, and Chemical unit processes. These are briefly introduced below: 


\section{1) Physical Processes}

Physical unit processes mainly utilize such principles as settling, sieving, screening, cyclone techniques, or straining. Their main purpose is to separate as many of the suspended solids from the liquid portion of wastewaters. Colloidal solids can also be removed with physical methods b, for example, floating colloids to the surface through the use of diffused air, the bubbles of which will carry colloids to the surface of tanks and hence be skimmed. Although physical unit processes describe one of the older forms of wastewater treatment, they are still used in the primary stages of modern treatment plants. Examples of physical separation methods in a modern wastewater treatment plant are the following: bar screens or sieves, comminutors, grit removal units, dissolved air flotation units, and clarifiers (primary or secondary).

\section{2) Biological Processes}

Microorganisms in nature consume a wide variety of organic (and sometimes inorganic) compounds. In fact, what seems to be our waste, it is food for microorganisms (primarily aerobic bacteria). Microbes have the capacity to consume suspended organic matter, but more importantly, they have the capacity to consume dissolved organic matter. We have observed these traits of microorganisms, as well as their growth patterns, and we have been since employing them as our primary wastewater treatment agents in modern treatment plants. In the secondary treatment stages of a modern treatment plant microbial communities are cultivated by providing appropriate conditions of steady source of food (i.e. the waste that needs to be removed from wastewater), a good supply of oxygen, and appropriate conditions of temperature, $\mathrm{pH}$ and absence of toxic chemicals. By emulating nature, we have been using microorganisms to remove dissolved substances from our wastewaters. The populations of microorganisms that are formed in this process are called activated sludge and they are carefully controlled by a carefully designed system of recycling and wasting activated sludges, which employ such physical separation methods as clarifiers. Microorganisms are also used in the tertiary portion of wastewater treatment, especially as nitrogen removal from wastewaters is concerned. This is achieved by creating an interchange of aerobic and anoxic conditions in the sequence of treatment units.

\section{3) Chemical Processes}

The use of chemicals in biological wastewater treatment is less evident in a modern plant, and it is always combined with an appropriate physical separation process. Examples of how chemicals are used in wastewater treatment are provided by the use of such substances as alum or polyelectrolytes, which are substances that have the ability to make small particles clamp together (stick to each other) in a process known as coagulation and flocculation. The larger clamps that are formed can then settle down faster and more efficiently in clarifiers. Phosphorus (one of the main macronutrients found in sewage) is also removed in a similar fashion from wastewater. 


\subsection{Primary, Secondary, Tertiary Treatment}

In a typical, modern, facility for the treatment of municipal wastewater, a combination of physical, biological, and chemical-based processes is used. These processes, known as unit-processes, are categorized as Primary, Secondary, and Tertiary treatment.

\section{1) Primary Treatment}

A typical wastewater treatment facility starts with the unit processes of primary treatment. It is not uncommon for primary treatment to be preceded by preliminary treatment units. Specifically, when raw wastewater enters a treatment plant, it will be directed to flow through screens or sieves, which hare designed to removes large objects, such as sticks, pieces of cloth, diapers, plastics, dead rats, bottles, etc. Such material may create problems in the piping and pumping system of the treatment plant and must be removed early on during the process. Screens are placed at an incline, alongside a channel through which water flows. The inclined screens catch debris on their surface which are then removed mechanically and disposed of in landfills. After the screens, comminutors are unit processes that are sometimes encountered in modern treatment facilities. These unit processes are designed to grind large solids into smaller particles that are less likely to clog pipes and harm pumps downstream. The uniform mixture of liquid and small suspended particles that results from comminutors can be then directed to clarifiers (settling tanks), where suspended particles are allowed to rest and settle to the bottom of those tanks. Whether a comminutor follows a screen or not, what is always found in wastewater treatment plants are grit-removal unit processes. Grit is a mixture sand, gravel, and small stones that if not removed from the waste stream they will cause wear and tear of mechanical equipment (such as pumps), or clog aeration diffusers, that are encountered downstream in the plant, thus creating serious operational problems. The grit removed is directed to landfills for final disposal. The final step in primary treatment stages of a modern wastewater treatment plant comes in the form of a sedimentation tank, or clarifier. While large particles have already been removed, or have been crushed into smaller ones, a significant number of suspended solids still remains in wastewater. These suspended solids may be organic or inorganic in nature and still need to be removed. This removal is achieved by directing our wastewater into tanks in which solids are allowed a low-energy environment, and thus the ability to settle. This settling may be further aided by the addition of chemicals in a preceding step that is called coagulation \& flocculation. The settled solids that are collected in the bottom of clarifiers is knows as raw or primary sludge.

\section{2) Secondary Treatment}

After the Primary Treatment unit processes, wastewater it directed into a couple of additional unit processes that are known as secondary treatment. 
Where primary treatment employed primarily physical separation methods, secondary treatment employs primarily biological waste removal processes. Up to $90 \%$ of the organic matter in wastewater can be removed through the use of biological treatment in the secondary treatment stages of a plant. The main stage of secondary treatment is known as a reactor or as an aeration tank, or an activated sludge tank. Air is diffused into this tank, which provides the necessary oxygen for the cultivation of a carefully controlled microbial population that acts as the agents of consuming the dissolved solids that are still present in our wastewater. While dissolved solids are consumed, the population of the microbial community increases. The wastewater, that by now is almost void of dissolved solids but full of the bodies of microbes, is directed into a secondary clarifier. In this clarifier, the bodies of microbes are allowed to settle to the bottom. The sludge that forms is called activated sludge. Most of this sludge is returned back to the reactor (thus maintaining a healthy microbial population to keep cleaning influent wastewater), while the excess sludge is wasted. The wasted biomass / sludge are further treated before being reused or disposed of. Reactors, in secondary treatment, are commonly found in one of two forms; attached growth reactors and suspended growth reactors. Attached growth reactors will not be detailed in this document; however, it should be noted that the biology that governs this process is very similar to the ones discussed in the suspended growth processes (described above). Suspended growth processes remove biodegradable matter and organic nitrogen in a process where microbial populations are suspended in an aerated water mixture. Suspended growth process units come in such variations as activated sludge systems, oxidation ditches or sequencing batch reactors. Suspended growth reactors optimize the manner in which aerobic bacteria break down organic matter in sewage.

\section{3) Tertiary Treatment}

Municipal wastewaters contain a rich number of microorganisms, many of which are pathogenic (i.e. have the ability to cause human diseases). Disinfection is, therefore, necessary to eliminate these pathogenic microorganisms from treated wastewaters before their final discharge into natural bodies of water or on soil. Disinfection processes kill or deactivate these microorganisms. While the use of chlorine (a very powerful oxidizing agent) is the most widely used method of disinfection, ozone (another powerful oxidizer) or ultraviolet radiation are also used for wastewater disinfection.

Tertiary treatment are processes or technologies used in conjunction to secondary biological treatment that are meant to further stabilize BOD in wastewaters, or primarily used to remove such nutrients as nitrogen and phosphorus. Other treatment processes employed in tertiary treatment include physical-chemical separation techniques like adsorption, coagulation/flocculation/precipitation, membranes (used for ultra-filtration), ion exchange processes and materials (e.g. zeolites), or reverse osmosis processes. 
All of these unit processes are used in varying combinations, depending on the quality of effluent that is desired. The main tradeoff in the use of more complex unit processes is the added cost (capital investment and operational costs), alongside the complexity added to the operation of a modern wastewater treatment station. In modern times, treated effluents are often reused in agricultural irrigation, in landscaping, in industrial cooling, or for groundwater recharge (and more rarely, even for indirect augmentation of drinking water supplies). The level of treatment that is achieved in a modern wastewater treatment plant can well exceed the efficiency of 99.5\% removal rates for all of the common wastewater constituents introduced in a previous section of this chapter.

\section{4) Solids (Sludge) Treatment}

Sludges are suspended solids that have been collected from primary (raw or primary sludge) or secondary (activated sludge) clarifiers. This sludge is primarily of organic nature (with its vast majority comprising of the bodies of microorganisms that have been created during the secondary treatment stages). This sludge is also known as Biosolids. Sludge must be treated before it can be used as a value-added by-product (especially used as a fertilizer on land or as a soil conditioner) or landfilled. Prior to their utilization or their disposal, sludges are stabilized to achieve odor control and to reduce the number of pathogenic microorganisms. Sludge, when separated from the wastewater, is about $98 \%$ water. Sludge is first digested and then thickened or dewatered to reduce its volume (making it more cost feasible to transported for final processing, disposal, or use). Digestion is a form of stabilization where the bodies of microorganisms (known as volatile suspended solids) can decompose naturally and the potential for odor production is reduced. Digestion without air in an enclosed tank (anaerobic solids digestion) has the added benefit of producing methane gas which can be used as a source of energy. After digestion, dewatering can be achieved through drying beds, belt filter presses, or centrifuges. Chemicals such as lime, ferric chloride, or polymers are used to improve dewatering effectiveness.

\subsubsection{Solid Waste}

When people think about solid waste management, they probably associate it with garbage being dumped in landfills or incinerated. While such activities comprise an important part of the process, a variety of elements is involved in the creation of an optimal integrated solid waste management system. For example, treatment techniques act to reduce the volume and toxicity of solid waste. These steps can transform it into a more convenient form for disposal. Waste treatment and disposal methods are selected and used based on the form, composition, and quantity of waste materials. However, other steps precede final disposal, i.e. recycling and reuse. 


\subsection{Recycling}

Recycling is called the conversion of waste into new and useful materials and products. A material's recyclability is defined by its ability to recapture the properties that it had in its original state. As an alternative to waste disposal, recycling can save raw material and energy, while lowering environmental impacts and pollution, and reducing greenhouse gas emissions.

Recycling is a key component of modern waste management and is part of the "Reduce, Reuse, and Recycle" motto. Recycling helps achieve environmental sustainability by reintroducing waste into the economic system of production while reducing raw material inputs. ISO standards such as ISO 15270:2008 (concerning plastic waste) and ISO 14001:2015 (concerning environmental management control of recycling practice) are related to recycling.

Common recyclable materials include paper, plastic, glass, metals, textiles, batteries, wood, and electronics. Recyclable materials are picked up from homes, then sorted, cleaned, and reprocessed into new materials that are subsequently used to manufacture new products.

Recycling of a material would, ideally, produce new material of the same sort. For example, used office paper should be converted into new office paper. However, this is not always achievable due to technical limitations or due to high associated costs, since most materials lose their purity when recycled too many times. Only few materials, such as metal cans, can be recycled indefinitely, without losing much of their initial properties. Therefore, "recycling" of many products or materials involves their reconditioning in producing similar (yet different) materials (for example, office paper is turned into paperboard) instead.

Salvage of certain materials from complex products (e.g. lead from car batteries, or gold from printed circuit boards), is another form of recycling, and is also exercised for materials that due to their hazardous nature (e.g. removal and reuse of mercury from thermometers and thermostats) need to be salvaged as opposed to being disposed of in landfills.

\subsection{Solid Waste Treatment \& Disposal}

Nowadays, a great variety of waste treatment and disposal methods for solid waste are available. For illustration purposes, and to serve as a starting point for further study, the following are presented:

1. Thermal waste treatment is a process through which heat is used to treat waste materials. Commonly used thermal waste treatment techniques include the following:

- Incineration is one of the most common thermal waste treatment process. In this process, combustion of waste is achieved in the presence of controlled levels of oxygen. This method is also used to recover energy that can be subsequently used for electricity production or for heating. Among the advantages of this process, the following are included: it re- 
duces the volume of solid waste and the associated problems with its transportation or final disposal in increasingly-hard-to-find spaces, and decreases the emission of greenhouse gas.

- Gasification and Pyrolysis are two methods that are similar in the sense that they both decompose organic waste materials by exposition to no oxygen (gasification) or very low levels of oxygen (pyrolysis) while maintaining very high temperatures. Gasification allows the recovery of energy while causing no air pollution, hence it is the preferred method of the two.

- Open Burning is a least preferred approach of thermal waste treatment, since it is environmentally harmful. Incinerators employed in such process usually have no pollution control devices, hence such harmful (toxic) chemicals as hexachlorobenzene, dioxins, carbon monoxide, particulate matter, volatile organic compounds, and polycyclic aromatic compounds are released to the environment. Unfortunately, this method is still practiced today due to its extremely low cost in implementation.

2. Sanitary landfills provide the most commonly used final disposal option for solid waste. Landfills are necessary so as reduce the risk of environmental or public health problems associated with solid waste. These sites are constructed in a manner that the solid waste disposed are isolated (contained) from the surrounding environment. Landfills are preferably located in areas characterized by clay soils (which are quite resistant to hazardous wastes seeping through) or are away from surface waters or groundwater aquifers, this minimizing the risk of water pollution. Sanitary landfills are associated with low health and environmental risks, but they require large tracts of land (which is increasingly difficult to find near urban centers), and entail a high cost of construction (when compared to other waste disposal options). Sanitary Landfills are designed and constructed so that to isolate the solid waste from the surrounding environment. To do so, bottom liners (composed of compacted clay, geomembranes, and leachate collection systems) are installed, and when full, a top cover (isolating the deposited solid waste from influent stormwater) is also put in place. Other features of landfills include a gas extraction system that is collecting biogas that is formed as a result of microbial decomposition of waste.

Bioreactor landfills present a more recent technological development, and they use controlled microbiological processes to achieve faster decomposition of waste. Bioreactor landfills require the continuous addition of liquid to maintain optimal moisture for faster microbial digestion of solids. The moisture level is achieved through the recirculation of landfill leachate or the addition of sewage sludge obtained from wastewater treatment plants.

Biological Solid Waste Treatment Composting is a treatment method also commonly used for solid wastes of organic nature that are easily biodegradable. It is a treatment method that employs the controlled aerobic decomposition of organic waste matter achieved through the action of microorganisms or of 
invertebrates (e.g. redworm). Common composting techniques include windrow composting, in-vessel composting or vermin-composting. Composting produces a value-added by-product, humus, that can be used as a soil conditioner or as planting material in gardens.

Anaerobic Digestion is a broad category of approaches that uses biological agents (microbes) to decompose organic materials in the absence of oxygen. Microbes, in the absence of oxygen decompose the waste material while producing another value-added by-product; biogas (which is comprised primarily of methane).

\subsubsection{Hazardous Waste}

Although hazardous-waste management is challenging, due to the nature of the waste involved, there are several approaches and method that can be employed. Reduction and recycling of hazardous waste is by far the most desirable management options. However, it is impossible to avoid the disposal of all amounts of hazardous waste, which can cause much damage to human health and the environment, even in very small quantities.

Hazardous waste, as it is the case for wastewaters and solid waste, can be treated by chemical, thermal, biological, and physical methods. Chemical methods include ion exchange, precipitation, oxidation and reduction, and neutralization. Thermal methods include high-temperature incineration, which can detoxify certain organic wastes as well as destroy them. Special types of thermal equipment are used for burning solid, liquid waste or sludges. Such equipment includes fluidized-bed incinerators, multiple-hearth furnaces, rotary kilns, and liquidinjection incinerators. The incineration of hazardous waste, however, carries with it a high risk for atmospheric contamination, thus necessitating the use of expensive air pollution abatement technologies (e.g. wet scrubbers, baghouse filters, or electrostatic precipitators).

Biological treatment of certain organic wastes (e.g. waste from the petroleum industry) is also possible. One such method is landfarming, which is a technique that requires the careful mixing of waste with surface soil on a suitable land area. The addition of microbes (sometimes genetically engineered species), alongside necessary nutrients, can metabolize waste. The areas used for the landfarming approach become obsolete to subsequent farming activities. A similar approach, through which microbes are used to stabilizing hazardous wastes on contaminated sites (brownfields), is called bioremediation.

While chemical, thermal, and biological treatment methods change the molecular form of waste, physical treatment concentrates, solidifies, or reduces the volume of the waste by such methods as shredding. Physical processes include evaporation, sedimentation, flotation, filtration, solidification (which can be achieved by encapsulating the waste in concrete, asphalt, or plastic, hence producing a solid mass of material that does not allow the leaching of the hazardous material to the environment). 
Hazardous wastes that are not destroyed by incineration or other chemical processes need to be disposed of properly. For most such wastes, land disposal, although not desired because of the environmental risks involved, is the ultimate destination. Two basic methods of land disposal include landfilling and underground injection. Landfilling of hazardous solid faces much stricter regulations than landfilling of municipal solid waste. Hazardous wastes must be deposited in secure landfills that have such special features as a minimum separation of three meters between the bottom of the landfill and the underlying bedrock. A secure hazardous-waste landfill must have two impermeable liners and leachate collection systems. Apart from the specially designed bottom liners, double leachate collection system (and associated wastewater treatment), and top cover, a groundwater monitoring system is also required for secure landfills. If contamination of groundwater is noticed at any point, then water must be pumped and directed for appropriate treatment (which is a very expensive endeavor), until the leak is stopped. Another option for disposing liquid hazardous waste is deepwell injection. In this procedure liquid waste is pumped through a steel casing (also known as sleeve) into a porous layer of limestone or sandstone. High pressures applied, force the liquid into the pores and fissures of the rock, hence permanently sealing it into the rock. Special geological conditions must prevail in the area where this approach is exercised, as well as specific siting regulations govern the design of this approach. Deep-well injection while relatively cheap, it has a high risk of eventually leaking hazardous waste into underground aquifers.

\subsection{Best Management Practices for Marinas}

This chapter is introducing some more practical matters, with regards to managing waste in marinas. Some theoretical backdrop is provided for some of the technologies or approaches introduced, however, the material presented is taking the form of practical guidelines.

\subsubsection{Siting, Design, and Habitat}

Siting and design are among the most significant elements in the construction and subsequent operation of marinas, especially due to the effect that these choices will have on water quality. The location of a marina, whether it is located directly on a river or the sea or whether it is located in a protected area, affects its circulation and flushing characteristics of the surrounding water (also influenced by other factors such as basin configuration and prevailing winds or water currents). Circulation and flushing are important to the dispersion and dilution of potential contaminants. The final design should consider the tradeoffs between a marina's capacity, services and cost and the anticipated environmental impacts (including those that may ensue from dredging requirements). The goal of marina siting and design management practices is to ensure that marinas do not cause negative impacts on water quality, nor threaten the health of marine and coastal 
life and habitats. An Environmental Impact Assessment is an imperative for the permitting of any marina (according to EU Directive 2014/52/EU) and should be able to capture the items listed above.

One of the most important factors that may influence a marina's possible impact on adjacent water quality and waterway is site selection. Specifically, choosing a site with desirable hydrographic characteristics and does not undergo much modification can reduce environmental impacts such as low levels of dissolved oxygen.

The following provides a brief overview of selected siting and design-related measures, alongside several illustrative practices for each measure.

The water quality inside a marina depends largely on flushing as this is determined by proper water circulation (Tsinker, 1992). An improperly flushed marina will result in the accumulation of pollutants in the water and the sediments, hence affecting fauna and flora (NCDEM, 1991). Flushing can be better managed by siting and designing marinas so that marine currents (and tides) will allow for more frequent water exchanges. Some indicative practices towards achieving better flushing (and pertinent to siting and design stages) are the following: 1) marinas should be designed in a way that their waterway entrance is not deeper than neighboring boating waters (except in cases where the bottom is home to natural benthic life). 2) The design should include as few segments as possible to promote circulation, while designing entrance channels can enhance flushing. 3) openings should be located opposite from each other to allow for water flow-through.

Water quality should be assessed before the siting of a marina, to determine whether the marina will result in poor water quality. A monitoring program of the marina and surrounding waters should be established, including flushing and water quality characteristics (focusing on at least dissolved oxygen and on pathogenic microbial indicators such as fecal coliforms).

The natural habitat should be assessed so as the siting and the design of a marinas minimizes impacts on coastal, wetland, riparian, or marine fauna and flora. To achieve this, the project site should be 1) a priori surveyed and characterized, 2) site a marine on an already disturbed location, 3) examine the possibility of, and compare, alternative sites, 4) use bioassessment techniques that can quickly indicate impacts on biota, 5) examine the existing habitat functions.

Shorelines should be stabilized, especially when coastal erosion mechanisms are present in the area. Vegetation should be preferably used for shore stabilization, but is highly subjective to the appropriateness of soils and their ability to sustain plants. When use of vegetation is not feasible, such structural methods as jetties and breakwaters (alongside gabions, riprap, and sloping revetments) may be used for shore stabilization, although amenable to accelerated scouring and increased erosion in downstream shorelines.

\subsubsection{Stormwater Management}

Stormwater runoff may be defined as the water from rain and snow melt (or any other form of precipitation) that flows across the land. This water has the capacity 
to collect pollutants from land and transport them into nearby bodies of water, hence negatively impacting water quality and endanger aquatic habitats. Any type of development (that increases the imperviousness of land) can increase the amount of stormwater runoff by changing natural drainage patterns, while simultaneously increasing the pollutants (concentration and types) carried by the runoff.

For marinas, runoff can become a major issue, especially in areas used for boat maintenance. Due to the materials used for controlling fouling and corrosion, or for repairs of boats, the wastes generated by such processes as sanding, scraping, or painting/varnishing, among others, can contain harmful for the environment substances like metals, solvents and hydrocarbons.

For example, preparing a boat for painting can generate paint chips, dust and particles that may contain metals such as copper, zinc, and lead. If such metals are not handled properly and end up into the adjacent water, they can be detrimental to marine organisms even at very low levels (concentrations of such substances are often measured in parts per billion). Also, many contaminants often attach to soil and other solid particles that abound in boat maintenance areas. Besides from the danger of contamination of the water column in marina basins, accumulation of such toxins in sediments will become a real threat, especially when dredging activities become necessary with time.

Therefore, it is of utmost importance that plans to reduce pollution from stormwater runoff from a variety of sources in marinas be instated. Such management plans mostly employ Best Management Practices (BMPs) rather than installing specific pollution abatement technologies. BMPs can involve a wide range of activities including new structures, using specific equipment or products, or changing operating procedures and improving housekeeping practices. The selection of the most appropriate BMPs will depends on the marina, as this is defined by such factors as its facilities, the adjacent environment, or the predominant meteorological conditions. All marinas are different and probably unique (size, services offered, operation, boat use, etc.). It is important to remember that a BMP that works well at one marina might be totally inappropriate for another because of location, site, economic or operational considerations. Therefore, each marina must be examined on case-specific basis.

Concerning stormwater management in marinas, there are a number of BMPs often suggested for reducing potential pollution (especially from boat maintenance areas). These are often categorized into two types commonly known as Sourcecontrol and Stormwater-treatment. Source-control emphasizes keeping stormwater from becoming contaminated. Stormwater-treatment entail structures and technologies that treat runoff. Source-control is preferred due to the significantly lower cost of implementation; however, it is not always feasible to achieve since some stormwater will eventually get polluted.

\subsubsection{Stormwater Treatment BMPs}

Stormwater treatment include technologies (in the form of structures and devices) that are used to, first manage, and possibly treat contaminated runoff 
water. Sometimes, these technologies may be used to keep stormwater away from areas that are laden with pollutants. These technologies often capture water and achieve its filtration by allowing it infiltrate in the ground or allow pollutants to settle to the bottom of these detention structures.

As with any technology, such stormwater treatment BMPs (that employ specific structures or devices) should best be designed by qualified engineers. However, a general understanding of the mechanism with which they function, is valuable for operators or owners of marinas in evaluating their options.

Generally, the best approach for stormwater is reduction of the volume that results to or from the marina's facilities, through the use of porous pavements or other permeable material like gravel. Such permeable pavements reduce the amount of runoff by prolonging the time that it takes to flow inside or outside of desired areas and thus giving the chance to infiltrate the ground, as opposed to ending up in adjacent natural aquatic systems. It should be attempted to collect and treat runoff that results from work areas, since those are the ones that will impart most of the pollutants to stormwater.

There are a large number of stormwater treatment BMPs. However, several of them may not be applied to marinas due to space limitations, site conditions, safety concerns, or due to the high capital investment required. Some examples of technologies / approaches that could be employed in marinas are hereby presented.

Vegetated Filter Strips are strips of land, usually running alongside the shoreline that are planted with appropriate vegetation (e.g. Spartina patens or Puccinellia distans) that can withstand inundation conditions. These structures can be quite effective in removing pollutants that take the form of larger particles (i.e. paint chips or other large suspended solids). Also, the vegetation can assist in removing nutrients or other chemicals with which stormwater is laden. The reduction in suspended solids reaching coastal waters not only prevents chemical contamination but also reduces the sediments that may accumulate over time, hence dictating future dredging operations. Vegetated filter strips can significantly add to the aesthetics of marina grounds, especially if properly landscaped. A functional width for these structures is more than 6 meters and should be evenly sloped to a degree of less than 5\%. (since water has to flow evenly over the strip for it to be effective). Regular maintenance is required for these structures, especially if they will be used for their aesthetic value as well.

Infiltration Trenches are shallow trenches (about $1-2$ meters deep) that are filled with stones or large gravel, thus creating an underground reservoir (detention space) for stormwater that will allow time for it to percolate into the soil. Pollutants (suspended or dissolved) adsorb to the soil, are strained by the soil particles, or are broken down by the microbial communities that will develop in the subsurface. These structures do not require much space and can easily be employed in marinas with limited space. If the groundwater table is very shallow, infiltration trenches may not be feasible. Furthermore, they are susceptible to clogging, hence they would best be preceded by vegetated filter strips. These trenches are normally designed to provide a 6-hour detention time for water, and they should be fully drained after about 3 days. Another approach, that functions 
on similar principles is offered by Dry Wells (usually deeper than trenches and cater mostly to runoff from rooftops of buildings, which carries little suspended solids and other pollutants). For dry wells to work properly, the permeability of surrounding soil must be high (e.g. sandy soils).

Vegetated Swales look like road-side ditches, even though wider. They are also known as "biofilter" swales. Their appearance and treatment mechanism resemble that of vegetated filter strips, although have a smaller capacity to handle larger volumes of water. They can make an excellent replacement of gutters or pipes that are more conventionally used for stormwater control. The soil of swales should never be compacted and should have high permeability.

Deep Sump Catch Basins (also known as grease traps or oil catch basins) are underground systems that are designed to retain water while removing suspended particles as well as oils and grease. These engineered structures (that are moderately expensive when compared to other approaches already introduced) work by directing contaminated stormwater through a series of underground chambers that are permanently flooded. While oils float to the surface of these sumps, solids will settle to the bottom of these chambers, much like a sedimentation tank in wastewater treatment. The minimal space requirements make them excellent candidates for areas where space may not be available for other approaches already mentioned above. Oil catch basics can also serve as pretreatment steps for swales or trenches. Oil-absorbing material can be installed in the basin to enhance removal of hydrocarbons.

\subsubsection{Boat Maintenance Areas}

Boat maintenance areas can be either indoors or outdoors. Indoor spaces are more contained and less susceptible to stormwater contamination; however, cost more and more limited in their potential uses. Outdoor spaces allow for more flexibility in the maintenance activities that can be undertaken, but they may present additional challenges that relate to waste management and pollution control.

Indoor maintenance areas should have floors that allow for easy cleaning have hard floors to facilitate clean up. They are often constructed as temporary structures that may even be moveable. Operations like painting or work with fiberglass should require the use of equipment that allows for adequate health and safety conditions (e.g. good ventilation systems)

For marinas, outdoor working areas are often more practical and cost efficient then indoor spaces, especially with regards to boat maintenance activities. The fact that areas are located outdoors should not translate to undelineated, or poorly marked or managed locals, especially with regards to the handling and disposal of chemicals that have a high potential to cause detrimental pollution. Outdoor maintenance areas should be far away from natural waters, and should have impermeable floors so that infiltration of pollutants (e.g. solvents or other petrochemicals) in to the soil and groundwater is prevented and that make 
cleaning easier. Proper maintenance and operation are necessary so as to prevent the dispersion of pollutants (especially such chemicals as chemical paint strippers that are of high environmental concern) in surrounding areas (especially with wind), and they should be shielded from the inflow of stormwater from other areas (i.e. make use of curbs or stormwater treatment technologies discussed).

\subsubsection{Petroleum Control \& Boat Cleaning-related chemicals}

Fuel and oil are some of the most common releases into waters in marinas, and they are associated with fueling of vessels (often boat fuel tanks are "toppedoff"), with bilge pumping (oil and grease end up in bilges during the operation and maintenance of inboard engines of boats), and with direct accidental spills. Also, boats often perform cleaning operations while they are still in the water resulting in releases of harmful cleaners / solvents or paint remnants (from hull cleaning).

Fuel control can be managed through several practices. For example, automatic shut-off nozzles and fuel/air separators on air vents or tank stems of inboard fuel tanks can reduce the amount of fuel spilled in water during fueling operations. The use of oil-absorbing materials in the bilge areas of all boats with inboard engines should also help reduce petroleum products from ending up in the water. Proper inspection of such material and frequent replacement should be exercised.

To minimize the release of metals (e.g. copper, zinc, arsenic, lead, tin), cleaners and solvents in the water, the following practices could be considered: 1) exercise hand washing of the boat hull that can be reached (above the waterline). Boats should be cleaned on shore, if possible and debris should be properly collected and disposed. 2) Minimal amounts of eco-friendly detergents and cleaners (biodegradable and phosphate-free) should be used. Detergents containing such chemicals as ammonia, sodium hypochlorite, chlorinated solvents, petroleum distillates, or lye should be avoided. 4) Care should be taken so that paint is not scraped off from the hulls of boats during underwater cleaning, as antifoulant paints usually contains high levels of toxic metals.

Finally, other dangerous liquids, such as oil, harmful solvents, antifreeze, and paints, should be properly contained and stored at all times, and their disposal should be done in proper facilities that are managed by licensed contractors. The use of curbs or other barriers is necessary to contain accidental spills of dangerous liquids. Proper storage and labelling should be exercised.

\subsubsection{Sewage Handling}

Marinas that do not possess central sewage collection facilities (in which case, extensive reference to the approaches taken for sewage treatment was made in Chapter 4) should install a number of components through which sewage can be 
handled. Specifically, such facilities as restrooms, pumpouts, and dump stations are necessary so as to avoid the release of sewage to adjacent waters. Access to these facilities should be easy and proper signs will allow for more boaters to properly use them.

Three types of onshore collection systems are available: fixed point systems, portable/mobile systems, and dedicated slip-side systems.

Fixed-point collection systems include central sewage pump outs. These are generally located at the end of a pier. A boat requiring such services docks adjacent the station where a hose connects that boat's wastewater system to the pum pout and wastewater is moved to the marina's central treatment system. Portable/ mobile systems are similar to fixed-point systems but, in this case, they include a pump and a storage tank. Wastewater is pumped from boats to the storage tank. Storage tanks are emptied into the marina's central wastewater service. Portable systems may be the most convenient and easily accessible systems through which disposal of boat sewage can be achieved (Natchez, 1991). Dedicated slipside systems provide continuous wastewater collection at a slip and can be provided to live-aboard vessels.

Proper signs should be posted alerting users of the marina of pertinent laws (i.e. no discharge of sewage in waters), and providing information on the location and procedures for using marina sewage services and facilities.

\subsubsection{Solid Waste Management and Recycling}

Solid waste produced, by all operations in the marina, should be properly disposed of, hence avoiding disposal of any kind to adjacent waters or surrounding land.

Waste characterization in a marina will assure proper handling and disposal of solid waste. Hazardous waste should never be mixed with solid waste, and neither should liquid waste be contaminated with solid waste and vice versa. Hazardous waste should be handled through specific procedures set by the marina management.

The solid waste management systems should be designed with adequate capacity (i.e. holding bins and collection schedules) so as to avoid entry of waste in adjacent waters. Towards this end, several measures can be adopted, some of which are suggested below.

Boat maintenance and cleaning activities should not be performed below the waterline. In this way debris falling into the water are avoided. Further, work areas for boat maintenance (and repair) should be available, accessible, and properly marked. Working outside of such designated areas should be prohibited. Maintenance areas should be cleaned regularly, preferably through vacuum pumping (especially for sandings, paint chips, etc.). Sandblasting activities should be performed in enclosed spaces or by surrounding spaces of activity with plastic tarps, while avoiding such activities during wind days. 
Proper and adequate in capacity disposal facilities should be made available, with the primary preference being covered dumping receptacles. Covering of these receptacles will help avoid increased leachate being formed with rain, avoid leaching of possibly toxic material in surrounding land or water, and avoid spreading of solid waste by wind. On top of disposal facilities, it is imperative that properly marked recycling receptacles (for such varied types of waste as metal, glass, paper, plastic, wood, batteries, etc.) are also made available and their use should be encouraged. A licensed recycler should be employed to transfer this type of waste away from the marina grounds (especially as certain types of waste is concerned (i.e. lead batteries).

\section{Bibliographical References}

Basu, R. (2009). Solid Waste Management-A Model Study. SIES Journal of Management, 6, 20-24.

Brunner, P. H., \& Rechberger, H. (2014). Waste to energy-key element for sustainable waste management. Waste Management, 37, 3-12. https://doi.org/10.1016/j. wasman.2014.02.003

Chandler, A. J., Eighmy, T. T., Hjelmar, O., Kosson, D. S., Sawell, S. E., Vehlow, J., Sloot, H. A. (1997). Municipal Solid Waste Incinerator Residues. Amsterdam: Elsevier

Demirbas, A. (2011). Waste management, waste resource facilities and waste conversion processes. Energy Conversion \& Management, 52(2), 1280-1287. https:// doi.org/10.1016/j.enconman.2010.09.025

Dijkema, G. P. J., Reuter, M. A., \& Verhoef, E. V. (2000). A new paradigm for waste management. Waste Management, 20(8), 633-638. https://doi.org/10.1016/ S0956-053X(00)00052-0

Dixon, N., \& Jones, D. R. V. (2005). Engineering properties of municipal solid waste. Geotextiles \& Geomembranes, 23(3), 205-233. https://doi.org/10.1016/j. geotexmem.2004.11.002

European Union. (2018). Directive 2008/98/EC of the European Parliament and of the Council of 19 November 2008 on waste and repealing certain Directives (aka Waste Framework Directive). https://eur-lex.europa.eu/legal-content/EN/ TXT/HTML/?uri=CELEX:02008L0098-20180705\&from=EN. Accessed July 1, 2020.

Natchez, D.S. 1991. Are Marinas Really Polluting? International Marina Institute, Wickford, RI.

NCDEM. 1991. Coastal Marinas: Field Survey of Contaminants and Literature Review. North Carolina Division of Environmental Management, Raleigh, NC. Report No. 91-03.

Pichtel, J. (2005). Waste Management Practices: Municipal, Hazardous, and Industrial. CRC Press. 
Tchobanoglous, G., Theisen, H., \& Vigil, S. (1993). Integrated Solid Waste Management: Engineering Principles and Management Issues. Water Science \& Technology Library, 8(1), 63-90.

Tsinker, G.P. 1992. Small Craft Marinas. In Handbook of Coastal and Ocean Engineering: Vol. 3, Harbors, Navigational Channels, Estuaries, Environmental Effects, ed. J.B. Herbich, pp. 1115-1167. Gulf Publishing, Houston, TX.

Vergara, S. E., \& Tchobanoglous, G. (2012). Municipal Solid Waste and the Environment: A Global Perspective. Environment and Resources, 37(37), 277-309. https://doi.org/10.1146/annurev-environ-050511-122532

White, P. R., Franke, M., \& Hindle, P. (1995). Integrated Solid Waste Management: A Lifecycle Inventory. Berlin: Springer.

Williams, P. T. (2005). Waste Treatment and Disposal. London, New York: John Wiley \& Sons. https://doi.org/10.1002/0470012668

Wilson, D. C. (2007). Development drivers for waste management. Waste Management \& Research the Journal of the International Solid Wastes \& Public Cleansing Association ISWA, 25(3), 198-207. https://doi.org/10.1177/0734242X07079149 


\section{Chapter 4 \\ Green technology}

Nicholas Christofides

SUMARY: 4. Photovoltaic systems for marinas and yachts. -4.1 Introduction. -4.2 Solar geometry.-4.3 Photovoltaic technologies and basic electrical parameters of PV modules. 4.3.1 PV Technologies. 4.3.1.1 Silicon based. 4.3.1.2 Thin film Technology. 4.3.1.3 Electrical Parameters of PV modules. - 4.4 Calculations related to photovoltaic (PV) systems. 4.4.1 Calculating the efficiency of PV panels. 4.4.2 Assessing the Performance of a PV System.-4.5 Categories of photovoltaic (PV) systems. 4.5.1 PV systems for residential applications. 4.5.1.1 Net-metering grid-connected PV systems. 4.5.1.2 Independent grid-connected PV systems. 4.5.1.3 Hybrid grid-connected PV systems. 4.5.1.4 Off-grid PV systems (stand-alone). 4.5.1.5 CASE STUDY 1 - OFF-GRID PV SYSTEM DESIGN. 4.5.1.6 CASE STUDY 2 - OFF-GRID PV SYSTEM DESIGN (to be solved by the student). 4.5.2 Self-consumption PV systems - Grid-connected PV systems for energy saving by commercial consumers. 4.5.2.1 CASE STUDY 3 - LARGE-SCALE SELF-CONSUMPTION PV SYSTEM. 5 SMALL SCALE WIND TURBINES.-5.1 Introduction.-5.2 Wind Turbines.-5.3 Wind as a resource of energy. 5.3.1 Definitions and theoretical background. 5.3.2 Study of the wind characteristics. 5.3.3 Basic considerations for residential wind turbines.-5.4 Estimating Annual Energy Output. 5.4.1 Power output Power curve. 5.4.2 Energy output from wind turbines. 5.4.3 Grid-Connected Small Wind Electric Systems. 5.4.4 Wind Power in off-grid / Stand-Alone Systems.-5.5 Small scale wind turbines and applications. 5.5.1 CASE STUDY 1 - Energy output calculation based on wind turbine manufacturer's power curve. 5.5.2 CASE STUDY 2 - Alternative Energy output calculation method. 5.5.3 CASE STUDY 3 - Energy output calculation comparison between two regions - The United Kingdom and Cyprus. 5.5.4 CASE STUDY 4 - Sizing of wind turbine based on specific energy requirements. 6 References and on-line tools.-6.3 On-line Internet Tools. 7 Appendix.-7.1 Semtive vertical axis wind turbine.-7.2 Bergey Excel 10 Wind turbine technical datasheet 


\subsection{Photovoltaic systems for marinas and yachts}

\subsubsection{Introduction}

The photovoltaic power potential, for purposes of analysing solar photovoltaics (PV) and PV system design, is in general measured in $\mathrm{kWh} / \mathrm{kWp}$. The kilowatt-hour (kWh) is the unit for measuring energy and in the context of this work, electrical energy either consumed or generated by PV systems. The $\mathrm{kWp}$ is the unit for measuring the installed nominal power of PV systems. The letter "p" is used to differentiate it from the conventional measurement unit, the $\mathrm{kW}$, which is the measurement unit for the power consumed by loads or generated by conventional power sources such those in power stations using coal, natural gas etc. The letter "p" stands for the word photovoltaic or "peak". They are both used to attribute the letter "p". As we will see later on, PV systems can generate their nominal power under specific conditions and this why the word "peak" arises. Areas of Europe such as the eastern Mediterranean present amongst other the highest photovoltaic power potential as can be seen from Figure 4.1, [1]. In Cyprus it can be seen that for every installed kWp of photovoltaics, between 1600-1800 kWh of electrical energy can be generated. ${ }^{1}$ This of course does not take into consideration systems on tracker systems which can generate even $40 \%$ more because they

\section{Figure 4.1 Europe's photovoltaic power potential ${ }^{1}$}

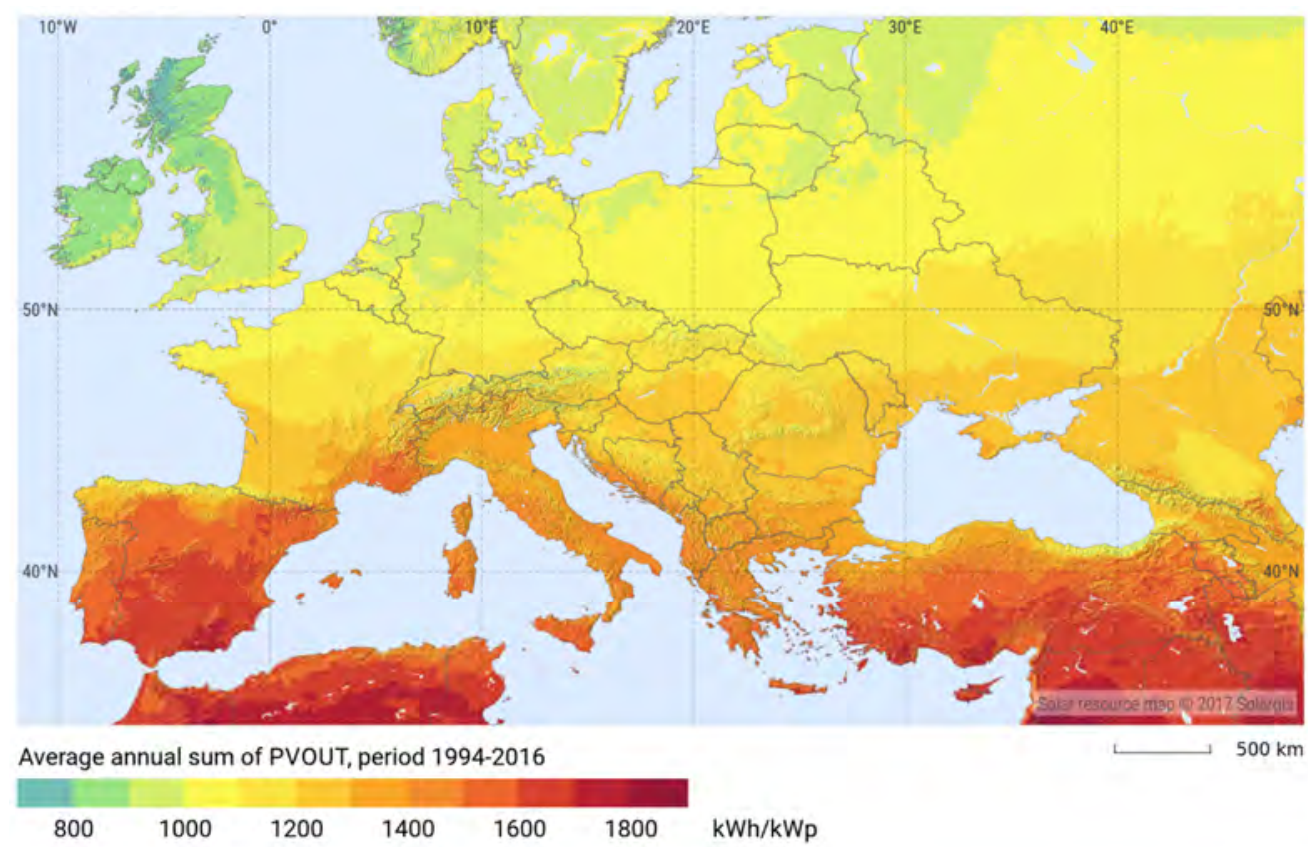

${ }^{1}$ https://solargis.com/, accessed January 2021 
are always facing the sun directly. A more in-depth analysis will be given later on to show how the orientation, inclination angle and other parameters affect the performance and power output (consequently energy output) of photovoltaics.

Figure 4.2 shows the global horizontal irradiation for Europe. This is very much different compared to Figure 4.1. It is seen that the measurement units are $\mathrm{kWh} / \mathrm{m}^{2}$ which is the usual measurement unit for solar irradiation (SI). The map shows SI measured on the horizontal as most meteorological services do. Depending on the inclination angle and the azimuth (orientation) of the PVs the incident irradiation varies and this in turn affects the expected PV power output. There are mathematical algorithms and software tools (on-line and off-line) that can be used to estimate the expected power and energy for a specific PV system given its specific conditions.

Figure 4.2 Europe's solar horizontal irradiation map ${ }^{2}$

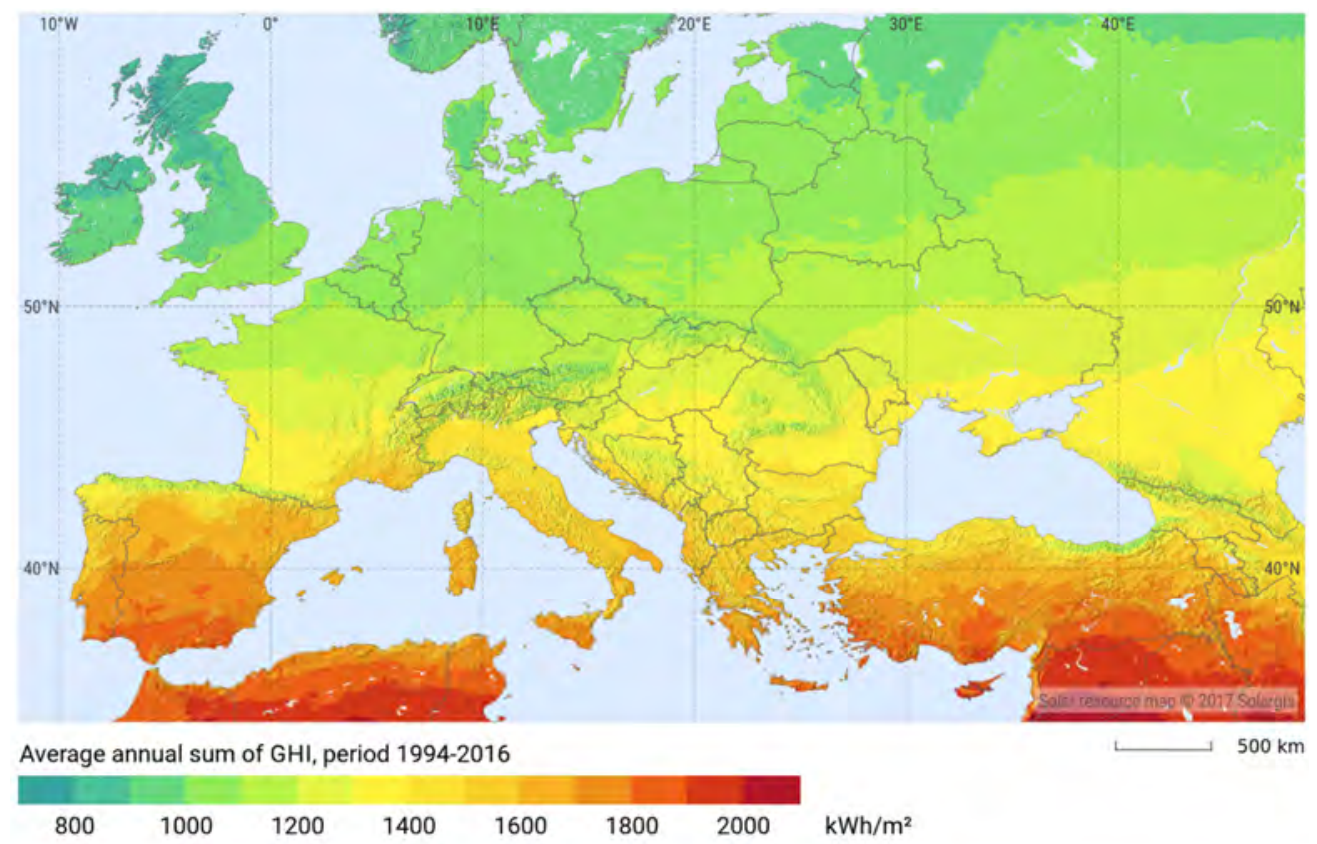

\subsubsection{Solar geometry}

It is well known that the motion of the sun is not real but it is because the earth rotates on its own axis creating this apparent motion effect. Depending on where someone is on earth, he will have a different perspective of the sun's position. It of course depends on the location, time of day and time of year. The apparent position of the sun has a major influence on the solar radiation intensity received by a

\footnotetext{
${ }^{2}$ http://www.timeanddate.com/
} 
photovoltaic module. A PV module generates peak power when the sun's rays hit the module perpendicularly. As a result, a module cannot generate the same amount of power during a day and depends on the geographical longitude and latitude.

On every place on earth, the sun will at some time during the day be at the highest position in the sky. This time is known as local solar time (LST) and occurs around 12 o'clock noon. The local time (LT) can be different from LST as a result of the different time zones and human time adjustments. The reference meridian is Prime Meridian used for Greenwich Mean Time. From then on, the earth's surface is divided into time zones with each time zone separated by $15^{\circ}$ of longitude. More details about time zones and time correction factors can be read in [2]. As an example, if we consider Cyprus we have the following related figures:

Cyprus is $30^{\circ}$ east of the prime meridian, meaning that the local standard time meridian (LSTM) for Cyprus is +2 . Note that every $15^{\circ}$ is considered one hour $\left(360^{\circ} / 24 \mathrm{~h}=15^{\circ}\right)$. So, at $12 \mathrm{o}^{\prime}$ clock noon local solar time (time when sun is highest in the sky), what is the local time in Cyprus? The answer is that it depends on the time of year. On the 21st of December the local time would be 11:42 but on the 30th of June the local time would be 12:49. There are various tools and sites that the reader can refer to for further reading.

Note also that the European Parliament has voted to stop moving clocks forward an hour in spring and back again in the autumn. Politicians passed the measure by 410 votes to 192 in March 2019 - meaning seasonal time shifts, which were introduced during World War One to save energy, will end in 2021. "However, the likelihood of the EU abolishing DST in 2021 is very slim. Europe, like the rest of the world, has been busy handling the health and economic effects of Covid-19. Negotiations have not yet started in the European Council, making it very unlikely for the new rules, even if agreed rapidly to apply in 2021. The draft law proposes that 2021 will be the last time EU Member States and affiliated countries follow the seasonal clock change. For this reason, all subsequent clock changes in European nations are marked as preliminary on timeanddate.com." ${ }^{3}$.

\subsubsection{Photovoltaic technologies and basic electrical parameters of PV modules}

\section{PV Technologies}

The main PV technologies currently commercially available are the following:

\subsubsection{Silicon based}

Examples of silicon-based PV modules are:

- multi and mono crystalline (c-Si)

- amorphous Silicon (a-Si)

\footnotetext{
${ }^{3}$ https://www.timeanddate.com/news/time/europe-dst-end-2020.html
} 
It is the dominant PV technology used worldwide because it is the most efficient and perhaps the most promising and stable technology.

\subsubsection{Thin film Technology}

Amorphous (uncrystallised) silicon is the most popular thin film technology with cell efficiencies of 5-7\% and double- and triple-junction designs raising it to $8-10 \%$. Research has shown that the efficiency of amorphous silicon might in future go beyond than 19\% [1]. It is however vulnerable to degradation. Some of the varieties of amorphous silicon are:

- Amorphous silicon carbide (a-SiC)

- amorphous silicon germanium (a-SiGe)

- microcrystalline silicon (c-Si)

- amorphous silicon-nitride (a-SiN)

Thin-film solar cells are basically thin layers of semiconductor materials applied to a solid backing material. Thin films greatly reduce the amount of semiconductor material required for each cell when compared to silicon wafers and hence lowers the cost of production of photovoltaic cells. Some other examples of thin film technologies are:

- copper indium gallium diselenide (CIGS)

- cadmium telluride (CdTe)

- titanium dioxide (TiO2)

- cadmium sulphide (CdS)

The U.S. Department of Energy's solar-power initiative is offering up to $\$ 12$ million in new research funding aimed at closing the gap between today's solar cell efficiencies and the "Shockley-Queisser Limit," which says that typical single-junction photovoltaics can convert no more than 33.7 percent of the sun's energy into electricity. Figure 4.3 illustrates clearly results recorded at various research institutes and universities who examine new materials and technology combinations for PV cells (multi-junction cells). The chart below shows how dynamic the field of PV technology with regards cell efficiency is.

\subsubsection{Electrical Parameters of PV modules}

The main electrical parameters of PV modules include the open-circuit and rated voltage, short-circuit and rated current, the rated and $\mathrm{P}_{\text {mpp }}$ powers, the efficiency at STC and NOCT.

The electrical parameters are necessary when dimensioning a PV system but also when needed to assess the performance of a module for warranty purposes. The open-circuit voltage and short-circuit current data can also be used to perform simple measurements on a module in order to check if it generates voltage and current near the rated values. 
Figure 4.3: Solar cell efficiency chart ${ }^{4}$

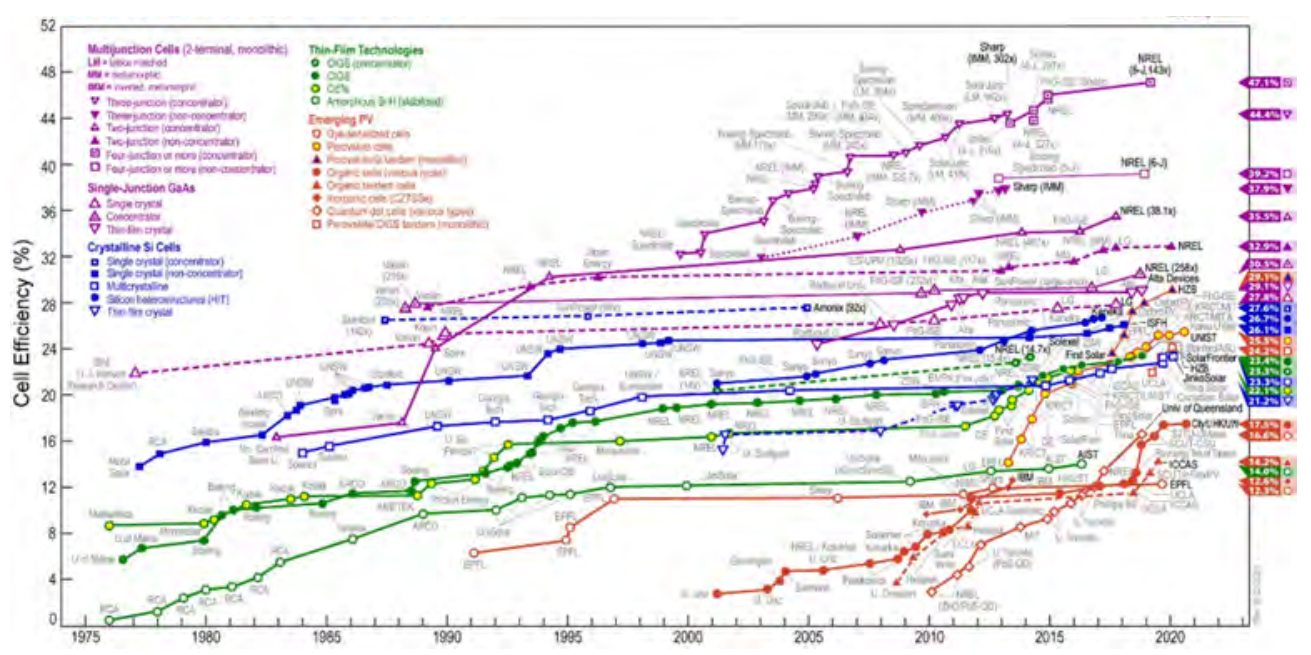

The module should of course be directed towards the sun and inclined at such an angle so that the sun's rays strike the module perpendicularly. It is therefore necessary to know in advance the time of day at which the sun has its maximum radiation and at what angle the module should be inclined so that it generates maximum power. Another parameter that may seriously affect measurements is temperature. Looking carefully at the data sheet of PV module manufacturers, it is evident that all manufactures state the module specifications at standard test conditions. The standard test conditions, or STC for short, have been universally adopted as a standard so that there is consistency between manufactures and comparisons can be made between modules. There are three main parameters that define STC: ${ }^{4}$

- Solar Irradiation: this should be $1000 \mathrm{~W} / \mathrm{m}^{2}$

- Module Temperature: this should be $25^{\circ} \mathrm{C}$

- Atmospheric Pressure: this must be $1.5 \mathrm{AM}$

When all three above parameters coexist and if the sun strikes the module perpendicularly, a module should generate its rated power or perhaps even more depending on the tolerance. It is therefore appreciated that testing a module onsite can prove very difficult as very careful planning must initially take place and the unpredictable nature of weather can also ruin the preparation. Figure 4.4 below summarizes the main electrical parameters of a module.

Another electrical parameter that can be used to compare modules is NOCT which stands for nominal cell operating temperature ${ }^{5}$. A PV module will be typically rated at $25{ }^{\circ} \mathrm{C}$ under $1000 \mathrm{~W} / \mathrm{m}^{2}$. However, when operating in the field, they typically operate at higher temperatures and at somewhat lower irradiation

\footnotetext{
${ }^{4}$ https://www.nrel.gov/

${ }^{5}$ http://pvcdrom.pveducation.org/MODULE/NOCT.htm
} 
Figure 4.4: Electrical data of SHARP's NU-JD $440 \mathrm{Wp}$ monocrystalline module

\begin{tabular}{|c|c|c|c|}
\hline \multicolumn{4}{|l|}{ Electrical data (STC) } \\
\hline & \multicolumn{3}{|c|}{ NU-JD440 } \\
\hline Maximum power & $P_{\max }$ & 440 & $W_{p}$ \\
\hline Open-circuit voltage & $V_{\propto}$ & 49.77 & V \\
\hline Short-circult current & lac & 11.49 & A \\
\hline Voltage at point of maximum power & $V_{\text {mip }}$ & 41.20 & V \\
\hline Current at point of maximum power & $\ln \infty$ & 10.68 & A \\
\hline Module efficiency & $\eta_{m}$ & 19.9 & $\%$ \\
\hline \multicolumn{4}{|c|}{ 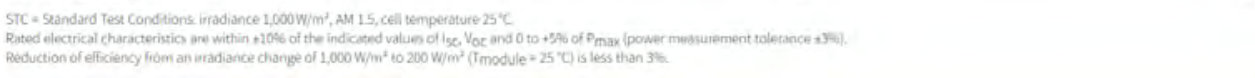 } \\
\hline \multicolumn{4}{|l|}{ Electrical data (NMOT) } \\
\hline & \multicolumn{3}{|c|}{ NU-JD440 } \\
\hline Maximum power & Pmar & 329.14 & $W_{p}$ \\
\hline Open-circuit voltage & $V_{o c}$ & 46.07 & v \\
\hline Short-citcuit current & ls & 9.21 & A \\
\hline Voltage at point of maximum power & $V_{\text {mivo }}$ & 36.98 & v \\
\hline Current at point of maximum power & $\operatorname{limpp}$ & 8.95 & A \\
\hline
\end{tabular}

conditions. In order to determine the power output of the solar cell, it is important to determine the expected operating temperature of the PV module. The Nominal Operating Cell Temperature (NOCT) is defined as the temperature reached by open circuited cells in a module under the conditions as listed below:

Irradiance on cell surface $=800 \mathrm{~W} / \mathrm{m}^{2}$

Air Temperature $=20^{\circ} \mathrm{C}$

Mounting $=$ open back side.

It can therefore be concluded that cells with lower NOCT behave better than those with higher NOCT values. The NOCT equation, below, can be used to calculate the theoretical cell temperature at any irradiance level.

$$
T_{C E L L}=T_{A I R}+\frac{N O C T-20}{80} S
$$

\subsubsection{Calculations related to photovoltaic (PV) systems}

\subsubsection{Calculating the efficiency of PV panels}

The performance of a PV panel can be calculated from the technical characteristics given on the module data sheet. In actual fact, the performance of each module is mentioned on the module data sheet. It can also however be calculated using the equation below: 


\section{$k W h=k W h / m^{2} /$ day $\times$ efficiency $\times m^{2}$ \\ $k W h=\left(k W h / m^{2}\right) /$ day $\times$ panel power in $k W p$}

Figure 4.1 shown earlier illustrates a solar irradiation map from which the areas with high solar irradiation intensity can be clearly identified. Cyprus lies in an area with high irradiation levels. Photovoltaic systems in Cyprus can generate more than $1600 \mathrm{kWh} / \mathrm{kWp}$ per year. In Germany for example PV system generate around $1000 \mathrm{kWh} / \mathrm{kWp}$. It is very common and useful for PV systems to be compared based on $\mathrm{kWh} / \mathrm{kWp}$ indicator. This allows systems to be compared irrespective of location and nominal system power. It is a very power indicator as it can indicate whether a system performs adequately or not.

The daily radiation striking the plane of a PV array can be determined by employing appropriate software. This is perhaps one of the most decisive parameters for the viability of a PV system or for any feasibility study. A very user friendly and free software that can be employed is RETScreen (http://www. retscreen.net/ang/home.php).

It has been created by the Canada's natural resources agency and can be used with very good accuracy to determine the daily, monthly average or annual average radiation in the plane of a PV array. Figure 4-5 depicts a screenshot from RETScreen. It can be seen that for 25-degree slope PV array the monthly average daily radiation varies from month to month.

This is obviously because of the seasonality and the different sun angle position. The average of the 12 monthly averages can give a good indication of the expected yield from a PV system. System losses are of course not considered here. Typical system losses can be anywhere from 10 to $20 \%$ depending on the system equipment, shading, temperature etc. An indicator that gives information about the system performance is the performance ratio which is discussed later.

\subsubsection{Assessing the Performance of a PV System}

The performance of a PV system can be calculated using predicted and actual output data. This is more generally known as performance ratio. The predicted energy from a PV system can be determined if solar irradiation measurements are available for the system under examination together with details about the PV modules installed.

The required data for calculating the performance ratio are the following:

- Total area occupied by the PV modules

- Efficiency of PV modules

- Real output energy measurements (kWh) from inverter or from electricity meter (preferable the electricity meter)

- Daily average solar irradiation measured on site in $\mathrm{kWh} / \mathrm{m}^{2} /$ day 
Figure 4.5: screen shot from RETScreen software

\begin{tabular}{|c|c|c|c|c|c|}
\hline \multicolumn{3}{|c|}{ Site Latitude and PV Array Orientation } & Estimate & \multirow{2}{*}{\multicolumn{2}{|c|}{$\begin{array}{c}\text { Notes/Range } \\
\text { See Weather Database }\end{array}$}} \\
\hline \multirow{5}{*}{\multicolumn{2}{|c|}{$\begin{array}{l}\text { Nearest location for weather data } \\
\text { Latitude of project location } \\
\text { PV array tracking mode } \\
\text { Slope of PV array } \\
\text { Azimuth of PV array }\end{array}$}} & - & Cyprus & & \\
\hline & & ${ }^{\circ} \mathrm{N}$ & 34.0 & \multirow{4}{*}{\multicolumn{2}{|c|}{$\begin{array}{c}\text { See Weather Database } \\
-90.0 \text { to } 90.0 \\
0.0 \text { to } 90.0 \\
0.0 \text { to } 180.0\end{array}$}} \\
\hline & & - & Fixed & & \\
\hline & & $\circ$ & 25.0 & & \\
\hline & & $\circ$ & 0.0 & & \\
\hline \multicolumn{6}{|l|}{ Monthly Inputs } \\
\hline Month & $\begin{array}{c}\text { Fraction of } \\
\text { month } \\
\text { used } \\
(0-1)\end{array}$ & $\begin{array}{l}\text { Monthly average } \\
\text { daily radiation } \\
\text { on horizontal } \\
\text { surface } \\
\left(\mathrm{kWh} / \mathrm{m}^{2} / \mathrm{d}\right)\end{array}$ & $\begin{array}{l}\text { Monthly } \\
\text { average } \\
\text { temperature } \\
\left.\text { ( }{ }^{\circ} \mathrm{C}\right)\end{array}$ & $\begin{array}{l}\text { Monthly average } \\
\text { daily radiation } \\
\text { in plane of } \\
\mathrm{PV} \mathrm{array} \\
\left(\mathrm{kWh} / \mathrm{m}^{2} / \mathrm{d}\right)\end{array}$ & $\begin{array}{l}\text { Monthly } \\
\text { solar } \\
\text { fraction } \\
\text { (\%) }\end{array}$ \\
\hline January & 1.00 & 2.56 & 12.5 & 3.50 & - \\
\hline February & 1.00 & 3.58 & 12.0 & 4.52 & - \\
\hline March & 1.00 & 4.92 & 13.7 & 5.62 & - \\
\hline April & 1.00 & 5.25 & 16.5 & 5.41 & - \\
\hline May & 1.00 & 6.33 & 19.2 & 6.10 & - \\
\hline June & 1.00 & 7.53 & 22.5 & 6.99 & - \\
\hline July & 1.00 & 7.58 & 25.3 & 7.14 & - \\
\hline August & 1.00 & 7.06 & 26.3 & 7.11 & - \\
\hline September & 1.00 & 5.47 & 25.1 & 6.02 & - \\
\hline October & 1.00 & 4.39 & 22.2 & 5.45 & - \\
\hline November & 1.00 & 3.08 & 18.1 & 4.23 & - \\
\hline December & 1.00 & 2.67 & 14.0 & 3.90 & - \\
\hline & Annual & \multirow{4}{*}{\multicolumn{2}{|c|}{$\begin{array}{c}\text { Season of use } \\
1.84 \\
2.01 \\
19.0 \\
\end{array}$}} \\
\hline \multirow{3}{*}{\multicolumn{2}{|c|}{$\begin{array}{l}\text { Solar radiation (horizontal) } \\
\text { Solar radiation (tilted surface) } \\
\text { Average temperature }\end{array}$}} & $\mathrm{MWh} / \mathrm{m}^{2}$ & 1.84 & & \\
\hline & & $\mathrm{MWh} / \mathrm{m}^{2}$ & 2.01 & & \\
\hline & & ${ }^{\circ} \mathrm{C}$ & 19.0 & & \\
\hline \multicolumn{3}{|l|}{ Load Characteristics } & Estimate & \multirow{2}{*}{\multicolumn{2}{|c|}{ Notes/Range }} \\
\hline \multirow{2}{*}{\multicolumn{2}{|c|}{ Application type }} & - & On-grid & & \\
\hline & & & & \multicolumn{2}{|c|}{ Return to Energy Model sheet } \\
\hline
\end{tabular}

Table 4.1 illustrates an example of measurements carried out on a real PV system. The table shows the daily solar radiation measurements, the monthly average solar radiation (bottom of third column) and the total energy output in $\mathrm{kWh}$. The data in the table together with the predicted energy output from the system can be used to calculate the system performance ratio. The system performance ratio is very useful as it can be calculated every year indicating in this way how much degradation the PV modules have undergone.

This is because it can be assumed that all other equipment does not suffer degradation in performance such as the inverter or cables for example. The only component that suffers degradation are the PV modules. Therefore, if there is a decrease in the annual performance ratio of a PV system it will most probably be down to the PV modules. The percentage decrease in the PV module performance can be calculated therefore and compared against the manufacturer's performance warranty.

The performance ratio can be calculated using the equation below: 
Table 4.1: Example of on-site measurements for PV system performance ratio calculations

\section{Energy per inverter}

\begin{tabular}{|c|c|c|c|c|}
\hline \multirow[t]{3}{*}{ Date } & \multirow[t]{3}{*}{ System state } & \multirow{2}{*}{$\begin{array}{l}\text { Irradiation }\left[\mathbf{k W h} / \mathbf{m}^{2}\right] \\
\text { Sensor Card/Box (SC } 1)\end{array}$} & \multicolumn{2}{|l|}{ Energy $[\mathbf{k W h} / \mathbf{k W p}]$} \\
\hline & & & $\begin{array}{l}\text { Total system } \\
9945 \text { Wp }\end{array}$ & $\begin{array}{l}\text { Fronius IG Plus 120V-3 (INV 1) } \\
\qquad 9945 \text { Wp }\end{array}$ \\
\hline & & {$\left[\mathrm{kWh} / \mathrm{m}^{2}\right]$} & $\mathrm{kWh}$ & $\mathrm{kWh}$ \\
\hline 01.01 .2012 & OK & 2.3122 & 13.8726 & 13.8726 \\
\hline 02.01 .2012 & OK & 7.6120 & 35.6542 & 35.6542 \\
\hline 03.01 .2012 & OK & 8.7220 & 40.3615 & 40.3615 \\
\hline 04.01 .2012 & $\mathrm{OK}$ & 7.8220 & 36.7736 & 36.7736 \\
\hline 05.01 .2012 & OK & 6.5810 & 31.7134 & 31.7134 \\
\hline 06.01 .2012 & OK & 4.1892 & 3.7800 & 3.7800 \\
\hline 07.01 .2012 & OK & 1.1020 & 10.8942 & 10.8942 \\
\hline 08.01 .2012 & OK & 1.8760 & 18.1638 & 18.1638 \\
\hline 09.01 .2012 & OK & 4.2215 & 40.6472 & 40.6472 \\
\hline 10.01 .2012 & OK & 4.0652 & 38.7578 & 38.7578 \\
\hline 11.01 .2012 & OK & 2.5618 & 24.8126 & 24.8126 \\
\hline 12.01.2012 & OK & 2.5672 & 25.2722 & 25.2722 \\
\hline 13.01 .2012 & OK & 3.3665 & 32.9681 & 32.9681 \\
\hline 14.01 .2012 & OK & 3.7085 & 35.5411 & 35.5411 \\
\hline 15.01 .2012 & OK & 1.8805 & 18.7672 & 18.7672 \\
\hline 16.01 .2012 & $\mathrm{OK}$ & 3.2105 & 31.4902 & 31.4902 \\
\hline 17.01 .2012 & OK & 3.6472 & 36.0453 & 36.0453 \\
\hline 18.01 .2012 & OK & 4.5710 & 44.6075 & 44.6075 \\
\hline 19.01 .2012 & OK & 4.2640 & 42.2270 & 42.2270 \\
\hline 20.01 .2012 & OK & 4.5652 & 44.4297 & 44.4297 \\
\hline 21.01 .2012 & $\mathrm{OK}$ & 1.9072 & 18.8576 & 18.8576 \\
\hline 22.01 .2012 & OK & 1.5832 & 15.9368 & 15.9368 \\
\hline 23.01.2012 & OK & 3.7402 & 36.1235 & 36.1235 \\
\hline 24.01 .2012 & $\mathrm{OK}$ & 2.3470 & 23.2775 & 23.2775 \\
\hline 25.01 .2012 & OK & 1.8752 & 18.3067 & 18.3067 \\
\hline 26.01 .2012 & OK & 2.0155 & 19.8371 & 19.8371 \\
\hline 27.01 .2012 & OK & 3.5800 & 35.3200 & 35.3200 \\
\hline 28.01 .2012 & OK & 3.6600 & 35.1300 & 35.1300 \\
\hline 29.01 .2012 & OK & 1.6212 & 16.7934 & 16.7934 \\
\hline 30.01 .2012 & OK & 1.2225 & 12.4525 & 12.4525 \\
\hline 31.01 .2012 & OK & 2.1200 & 21.4700 & 21.4700 \\
\hline & & 3.5466 & 838.8143 & 838.8143 \\
\hline
\end{tabular}

Performance ratio $=($ real output energy generated $) /($ predicted energy output $)$

As mentioned earlier, the real output energy generated must be measured from the inverter monitoring system or the electricity meter. It is preferred if the 
energy is measured from the electricity meter as it this will also involve any losses on the cable from inverter to common point of coupling on the grid.

\section{Example of PR calculation}

Calculate the performance ratio of a system given the following characteristics:

- 51 modules 195Wp, 1474x995mm

- Real generated energy for January 838.8143kWh

- Daily average solar irradiation for January $3.5466 \mathrm{kWh} / \mathrm{m}^{2}$

- Module efficiency 14,5\%

The answer to the above question as follows:

PerformanceRatio $=\frac{838.8143}{(1.474 \times 0.995) \times 51 \times 0.145 \times 31 \times 3.5466}=\frac{838.8143}{1192.4293}=70.34 \%$

Where in the denominator,

$31=$ number of month days

$0.145=$ module efficiency

$51=$ number of modules

$3.5466=$ measured on-site daily average solar irradiation for month

$1.474 \times 0.995=$ module area

It is important to realize that the performance ratio should be calculated every month and at the end of the year the annual performance ratio is calculated which is basically the average of the 12 months. In this way, the PR can be compared for consecutive years in an attempt to determine the percentage of PV module degradation.

\subsubsection{Categories of photovoltaic (PV) systems}

Over the years, photovoltaics have been used in many different ways. The requirement was always the need for electrical energy. Before photovoltaics became widely and commercially available, they were of course used in space for generating electrical energy in conjunction with battery storage. Their application in calculators is also something previous generations might remember. Nowadays, they have become so widely available at a very competitive cost. This subunit examines the various types of PV systems and how these can be designed and implemented to meet specific requirements. 


\subsubsection{PV systems for residential applications}

\subsection{Net-metering grid-connected PV systems}

Countries have been adopting various policies and approaches for residential PV systems. Perhaps the most common and widespread approach is the netmetering system in which the generated power is credited towards the consumption of the residence. There are various billing mechanisms for the net-metering system. Every country or state adopts a billing mechanism based on technical, economic and political parameters. In Cyprus for example the current PV netmetering system is first of all restricted to a maximum of $10 \mathrm{kWp}$. The reason for this is rather complicated and relates to the specifics of the electricity grid. As far as the billing mechanism is concerned, the electricity meter used records separately the generated PV energy and the consumed energy. At the end of the billing period (can be 2 months or 1 month) the net energy in kWhs is calculated and the consumer is billed depending to the billing policy.

An example of a net-metering system installed in Cyprus can be seen Figure 4.6. This is $5.13 \mathrm{kWp}$ PV system installed on a residential roof top. The system has a private electricity meter through which the energy balance can be clearly examined and analysed. The reader is invited to click on the energy balance (Figure 4.6 below) tab and try to understand the concept of this net-metering system approach. The energy from grid, energy to grid and own consumption are clearly illustrated.

\section{Figure 4.6 Example of a 5.13 kWp PV net-metering system in Cyprus}

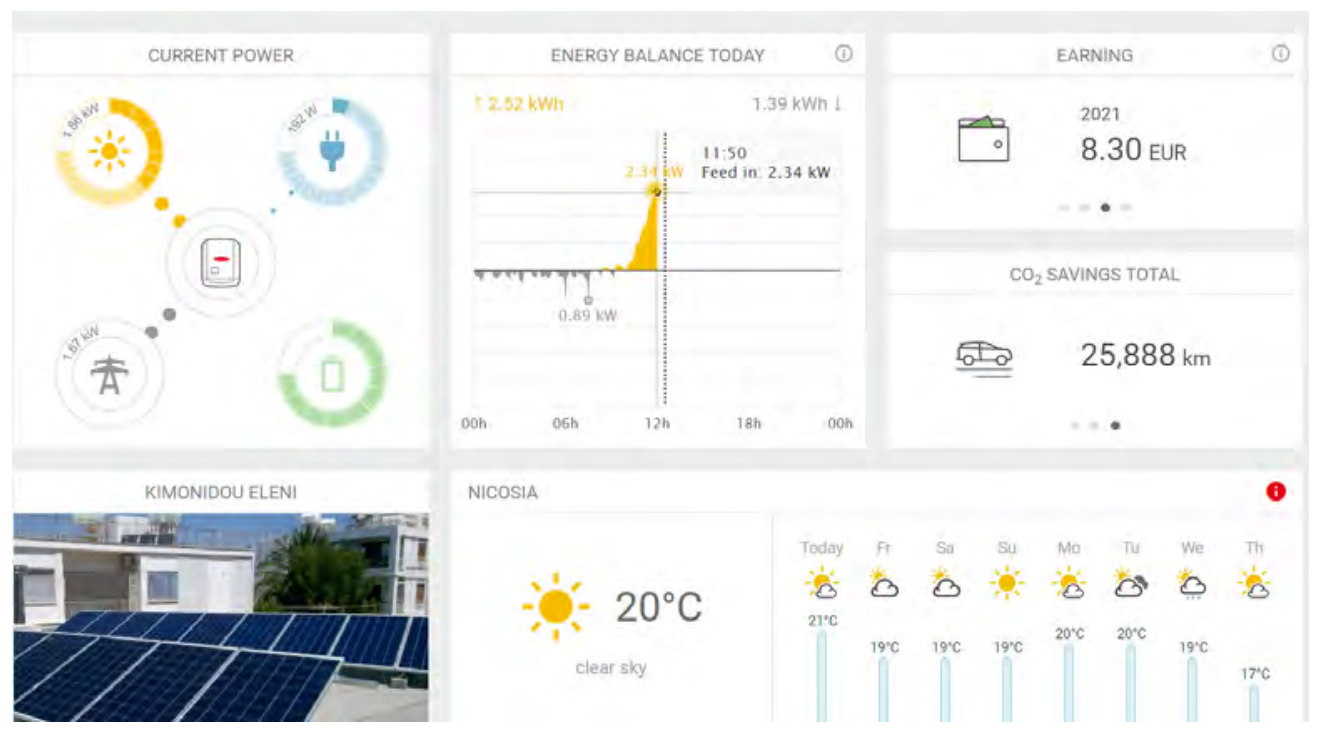




\subsection{Independent grid-connected PV systems}

Another approach for residential PV systems is the so-called independent PV system. This approach was adopted for many years in many countries around the world and many such systems are still in operation. This is based on a separate feed-in tariff policy which is made possible only through a separate utility electricity meter. The generated energy is fed to grid and recorded through a separate utility electricity meter. Prior to the connection to the grid, an agreement is signed between the system owner and the utility company specifying the feed-in tariff and the period of the agreement. The last time this system category was used in Cyprus provisioned a feed-in tariff of $€ 0.383 / \mathrm{kWh}$ for a period of 20 years. This meant that the PV system owner was compensated $€ 0.383$ for every kWh that was generated and fed to grid. There was another option when this scheme was in operation which gave the option for the system owner to obtain a $55 \%$ grant on the system cost with a feed-in tariff of $€ 0.225 / \mathrm{kWh}$. An example of such a system can be seenin Figure 4.8. This system was installed in January 2011 and the feedin tariff is $€ 0.383 / \mathrm{kWh}$. The historical data of the system can be examined through the archive tab and important conclusions can be made with regards the efficiency of the system, Figure 4.7. This system is also equipped with solar irradiance, ambient module temperature as well as wind sensors which can be monitored individually, Figure 4.8.

Figure 4.7: Residential PV system with separate electricity utility meter and feed-in tariff of $€ 0.383 / \mathrm{kWh}$

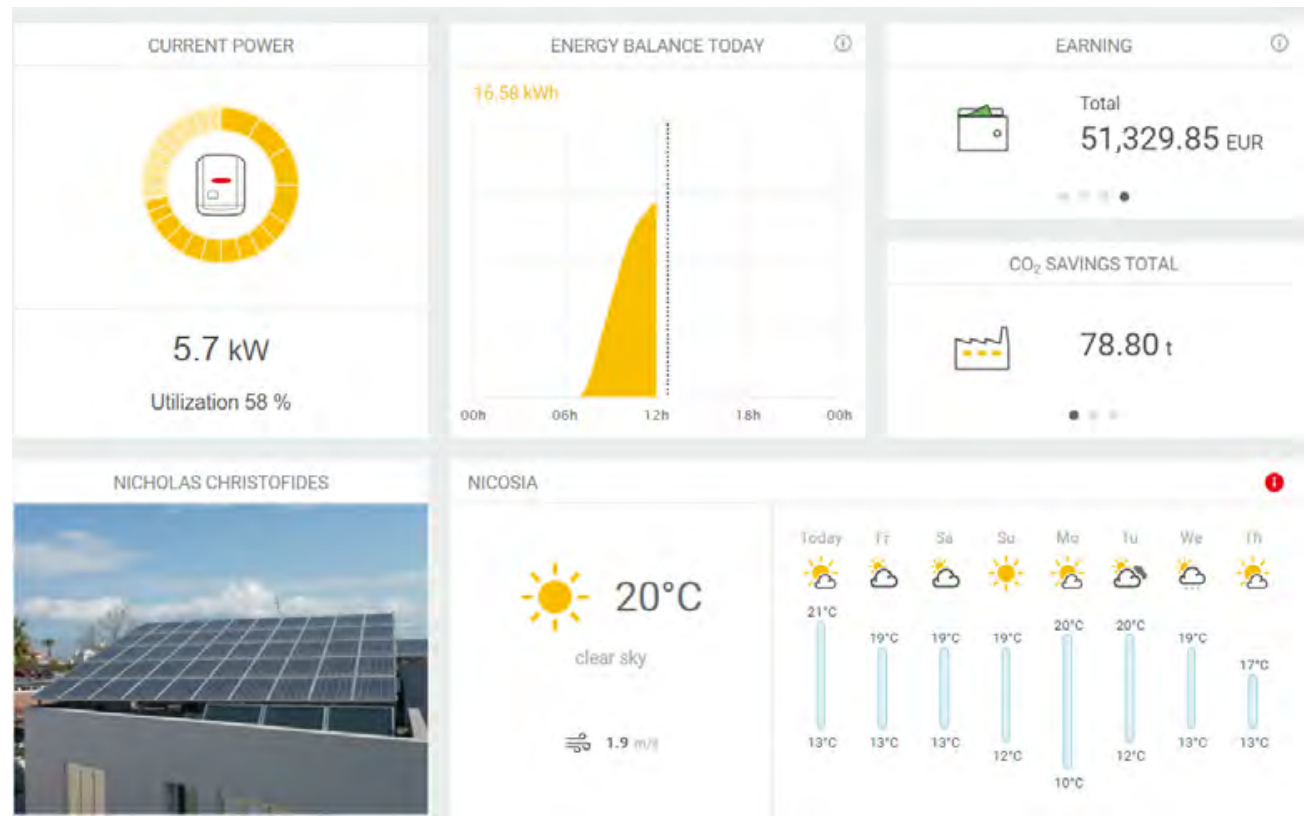


Figure 4.8: Monitoring solar irradiance, ambient/module temperature and wind using sensors at a PV residential installation

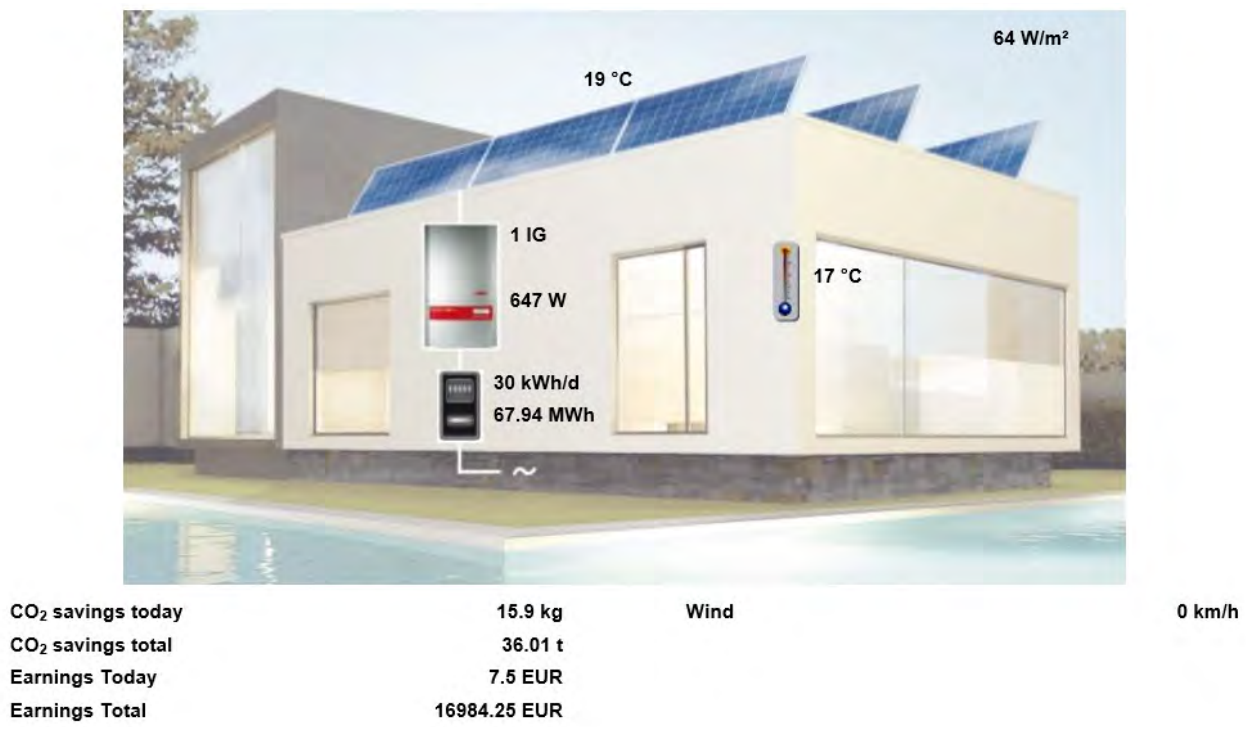

\subsection{Hybrid grid-connected PV systems}

Figure 4-9 below illustrates a hybrid PV system. This type of system can be described as a combination of grid-connected and off-grid connected system. The generated power from the photovoltaics can be directed towards the load, used to charge the battery system or fed to the grid. The inverter takes continuous decisions as to where to feed the PV generated power depending mainly on the size of the load and the state of the battery system. As an example, Figure 4.10 illustrates possible feed-in points of the generated PV power. If the load demand for example is less than the generated power the generated power will then be used to charge the battery system.

If the battery system is fully charged the generated power will be fed to the grid and depending on the billing policy the system owner can be reimbursed. As can be imagined, there can be various scenarios in the operation of a hybrid PV system depending on the state of the system components. The load may also be supplied from the utility in case there is not enough power from the PV or battery systems.

\subsection{Off-grid PV systems (stand-alone)}

Off-grid PV systems are used in remote areas where there is no electric utility. It can also be used by those who simply do not wish to be connected to the electric utility if of course this is permitted by the local regulations and legislation. The design of an off-grid connected system mainly depends on daily energy 
Figure 4.9: A hybrid PV system

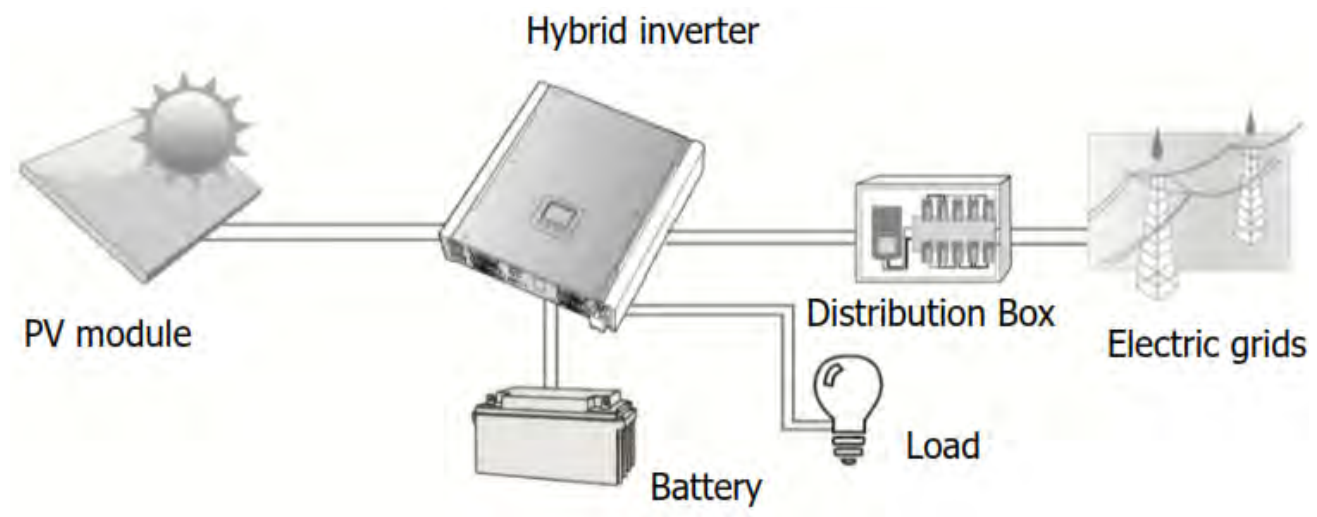

Figure 4.10 Possible feed-in points of generated PV power

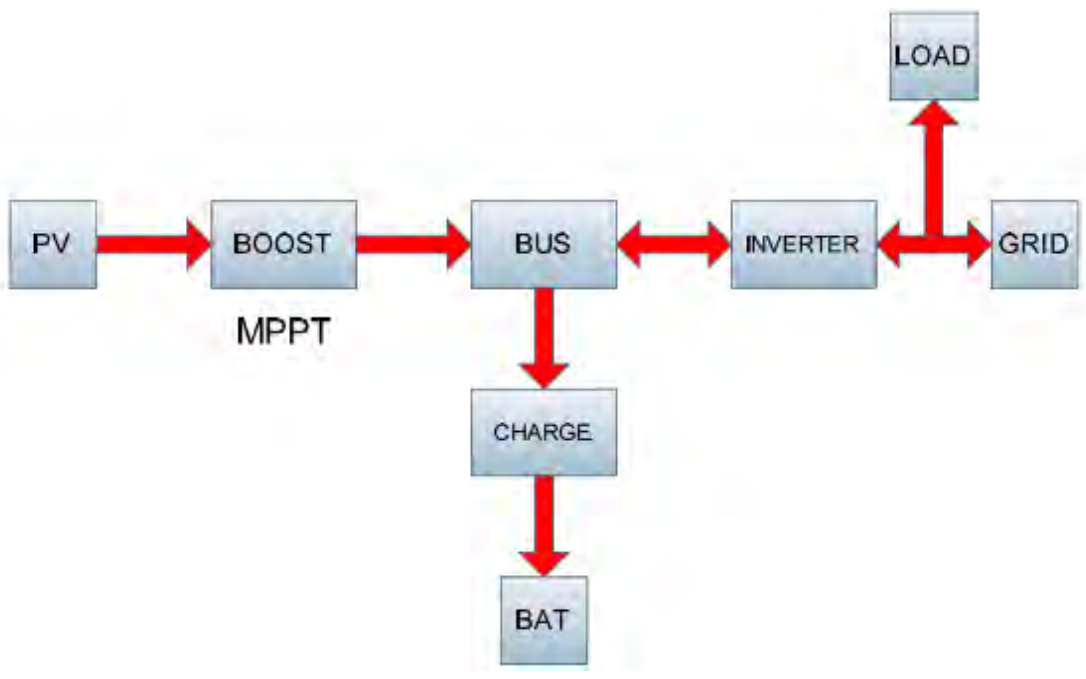

requirements and the autonomy required. The procedure for the design of an offgrid connected system involves various steps and it also depends on regional solar irradiance levels or more accurately, the monthly daily average solar radiation.

\subsection{CASE STUDY 1 - OFF-GRID PV SYSTEM DESIGN}

As an example, consider a boat with the following energy requirements (loads). Two days autonomy is required for this off-grid system and the loads are the following:

1. Lighting $-6 \times 40 \mathrm{~W}$ lamps, 2-3-hour daily operation 
2. Radio alarm clock, 5-6-hour daily operation

3. TV, 5-6-hour daily operation

Typical efficiency values of equipment used in off-grid systems are:

- Inverters - 90-95\%

- Batteries - discharge level 50-60\%, efficiency 90\%, Figure 4-11

- Charging regulator controller -95\%, Figure 4-12

Figure 4.11 OPzS type batteries used in PV off-grid systems

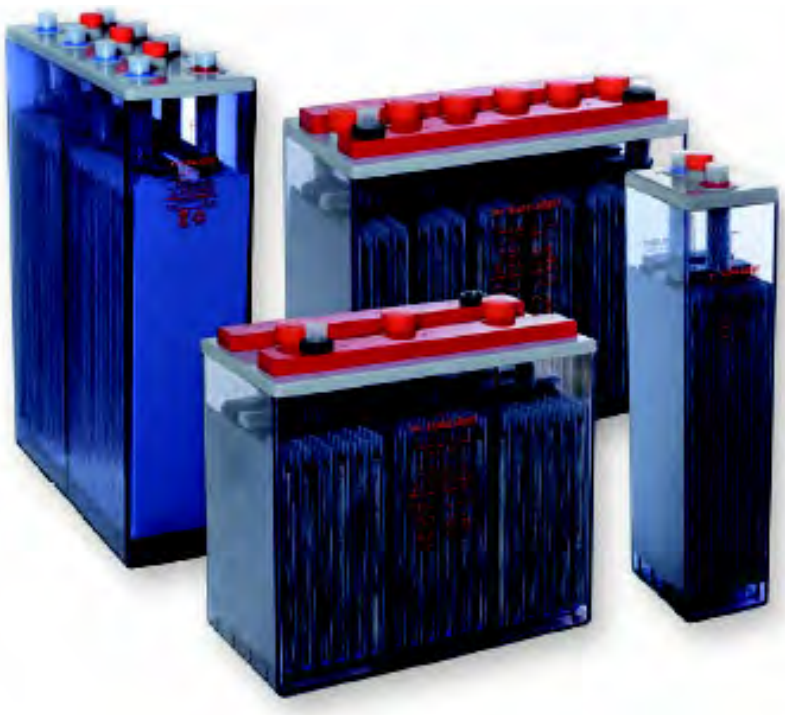

Figure 4.12 Examples of charge controllers/regulators

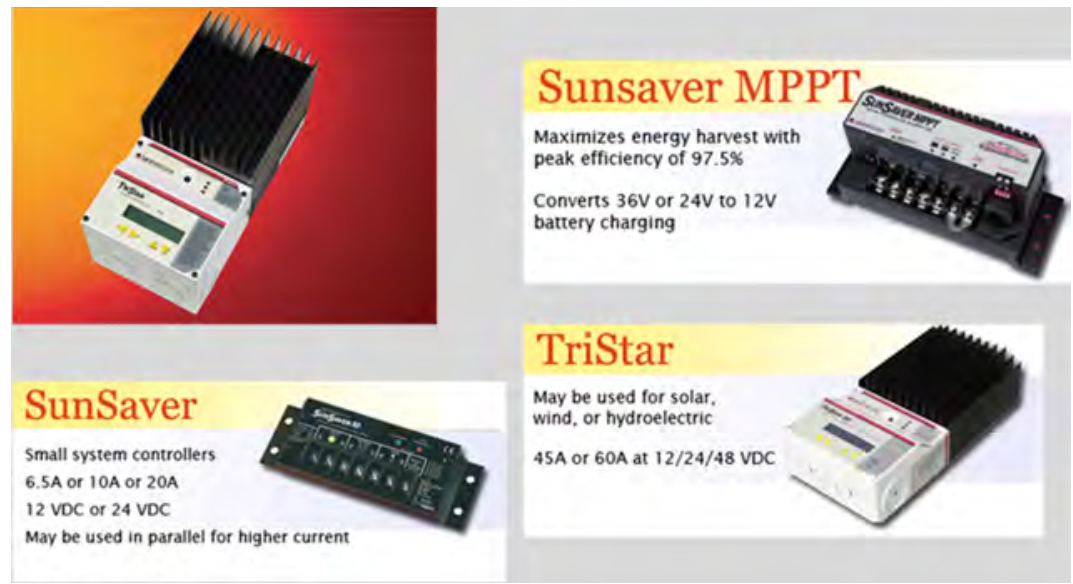


Figure 4.12 Examples of charge controllers/regulators

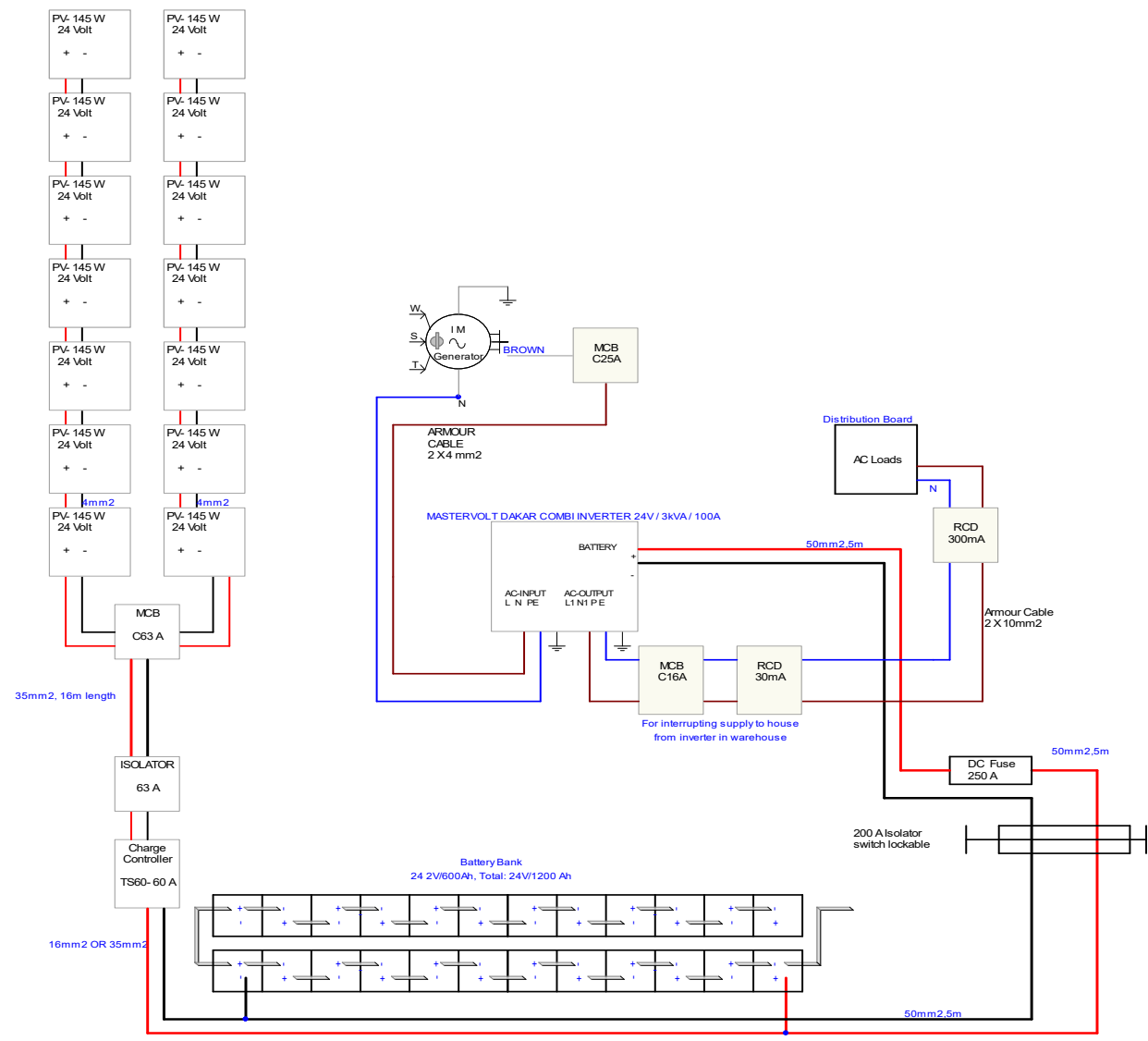

The step by step sizing procedure for the off-grid system described above is provided below:

\section{Determining daily energy needs in kWh}

The daily energy in kWh must first be determined as shown below. This is a simple calculation where the load power for each appliance is required together with the daily usage in hours. Before the design of the system, the information concerning the loads to be supplied by the off-grid PV system must be readily available so that the calculation below can be carried out.

$$
(6 \times 40 \times 3)+(6 \times 150)+(6 \times 20)=720+900+120=1.74 \mathrm{kWh}
$$




\section{Selecting the inverter for the system}

The inverter is the device that will invert/transform the dc voltage and current into ac voltage and current. Most household appliances operate with ac voltage and current and the inverter is in most cases an absolute necessity. In order begin selecting the inverter 2 important specifications must be known. The first is the battery system voltage and the second is the maximum power output of the inverter. The battery system voltage can sometimes depend on the inverter. This is because low power output inverters up to around $2 \mathrm{kVA}$ can be $12 \mathrm{~V}$ or $24 \mathrm{~V}$. Inverters in the range of $2 \mathrm{kVA}$ to 5 or $6 \mathrm{kVA}$ are usually $24 \mathrm{~V}$. Inverters over $6 \mathrm{kVA}$ can be $48 \mathrm{~V}$ or even $60 \mathrm{~V}$. For this reason, it might be better sometimes to determine the maximum load demand at any time so that the size of the inverter in $\mathrm{kVA}$ is firstly determined. The inverter selected will subsequently dictate the batter system voltage which in turn will allow decisions to be made about the PV modules and charge controller (see next steps).

The kVA rating of the inverter selected must take into consideration the power factor of the loads. For typical household applications the load power factor is usually around $0.85-0.9$. Loads are usually characterised by their wattage in Watts and their power factor. In the example studied the maximum demand is calculated by adding all the loads between them which comes out equal to $410 \mathrm{~W}$ (Watts). If we take into consideration a power factor of 0.85 , the kVA rating of the inverter should be around $410 / 0.85$ which is equal to approximately 500VA. An inverter in the range 0.5 to $1 \mathrm{kVA}$ should therefore be chosen for this system. Such an inverter is most probably $12 \mathrm{~V}$. It is not unlikely however to find inverters in this range at $24 \mathrm{~V}$. The design of the system presented in this case study is carried out considering a $24 \mathrm{~V}$ battery system voltage.

\section{Determining the battery system voltage and capacity in Ah:}

Since 2 days autonomy is required, this is accounted for by the following calculation:

$1.74 \times 2=3.5 \mathrm{kWh}-$ the battery system must therefore be able to provide $3.5 \mathrm{kWh}$ so that the 2 days autonomy satisfied.

Subsequently, the following calculation is carried out to account for the efficiency of the batteries. Common practise is to not allow a battery to discharge more than $50 \%$ of its capacity. In this way, the lifetime of the battery is prolonged as frequent in-depth discharges are avoided. The 0.5 factor is for the $50 \%$ depth of discharge consideration. The 0.9 factor accounts for the efficiency of the batteries.

$3.5 /(0.5 \times 0.9)=7.78 \mathrm{kWh}$

Considering the efficiency of the inverter (0.9 factor):

$7.78 / 0.9=8.64 \mathrm{kWh}$

The battery capacity is therefore calculated (for a $24 \mathrm{~V}$ system) as follows:

$8.64 / 24 \mathrm{~V}=360 \mathrm{Ah}\left(\mathrm{C}_{48}\right)$ - diving by $\mathrm{kWh}$ by the system voltage will give the battery capacity in Ah. 
The main specifications of a battery are the voltage and its capacity in Ah. The latter is fundamentally the current a battery can provide multiplied by the time. If Ah is multiplied by the voltage, one can determine the energy in Wh that the battery can supply. Batteries are also characterised by their constant current discharge " $\mathrm{C}$ " rating. This is a rating given in hours and gives information about how much current can be drawn from the battery for a given time. $\mathrm{C}_{10}$ and $\mathrm{C}_{20}$ are two most common ratings provided by manufacturers. The more current drawn from the battery the less energy in Ah and consequently Wh the battery can provide. This can be clearly demonstrated by Table $4-2$ below. It can be seen for example that at 1.65 volts and at $\mathrm{C}_{10}$, the battery can provide $706 \mathrm{Ah}(10 \mathrm{~h} \times 70.6 \mathrm{~A})$. On the other hand, again at 1.65 volts but at $\mathrm{C}_{20}$, the battery can provide $764 \mathrm{Ah}$ (20h x 38.2). As mentioned earlier, a battery can provide more energy if small levels of current are drawn (the lower current drawn the more hours the battery can provide). In the example above, the battery capacity found by calculation is $360 \mathrm{Ah}$ and this should be over the 2 days, hence the $\mathrm{C}_{48}$ for 48 hours. If detailed manufacturer information about the batteries is available in conjunction with knowledge about the load current, the battery selection can consider all the above considerations.

Batteries are very sensitive and in order to prolong their lifetime, the manufacturer's specifications should be followed with great care. The way batteries are charged is extremely important. Manufacturers explicitly state with much current a battery should be charged and for how long depending on the battery level of discharge. A common problem with off-grid photovoltaic systems is that they cannot provide the required charging current both in terms of magnitude and duration. Depending on the criticality of the system it should therefore be carefully designed and assisted with a generator for example if necessary.

\section{Table 4.2: Examples of battery discharge times}

\begin{tabular}{|c|c|c|c|c|c|c|c|c|c|c|c|c|c|}
\hline \multirow[b]{2}{*}{ Uend } & \multicolumn{13}{|c|}{ Discharge Time } \\
\hline & $15 \mathrm{~min}$ & $30 \mathrm{~min}$ & $45 \mathrm{~min}$ & $1 \mathrm{~h}$ & $1.5 \mathrm{~h}$ & $2 \mathrm{~h}$ & $3 \mathrm{~h}$ & $4 \mathrm{~h}$ & $5 \mathrm{~h}$ & $6 \mathrm{~h}$ & $8 \mathrm{~h}$ & $10 \mathrm{~h}$ & $20 \mathrm{~h}$ \\
\hline $1.60 \mathrm{~V}$ & 626.4 & 496.9 & 406.7 & 352.8 & 278.1 & 229.5 & 174.6 & 143.0 & 119.5 & 104.9 & 83.2 & 71.2 & 38.4 \\
\hline $1.65 \mathrm{~V}$ & 570.4 & 466.1 & 389.0 & 342.2 & 272.3 & 225.5 & 172.2 & 141.3 & 118.0 & 103.8 & 82.3 & 70.6 & 38.2 \\
\hline $1.70 \mathrm{~V}$ & 509.1 & 425.8 & 363.7 & 325.2 & 263.1 & 219.5 & 168.7 & 138.9 & 116.2 & 102.3 & 81.2 & 69.7 & 37.8 \\
\hline $1.75 \mathrm{~V}$ & 442.3 & 380.7 & 332.4 & 301.9 & 248.1 & 210.4 & 163.7 & 135.8 & 113.3 & 99.3 & 78.4 & 67.4 & 37.2 \\
\hline $1.80 \mathrm{~V}$ & 366.1 & 320.5 & 285.2 & 262.5 & 224.1 & 193.4 & 154.5 & 128.8 & 109.1 & 96.7 & 77.5 & 65.6 & 36.6 \\
\hline $1.83 \mathrm{~V}$ & 316.6 & 282.0 & 254.6 & 236.7 & 205.2 & 179.3 & 144.5 & 121.7 & 104.1 & 92.9 & 75.1 & 63.3 & 35.4 \\
\hline $1.85 \mathrm{~V}$ & 286.5 & 256.2 & 234.2 & 219.7 & 190.4 & 166.5 & 135.6 & 116.6 & 99.9 & 89.5 & 72.4 & 61.4 & 34.3 \\
\hline $1.87 \mathrm{~V}$ & 253.7 & 231.2 & 211.8 & 199.0 & 174.5 & 155.4 & 127.5 & 109.5 & 95.1 & 84.4 & 68.1 & 58.3 & 33.0 \\
\hline $1.90 \mathrm{~V}$ & 211.0 & 190.2 & 177.0 & 168.1 & 149.7 & 134.5 & 111.6 & 97.0 & 84.6 & 75.7 & 61.9 & 53.5 & 30.1 \\
\hline
\end{tabular}

\section{PV power sizing}

Having determined the installation conditions and subsequently the monthly daily average solar radiation for the particular area, the PV power can be calculated. For this study case, the monthly daily average solar radiation 
considered is $4.1 \mathrm{kWh} / \mathrm{m}^{2} /$ day. The size of the $\mathrm{PV}$ system can therefore be calculated as follows:

Efficiency of charging regulator controller $95 \%$ (0.95 factor below)

$(3.5 \mathrm{kWh} / 0.95) /(4.1)=0.9 \mathrm{kWp} \sim 1 \mathrm{kWp}-$ the monthly daily average solar radiation is used to determine the nominal power of the photovoltaics by diving the required $\mathrm{kWh}$ by the daily average solar radiation

It is now evident that the power of the photovoltaics should be around $1 \mathrm{kWp}$. Depending now on module availability and on the choice of the charge controller, the designer must decide on the number of modules and on the power of each module. It can for example be 460 cell modules of nominal power $250 \mathrm{Wp}$ each or 636 cell modules of nominal power $175 \mathrm{Wp}$ each (the latter will give a total nominal power greater than $1 \mathrm{kWp}$ ).

\section{Selection of charge controller/regulator}

The PV or solar charge regulator is a controller for charging the battery system from the PV. The two types of charge controllers most commonly used in today's solar power systems are pulse width modulation (PWM) and maximum power point tracking (MPPT). Both adjust charging rates depending on the battery's charge level to allow charging closer to the battery's maximum capacity as well as monitor battery temperature to prevent overheating.

If maximizing charging capacity were the only factor considered when specifying a solar controller, everyone would use a MPPT controller. But the two technologies are different, each with its own advantages. The decision depends on site conditions, system components, size of array and load, and finally the cost for a particular solar power system.

An MPPT controller is better suited for colder conditions. As solar module operating temperature goes down, the $\mathrm{Vmp}^{1}$ increases. That's because the voltage of the solar panels operating at their peak power point at Standard Testing Conditions ( $\mathrm{STC}$ is $25 \mathrm{C}^{\circ}$ ) is about $17 \mathrm{~V}$ while the battery voltage is about $13.5 \mathrm{~V}$. The MPPT controller is able to capture the excess module voltage to charge the batteries. As a result, a MPPT controller in cool conditions can produce up to 20 - 25\% more charging than a PWM controller.

In comparison, a PWM controller is unable to capture excess voltage because the pulse width modulation technology charges at the same voltage as the battery. However, when solar panels are deployed in warm or hot climates, their $\mathrm{V}_{\text {mpp }}$ decreases, and the peak power point operates at a voltage that is closer to the voltage of a $12 \mathrm{~V}$ battery. There is no excess voltage to be transferred to the battery making the MPPT controller unnecessary and negating the advantage of an MPPT over a PWM.

The operating voltage (for the system in this case study) is $24 \mathrm{~V}$ and the charge controller if it is PWM type should also be suitable for charging a $24 \mathrm{~V}$ battery system. This is a disadvantage of PWM controllers since all components of the system must be rated at 24V (PV modules, batteries and charge controller). MPPT 
controllers on the other hand can regulate the voltage of the PV modules according to the battery system voltage. It therefore gives more flexibility to combine components that do not have the same nominal voltage. If the charging regulator controller is the MPPT type, there is software available by the manufacturers for PV string sizing and controller selection. Some well-known charging regulator manufacturers are

MorningStar (http://www.morningstarcorp.com/),

Outback (http://www.outbackpower.com/outback-products/inverters-chargers) and Victron Energy (http://www.victronenergy.com/)

In a scenario where the solar array is large relative to the power draw from the batteries by the load, the batteries will stay close to a full state of charge. A PWM controller is capable of efficiently maintaining the system without the added expense of an MPPT controller.

Low power systems are better suited to a PWM controller because:

- A PWM controller operates at a relatively constant harvesting efficiency regardless of the size of the array

- A PWM controller is less expensive that a MPPT, so is a more economical choice for a small system

- A MPPT controller is much less efficient in low power applications. Systems $170 \mathrm{~W}$ or higher tickle the MPPT's sweet spot

Stand-alone off-grid solar modules are typically 36-cell modules and are compatible with both PWM and MPPT technologies. Some grid-tie solar modules on the market today are not the traditional 36-cells modules that are used for off-grid power systems. For example, the voltage from a 60 -cell $250 \mathrm{~W}$ panel is too high for 12 -Volt battery charging, and too low for 24-Volt battery charging. MPPT technology tracks the maximum power point (thus MPPT) of these less expensive grid-tie modules in order to charge the batteries, whereas PWM does not.

MPPT controllers are typically more expensive than PWM's but are more efficient under certain conditions, so they can produce more power with the same number of solar modules than a PWM controller. One must then analyse the site to verify that the MPPT can indeed perform more efficiently when used in that system's given set of conditions.

When specifying one technology over the other, the cost of the controller becomes less important than the total cost of the system. To specify a controller technology simply based of cost, be sure to perform a close analysis of realized efficiencies, system operation, load and site conditions.

The above study case was for a small off-grid system. The reader may contact the module writer in case further assistance or information is needed.

http://www.victronenergy.com/blog/2014/07/21/which-solar-charge-controllerpwm-or-mppt/

http://solarcraft.net/articles/comparing-pwm-and-mppt-charge-controllers/ 


\subsection{CASE STUDY 2 - OFF-GRID PV SYSTEM DESIGN \\ (to be solved by the student)}

A feasibility study for a stand-alone PV system is to be examined in order to decide whether investing in the stand-alone PV system is a viable solution. Given the information below, suggest whether it is advisable to invest in such a system. Justify your answer. You may make any other assumptions you judge is necessary for the study.

i. Current/Alternative electricity supply: Generator with consumption rate $0.315 \mathrm{Lt} / \mathrm{kWh}$

ii. Cost of Diesel: $€ 1.43 / \mathrm{Lt}$

iii. Loads and consumption as given in Table 4-3 below

Table 4.3: Load consumption data

\begin{tabular}{|l|c|c|c|}
\hline \multicolumn{1}{|c|}{ LOAD } & WATTAGE & NUMBER OF UNITS & HOURS PER DAY \\
\hline Fridge & 200 & 1 & 10 \\
Television & 220 & 2 & 8 \\
lights (LED) & 5 & 30 & 10 \\
water pump & $1 \mathrm{HP}$ & 2 & 0.75 \\
air condition & 1000 & 2 & 6 \\
\hline Pc & 200 & 2 & 10 \\
water heater & 3000 & 1 & 1.5 \\
\hline
\end{tabular}

iv. Type of modules: LX_-250P

v. Cost of Photovoltaics per Wp: €0.75 / Wp

vi. Monthly average daily radiation: $4.8 \mathrm{kWh} / \mathrm{m}^{2} /$ day

vii. Battery Autonomy: 2 days

viii. Battery System Voltage: $24 \mathrm{~V}$

ix. Battery cost: €3.5 / Ah @ 24V

$\mathrm{x}$. Other system components cost (inverter, solar charging controller, installation cost, cabling, protective devices etc.): $€ 800.00 / \mathrm{kWp}$

\section{N.B. $1 \mathrm{HP}=746 \mathrm{~W}$}

4.1.5.4 Self-consumption PV systems - Grid-connected PV systems for energy saving by commercial consumers

As already explained, self-consumption PV systems aim towards saving on the electricity bill. This is achieved by self-consuming the energy generated by the system and drawing less energy from the grid. A very careful system design must initially take place by the engineer in order to determine the size of the system in $\mathrm{kWp}$ and the payback period of the investment. In order for this to take place the 
engineer must have the following information available (if they are not available he must request them):

1. Past electricity bills (for at least 2 years)

2. Consumption/load measurements per 10- or 20-minute intervals

3. PV power profile for $1 \mathrm{kWp}$ for the location under study per 10 - or 20 -minute intervals (convenient if the interval is the same with the interval of the consumption/load data

4. Software tools such as excel

5. indicative cost of PV system depending on the country/region

Having obtained the information listed above, the first step would then be to run various scenarios (for various PV system sizes) where the energy generated by the prospective PV system is compared against the consumed load data. The objective of this analysis is to determine how much can be saved with the PV system. It must be made clear that the size of the PV system is the crucial parameter here.

If a PV system is proposed that is bigger than the ideal, one should expect that the payback period of the investment will be delayed. It depends of course on the scheme adopted by the authorities in the region. In Cyprus for example, it is not beneficial to generate more than you consume in any 20 min interval since that energy will be reimbursed at a tariff much lower than actual selling tariff of each energy unit (kWh). As a result, it is important to calculate the system size by considering carefully the actual consumption for every 20 min period (as is the case in Cyprus). This is an optimization problem where the optimum PV system size must be determined and which will provide the greatest savings and the lowest payback period. The problem can be solved by trial and error or a sophisticated algorithm can be written to solve the problem.

Experienced engineers can propose a PV system size just by looking at the load data of the consumer. Inexperienced engineers however will require a more analytical approach.

Table 4.3 below illustrates an example of 20 -minute interval load data obtained after request to the electricity authority. The measurements include the kW and maximum load demand kVA. From the $\mathrm{kW}$ readings the $\mathrm{kWh}$ can be calculated by dividing each interval by 3 . This can be very useful when it is necessary to compare the load $\mathrm{kWh}$ with the $\mathrm{kWh}$ generated by the PV system in order to estimate to the excess energy that will occur in every interval.

Table 4.3: Example of 20 min interval load data

\begin{tabular}{|c|c|c|c|}
\hline Time & {$[\mathrm{tm}=20 \mathrm{~min}]$} & $\mathrm{kW}$ & $\mathrm{kVA}$ \\
\hline $03 / 11 / 2013$ & $00: 20: 00$ & 44.4 & 45.6 \\
\hline $03 / 11 / 2013$ & $00: 40: 00$ & 44.8 & 46.1 \\
\hline $03 / 11 / 2013$ & $01: 00: 00$ & 44.4 & 45.5 \\
\hline
\end{tabular}




\begin{tabular}{|c|c|c|c|}
\hline $03 / 11 / 2013$ & $01: 20: 00$ & 45.9 & 46.7 \\
\hline $03 / 11 / 2013$ & $01: 40: 00$ & 40.5 & 41.5 \\
\hline $03 / 11 / 2013$ & $02: 00: 00$ & 40.2 & 40.9 \\
\hline $03 / 11 / 2013$ & $02: 20: 00$ & 43.3 & 43.7 \\
\hline $03 / 11 / 2013$ & $02: 40: 00$ & 41.2 & 41.9 \\
\hline $03 / 11 / 2013$ & $03: 00: 00$ & 43.8 & 44.2 \\
\hline $03 / 11 / 2013$ & $03: 20: 00$ & 46.1 & 47.1 \\
\hline $03 / 11 / 2013$ & $03: 40: 00$ & 47.9 & 48.6 \\
\hline $03 / 11 / 2013$ & $04: 00: 00$ & 43.8 & 44.3 \\
\hline $03 / 11 / 2013$ & $04: 20: 00$ & 43.6 & 44 \\
\hline $03 / 11 / 2013$ & $04: 40: 00$ & 43.9 & 44.5 \\
\hline $03 / 11 / 2013$ & $05: 00: 00$ & 44 & 44.7 \\
\hline $03 / 11 / 2013$ & $05: 20: 00$ & 43.2 & 43.5 \\
\hline $03 / 11 / 2013$ & $05: 40: 00$ & 42.3 & 42.7 \\
\hline $03 / 11 / 2013$ & $06: 00: 00$ & 42.1 & 42.6 \\
\hline $03 / 11 / 2013$ & $06: 20: 00$ & 40.9 & 41.6 \\
\hline $03 / 11 / 2013$ & $06: 40: 00$ & 40 & 40.6 \\
\hline $03 / 11 / 2013$ & $07: 00: 00$ & 40.7 & 41.4 \\
\hline
\end{tabular}

Table 4.4 demonstrates an example of the analysis that can take place in excel in order to determine the optimum PV system size. The objective of the analysis is to compare the load data with the PV generated energy (in kWh) at every 20-minute interval as mentioned earlier. In addition to the $\mathrm{kWh}$ comparison, the max demand can also be compared in to determine how much can be saved from the maximum demand (in kVA) as well (if there are additional charges for maximum demand consumed for example - again it depends on the local distributor).

The analysis will subsequently allow the savings in kWh and kVA to be calculated and the total savings to be determined. This, together with information about the cost of the proposed system, will allow the payback period to be estimated. The proposal can then be presented to the prospective client/investor.

Once the PV system size has been determined (following the economic feasibility study as explained above) and after an agreement has been made, the electrical engineer will take over in order to design the system with more technical details that will lead to more precise cost estimation. It is important to note that in order to come up with the cost of the system the equipment for the PV system must be pre-decided. 
Table 4.4: Example of load data and PV generation data for determining the optimum PV system size

\begin{tabular}{|c|c|c|c|c|c|c|c|c|c|c|}
\hline \multirow[b]{3}{*}{ Date } & \multirow[b]{3}{*}{ StartTime } & \multirow[b]{3}{*}{ 7: Total Kw } & \multirow[b]{3}{*}{ CONSUMPTION (KWH) } & \multicolumn{4}{|c|}{ PROPOSED PV SYSTEM SIZE (KWP): $\quad 100.00$} & \multicolumn{3}{|c|}{ YIELD LOSS PERCENTAGE: $8.51 \%$} \\
\hline & & & & KW/KWP & KWP & KWH & KW & KWH & KWH & KWH \\
\hline & & & & PV OUTPUT & T PV OUTPUT & T PV YIELD & POWER DIFFERENCE & USEFUL PV YIELD & NET CONSUMPTION & WASTED PV YIELD \\
\hline $01 / 02 / 2014$ & 10:00:00 & 57.6 & $\quad 19.20$ & 0.58675 & 58.675 & $5 \quad 19.56$ & -1.075 & 19.20 & 0.00 & 0.36 \\
\hline $01 / 02 / 2014$ & 10:20:00 & 70.3 & 23.43 & 0.64094 & 64.094 & 21.36 & 6.206 & 21.36 & 2.07 & 0.00 \\
\hline $01 / 02 / 2014$ & 10:40:00 & 70.2 & 23.40 & 0.68333 & 68.333 & 22.78 & 1.867 & 22.78 & 0.62 & 0.00 \\
\hline $01 / 02 / 2014$ & 11:00:00 & 57.4 & 19.13 & 0.71549 & 71.549 & 23.85 & -14.149 & 19.13 & 0.00 & 4.72 \\
\hline $01 / 02 / 2014$ & $11: 20: 00$ & 71.4 & 23.80 & 0.74048 & 74.048 & 24.68 & -2.648 & 23.80 & 0.00 & 0.88 \\
\hline $01 / 02 / 2014$ & 11:40:00 & 70 & 23.33 & 0.75809 & 75.809 & 25.27 & -5.809 & 23.33 & 0.00 & 1.94 \\
\hline $01 / 02 / 2014$ & 12:00:00 & 63.3 & 21.10 & 0.78443 & 78.443 & 26.15 & -15.143 & 21.10 & 0.00 & 5.05 \\
\hline $01 / 02 / 2014$ & 12:20:00 & 69.8 & 23.27 & 0.79757 & 79.757 & 26.59 & -9.957 & 23.27 & 0.00 & 3.32 \\
\hline $01 / 02 / 2014$ & $12: 40: 00$ & 55.8 & 18.60 & 0.79539 & 79.539 & 26.51 & -23.739 & 18.60 & 0.00 & 7.91 \\
\hline $01 / 02 / 2014$ & 13:00:00 & 55 & 18.33 & 0.81051 & 81.051 & 27.02 & -26.051 & 18.33 & 0.00 & 8.68 \\
\hline $01 / 02 / 2014$ & 13:20:00 & 45.9 & 15.30 & 0.62358 & 62.358 & 20.79 & -16.458 & 15.30 & 0.00 & 5.49 \\
\hline $01 / 02 / 2014$ & 13:40:00 & 67.6 & 22.53 & 0.81908 & 81.908 & 27.30 & -14.308 & 22.53 & 0.00 & 4.77 \\
\hline $01 / 02 / 2014$ & 14:00:00 & 68.3 & 22.77 & 0.81513 & 81.513 & 27.17 & -13.213 & 22.77 & 0.00 & 4.40 \\
\hline $01 / 02 / 2014$ & 14:20:00 & 68.4 & 22.80 & 0.76193 & 76.193 & 25.40 & -7.793 & 22.80 & 0.00 & 2.60 \\
\hline $01 / 02 / 2014$ & 14:40:00 & 66.8 & 22.27 & 0.75825 & 75.825 & 25.28 & -9.025 & 22.27 & 0.00 & 3.01 \\
\hline $01 / 02 / 2014$ & 15:00:00 & 52 & 17.33 & 0.75554 & 75.554 & 25.18 & -23.554 & 17.33 & 0.00 & 7.85 \\
\hline $01 / 02 / 2014$ & $15: 20: 00$ & 67.7 & 22.57 & 0.55012 & 55.012 & 18.34 & 12.688 & 18.34 & 4.23 & 0.00 \\
\hline $01 / 02 / 2014$ & 15:40:00 & 68.3 & 22.77 & 0.61642 & 61.642 & 20.55 & 6.658 & 20.55 & 2.22 & 0.00 \\
\hline $01 / 02 / 2014$ & 16:00:00 & 77.3 & 25.77 & 0.60374 & 60.374 & 20.12 & 16.926 & 20.12 & 5.64 & 0.00 \\
\hline $01 / 02 / 2014$ & 16:20:00 & 43.2 & 14.40 & 0.47407 & 47.407 & 15.80 & -4.207 & 14.40 & 0.00 & 1.40 \\
\hline $01 / 02 / 2014$ & $16: 40: 00$ & 40 & 13.33 & 0.49261 & 49.261 & 16.42 & -9.261 & 13.33 & 0.00 & 3.09 \\
\hline
\end{tabular}

\subsection{CASE STUDY 3 - LARGE-SCALE SELF-CONSUMPTION PV SYSTEM}

The way currently large-scale self-production PV systems are logistically operated was explained earlier in the section. The objective of these systems is to save on the electricity bill of the business/commercial consumer. As a result, the generated energy from the PV system must be connected at the consumption path. In this way, the generated energy will be directly consumed. If the generated energy does not suffice, energy will also be drawn from the grid in order to satisfy the load requirements. In the event where the generated energy from the PV system is more than the energy required by the loads, the excess energy will be fed to grid.

Figure 4-15 illustrates part of the single-line electrical diagram of a selfproduction PV system. The connection arrangement of the main automatic disconnection device (labelled NEW PV AUTOMATIC DISCONNECTION MCCB, $\mathrm{C} 160 \mathrm{~A} 4 \mathrm{P}, 300 \mathrm{~mA}$ ) in the diagram can be seen. It is connected at the output of the main disconnection switch and the generated energy can therefore be directly supplied to the load or fed to the grid. Figure 4-16 illustrates the remaining singleline diagram of the PV system. The connection arrangement of the photovoltaics and the inverters depends explicitly on the inverter manufacturer and on the PV modules. There are various sizing tools available by inverter manufacturers that assist in the PV module-inverter sizing procedure. The reader is advised to use such software tools available by the manufacturers; a couple are listed below and can be downloaded:

1. http://www.fronius.com/cps/rde/xbcr/SID-D448382B-B05EEF69/fronius international/SE_SW_Fronius_Solar.configurator_MULTI_85521_snapshot. zip

2. http://www.sma-america.com/products/planning-software/sunny-design. html\#Downloads-136640 
Figure 4-14 below illustrates one such tool provided by Fronius $\mathrm{GmbH}$ depicting a configuration of 4 strings and 20 modules per string for each Symo inverter. In the particular system there are 5 such inverters and therefore 400 modules, 80 modules per inverter.

The inverter-PV modules sizing procedure is the job of the electrical engineer. In depth knowledge of electrical engineering is required which is beyond the scope of this course however, the student may contact the author if further information and guidance is required on the matter.

The diagrams in Figure 4.17 and Figure 4.18 illustrate the plan view of the PV modules installation. It can be noticed that very carefully planning is required for installation of PV modules on a roof. The most important parameter to note is that shading between adjacent rows of photovoltaics or any other permanently fixed equipment, constructions etc. must be avoided at least during the hours of highest production which are approximately between $10 \mathrm{am}$ and $3 \mathrm{pm}$. On inclined roofs such as the ones shown in Figure 4.18 and Figure 4.19 a), shading between adjacent PV rows cannot occur as the roof is tilted. There can be a problem however if there are extraneous constructions causing shading such as chimneys for example. 
Figure 4.14: The Fronius solar configurator tool

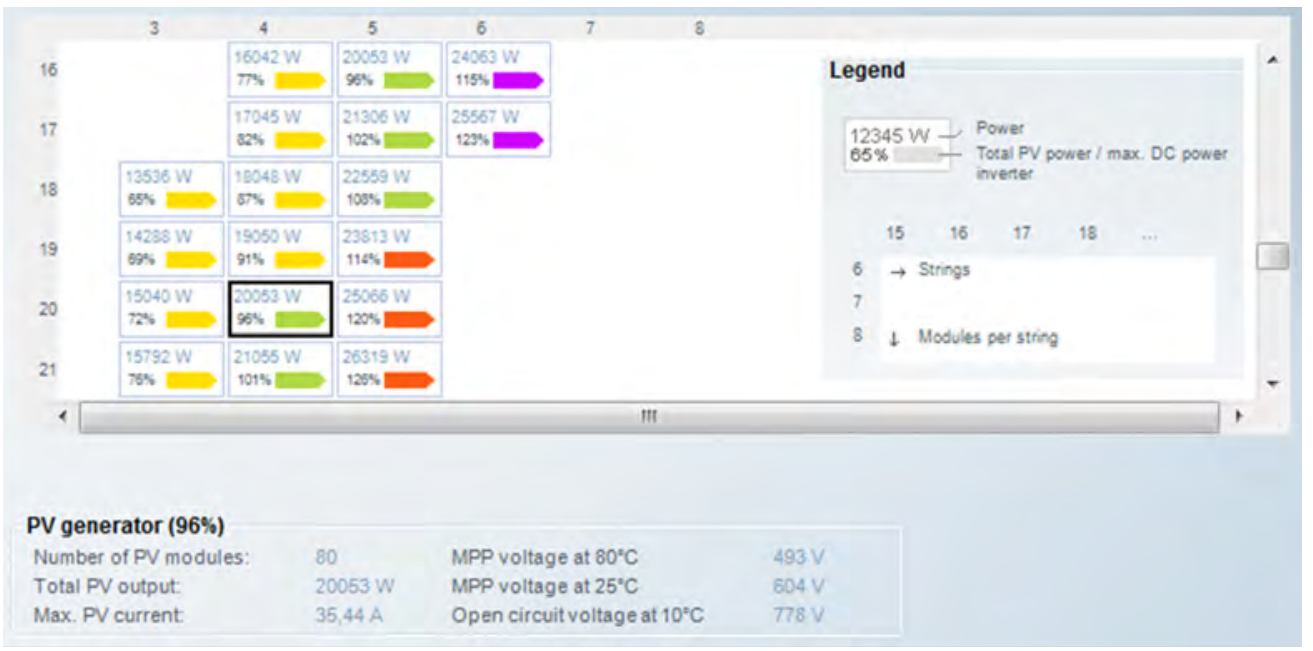

Figure 4.15: Part of the single-line electrical diagram of a self-production PV system

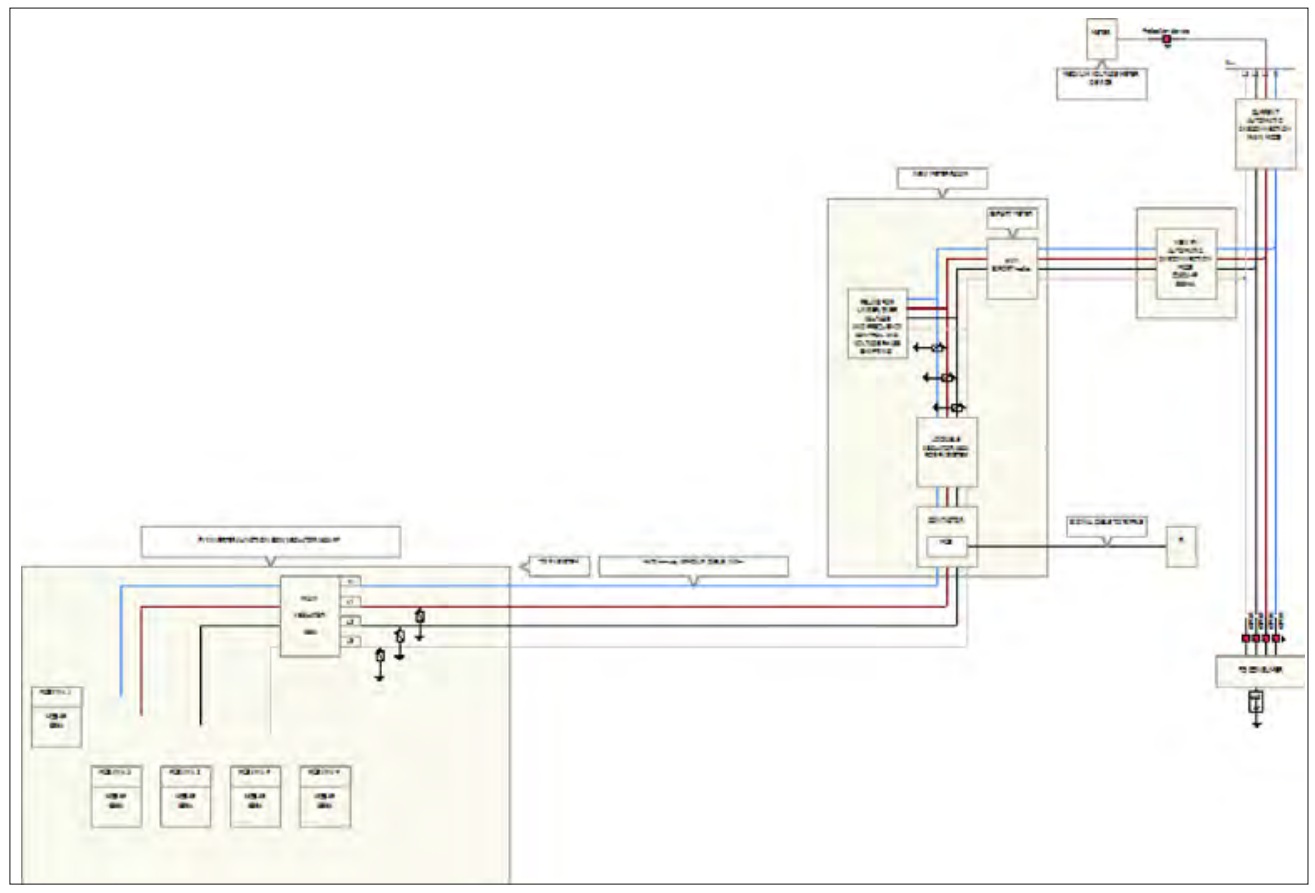


Figure 4.16: Remaining single-line electrical diagram of the self-production PV system

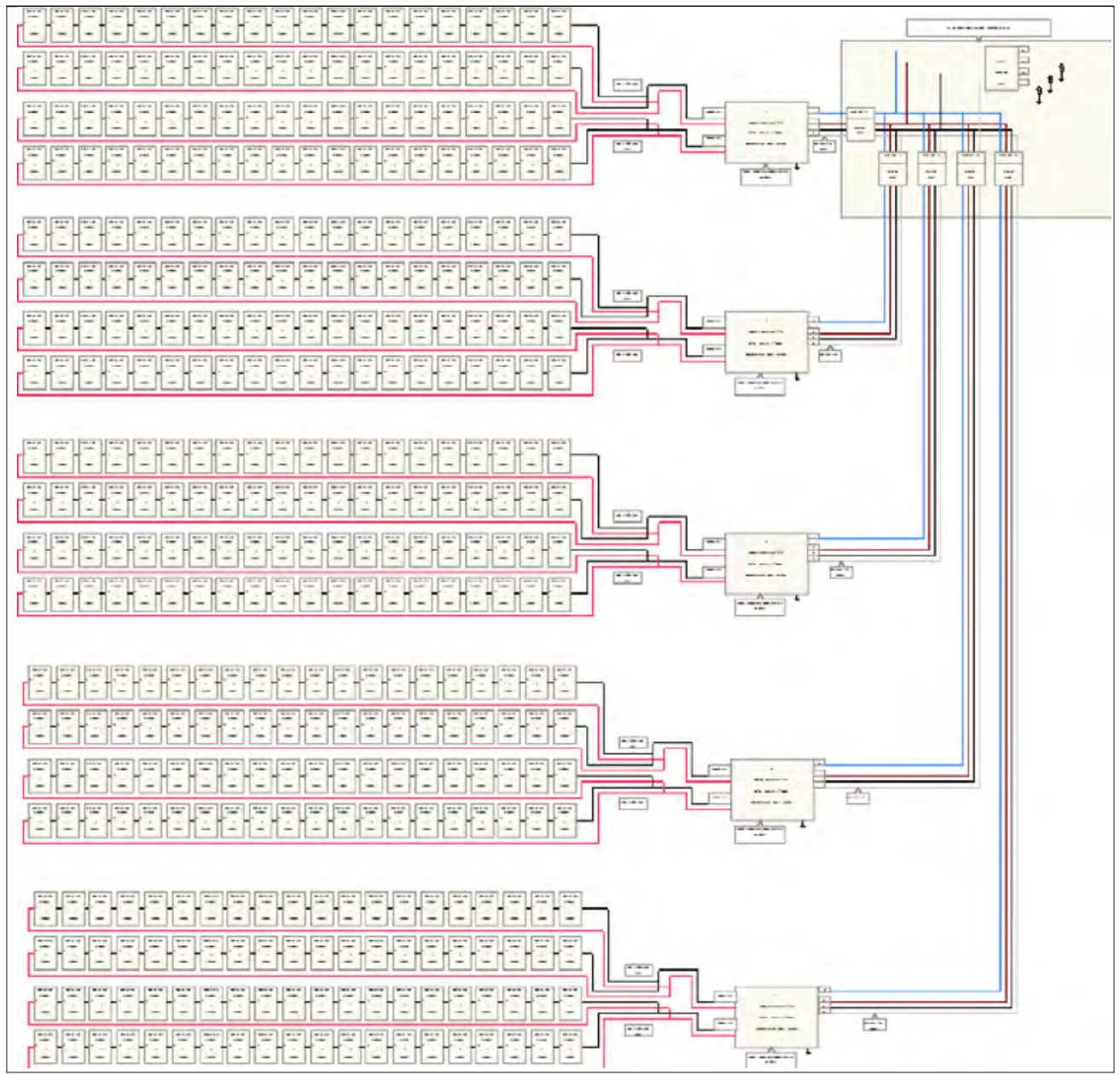


Figure 4.17: Plan view of PV module installation for a self-production system

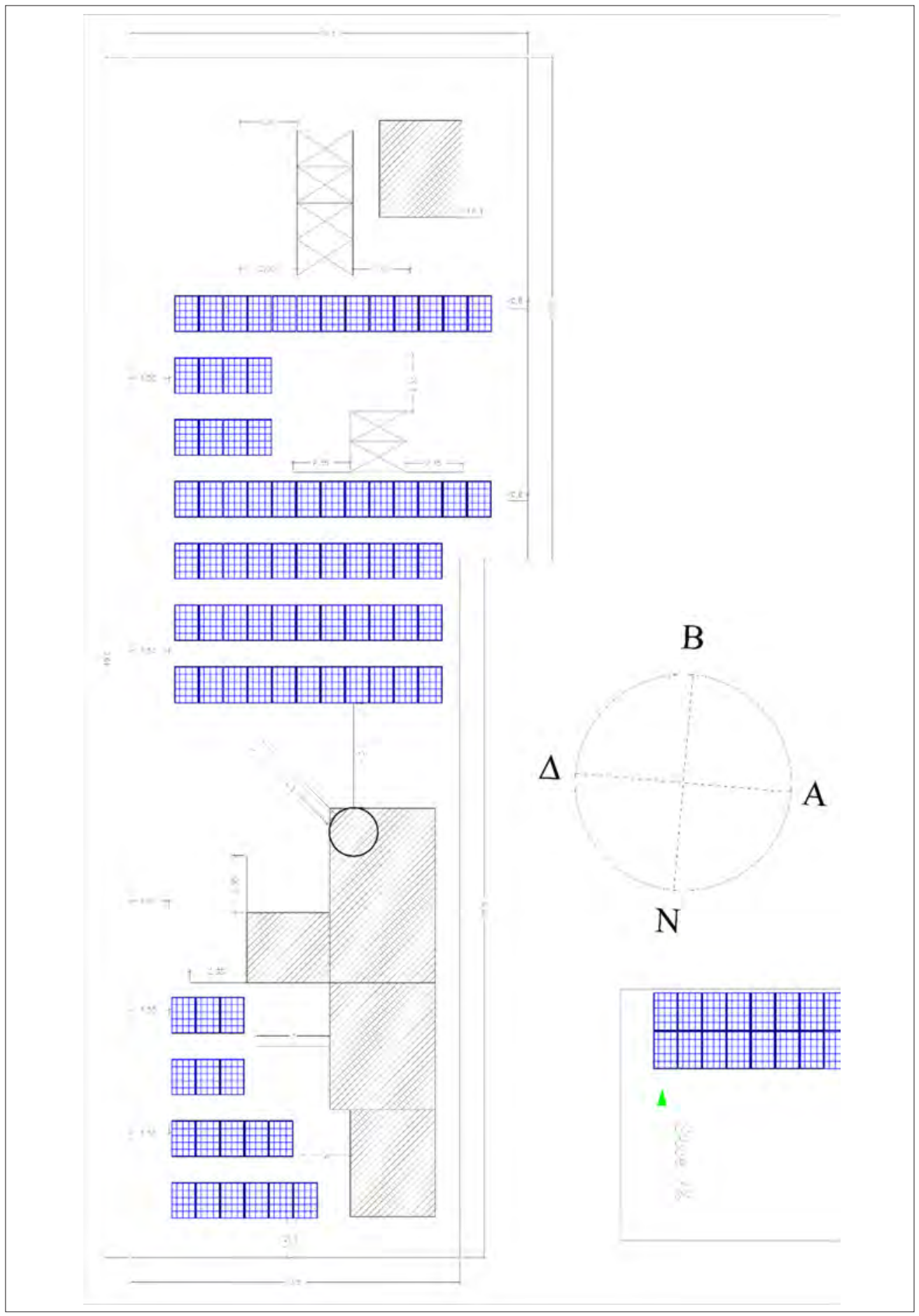


Figure 4.18: Plan view of PV module installation for a self-production system

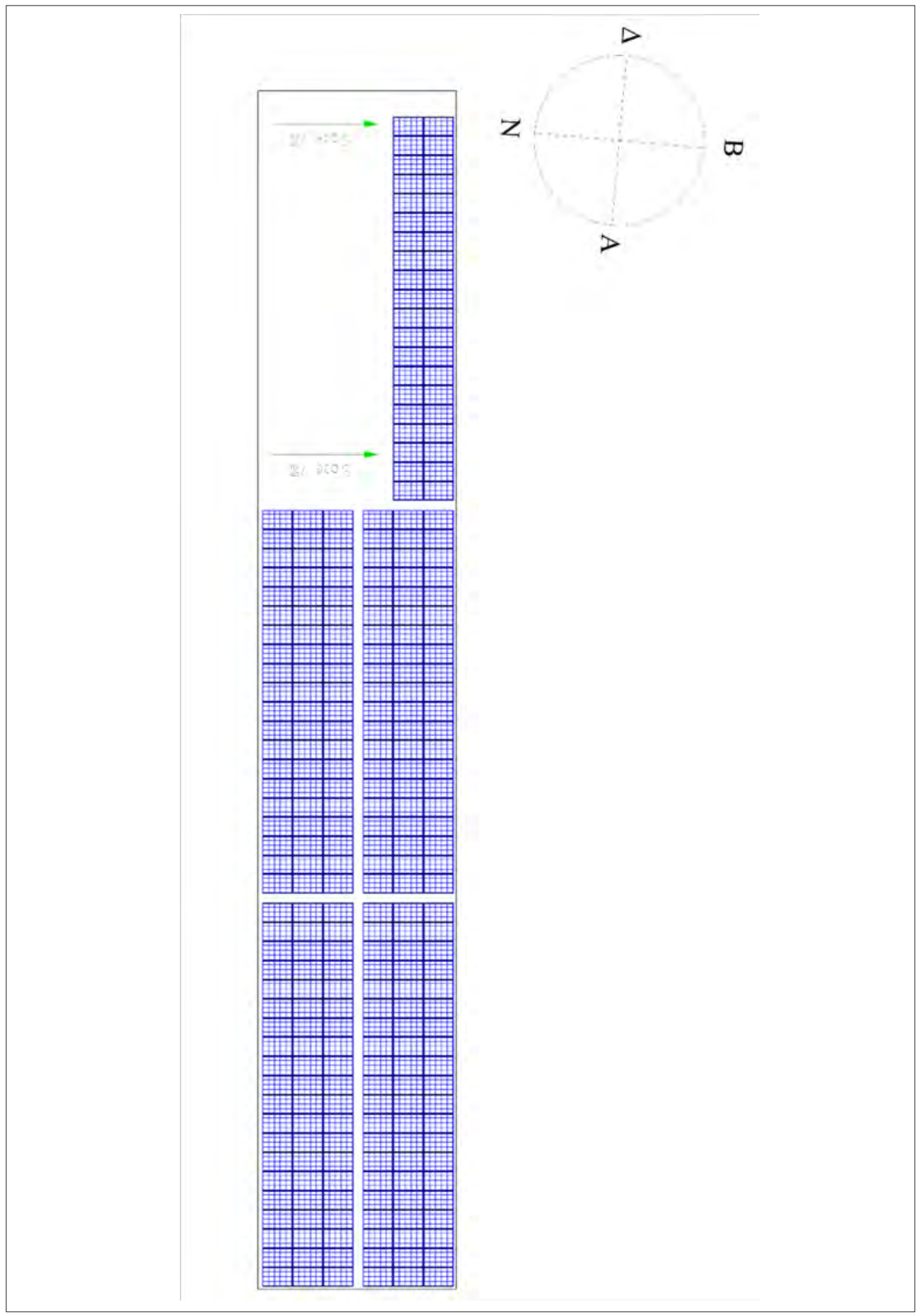


Figure 4.19: PV module installation photos

a) top left, b) top right, c) bottom left, d) top right

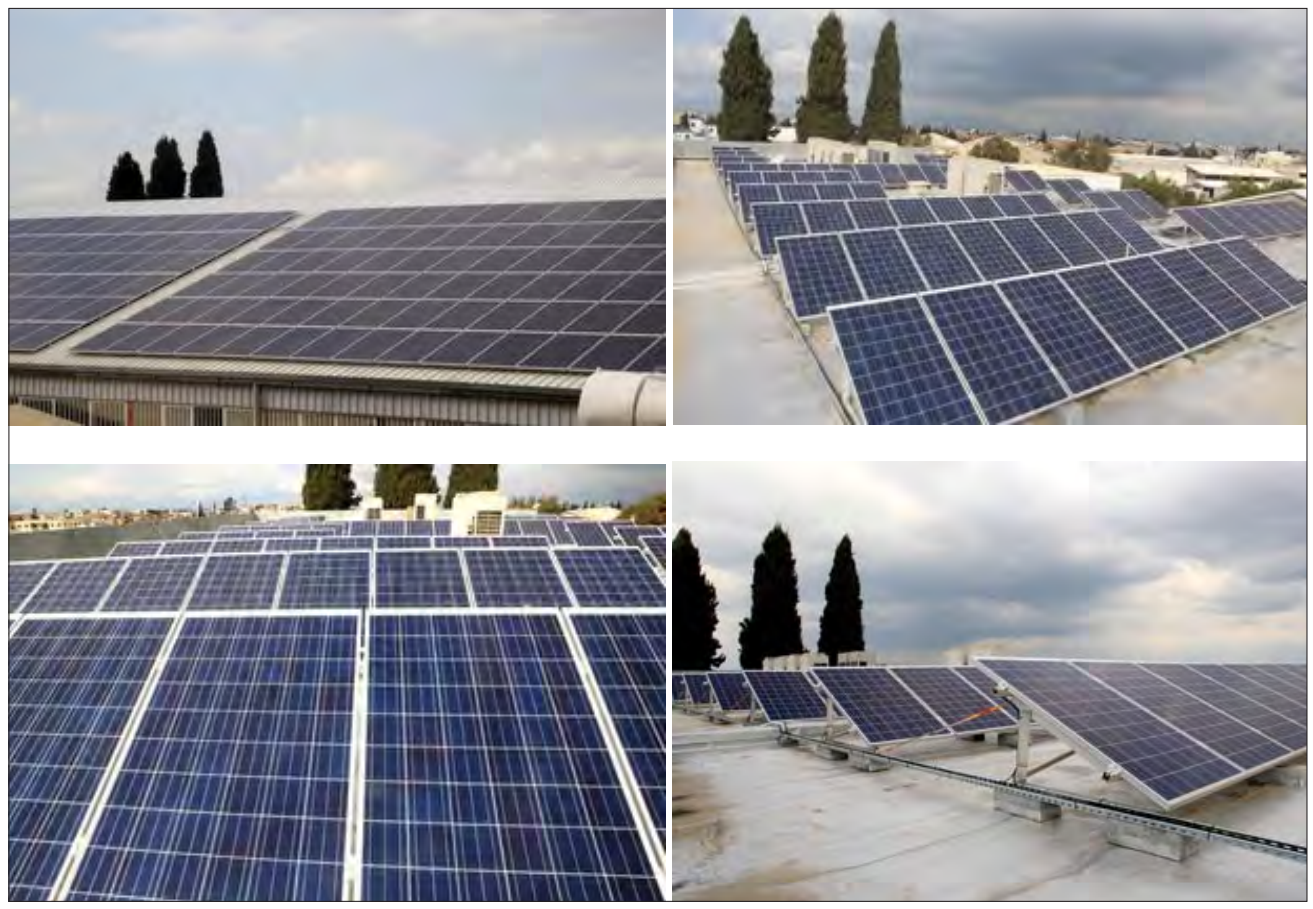


Figure 4.20 to Figure 4.23 illustrate the various electrical components of the self-production system. Depending on the country and the relevant electricity regulations the accessories required for PV systems may vary. For this reason, the author will not get into the detail of every electrical component used in the system. Those readers wishing more information about the electrical accessories may contact the author directly.

The specific system comprises of $520 \mathrm{~kW}$ inverters, seen in Figure 4-21 and 400 modules (some of them seen in Figure 4.19). The other components of the system such as cables, protective devices, relays, isolators, and electricity meters are all shown in the remaining Figures below.

Once in operation and depending on the monitoring system of the manufacturer, the system can be monitored and all data recorded for future analysis. Figure 4.24 below illustrates a screen shot of the system in operation. At the particular instance, the generated energy is $81.947 \mathrm{~kW}$ and the load demand is $118.724 \mathrm{~kW}$. This suggests a self-sufficiency of $69 \%$ as shown by the screen shot.

Figure 4.25 illustrates the generated energy for April 2015. The generated energy per inverter can be seen as well as the total energy at the top right corner, $16,6630 \mathrm{kWh}$. Most of this energy was consumed directly by the loads. A small portion of it was fed to the grid. The problem with feeding energy to the grid arises mainly during weekends when the loads are considerably lower than during weekdays as on weekends there are no operations. This can be also seen in Figure 4.25.

\section{Figure 4.20: Electrical switchgear detail for self-production PV system}

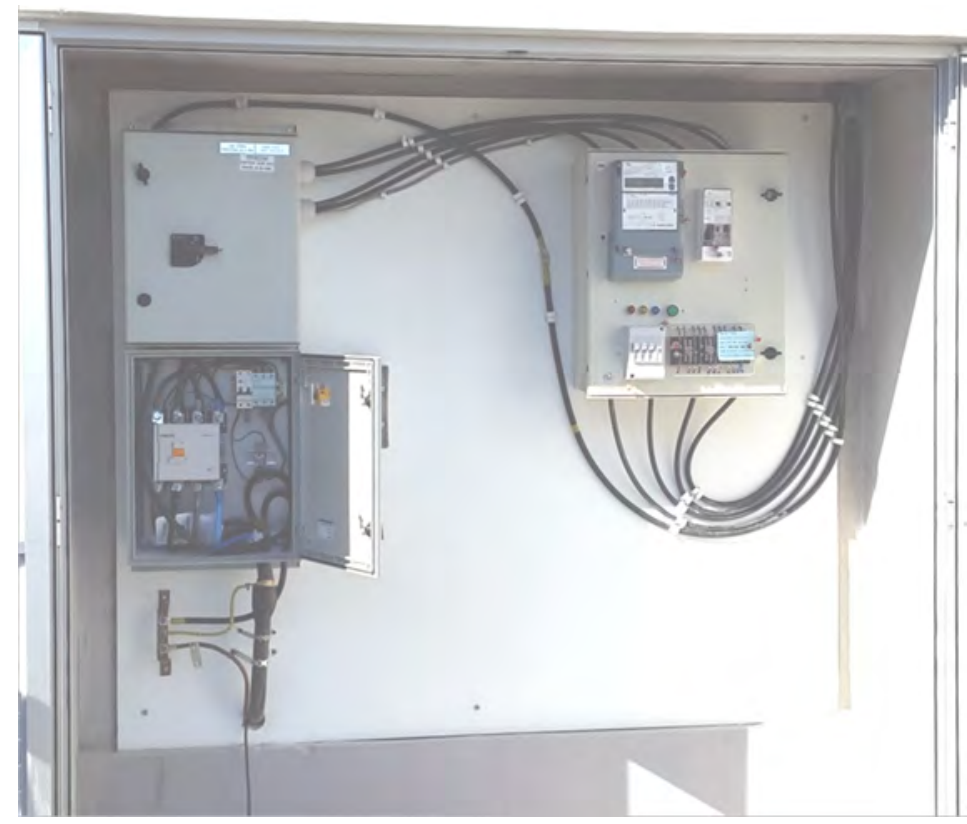


Figure 4.21: Inverter installation with switchgear

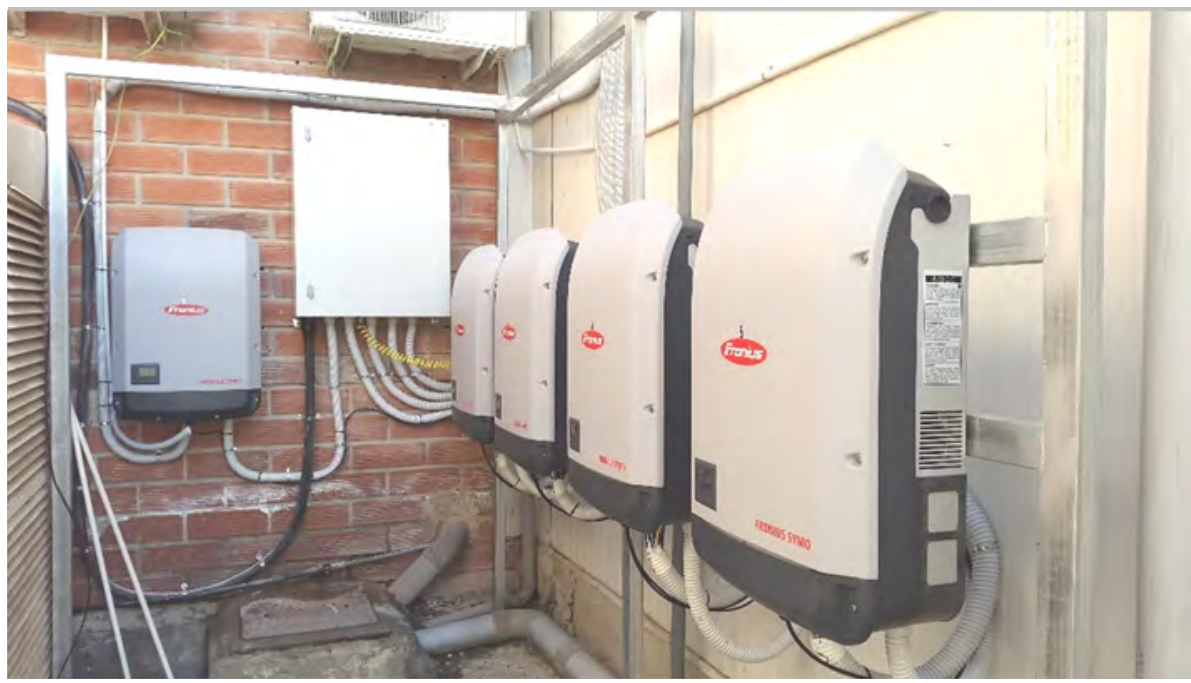

Figure 4.22: Detail diagram of monitoring relay installation (model Bender VMD 460)

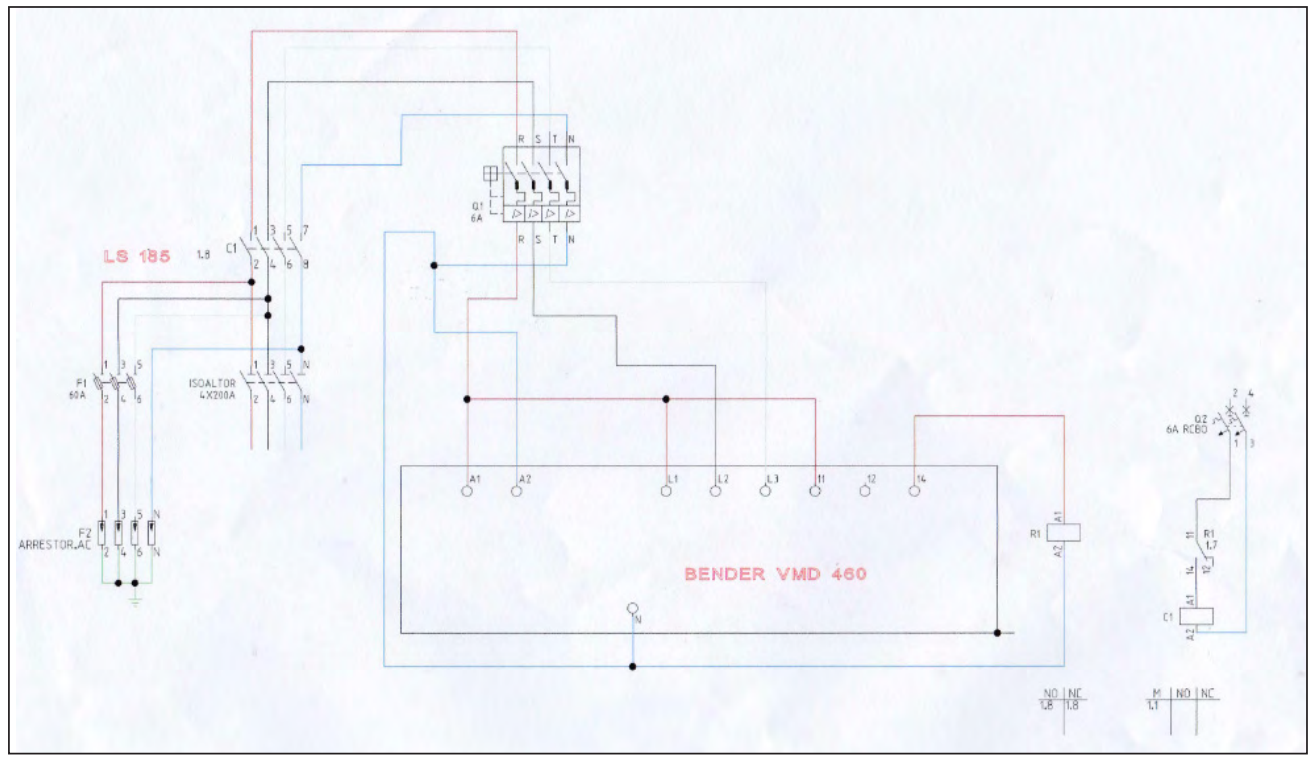


Figure 4.23: Main components of self-production PV system in single-line layout (not showing PV modules and inverters)

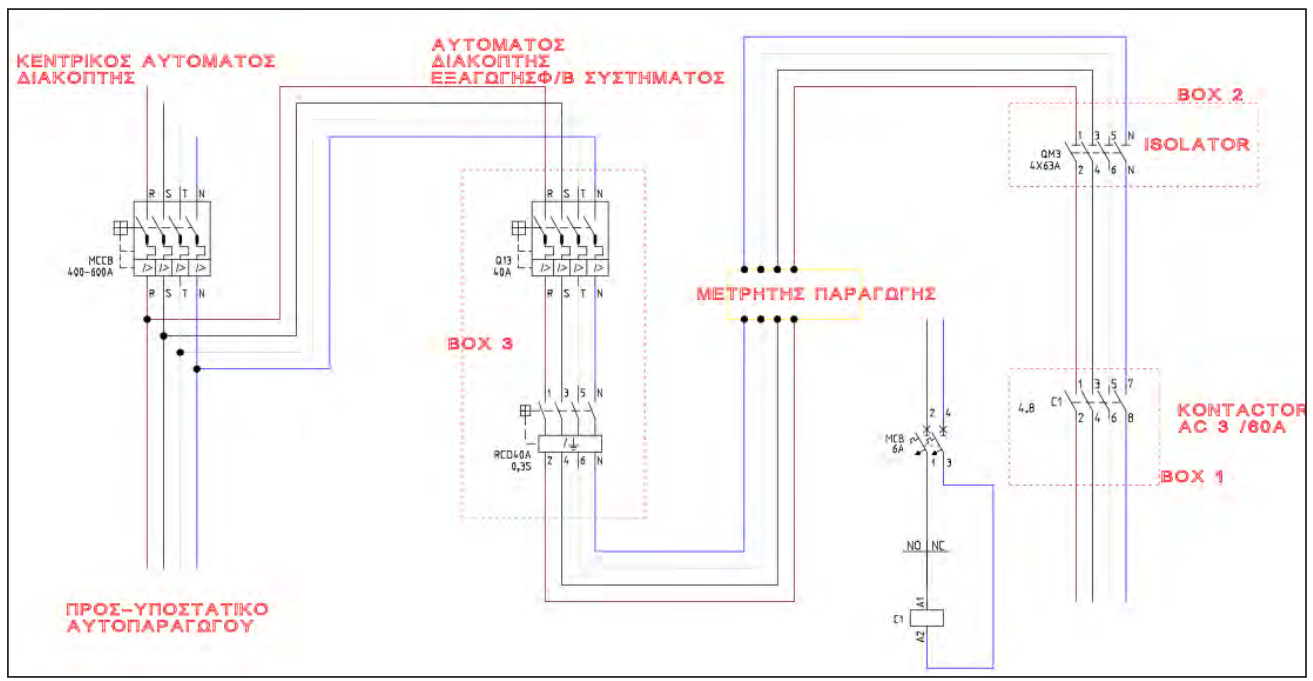

Figure 4.24: Illustration of self-production PV system

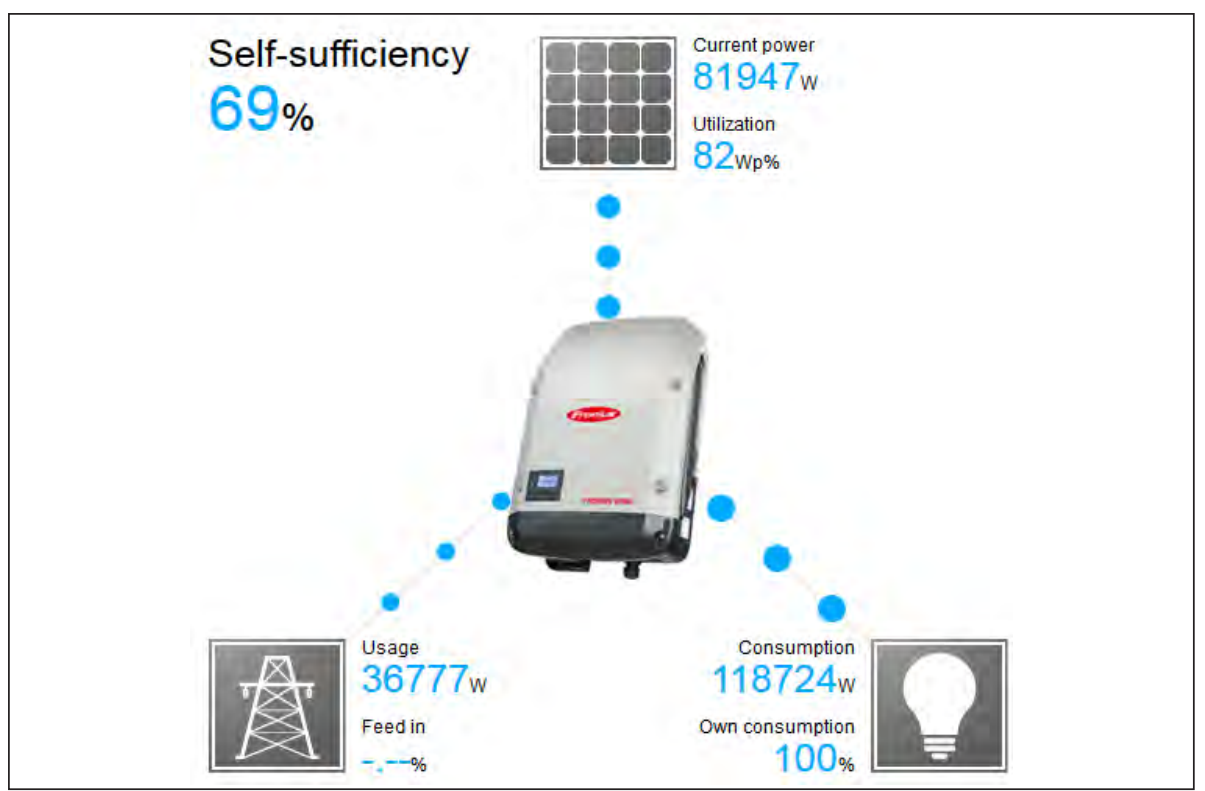


Figure 4.25: Generated energy from the self-production PV system

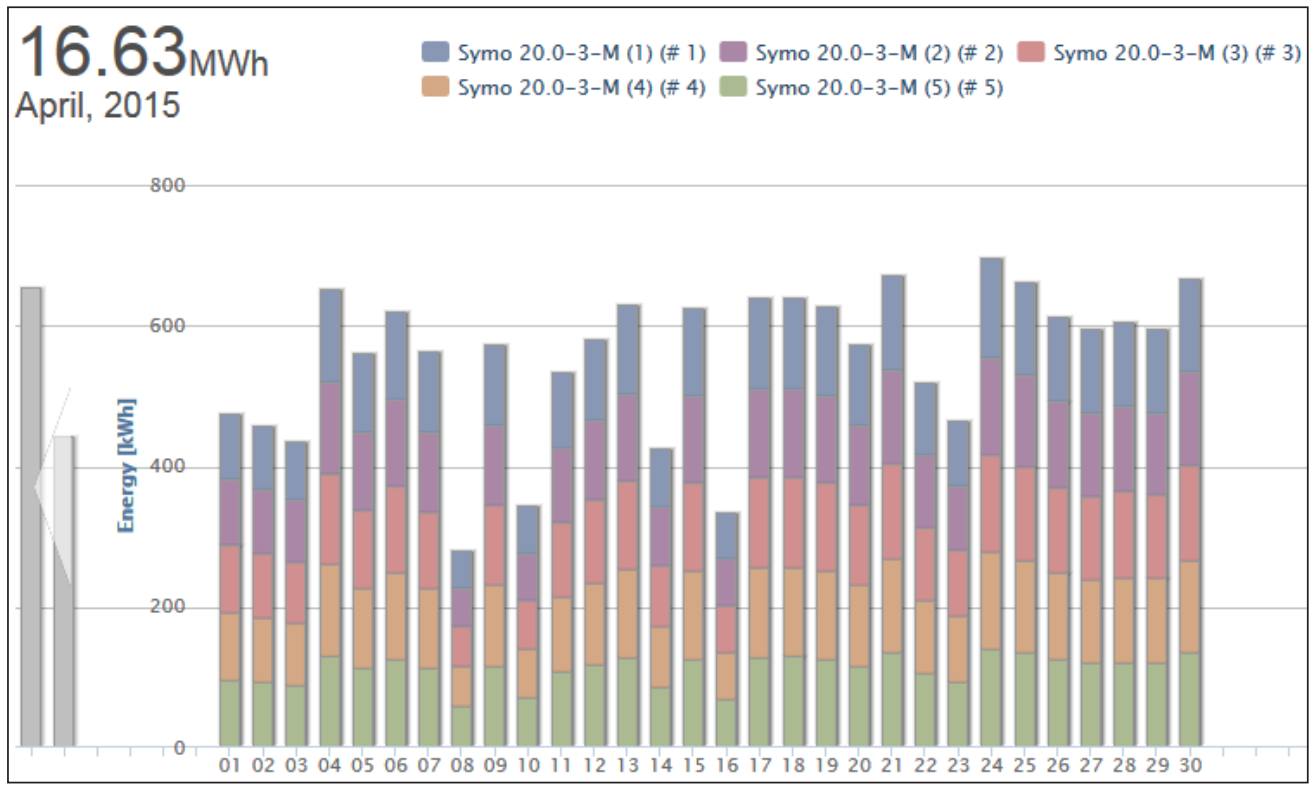

Figure 4.26: Energy balance for April 2015

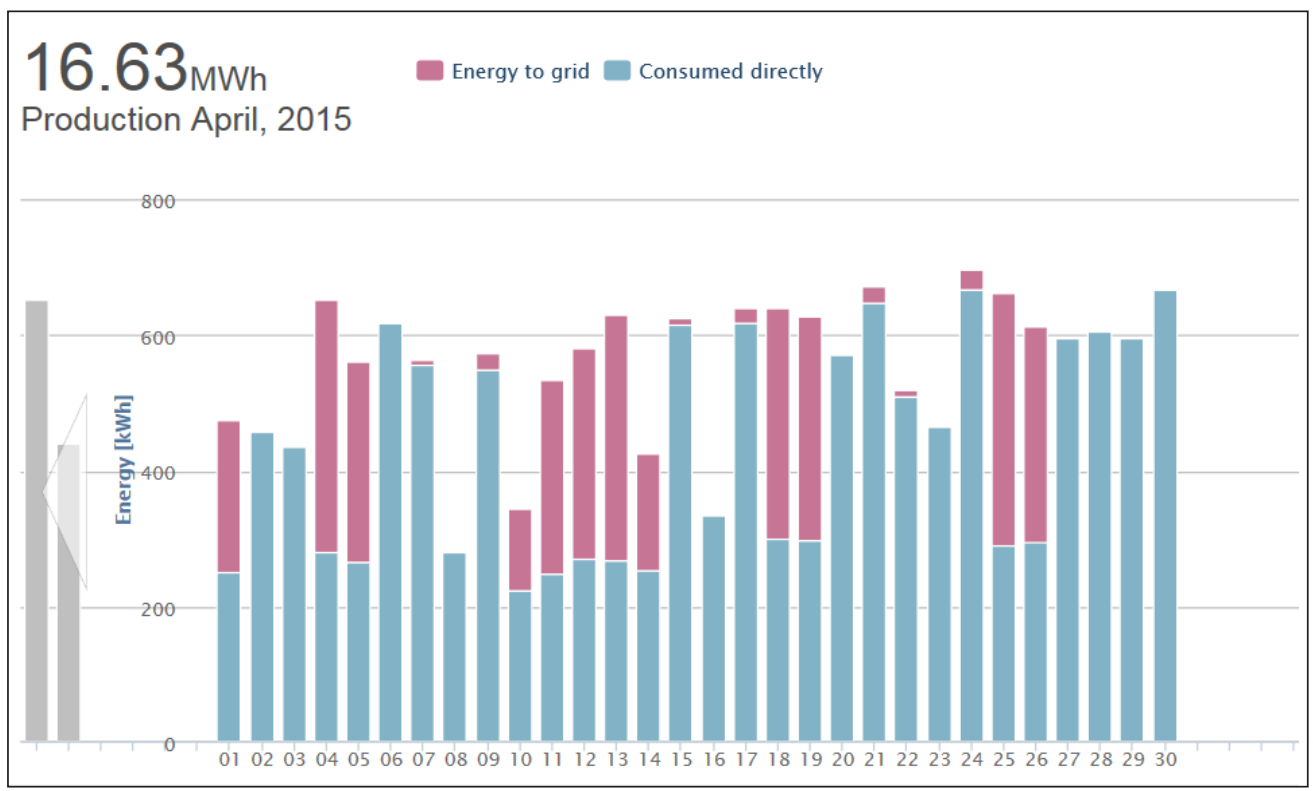




\subsection{Small scale wind turbines}

\subsubsection{Introduction}

Wind turbines these days are very complicated machines, Figure 4.27. The wind turbine blade works like an airplane wing. Blowing air passes around both sides of the blade. The shape of the blade causes the air pressure to be uneven higher on one side of the blade and lower on the other causing it to spin. The uneven pressure causes the blades to spin around the centre of the turbine. On the top, there's a weather vane that's connected to a computer and acting as the controller, keeping the turbine turned into the wind so it captures the most energy. The blades are attached to a rotor which only turns about 18 revolutions a minute which however, is not fast enough to generate electricity by itself. It is therefore connected to a set of gears that increase the rotation up to about 1800 revolutions per minute. And at that speed, the generator can begin to produce electricity.

Wind turbines are tall to capture as much wind as possible. Larger turbines can also capture wind energy more efficiently. The blades can sweep a circle in the sky, with a diameter longer than a football field. Wind turbines can be onshore or off-shore. Oceans and lakes provide a reliable and consistent source of wind ${ }^{6}$.

Figure 4.27: Components of a wind turbine and generator

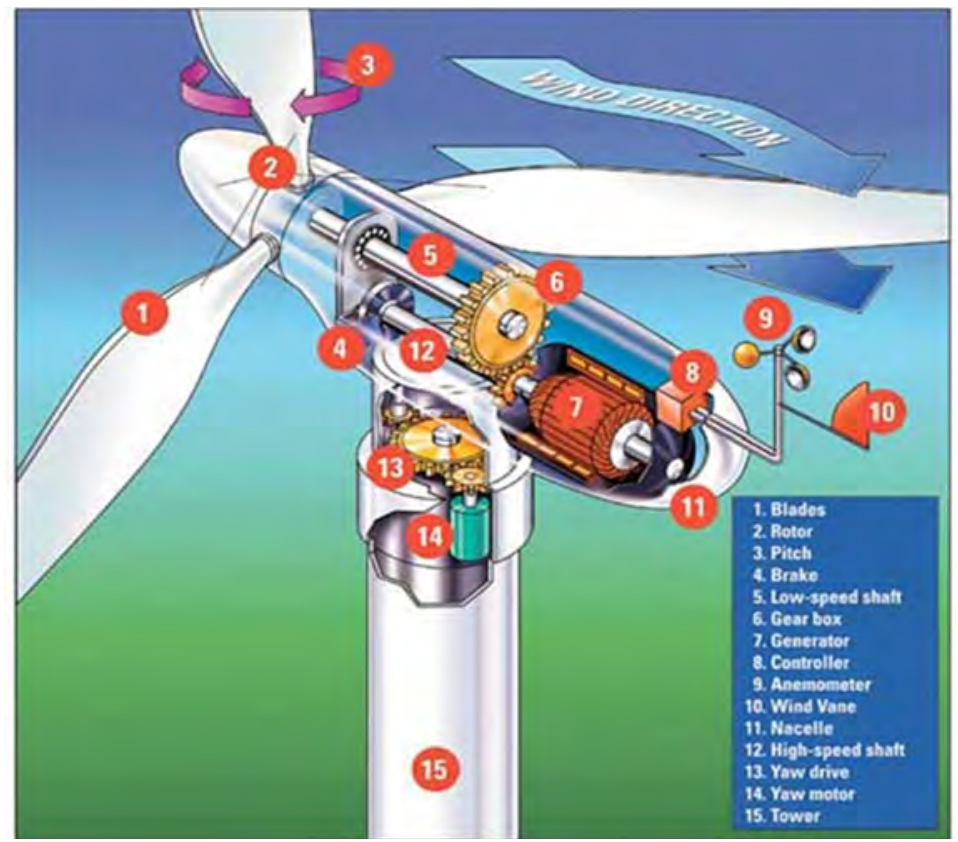

${ }^{6}$ https://www.energy.gov/eere/office-energy-efficiency-renewable-energy 


\subsubsection{Wind Turbines}

Small wind turbines used in residential applications typically range in size from 400 watts to 20 kilowatts, depending on the amount of electricity required to be generated. There are two types of wind turbine rotor axes; the horizontal and the vertical rotor axis. A vertical-axis wind turbine (VAWT) is a type of wind turbine where the main rotor shaft is set transverse to the wind (but not necessarily vertically) while the main components are located at the base of the turbine. Horizontal axis wind turbines utilize wind energy through blades directed on a horizontal axis parallel to the ground. HAWT face wind perpendicularly so that wind turbine blades turn following an aerodynamic lift. Horizontal axis WTs prevail in the wind energy market as their construction design allows to obtain more energy through full rotation of blades in terms of consistent wind flow. What is more, horizontal axis wind turbines are resistant to backtracking which is also beneficial in this type of power generation.

Figure 4.28: An image of a vertical axis wind turbine ${ }^{7}$

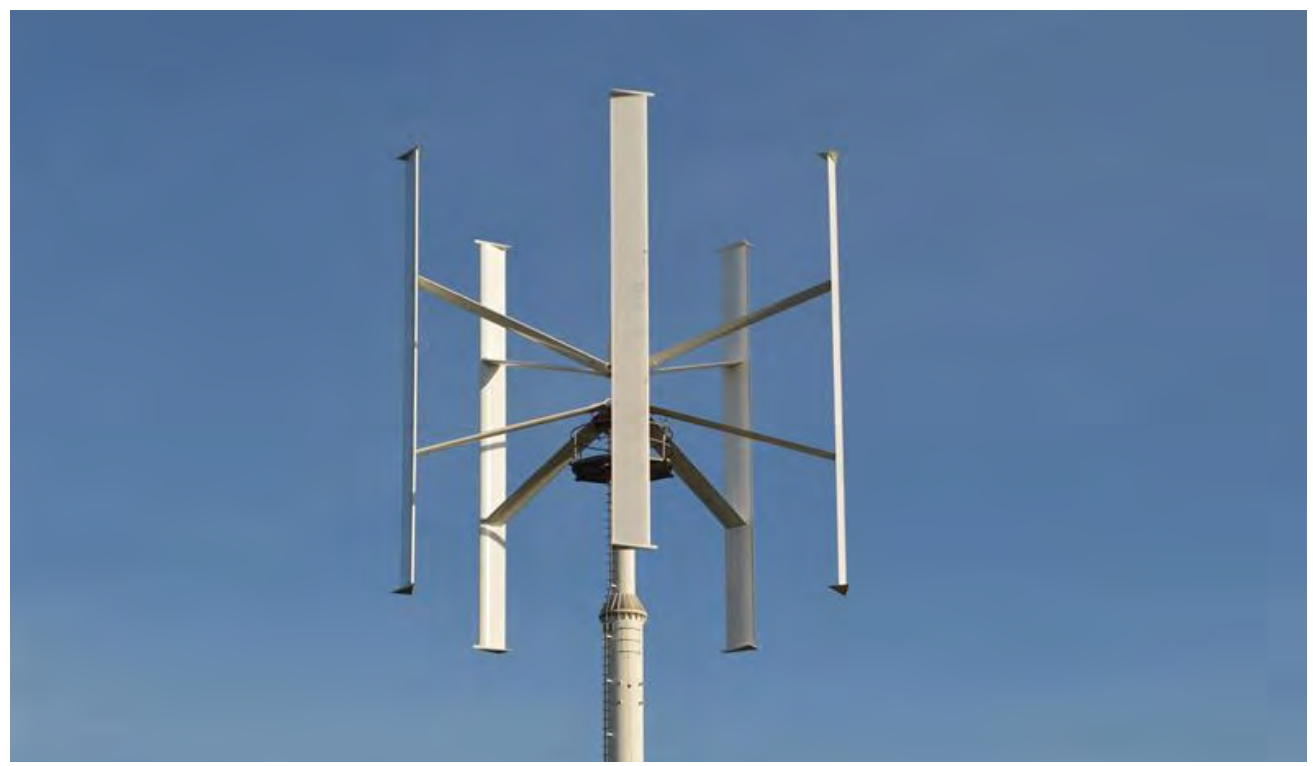

${ }^{7}$ https://news.cision.com/siemens-process-industries-and-drives/r/siemens-helps-make-verticalaxis-wind-turbine-a-reality,c9782168 
Figure 4.29: An image of a horizontal axis wind turbine ${ }^{8}$

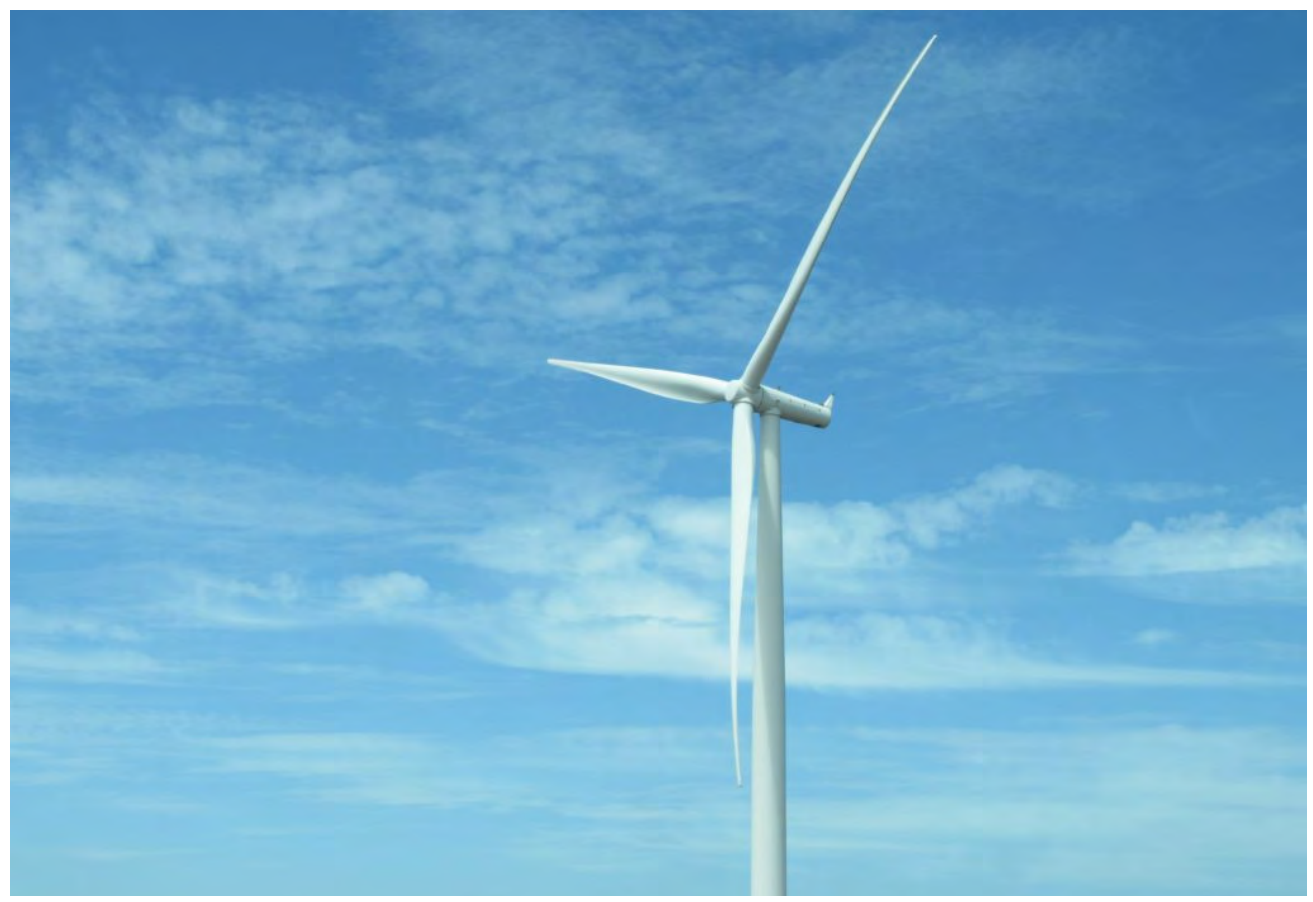

\subsubsection{Wind as a resource of energy}

\subsubsection{Definitions and theoretical background}

By definition, the theoretical wind potential is the total wind energy flowing in the environment (through modelling of the natural energy flow in the environment for a specific area and time period). The available potential is the upper limit of the energy that can be committed in an area without impact on the environment and without significant change of the main uses of the area and the primary energy, if the efficiency of the available primary energy conversion technology is $100 \%$.

The technological potential is the energy that can be committed with the available technology. Technological potential is determined by constraints that affect the efficiency and the energy production of selected technologies and ignores economic viability.

The Economically viable potential is the limit of energy that can be produced by a specific technology with economically viable facilities. It depends on the cost of the technologies and the policy (selling prices, incentives)

\footnotetext{
${ }^{8}$ https://www.aprisolar.com/horizontal-axis-wind-turbine-hawt/
} 
Wind energy is a by-product of solar energy where $2 \%$ of solar radiation is converted into winds. Wind energy is the kinetic energy of moving air. It is created by the Irregular heating of the earth's surface by the sun.

Winds are gaseous masses that move due to the different barometric pressures caused mainly by the uneven heating of different parts of the earth by the sun namely:

- Different latitude

- Land - sea

- Effect of earth rotation

Due to the curvature of the earth's surface, the sun's rays fall more and more sideways, as we go to greater and wider latitudes where the sun's rays have to travel more and more distance in the atmosphere, resulting in more solar energy being absorbed before it reaches on the surface of the earth.

A layer of air that will come in contact with the earth's surface will heat up and rise $(\sim 10 \mathrm{~km})$. Its place will be covered by a layer of colder air, which in turn will heat up and rise (warm air has a lower density than cold). This circular upward-downward motion of hot and cold fluid masses is called Vertical transfer.

In Europe, the winds are influenced by the east currents of the Atlantic, the cold north and the warm local areas of the Sahara. So, the main winds are southwest in winter and west and northwest in summer.

When the wind flow encounters an obstacle, a disturbance is created, i.e. the flow becomes turbulent, with the main characteristics being the decrease of the average wind speed and the increase of the turbulence. The installation and operation of a wind turbine downstream of an obstacle results in not only reduced efficiency, but also a reduction in engine life due to unwanted extra stress due to turbulent flow.

\subsubsection{Study of the wind characteristics}

The study of the wind characteristics includes:

a) Wind measurements

- Methods and instruments

- Density and duration

b) Processing of measurements

- Annual frequency distribution

- Annual gear duration curve

- Annual validity curve

- Annual energy and average wind speed

c) Change of wind speed with the height from the ground

- height of the tower

- engine performance - voltages and oscillations - lifetime 
d) Atmospheric turbulence

e) Selection of locations

- High average speed and constant wind flow

The average wind speed is calculated given a series of measurements and given specific equations that take into consideration the average wind speed, the wind speed at the point of the measurements and the number of measurements. The standard deviation $\sigma$ is also calculated to show how much the measurements deviate from the mean value of the wind and is called turbulence intensity.

The measure of turbulence variability is a dimensionless quantity. With the term turbulence we call the disturbance of the wind speed (differences of instantaneous speed from the average speed value) and it is of special importance for the performance of the wind machines, but also the calculation of the endurance due to the alternating loads that develop and that lead to fatigue engine materials.

\subsubsection{Basic considerations for residential wind turbines}

A typical house in Cyprus for example consumes around $7000 \mathrm{kWh}$ per year for (about $580 \mathrm{kWh}$ per month) ${ }^{9}$. Depending on the average wind speed in the area, a wind turbine rated in the range of 5-15 kilowatts would be required to make a significant contribution to this demand. A 1.5-kilowatt wind turbine will meet the needs of a home requiring 300 kilowatt-hours per month in a location with a $14 \mathrm{mph}(6.26 \mathrm{~m} / \mathrm{s})$ annual average wind speed.

To determine what size of turbine is required for a house or any other type of building, such as a marina administration building for example, the annual energy consumption is required. It is worth mentioning here that it is always a good and beneficial idea to initially try to decrease the energy requirements through energy saving. This will in turn lower the consumed annual energy in kWh and consequently require a smaller wind turbine leading to lower initial capital cost and faster payback period.

The height of a wind turbine's tower also affects how much electricity the turbine will generate. Wind turbine manufacturers may assist in determining the tower height required.

Siting a wind turbine is not a simple matter and it may involve the following:

- Wind potential - measurements

- Effects on the environment

- Visual-auditory nuisance

- Effects on birds

- Electromagnetic interaction

${ }^{9}$ https://www.mof.gov.cy/mof/cystat/statistics.nsf/energy_environment_81main_gr/energy_ environment_81 main_gr?OpenForm\&sub $=1 \&$ sel $=2$ 
- General regulations and restrictions on land use

- Spatial framework

- Meteorological problems - extreme conditions (frost, too strong winds, turbulence, airborne materials)

- Acceptance by the public

- Satisfactory area

- Ease of access (existence of road network near the area of interest)

- Electrical network - substation

- Not high altitude

- No big slopes

Figure 4.30: Residential wind turbine example ${ }^{10}$

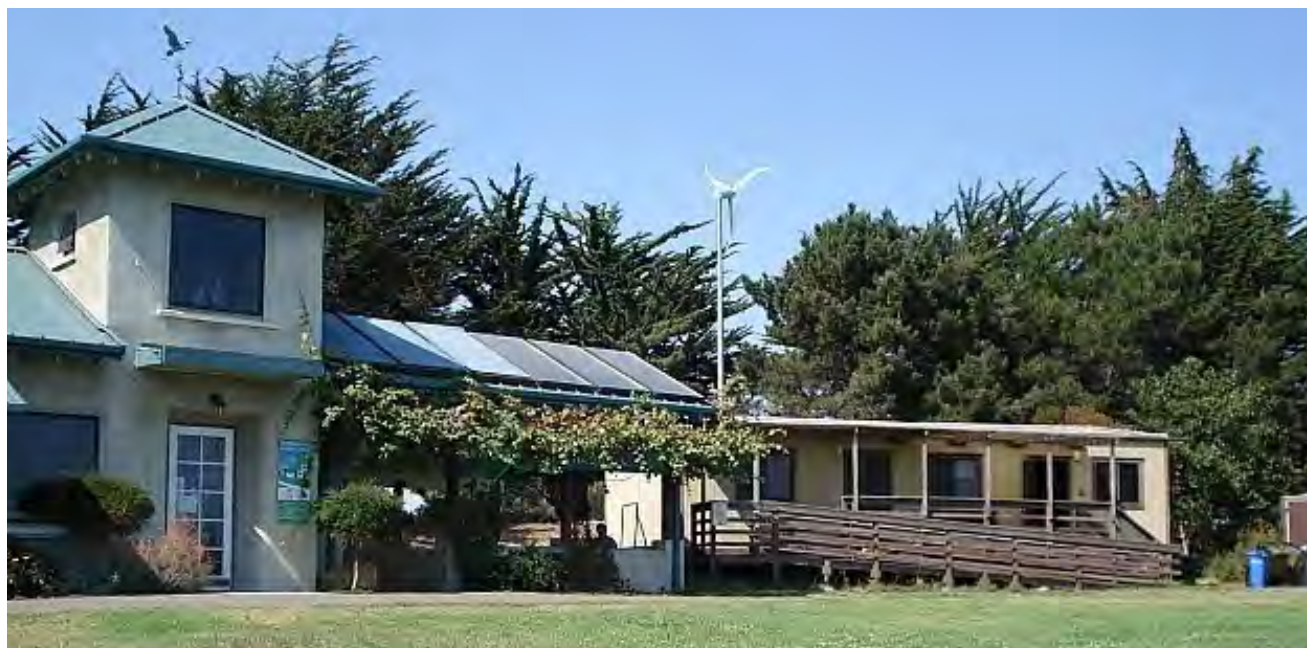

\subsubsection{Estimating Annual Energy Output}

Figure 4.31 and Figure 4.32 below provide an indication of the variation of wind on hourly and monthly basis. The measurements show that the average annual wind speed varies hourly and monthly. It is also very dependent on the region and whether off-shore or on-shore. It is considered necessary to have wind measurements of at least 12 months at the installation site depending of course on the type of system. Talking about large scale wind farms for example, the measurement period could very well depend also on local regulatory legislation. Correlation with long-term measurements in the wider area may also be necessary and advisable and in addition to knowing the average annual speed. It is also

${ }^{10}$ https://www.energy.gov/energysaver/installing-and-maintaining-small-wind-electric-system\#: $\sim:$ text $=$ Small\%20wind\%20turbines\%20used\%20in,kilowatt\%2Dhours\%20per\%20month 
useful to know the seasonal variation of wind speed, as well as the duration of the wind.

Figure 4.31: Indicative Average hourly wind speed variation

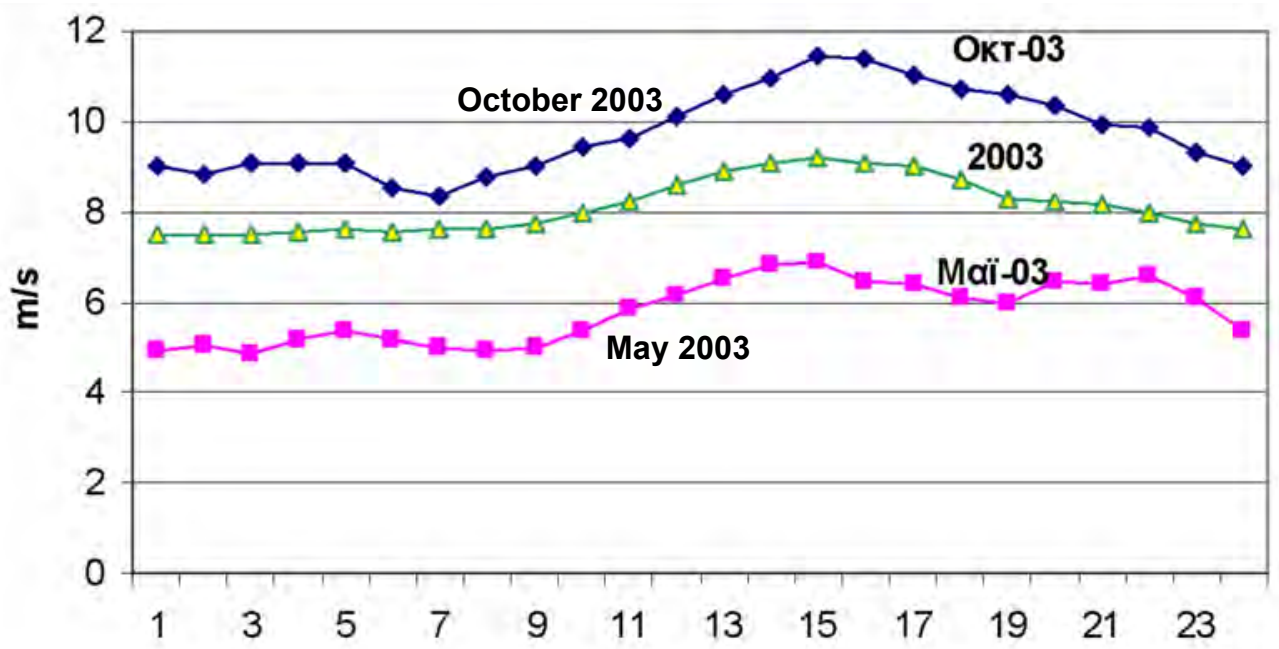

Figure 4.32: Indicative Average monthly wind speed variation

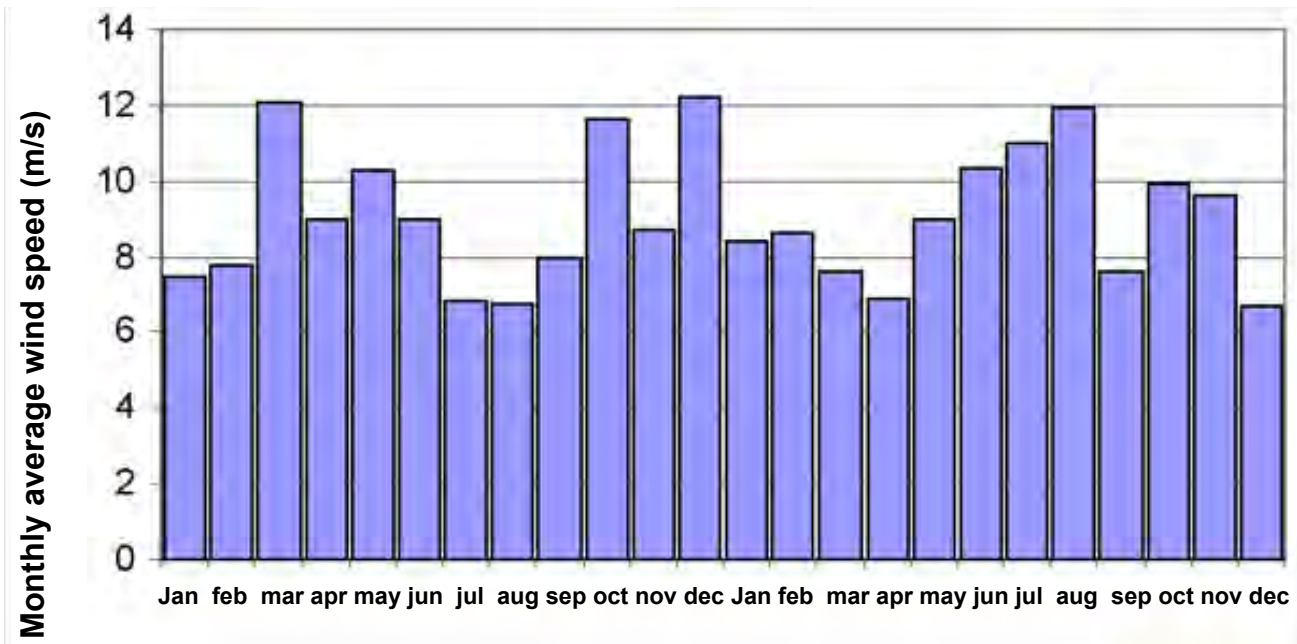

Anemometers record the speed and direction of the wind, Figure 4, converting the kinetic energy of the air into mechanical torque that rotates an axis connected to the measuring device. 'Sonic' anemometers, laser Doppler and others that measure the thermal energy transferred from the air, in an electrified cable exposed to the wind. 
Figure 4.33: Beginning from the left, the figure shows anemometer, weather vane and thermometer
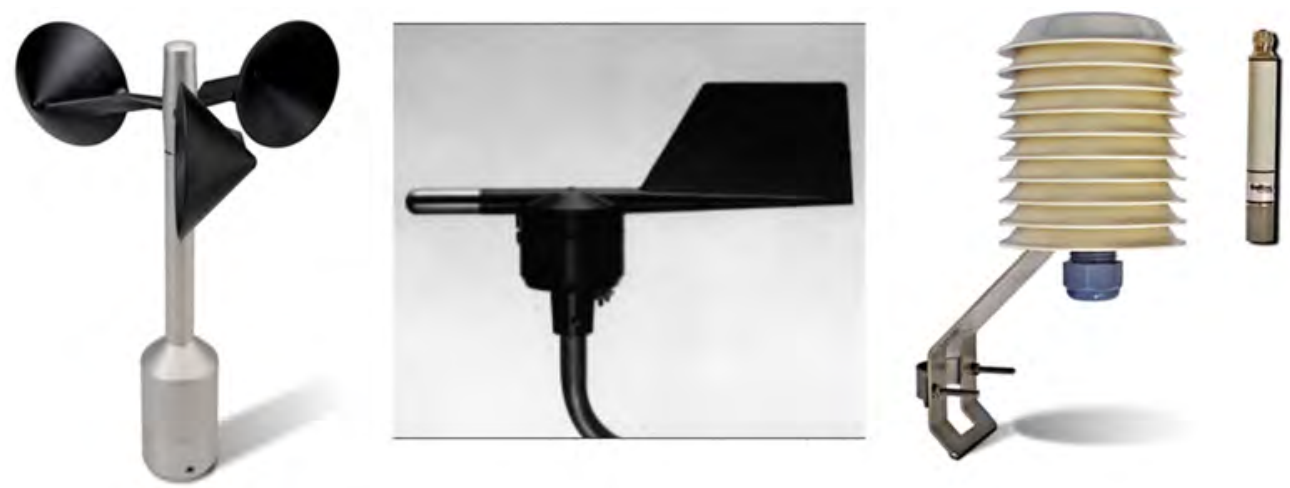

Figure 4.34: Example of wind measuring instrument system ${ }^{11}$

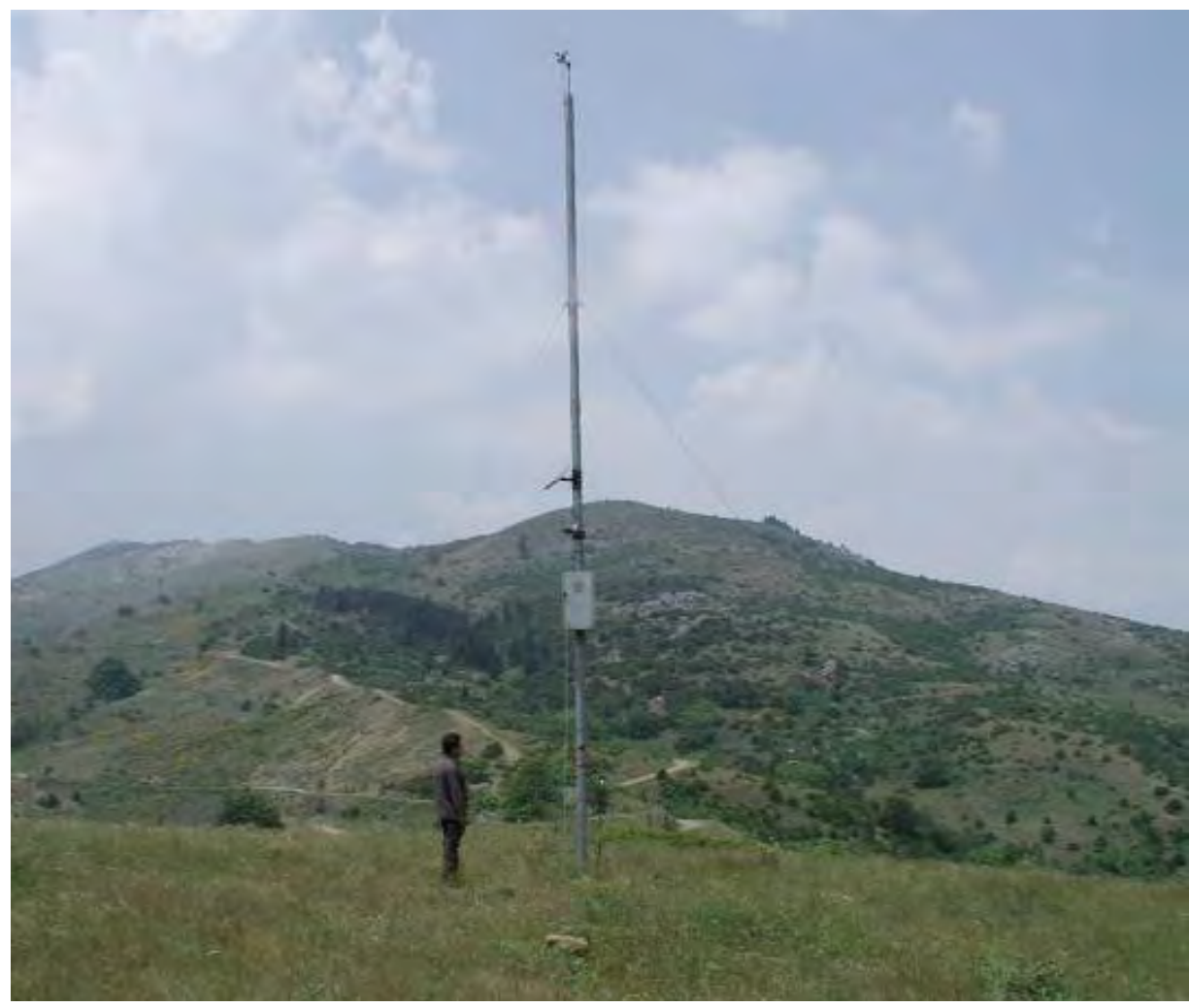

11 https://globalwindatlas.info/en/area/United\%20Kingdom?print=true 
Figure 4.35: Example of wind measuring instruments ${ }^{12}$

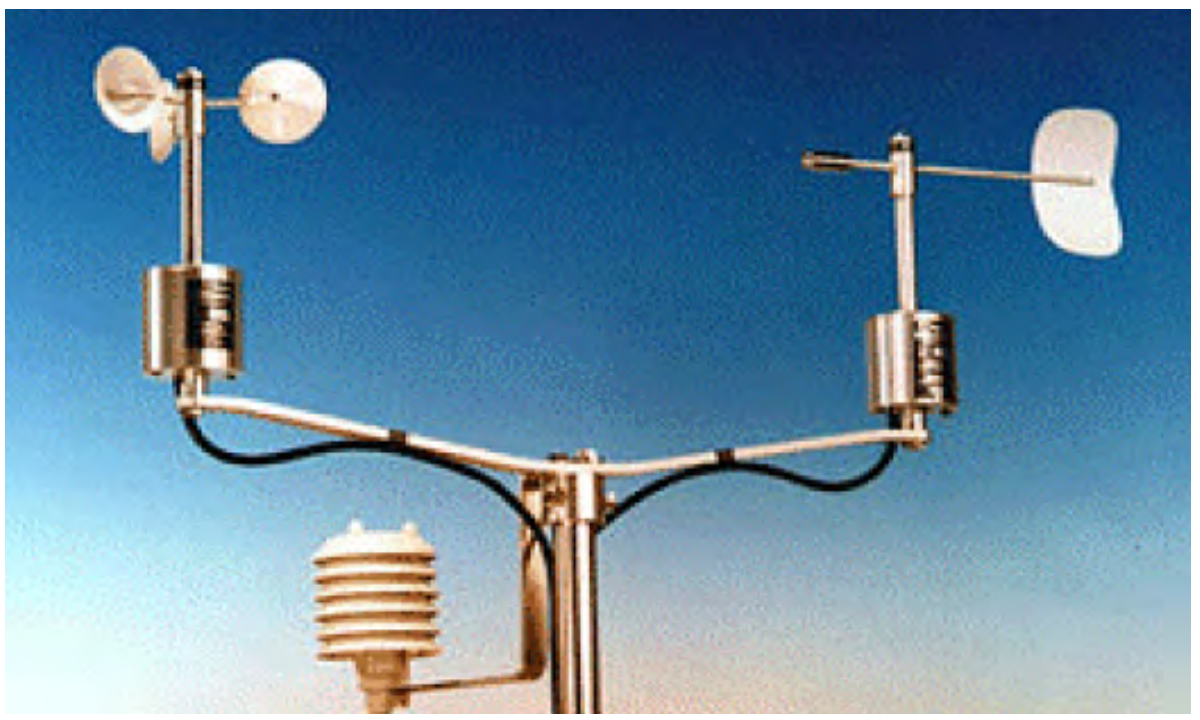

Figure 4.36: Example of wind measuring instruments on a wind turbine

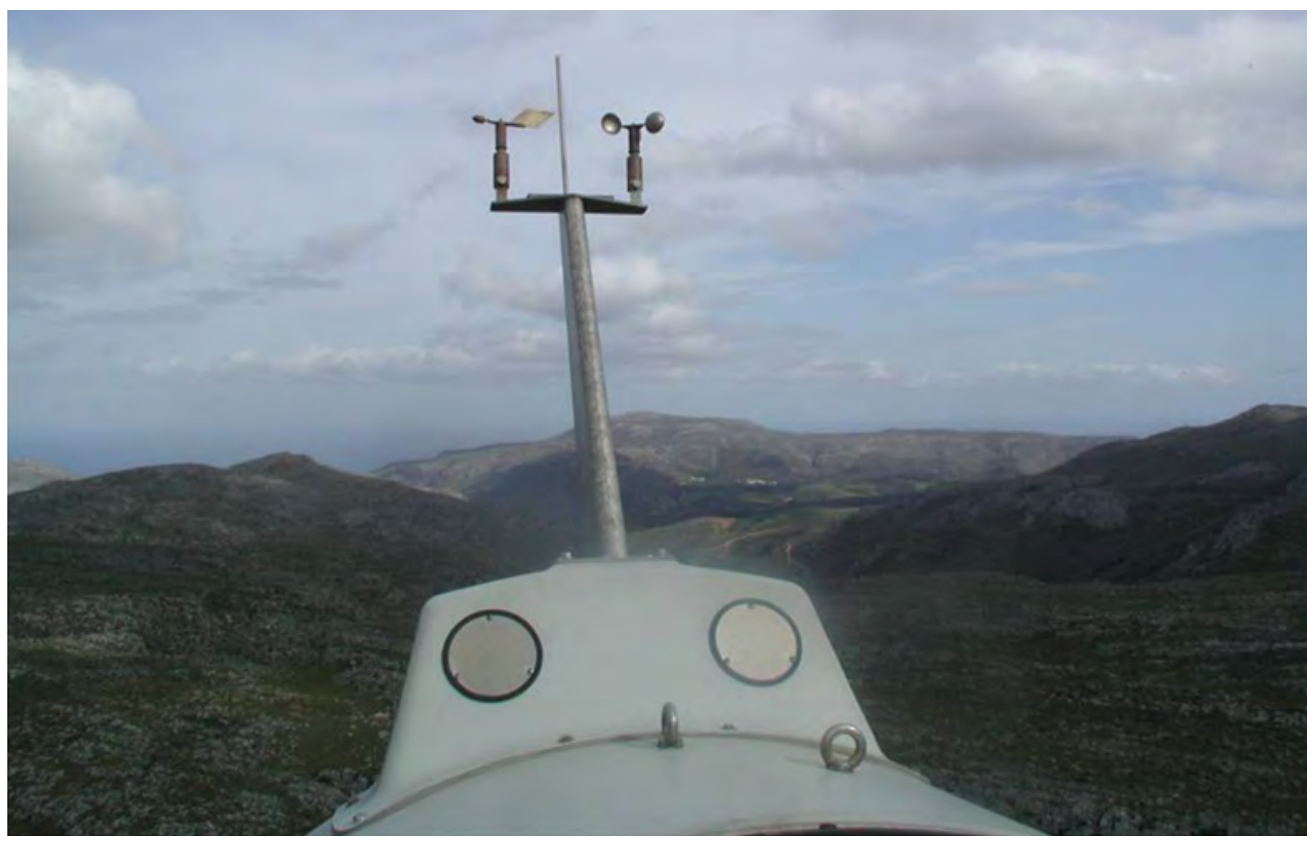

12 http://www.cres.gr/cres/index.html 


\subsubsection{Power output - Power curve}

Wind turbine manufacturers usually provide the so-called wind turbine power curve which allows designers, engineers technicians etc. to determine the output power from a wind turbine and consequently the energy generated from a wind turbine. The equation below is employed to calculate the power output from a WT where,

- $\mathrm{Cp}$ is the efficiency of the WT

- $\rho$ is the air density, usually taken as $1.225 \mathrm{~kg} / \mathrm{m}^{3}$ at $1013.25 \mathrm{hPa}(\mathrm{abs})$ and $15^{\circ} \mathrm{C}$

- A is the area of the rotor calculated by $\pi r^{2}$ with the rotor radius in meters

- $\mathrm{V}$ is the mean wind speed in $\mathrm{m} / \mathrm{s}^{13}$

$$
\mathrm{P}=C p \cdot \frac{1}{2} \cdot \rho \cdot \mathrm{A} \cdot \mathrm{V}^{3}
$$

Figure 4.37 and Figure 4.38, show the power curves of wind turbine manufactures that can be used to calculate the power output. As noticed, the main parameter required is the average wind speed. Note also that these power curves are unique for every wind turbine manufactured.

Figure 4.37: Residential Wind turbine Power curve P $^{13}$

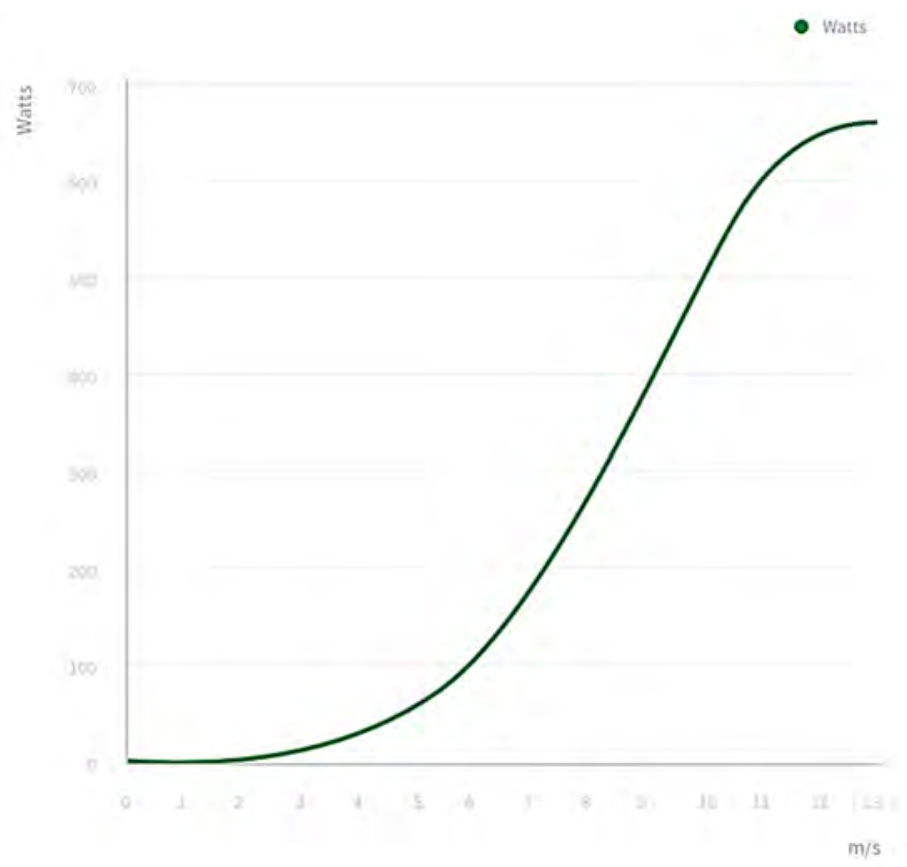

${ }^{13}$ https://semtive.com/residential/ 
Figure 4.38: Wind turbine Power curve

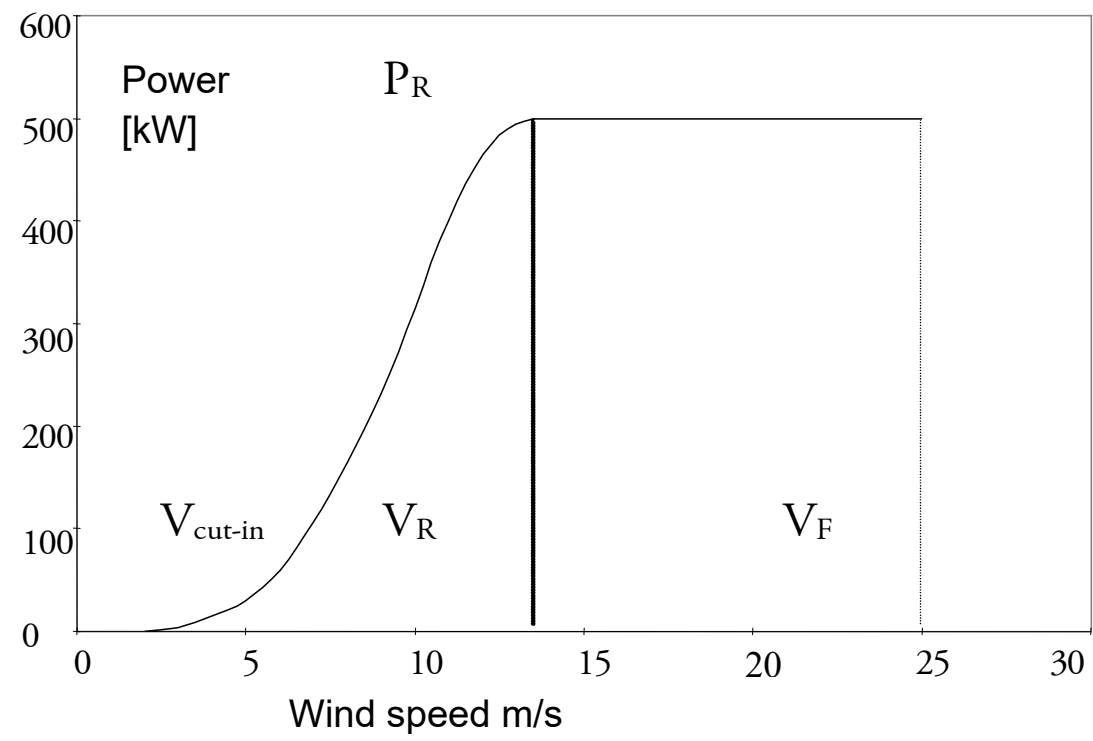

\subsubsection{Energy output from wind turbines}

An estimate of the annual energy output from a wind turbine in $\mathrm{kWh}$ is the best way to determine whether the WT and the tower will produce enough electricity to meet the required energy needs.

Usually wind turbine manufacturers provide data for the expected annual energy production someone would expect. The manufacturer will use a calculation based on these factors:

- Particular wind turbine power curve

- Average annual wind speed at the site

- Height of the tower

- Frequency distribution of the wind -- an estimate of the number of hours that the wind will blow at each speed during an average year.

The manufacturer should also adjust this calculation for the elevation of the particular site.

To get a preliminary estimate of the performance of a particular wind turbine, you can use the following formula:

$$
A E O=0.01328 D^{2} V^{3}
$$


Where:

- aeo = annual energy output (kilowatt-hours/year)

- $\mathrm{d}=$ rotor diameter, feet

- $\mathrm{v}=$ annual average wind speed, miles-per hour (mph), at your site

Note: the difference between power and energy is that power (kilowatts) is the rate at which electricity is consumed, while energy (kilowatt-hours) is the quantity consumed.

Section 5.5 that follows provides example calculations of wind turbine sizing.

As an example of wind speed potential, Figure 4.39 and Figure 4.40 illustrate the mean wind speed resource or potential in the United Kingdom and Cyprus. The available wind potential is evidently dependent on the location. Cyprus for example has a mean wind resource ranging between 4 and $6 \mathrm{~m} / \mathrm{s}$ whereas in the UK it ranges between 6 and $10 \mathrm{~m} / \mathrm{s}$. Someone can clearly envisage the difference in the energy output from wind turbines in the two regions. Unlike the photovoltaic power potential, for the case of wind, the Mediterranean is not that favourable when it comes to wind.

Wind speed is usually measured in metres per second $[\mathrm{m} / \mathrm{s}]$ but depending on the continent it can also be given in miles per hour [mph] or kilometres per hour [kmph]. A useful online conversion can be found in ${ }^{14}$.

\section{Figure 4.39: Mean wind speed map for the United Kingdom ${ }^{15}$}

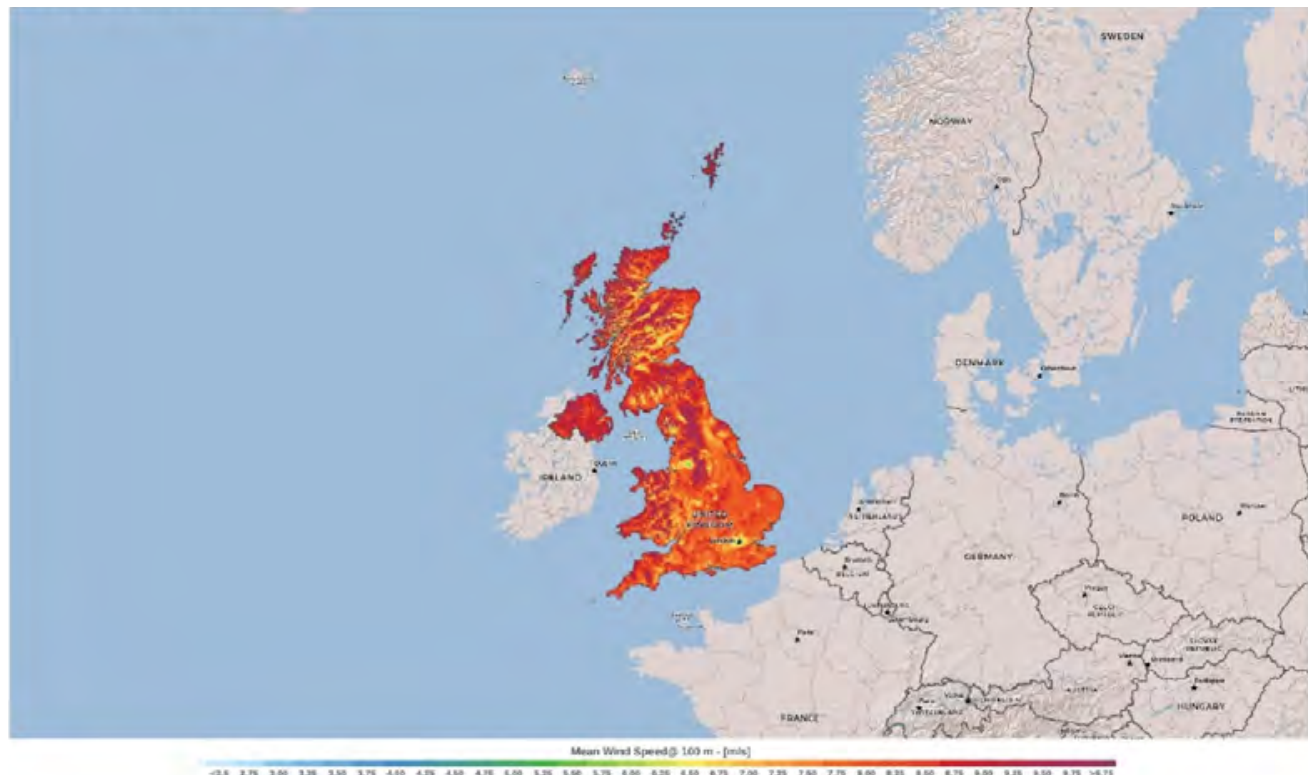

14 https://www.weather.gov/epz/wxcalc_windconvert

15 https://globalwindatlas.info/en/area/United\%20Kingdom?print=true 
Figure 4.40: Mean wind speed map for Cyprus ${ }^{16}$

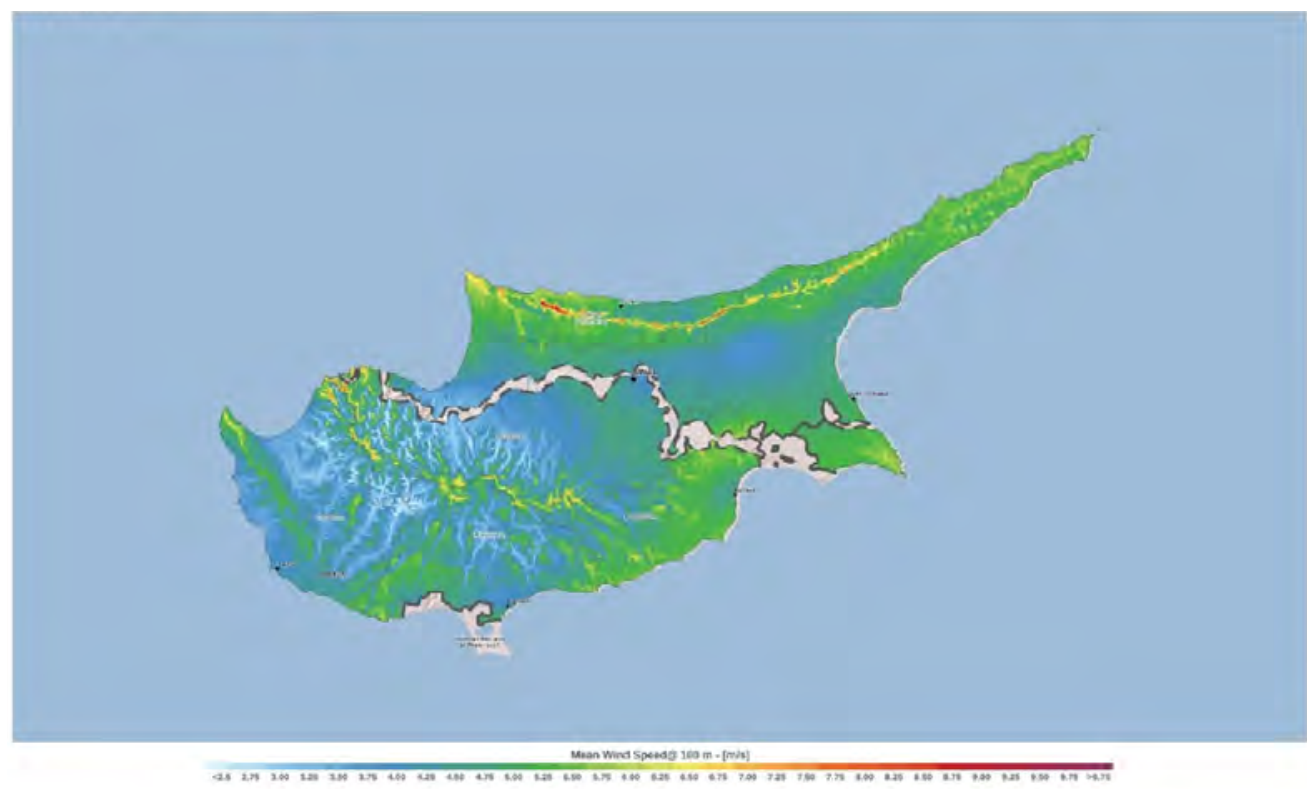

\subsubsection{Grid-Connected Small Wind Electric Systems}

Small wind energy systems can be connected to the electricity distribution system. These are called grid-connected systems. A grid-connected wind turbine can reduce the consumption of utility-supplied electricity for lighting, appliances, electric heat etc. If the turbine cannot deliver the amount of energy required, the utility makes up the difference. When the wind system produces more electricity than the one required, the excess is sent or sold to the utility depending on the local scheme available and perhaps national regulations.

With this type of grid connection, the wind turbine will operate only when the utility grid is available. During power outages, the wind turbine is required to shut down due to safety concerns.

Grid-connected systems can be practical if the following conditions exist:

- You live in an area with average annual wind speed of at least $10 \mathrm{mph}$ (4.5 $\mathrm{m} / \mathrm{s})$.

- Utility-supplied electricity is expensive (about 10-15 cents per kilowatt-hour).

- The utility's requirements for connecting the system to its grid are not prohibitively expensive.

\footnotetext{
${ }^{16}$ https://globalwindatlas.info/en/area/United\%20Kingdom?print=true
} 
There can be good incentives for the sale of excess electricity or for the purchase of wind turbines depending on local government schemes. This is something that must be examined locally by each interested party/organization. In every case, the utility company should be contacted before connecting to its distribution lines to address any power quality and safety concerns.

\subsubsection{Wind Power in off-grid / Stand-Alone Systems}

Wind power can be used in off-grid systems, also called stand-alone systems, not connected to an electric distribution system or grid. In these applications, small wind electric systems can be used in combination with other components -- including a photovoltaic system to create a hybrid system for example. Hybrid power systems can provide reliable off-grid power for homes, farms, or even entire communities (a co-housing project, for example) that are far from the nearest utility lines.

An off-grid, hybrid electric system may be practical if the items below apply:

1. The average annual wind speed is at least $9 \mathrm{mph}(4.0 \mathrm{~m} / \mathrm{s})$.

2. A grid connection is not available or can only be made through an expensive and prohibitive extension.

3. Energy independence from the utility is desired

4. For personal reasons, someone would like to generate clean power.

\subsubsection{SMALL SCALE WIND TURBINES AND APPLICATIONS}

Below are some examples/case studies for the design of small-scale wind turbine systems.

\subsubsection{CASE STUDY 1 - ENERGY OUTPUT CALCULATION BASED ON WIND TURBINE MANUFACTURER'S POWER CURVE}

The power curve below is from a wind turbine manufacturer. This is a vertical axis wind turbine. It is rated at $2.4 \mathrm{~kW}$ (see appendix 7.1 for full specs). The plot shows the power output of the wind turbine in Watts vs the wind speed in $\mathrm{m} / \mathrm{s}$. Its main application is for a grid connected system providing energy for the building's requirements. It can be a house, a small building or an organisation such as a marina etc. The main question is how many kWhs this wind turbine can generate during the year and what percentage of the energy requirements it can satisfy. It is therefore necessary to know what the energy requirements of the dwelling are. This information can be determined from the utility company or from previous electricity bills. The expected energy output from the WT will depend on the wind resource potential available at the site which in turn, is dependent on the considerations taken in mind during the installation. The wind resource is usually expressed as the mean speed at a specific height for a specific area or region. 
As an example, we may consider the mean wind potential for Cyprus. There are various online tools that can be employed to extract the required mean wind data for estimating the energy output in $\mathrm{kWh}$ from a wind turbine. The mean wind speed map for Cyprus shown in Figure 4.42 is the mean wind speed at $50 \mathrm{~m}$. For residential applications it is very unlikely to go above $50 \mathrm{~m}$. Even $50 \mathrm{~m}$ is a lot. Perhaps $10 \mathrm{~m}$ would be more realistic if data for $10 \mathrm{~m}$ or $30 \mathrm{~m}$ are available. Figure 4.41 shows the mean wind speed for Cyprus at $10 \mathrm{~m}$. The effect the height has on the wind speed can be clearly seen in these two maps. There can be a difference of $20 \%$ in the mean wind speed when the same regions for example are examined at these two heights.

Figure 4.41: Power curve for vertical axis $2.4 \mathrm{~kW}$ wind turbine ${ }^{17}$

\begin{tabular}{|lcc|}
\hline $\begin{array}{l}\text { Power } \\
\text { Nominal power. }\end{array}$ & $2400 \mathrm{~W}$ \\
Dimensions & $3 \mathrm{~m}$ & $9.8 \mathrm{ft}$ \\
Height & $3 \mathrm{~m}$ & $9.8 \mathrm{ft}$ \\
Width & $140 \mathrm{~kg}$ & $308.6 \mathrm{lb}$ \\
Weight & & \\
Operation & $5 \mathrm{~km} / \mathrm{h}$ & $3.1 \mathrm{mph}$ \\
Cut-in speed.* & $40 \mathrm{~km} / \mathrm{h}$ & $24.8 \mathrm{mph}$ \\
Nominal speed & $209 \mathrm{~km} / \mathrm{h}$ & $130 \mathrm{mph}$ \\
Maximum speed & & \\
Generator & & \\
Type & Permanent magnet \\
Voltage & $110 / 220$ & \\
Connection type & Grid-tie \\
Warrantyt & 20 years \\
\hline
\end{tabular}

Let us however consider the map with the data for $10 \mathrm{~m}$. If we select a location in Larnaca for example shown by the red dot in Figure 4.42 we notice that the mean wind speed is around $3.5 \mathrm{~m} / \mathrm{s}$. Given the power plot of the specific wind turbine that we are examining, at $3.5 \mathrm{~m} / \mathrm{s}$ the power output of the WT will be around $100 \mathrm{~W}$. If we consider that the WT will give this output constantly every hour, the expected energy output of the WT can be calculated as follows:

expected approx. annual energy in $\mathrm{kWh}$ at $10 \mathrm{~m}=0.1 \mathrm{~kW} \times 24 \mathrm{~h} \times 365$ days $=876 \mathrm{kWh}$

If the same calculation is performed at $50 \mathrm{~m}$ then:

expected approx. annual energy in $\mathrm{kWh}$ at $50 \mathrm{~m}=0.2 \mathrm{~kW} \times 24 \mathrm{~h} \times 365$ days $=1752 \mathrm{kWh}$

As the mean wind speed at $50 \mathrm{~m}$ is $5 \mathrm{~m} / \mathrm{s}$, the power output at this speed is around $200 \mathrm{~W}$.

17 https://semtive.com/residential/ 
Figure 4.42: Mean wind speed data for Cyprus at $50 \mathrm{~m}^{18}$

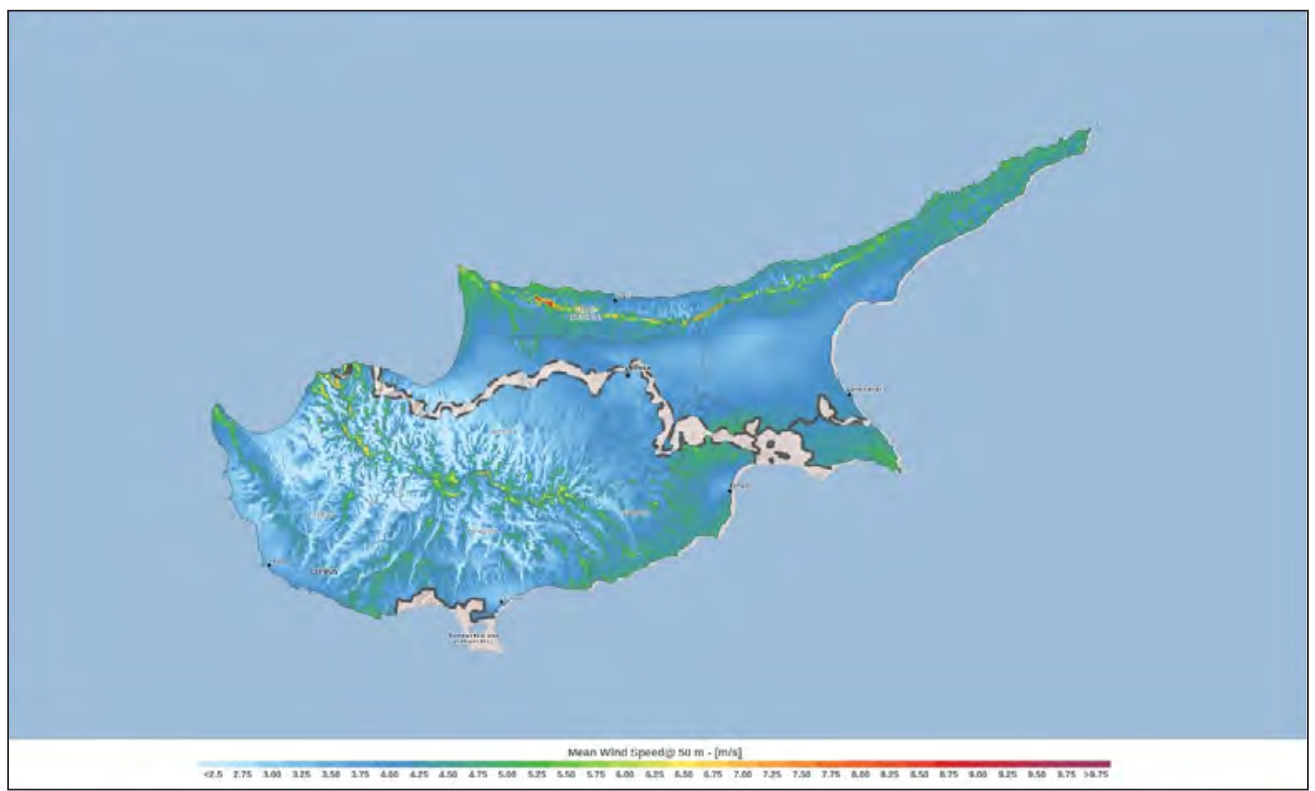

Figure 4.43: Mean wind speed data for Cyprus at $10 \mathrm{~m}^{19}$

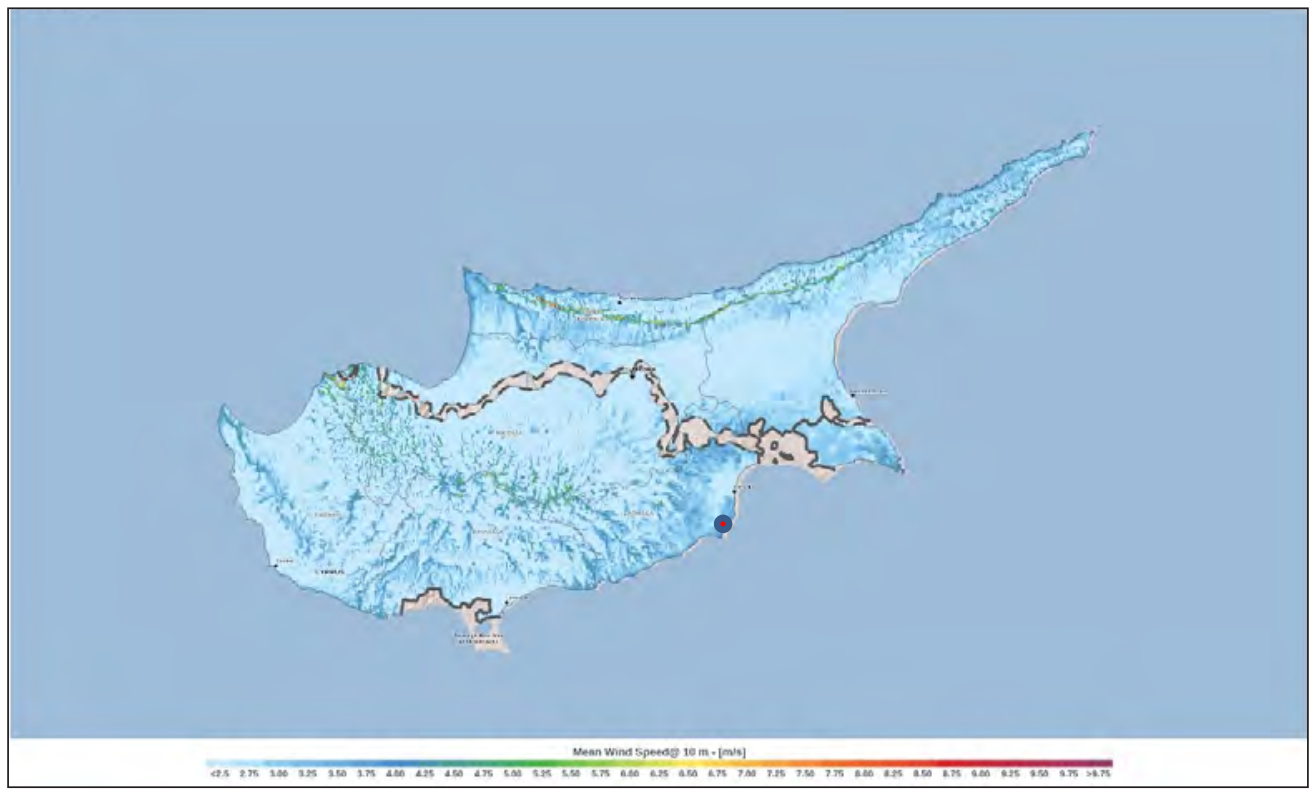

${ }^{18} \mathrm{https}: / /$ globalwindatlas.info/en/area/United\%20Kingdom?print=true

${ }_{19} \mathrm{https} / /$ globalwindatlas.info/en/area/United\%20Kingdom?print $=$ true 
The reader can clearly realize the effect that the height and the location have on the energy output expected from a wind turbine.

\subsubsection{CASE STUDY 2 - ALTERNATIVE ENERGY OUTPUT CALCULATION METHOD}

For horizontal axis wind turbines, in addition to the power curve provided by the WT manufacturer, the following equation can be used to determine the output power from the WT and consequently the energy output:

$$
\mathrm{P}=C p \cdot \frac{1}{2} \cdot \rho \cdot \mathrm{A} \cdot \mathrm{V}^{3}
$$

Where,

- $\mathrm{Cp}$ is the efficiency of the WT, usually in the range of 30-40\%

- $\rho$ is the air density, usually taken as $1.225 \mathrm{~kg} / \mathrm{m}^{3}$ at $1013.25 \mathrm{hPa}$ (abs) and $15^{\circ} \mathrm{C}$

- A is the area of the rotor calculated by $\pi \mathrm{r}^{2}$ with the rotor radius in meters

- $\mathrm{V}$ is the mean wind speed in $\mathrm{m} / \mathrm{s}$

Let us for example consider the BERGEY EXCEL 10 WT the technical datasheet of which is given in appendix. This WT has a rotor diameter of $7 \mathrm{~m}$. Using the $3.5 \mathrm{~m} / \mathrm{s}$ (10 m height) and $5 \mathrm{~m} / \mathrm{s}$ mean wind speeds (50 m height) as in the previous case study, 5.5.1, the power and energy output from this wind generator would be:

expected output power in $\mathrm{kW}$ at $10 \mathrm{~m}=0.3 \times 0.5 \times 1.225 \times \pi 3.5^{2} \times 3.5^{3}=0.303 \mathrm{~kW}$

expected approx. annual energy in $\mathrm{kWh}$ at $10 \mathrm{~m}=0.303 \mathrm{~kW} \times 24 \mathrm{~h} \times 365$ days $=2654 \mathrm{~kW}$

This is a bigger WT compared to the one in case study 5.5.1, specifically, it is an $8.9 \mathrm{~kW}$ WT rated at $11 \mathrm{~m} / \mathrm{s}$.

Repeating the above calculations with mean wind speed at $50 \mathrm{~m}$ we get:

expected output power in $\mathrm{kW}$ at $50 \mathrm{~m}=0.3 \times 0.5 \times 1.225 \times \pi 3.5^{2} \times 5^{3}=0.884 \mathrm{~kW}$

expected approx. annual energy in $\mathrm{kWh}$ at $50 \mathrm{~m}=0.884 \mathrm{~kW} \times 24 \mathrm{~h} \times 365$ days $=7744 \mathrm{~kW}$

Investigating the annual energy output given by the manufacturer in the specification sheet, appendix 7.2, we notice a considerable difference. One of the reasons is the height of the installation, which they recommend it to be 80-140 feet and of course, the most important parameter, is the wind speed. Being an American company, the energy output mentioned most probably corresponds to mean wind speeds for America. 


\subsubsection{CASE STUDY 3 - ENERGY OUTPUT CALCULATION COMPARISON BETWEEN TWO REGIONS - THE UNITED KINGDOM AND CYPRUS}

This case study demonstrates how mean wind speed data obtained from online wind simulation tools can be used in order to estimate and compare the expected energy output in $\mathrm{kWh}$ for two countries with considerable difference in the wind resource potential. These two countries are the United Kingdom and Cyprus. As previously mentioned, there are two ways by which the power and energy can be estimated from wind turbines [WT]. The first way is by referring to the WT manufacturer's power curve, and the second way is using the equation below, already discussed but presented here again.

$$
\mathrm{P}=C p \cdot \frac{1}{2} \cdot \rho \cdot \mathrm{A} \cdot \mathrm{V}^{3}
$$

Where,

- $\mathrm{Cp}$ is the efficiency of the WT, usually in the range of $30-40 \%$

- $\rho$ is the air density, usually taken as $1.225 \mathrm{~kg} / \mathrm{m} 3$ at $1013.25 \mathrm{hPa}$ (abs) and $15^{\circ} \mathrm{C}$

- A is the area of the rotor calculated by $\pi \mathrm{r}^{2}$ with the rotor radius in meters

- $\mathrm{V}$ is the mean wind speed in $\mathrm{m} / \mathrm{s}$

It is important for the reader to note that for both methods, it is necessary to know beforehand the mean wind speed for the specific region and height at which the WT will be installed. The most accurate way is to perform measurements at the particular region and height at which the WT will be installed. This however imposes many practical difficulties and is time consuming. To start with, it requires equipment and sometimes there is no source of energy available, especially if it is a remote site. For a such a case, a stand-alone renewable energy system will be required to provide power for the equipment. Even if however, there is power available, there is a significant cost associated with the purchase of the equipment, a minimum period of one year of measurements is required and it will be necessary for someone to frequently inspect and monitor the measuring system in order to check that it is up and running.

It is for this reason that depending on the criticality of the investment, sometimes the data available from on-line databases or simulation tools such as those in https://globalwindatlas.info/en/area/United\%20Kingdom?print=true and https://map.neweuropeanwindatlas.eu/ are a good compromise. In this case study, such tools are employed for comparison purposes. If the purpose is to carry out a techno-economic analysis to accurately determine the payback period of an investment for example, then a more serious consideration with regards the mean wind speed data to be used should be thought of. 
It will be considered here that the WT will be installed at a height of $10 \mathrm{~m}$ which is the minimum height at which mean wind speed data can be provided from on-line simulation tools. The next height at which mean wind speed data is provided is at $50 \mathrm{~m}$, however, it is not practical and feasible to install grid-tied or stand-alone WT in residential or small organizations or yachts at this height.

Two on-line simulation tools and databases will be considered mainly for comparison reasons between them. The first is from the New European Wind Atlas (NEWA) ${ }^{20}$ and the second from the Global Wind Atlas ${ }^{21}$.

Examining the mean wind speed from the Global Wind Atlas for the United Kingdom and Cyprus we find the following data (see red box shown in the figures where the mean speed is given).

1. Location: United Kingdom - Dover. Mean wind speed $4.5 \mathrm{~m} / \mathrm{s}$, Figure 4.44

2. Location: Cyprus - Larnaca. Dover. Mean wind speed 3 m/s, Figure 4.45

\section{Figure 4.44 United Kingdom - Dover. Mean wind speed $4.5 \mathrm{~m} / \mathrm{s}$ [Global Wind Atlas]}

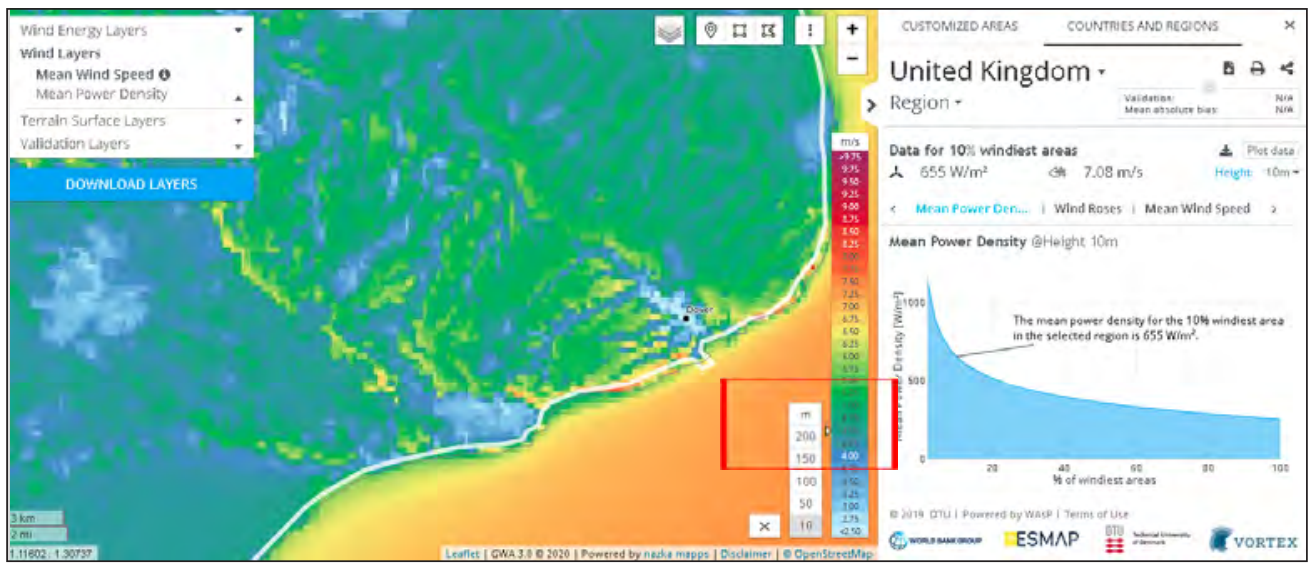

\footnotetext{
20 https://map.neweuropeanwindatlas.eu/

21 https:/globalwindatlas.info/en/area/United\%20Kingdom?print $=$ true
} 
Figure 4.45 Cyprus - Larnaca. Mean wind speed $3 \mathrm{~m} / \mathrm{s}$ [Global Wind Atlas]

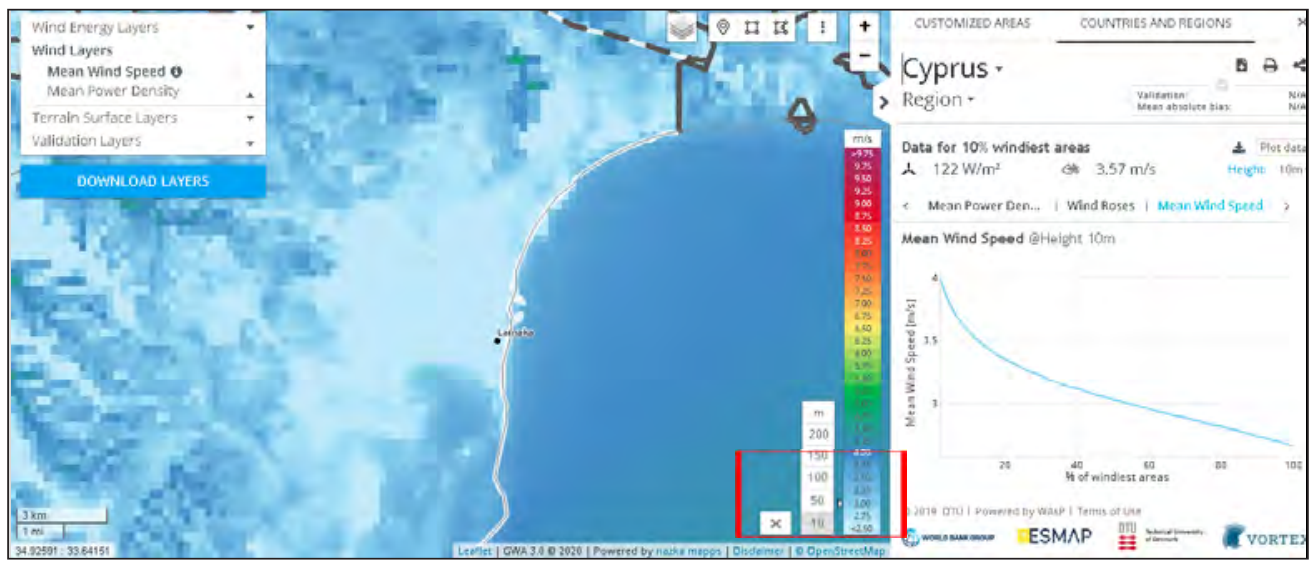

Examining the mean wind speed from the NEWA Wind Atlas for the United Kingdom and Cyprus we find the following data.

1. Location: United Kingdom - Dover. Mean wind speed $6.55 \mathrm{~m} / \mathrm{s}$, Figure 4.46 .

2. Location: Cyprus - Larnaca. Dover. Mean wind speed $3.63 \mathrm{~m} / \mathrm{s}$, Figure 4.47.

Figure 4.46: United Kingdom - Dover. Mean wind speed $6.55 \mathrm{~m} / \mathrm{s}$ [NEWA Wind Atlas]

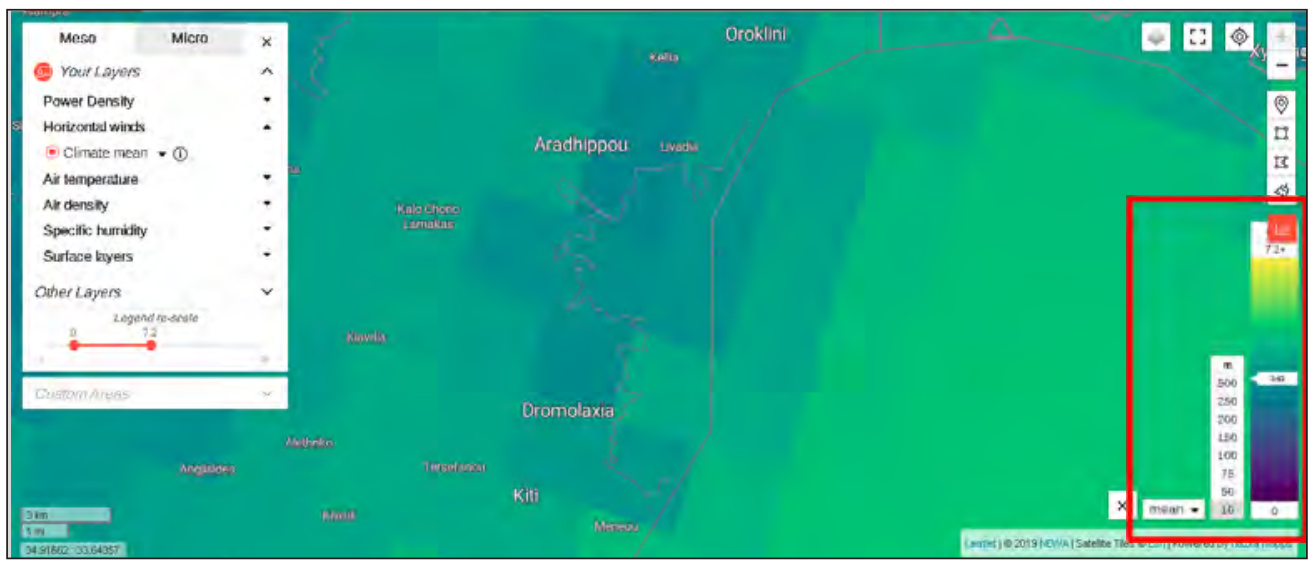


Figure 4.47: Cyprus - Larnaca. Mean wind speed $3.63 \mathrm{~m} / \mathrm{s}$ [NEWA Wind Atlas]

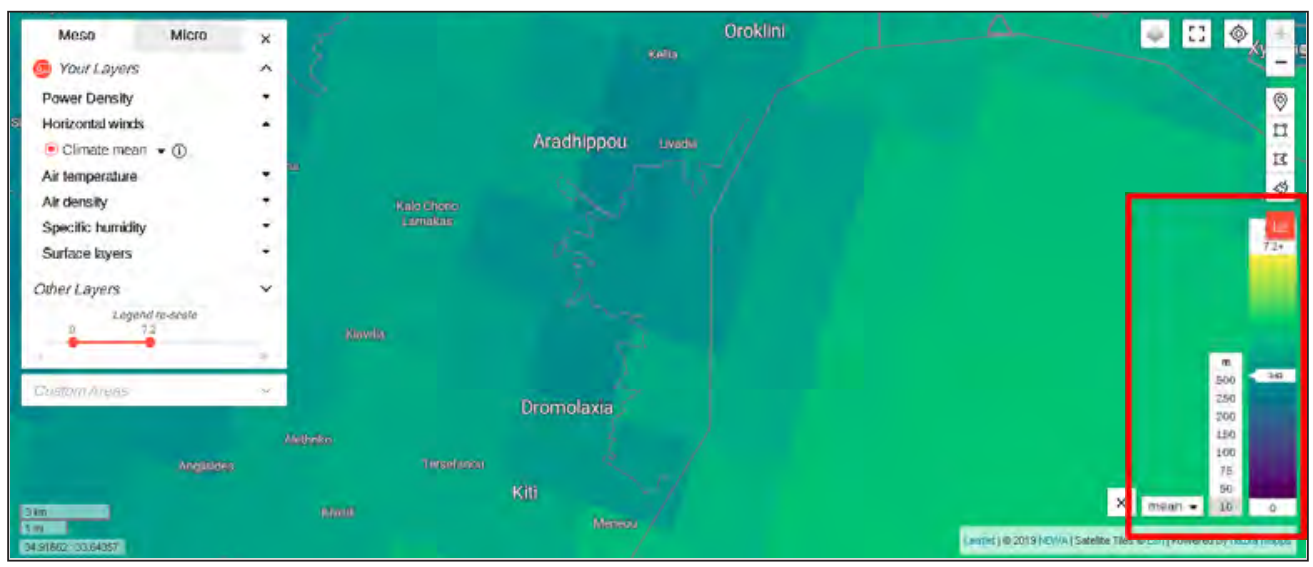

Comparing the data from NEWA and Global Wind Atlas it is observed that the mean wind speed measurements do not agree between them. The mean wind speed for Larnaca-Cyprus given by the two atlas is very close but for Dover-United Kingdom it is not. Care must be given to this uncertainty. For the purpose of this case study, the average of the two values will be determined as follows:

1. Location: United Kingdom - Dover. Average of Mean wind speeds given by NEWA and Global Wind Atlas: $(6.55+4.50 / 2=\underline{5.525 \mathrm{~m} / \mathrm{s}}$

2. Location: Cyprus - Larnaca. Dover. Average of Mean wind speeds given by NEWA and Global Wind Atlas: $(3.63+3) / 2=\underline{3.315 \mathrm{~m} / \mathrm{s}}$

Having determined the values of the mean wind speeds to be used for the case study it is now possible to continue with the calculation of the power and energy output expected from a wind turbine at these two locations. We will assume that the wind turbine with the technical specifications given below Figure 4.48 will be used. 
Figure 4.48: Southwest Windpower "Skystream 3.7" wind turbine [10]

\begin{tabular}{|c|c|}
\hline \multicolumn{2}{|c|}{ Technical Specifications } \\
\hline Rated Capacity & $2.4 \mathrm{~kW}$ \\
\hline Rotor Diameter & $12 \mathrm{ft}(3.72 \mathrm{~m})$ \\
\hline Weight & $170 \mathrm{lb}(77 \mathrm{~kg})$ \\
\hline Swept Area & $115.7 \mathrm{ft}^{2}\left(10.87 \mathrm{~m}^{2}\right)$ \\
\hline Type & $\begin{array}{l}\text { Downwind rotor with stall } \\
\text { regulation control }\end{array}$ \\
\hline Direction of Rotation & Clockwise looking upwind \\
\hline Blades & (3) Fiberglass reinforced composite \\
\hline Rated Speed & $50-330 \mathrm{rpm}$ \\
\hline Maximum Tip Speed & $216.5 \mathrm{ft} / \mathrm{s}(66 \mathrm{~m} / \mathrm{s})$ \\
\hline Alternator & Slotless permanent magnet brushless \\
\hline Yaw Control & Passive \\
\hline Grid Feeding & $\begin{array}{l}120 / 240 \text { VAC Split } 1 \mathrm{Ph}, 60 \mathrm{~Hz} \\
120 / 208 \text { VAC } 3 \text { Ph compatible, } \\
60 \mathrm{~Hz} \text { (Check with dealer for other } \\
\text { configurations) }\end{array}$ \\
\hline Battery Charging & $\begin{array}{l}\text { Battery Charge Controller kit available } \\
\text { for battery charging systems }\end{array}$ \\
\hline Braking System & $\begin{array}{l}\text { Electronic stall regulation with } \\
\text { redundant relay switch control }\end{array}$ \\
\hline Cut-in Wind Speed & $8 \mathrm{mph}(3.5 \mathrm{~m} / \mathrm{s})$ \\
\hline Rated Wind Speed & $29 \mathrm{mph}(13 \mathrm{~m} / \mathrm{s})$ \\
\hline User Monitoring & Wireless 2-way interface \\
\hline Survival Wind Speed & $140 \mathrm{mph}(63 \mathrm{~m} / \mathrm{s})$ \\
\hline Warranty & 5 year limited warranty \\
\hline
\end{tabular}


Using the WT specifications, we can calculate the power output and energy as follows using the equation given in the beginning of this case study:

\section{For Dover-United Kingdom}

expected output power in $\mathrm{kW}$ at $10 \mathrm{~m}=0.3 \times 0.5 \times 1.225 \times \pi 3.72^{2} \times 5.525^{3}=1.35 \mathrm{~kW}$ expected approx. annual energy in $\mathrm{kWh}$ at $10 \mathrm{~m}=1.35 \mathrm{~kW} \times 24 \mathrm{~h} \times 365$ days $=11826 \mathrm{~kW}$

\section{For Larnaca-Cyprus}

expected output power in $\mathrm{kW}$ at $10 \mathrm{~m}=0.3 \times 0.5 \times 1.225 \times \pi 3.72^{2} \times 3.315^{3}=0.291 \mathrm{~kW}$ expected approx. annual energy in $\mathrm{kWh}$ at $10 \mathrm{~m}=0.291 \mathrm{~kW} \times 24 \mathrm{~h} \times 365$ days $=2550 \mathrm{~kW}$

The reader can clearly realize the difference in the energy output expected from the same WT at these two different locations.

Examining however the expected output and energy in kWh given by the power curves of the manufacturer, a considerable deviation is seen. From the figure below, for a mean wind speed of $5.525 \mathrm{~m} / \mathrm{s}$, the annual energy output is 350 (as given by the graph) $\times 12$ months $=4200 \mathrm{kWh}$.

The reason for this considerable deviation has to do with the efficiency of the WT which is not constant for varying winds. This case study further demonstrates the importance of referring to the manufacturer's power curves when estimating the expected output power from a WT.

\section{Figure 4.49: Power and monthly energy output of Southwest Windpower "Skystream 3.7" wind turbine ${ }^{23}$}
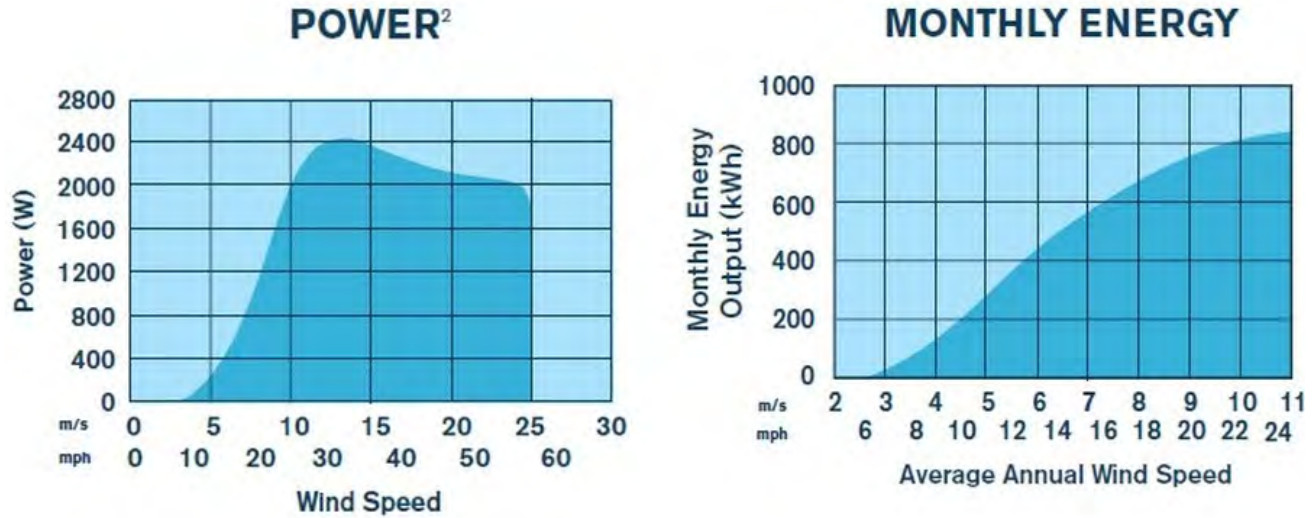

23 http://www.qualitytolast.com/skystream-37.html 


\subsubsection{CASE STUDY 4 - SIZING OF W IND TURBINE BASED ON SPECIFIC ENERGY REQUIREMENTS}

The case study presented in this in this section aims to guide the reader through the basic consideration steps for sizing a wind turbine [WT] based on specific energy requirements. The energy requirements (energy consumption in other words) can be obtained from the energy service provider of the building under study. The building can be a house, a company, a factory, a marina etc. It does not actually matter as renewable energy systems can be used by any building as an investment or to accommodate a decrease in the electricity bill. This depends on the governmental schemes available in a country/region and which are frequently re-evaluated, modified or even withdrawn sometimes.

The energy consumption is generally in kWh unless it is a big industrial building where, the energy consumption can be in kWh, kVAr or kVA. Again, this depends on the grid operator or the regulatory authorities of a country or region. The energy consumption presented in this case will be in $\mathrm{kWh}$ which is the most frequent unit used worldwide for measuring energy consumption. Table 4.6 below presents such a consumption profile as it is called. The billing period is again something that depends on the country or region. The billing period for the consumption profile presented is bi-monthly.

Table 4.6: Consumption profile of building

\begin{tabular}{|c|c|c|c|}
\hline \multicolumn{2}{|c|}{ PERIOD } & & \\
\cline { 1 - 2 } FROM & TO & & COST [€] \\
\hline $10 / 06 / 2020$ & $11 / 08 / 2020$ & 3.515 & 533,03 \\
$10 / 04 / 2020$ & $10 / 06 / 2020$ & 2.131 & 387,65 \\
$11 / 02 / 2020$ & $10 / 04 / 2020$ & 1.431 & 281,40 \\
\hline $10 / 12 / 2019$ & $11 / 02 / 2020$ & 3.401 & 730,58 \\
$10 / 10 / 2019$ & $10 / 12 / 2019$ & 2.757 & 610,97 \\
\hline $09 / 08 / 2019$ & $10 / 10 / 2019$ & 3.487 & 764,80 \\
$11 / 06 / 2019$ & $09 / 08 / 2019$ & 3.373 & 696,77 \\
$10 / 04 / 2019$ & $11 / 06 / 2019$ & 2.024 & 444,08 \\
\hline $11 / 02 / 2019$ & $10 / 04 / 2019$ & 1.537 & 317,64 \\
$11 / 12 / 2018$ & $11 / 02 / 2019$ & 1.974 & 417,02 \\
$10 / 10 / 2018$ & $11 / 12 / 2018$ & 2.092 & 486,83 \\
$09 / 08 / 2018$ & $10 / 10 / 2018$ & 3.97 & 857,43 \\
$11 / 06 / 2018$ & $09 / 08 / 2018$ & 3.157 & 638,93 \\
\hline $13 / 04 / 2018$ & $11 / 06 / 2018$ & 3.066 & 600,69 \\
$09 / 02 / 2018$ & $13 / 04 / 2018$ & 2.172 & 404,54 \\
$11 / 12 / 2017$ & $09 / 02 / 2018$ & 2.423 & 439,31 \\
$10 / 10 / 2017$ & $11 / 12 / 2017$ & 2.181 & 378,48 \\
$09 / 08 / 2017$ & $10 / 10 / 2017$ & 3.526 & 654,81 \\
\hline
\end{tabular}




\begin{tabular}{|l|c|c|c|}
\hline $12 / 06 / 2017$ & $09 / 08 / 2017$ & 3.587 & 678,84 \\
$11 / 04 / 2017$ & $12 / 06 / 2017$ & 2.112 & 410,07 \\
$09 / 02 / 2017$ & $11 / 04 / 2017$ & 1.937 & 389,09 \\
$09 / 12 / 2016$ & $09 / 02 / 2017$ & 2.558 & 484,08 \\
$11 / 10 / 2016$ & $09 / 12 / 2016$ & 2.65 & 469,59 \\
\hline $09 / 08 / 2016$ & $11 / 10 / 2016$ & 3.68 & 618,15 \\
\hline
\end{tabular}

Having such a consumption profile is very important and essential for sizing any renewable energy system [RES] especially if the purpose is to meet the energy requirements of the building and to reduce the electricity bill. Taking into consideration the last six bills which account for the annual consumption, we calculate that the total energy consumption in $\mathrm{kWh}$ is $16.722 \mathrm{kWh}$ (sixteen thousand seven hundred and twenty-two) and the total amount in euros is $€ 3,308.61$.

If the objective, as earlier mentioned, is to meet this energy consumption from a wind turbine system, the system should as a result, generate the above consumed energy. It is usual to round the energy consumption or even sometimes apply a safety factor as well, to account for inaccuracies in the calculations, unexpected circumstances in the wind profile of a year leading to lower wind potential or even increased consumption for any reason. If for example we were to apply a $20 \%$ safety factor, the consumption with which the calculations would proceed would be:

$16.722 \times 1.2=20.0664 \mathrm{kWh}$ or rouding this number we can say $20.000 \mathrm{kWh}$

Having therefore the estimate of the energy that is required to be generated from the wind turbine system the next steps are as follows:

1. Determine the wind potential at the site at which the WT will be installed having in mind the considerations mentioned earlier such as the installation height for example.

2. Select a wind turbine and its respective power curve. This will allow for the expected energy output from the wind turbine to be estimated.

3. Verify with theoretical calculations the expected generated energy from the wind turbine system.

4. Look for other buildings with wind turbine systems in the same area and enquire what is the energy generated from these systems.

It is always a good idea to talk with different WT manufacturers and try to get as many studies for a specific system. Such investments are big and the investor should decide based on the available quotes that he will get. Any results arising from such studies should be attempted to be verified somehow, since such systems have characteristics and peculiarities that depend on many factors.

The wind potential variation depending on the region was discussed in earlier sections. Some well-known online tools have been presented which can be used in 
order to estimate and give an idea of the size of the wind turbine required. It is almost impossible to estimate the size of the WT required without referring to the characteristics of the manufactures.

The output of a wind turbine depends on the turbine's size and the winds speed through the rotor. An average onshore wind turbine with a capacity of 2.5$3 \mathrm{MW}$ can produce more than 6 million $\mathrm{kWh}$ in a year - enough to supply 1,500 average EU households with electricity. This however does not mean anything and for small-scale systems it can all go horribly wrong.

Let's go through an example for this case study. The energy required to be generated for this case study is around $20.000 \mathrm{kWh}$ per year as previously elaborated. Using the online tool in reference [10] below, Figure 5-24, we notice that with a $4 \mathrm{~m}$ radius WT and 35\% efficiency, we can generate around 20000 $\mathrm{kWh}$ per year if the average wind speed is $6 \mathrm{~m} / \mathrm{s}$.

\section{Figure 4.50: Example (1) of yield calculation from a wind turbine ${ }^{24}$}

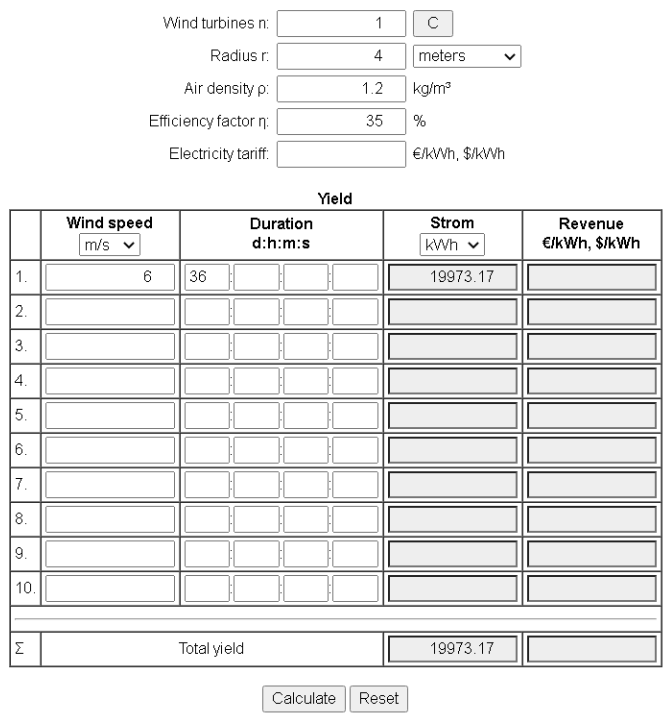

The next question is whether there is such a WT available and what its size is in $\mathrm{kW}$ as well as what the cost is. So, let's look at a couple of wind turbines and compare the manufacturer's expected output energy with the online tool presented above. Figure 4.51 below, presents the technical characteristics of a $15.6 \mathrm{~kW}$ WT. If these specifications are used as input data in the online tool presented above, we get the following: 
Figure 4.51: Example (2) of yield calculation from a wind turbine ${ }^{25}$

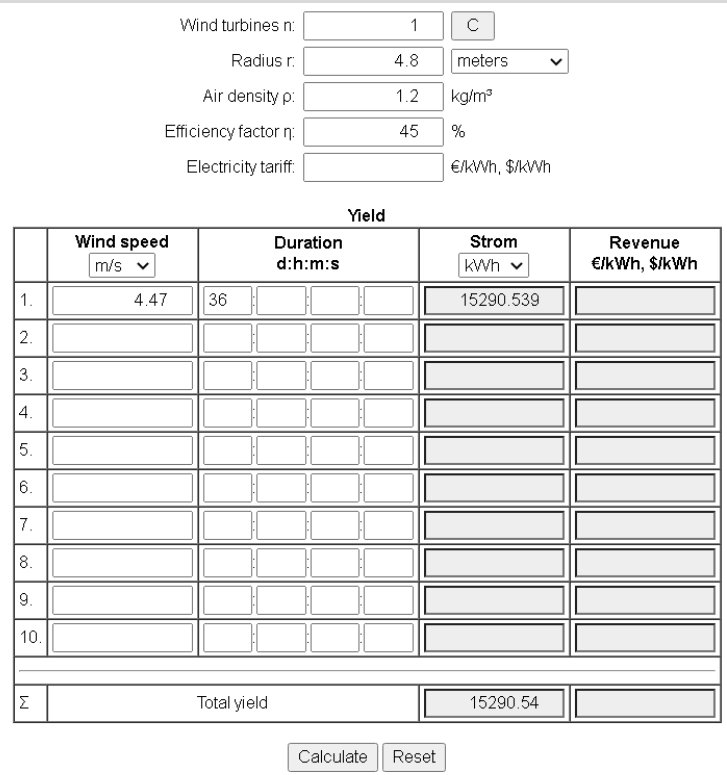

Comparing the results from the online tool in Figure 4.52 it is noticed that there is a $34.1 \%$ difference between what the manufacture gives as annual energy output $(23200 \mathrm{kWh})$ and what is estimated by the tool $(15290 \mathrm{kWh})$ at an average speed of $10 \mathrm{mph}$. Of course, what is unknown in the above example is the efficiency of the WT (45\% was used). Note also that the wind speed given in the specification sheet of the manufacturer is in $\mathrm{mph}$. This was converted to $\mathrm{m} / \mathrm{s}(4.47 \mathrm{~m} / \mathrm{s})$ before inserted in the online tool. The example shows that specific and accurate information is required if any online tool is to be used. It is always recommended that the manufacturer's specifications are used for a study. 
Figure 4.52: Technical datasheet of a $15.6 \mathrm{~kW}$ wind turbine ${ }^{26}$

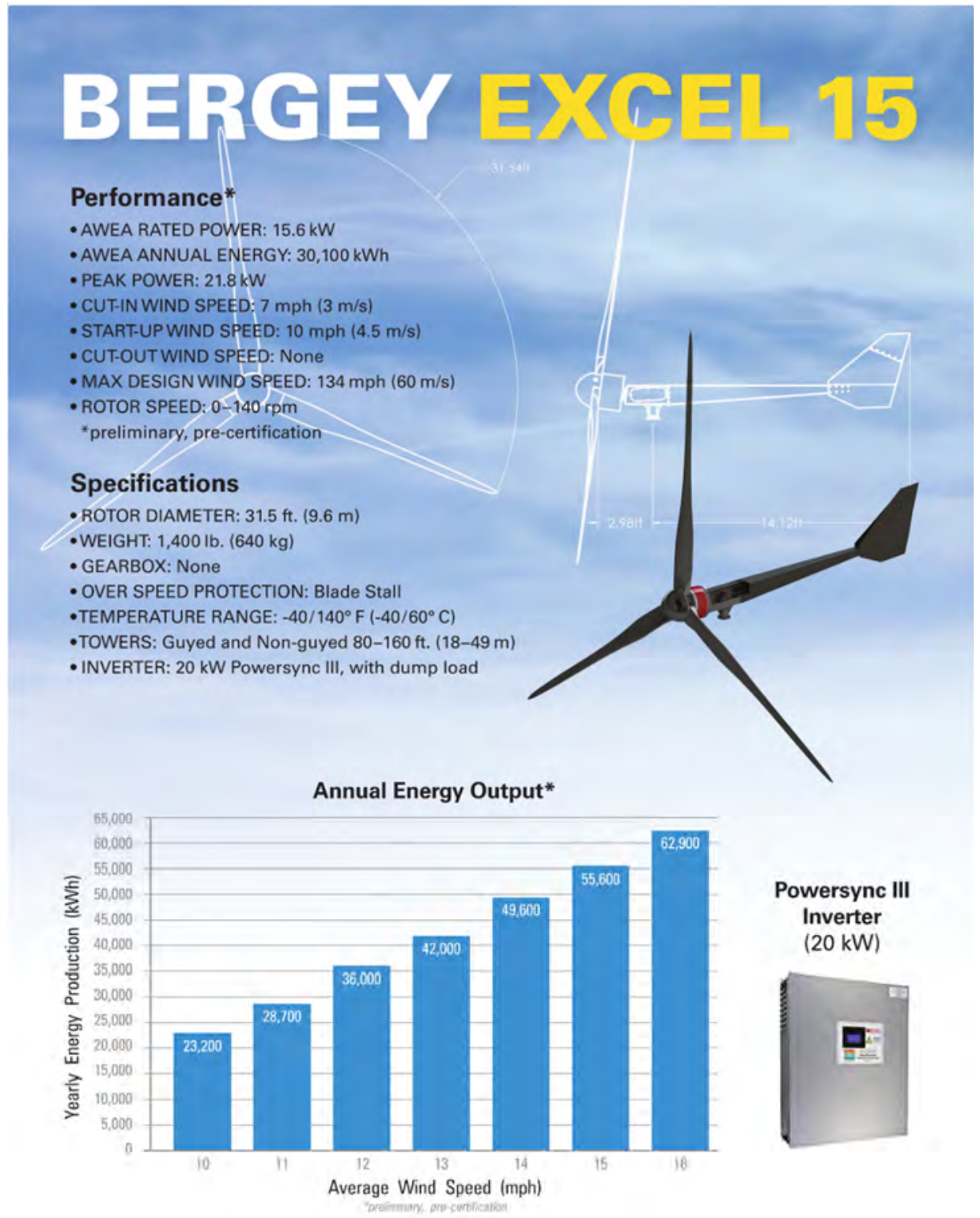

Examining the wind power of another WT, rated at $5.5 \mathrm{~kW}$ with a $2.15 \mathrm{~m}$ radius, the expected energy calculated by the online tool in [10] is $4293 \mathrm{kWh}$ per year at $5 \mathrm{~m} / \mathrm{s}$ average wind speed. For this WT the efficiency is known (45\%). Comparing the calculated result from the expected energy given in the specification

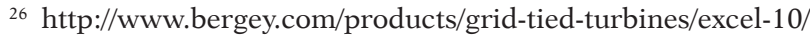


sheet below, Figure 5-27, there is a deviation of $37.7 \%$ between the calculated (4293 kWh per year) and the expected energy from the manufacturer $(6900 \mathrm{kWh}$ per year).

It is therefore important to appreciate the significance of having accurate and verified information when dealing with such investments. Especially for large scale systems, the smallest deviation in the expected power or energy may affect the financial investment numbers.

Figure 4.53: $5.5 \mathrm{~kW}$ Wind turbine power/energy specifications

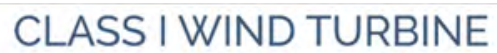

IEC 61400-2/NVI-A

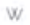

4800

4600

4400

4200

4000
3800

3600

3400

3200

3000

2800
2600

2400

2200

2000

1800

1600

1400
1200

1200
1000

800

600

600
200

0

Th

26400

25200

24000

22800

21600

20400

19200

18000

16800

15600

14400

13200
12000

10800

9600

8400

7200

4800

3600
2400

1200

0

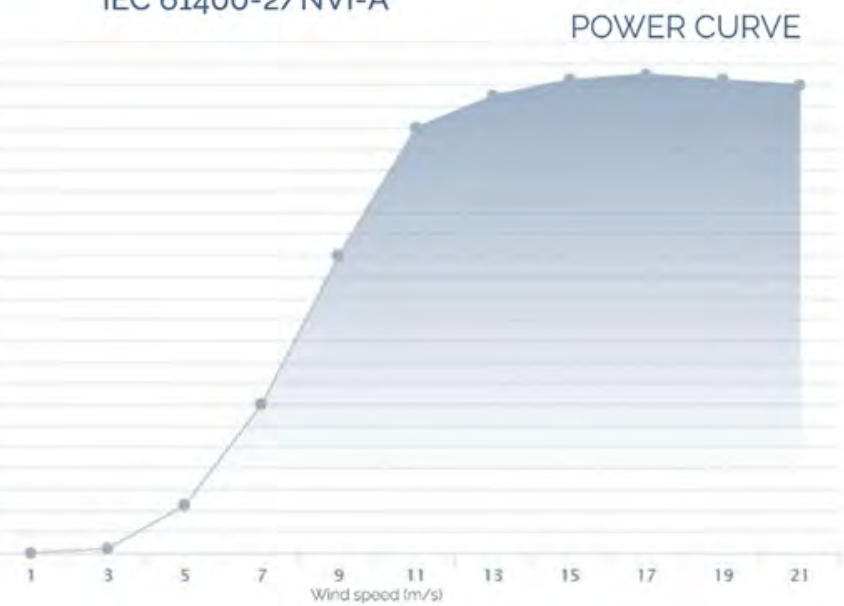

ANUAL PRODUCTION

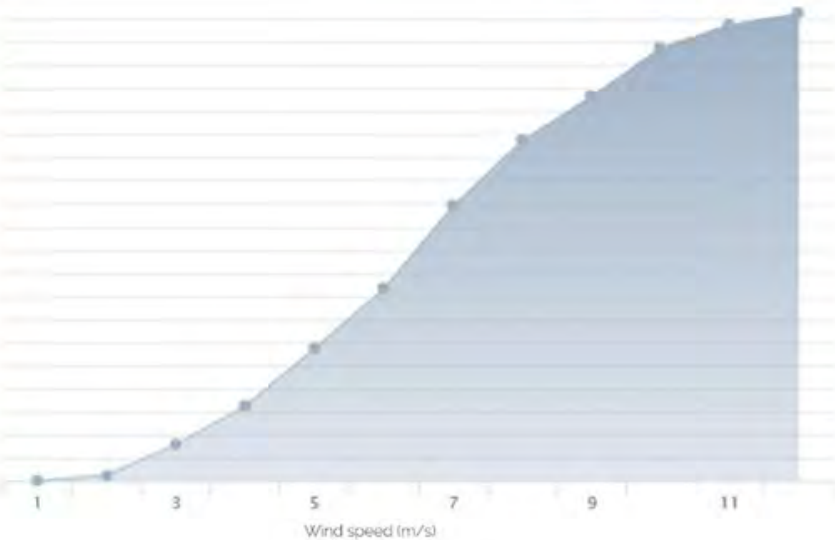




\subsection{References and on-line tools}

\subsubsection{On-line Internet Tools}

\section{PVTRIN}

http://pvtrin.eu/el/home/index.html

\section{PV EDUCATION}

https://pveducation.org/

3. Fronius

https://fronius.solarconfigurator.de/solar.configurator/quick

4. Sun angle

https://susdesign.com/sunangle/

5. PVGIS

http://re.jrc.ec.europa.eu/pvg_tools/en/tools.html\#PVP

6. CABLES

https://stephenstuff.wordpress.com/2016/06/11/dc-cable-selection-guide/

7. OTHER

http://www.pvresources.com

8. WIND LOAD CALCULATOR

https://skyciv.com/wind-load-calculator/

9. WIND TURBINE POWER CALCULATOR

https://rechneronline.de/wind-power/

10. WIND TURBINE ENERGY YIELD CALCULATOR

https://rechneronline.de/wind-power/yield.php

\subsubsection{Hyperlinks}

[1] https://www.solarweb.com/PvSystems/PvSystem?pvSystemId=1c23df39f49d-4904-8012-050662c29c8a

[2] http://212.50.112.34/ 


\subsection{Appendix}

\subsubsection{Semtive vertical axis wind turbine}

\section{Semtive turbine's advantages}

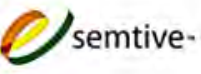

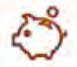

\section{Affordable}

Designed to provide an affordable solution combined with a rapid return on investment.

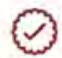

\section{Reliable}

Heavy duty construction,

$40+$ years of reliability.

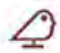

Noiseless

At any wind condition.

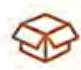

\section{Simple installation}

Less than one hour and just one

tool needed. Plug \& play connection, in a flat pack.

$\infty$

Minimum maintenance

No cleaning needed and only two moving parts.

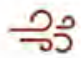

Wide operating window

From a light breeze to a hurricane.

Optimized to work at low wind speeds.

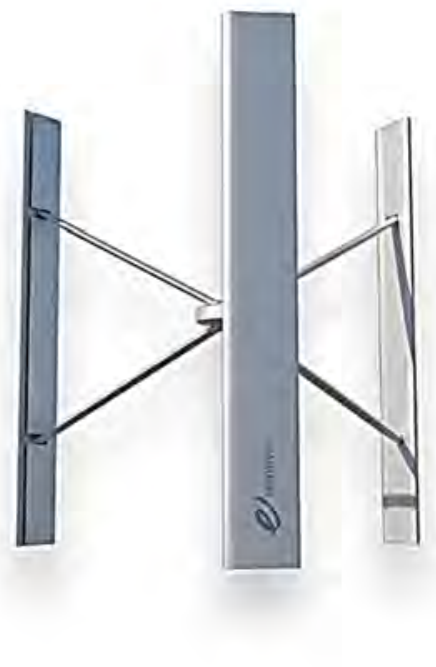


Product specification Nemoi M

\section{Power}

Nominal power:

$2400 \mathrm{~W}$

\section{Dimensions}

Height

$3 \mathrm{~m} \quad 9.8 \mathrm{ft}$

Width

$3 \mathrm{~m}$

$9.8 \mathrm{ft}$

Weight

$140 \mathrm{~kg}$

$308.6 \mathrm{lb}$

Operation

cut-in speed "

Nominal speed

$5 \mathrm{~km} / \mathrm{h} \quad 3.1 \mathrm{mph}$

Maximum speed

$40 \mathrm{~km} / \mathrm{h} \quad 24.8 \mathrm{mph}$

$209 \mathrm{~km} / \mathrm{h} \quad 130 \mathrm{mph}$

\section{Generator}

Type

Voltage

Permanent magnet

$$
110 / 220
$$

Connection type

Grid-tie

Warranty!

20 years

- Rated at 11 m/s 246 mphi

* Speed needed to move the turbine

1 According to the warranty cersificate from our IOM Manual

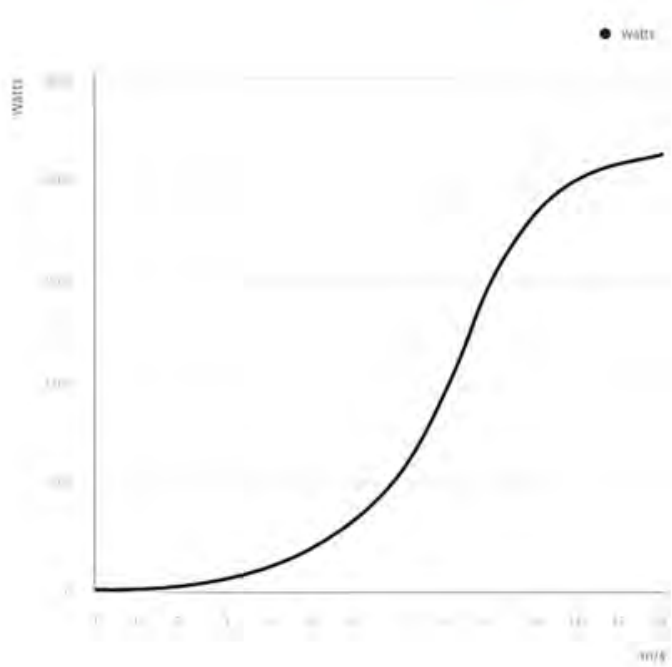

\section{Product specification Nemoi S}

\begin{tabular}{|c|c|c|}
\hline \multicolumn{3}{|l|}{ Power } \\
\hline Nominal power ${ }^{*}$ & $600 \mathrm{~W}$ & \\
\hline \multicolumn{3}{|l|}{ Dimensions } \\
\hline Height & $1.7 \mathrm{~m}$ & $5.58 \mathrm{ft}$ \\
\hline Width & $1.5 \mathrm{~m}$ & $4.94 \mathrm{ft}$ \\
\hline Weight: & $60 \mathrm{~kg}$ & $132 \mathrm{lb}$ \\
\hline \multicolumn{3}{|l|}{ Operation } \\
\hline Cut-in speed" & $5 \mathrm{~km} / \mathrm{h}$ & $3.1 \mathrm{mph}$ \\
\hline Nominalspeed & $40 \mathrm{~km} / \mathrm{h}$ & $24.8 \mathrm{mph}$ \\
\hline Maximum speed & $209 \mathrm{~km} / \mathrm{h}$ & $130 \mathrm{mph}$ \\
\hline \multicolumn{3}{|l|}{ Generator } \\
\hline Type & Permanent magnet & \\
\hline Voltage & $12 / 24$ & \\
\hline Connection type & Off-grid & \\
\hline Warrantyt & 20 years & \\
\hline
\end{tabular}

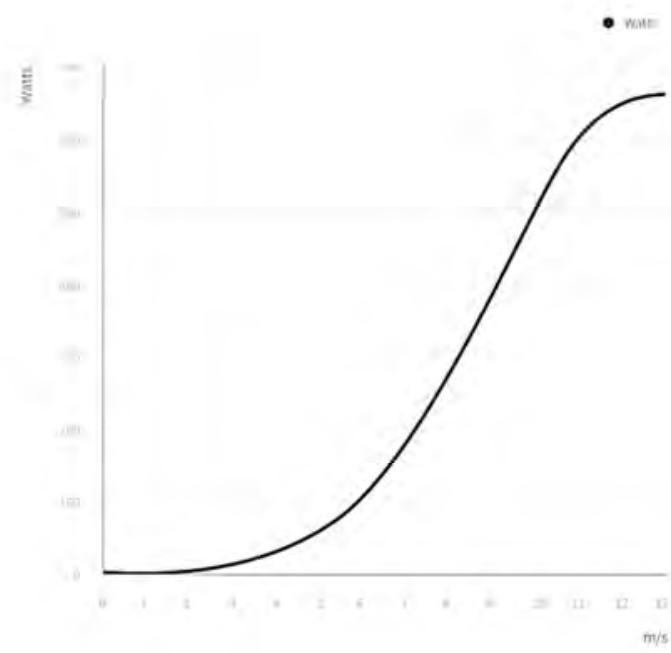

" Speed needed to moue the turbire 


\subsubsection{Bergey Excel 10 Wind turbine technical datasheet}

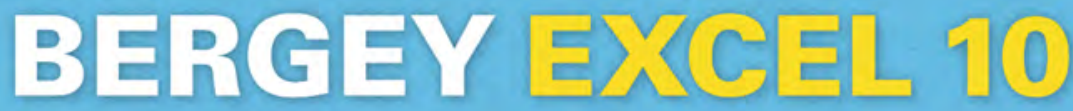

The wise choice for Performance, Reliability, and Ruggedness

The Bergey Excel 10 is ideal for homes, farms, and small businesses. Its extra large rotor and low cut-in wind speed give it exceptional performance, out producing all other turbines in its class. More energy means greater savings and a quicker payback.

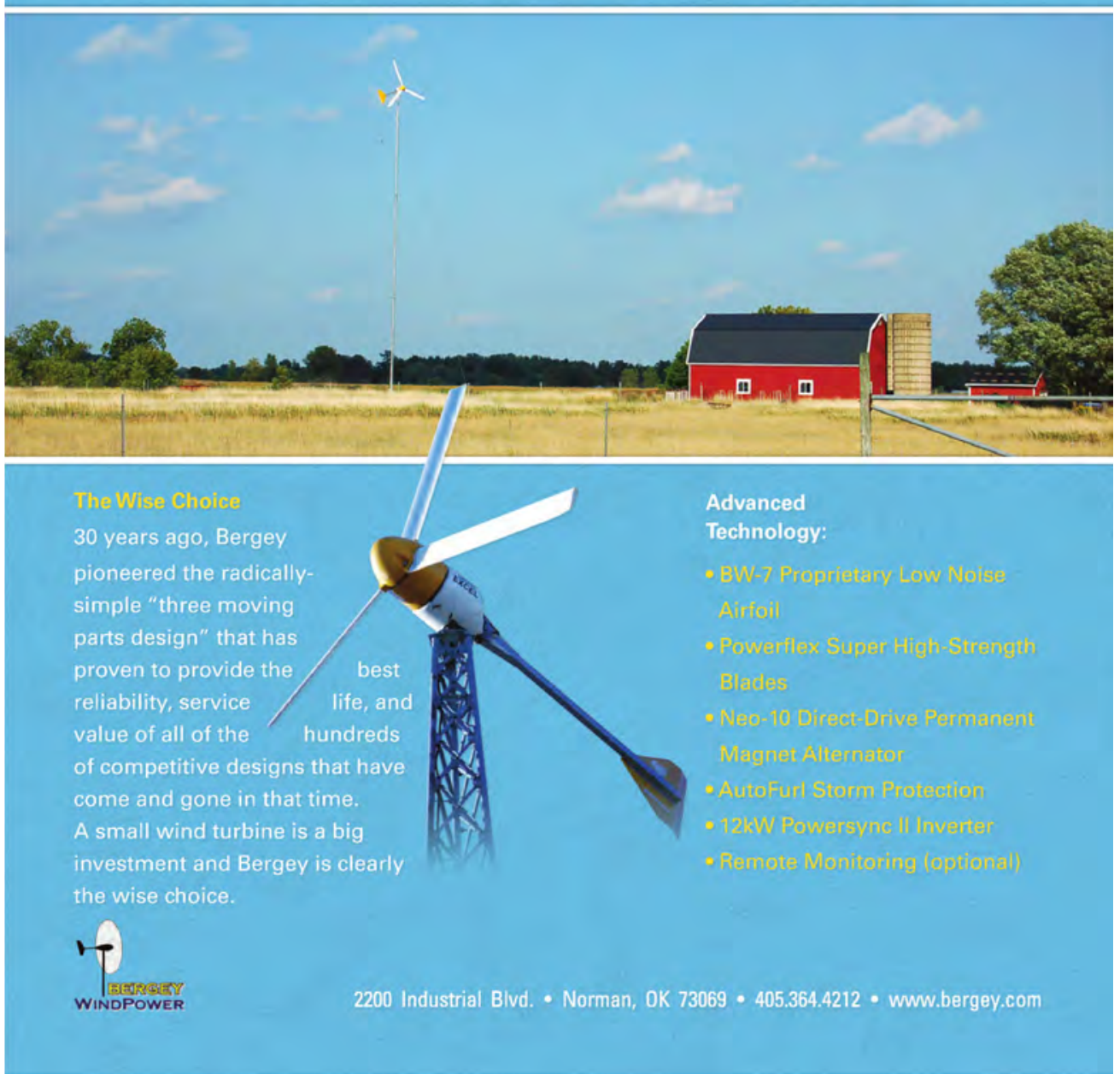


BERGEY

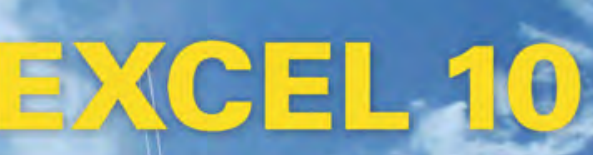

Performance

- AWEA RATED POWER: $8.9 \mathrm{~kW} @ 24.6 \mathrm{mph}$ ( $11 \mathrm{~m} / \mathrm{s}$ )

- PEAK POWER: $12.6 \mathrm{~kW}$

- AWEA ANNUAL ENERGY: 13,800 kWh @ $11 \mathrm{mph}$

$(5 \mathrm{~m} / \mathrm{s})$ Average

- CUT-IN WIND SPEED: $5.6 \mathrm{mph}(2.5 \mathrm{~m} / \mathrm{s})$

- CUT-OUTWIND SPEED: None

- FURLING WIND SPEED: 31-45 mph (14-20 m/s)

- MAX DESIGN WIND SPEED: $134 \mathrm{mph}(60 \mathrm{~m} / \mathrm{s})$

- NOMINAL ROTOR SPEED: 0-400 rpm

\section{Mechanical}

-TYPE: 3-Blade Upwind, Horizontal Axis

- ROTOR DIAMETER: $23 \mathrm{ft}$. $(7.0 \mathrm{~m})$

-WEIGHT: $1200 \mathrm{lb}$. $(545 \mathrm{~kg})$

- GEARBOX: None

- OVER SPEED PROTECTION: Autofurl ${ }^{\circledR}$

-TEMPERATURE RANGE: $-40 / 140^{\circ} \mathrm{F}\left(-40 / 60^{\circ} \mathrm{C}\right)$

-TOWERS: Guyed and Non-guyed 80-160 ft. (24-49 m)

- Alternator: $3 \varnothing$ Neo Permanent Magnet

- INVERTER: 12 kW Powersync II

- Remote Monitoring Via Internet and Smartphones (Optional)

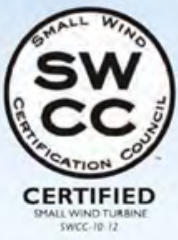

Annual Energy Output

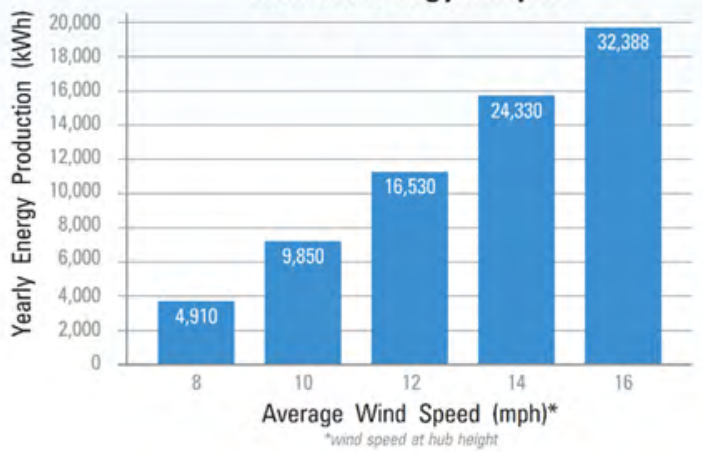

12 kW Powersync II Inverter

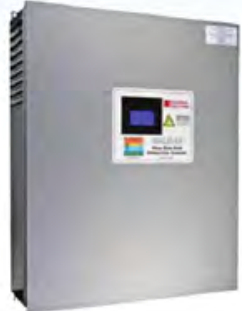





\title{
Chapter 5 \\ Leisure sports marina management and logistics
}

\author{
Sérgio Valdemar Camacho Castro \& Maria José Rodrigues Silva
}

SUMARY: 5.1 INTRODUCTION.-5.1.1. Nautical Tourism.-5.1.2 Marina Definition.-5.1.3 Importance of marinas in the economy.-5.1.4 Importance of the Manager's Role. 5.2 MARINA PLANNING.-5.2.1 Context Studies.-5.2.2 Site investigation and analysis.-5.2.3 Economic Appraisal.-5.2.4 Development Proposal and Pre-Planning Scoping.-5.2.5 Environmental Impact Assessment. 5.3 INFRASTRUCTURES.-5.3.1 Access infrastructures.-5.3.2 Berthing Facilities.-5.3.3 Entrance channel.-5.3.4 Interior channels and fairways.-5.3.5 Berth dimensions.-5.3.6 Mooring piles in double berths. - 5.3.7 Berths for hire charter yachts and power boats.-5.3.8 Walkways, fingers, and mooring points.-5.3.9 Gangway requirements.-5.3.10 Handrails.-5.3.11 Pontoon Materials. 5.4 SERVICES LOGISTICS.-5.4.1 Firefighting.-5.4.2 Water Supply.-5.4.3 Ligthing.-5.4.4 Electricity.-5.4.5 Fuel supply.-5.4.6 Sanitary facilities.-5.4.7 Waste Management.-5.4.8 Telephones.-5.4.9 On-land stormwater control and disposal. REFERENCES

\subsection{Introduction}

"Europe boasts close to $70,000 \mathrm{~km}$ coastline and 27,000 km of navigable inland waterways. It is a leading destination for boating and water sports enthusiasts from across the world. There are over 4,500 marinas in Europe, which offer 1.75 million berths for a total boat park of 6.3 million vessels. Today, $70 \%$ of boat charter takes place in Europe, with a significant part being held in the Mediterranean Sea. These activities represent an important income for coastal and insular economies with boating, water sports and marinas accounting for 180,000 jobs and generating approximately 17 billion euros in revenue per year across Europe" (European Boating Industry, 2020).

What is a Marina?

Whats the importance of Marinas in the economy?

Whats the importance of the marina manager role? 
Figure 5.1 Map of European Boating Industry ${ }^{1}$

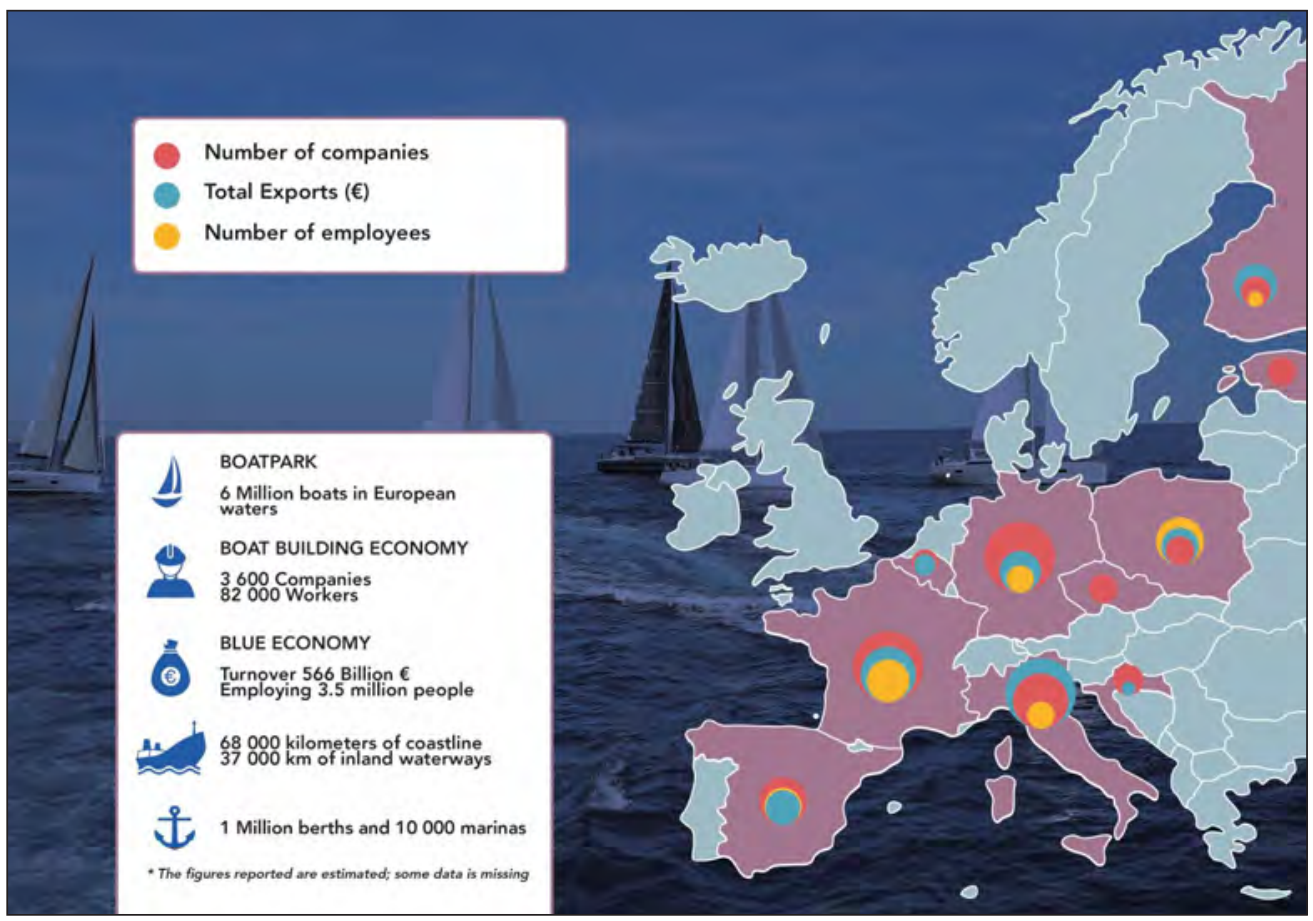

\subsubsection{Nautical Tourism}

The tourism industry experienced a period of excepcional growth, becoming the largest industry globally (10,3\% WORLD GDP), at the beginning of this century. It continues to have the highest growth rates, higher than any other industry. Within tourism, the nautical is the fastest growing, with rates around 8 to $10 \%$ per year. Its normal to understand the importance of recreational nautical infrastructures, considered an ocean of opportunity for this industry.

The following socio-economic impacts of nautical tourism are the following:

- Valued jobs;

- Greater tourist attraction, greater entertainment;

- Valuation of real estate;

- Job creation in recreational infrastructure companies;

- Job creation in other businesses, dependent on recreational infrastructure, but with base outside the area of influence of infrastructure;

- Increased quality of the tourist destination;

${ }^{1}$ Source: https://www.europeanboatingindustry.eu/about-the-industry/facts-and-figures 
- Improving the quality of life of residents;

- Boosting the nautical industry and increasing boat sales;

- Extension of the tourist season;

- Fixed and temporary staff training;

- Increase in tourist revenues.

Figure 5.2 Spanish Association of Nautical Stations ${ }^{2}$

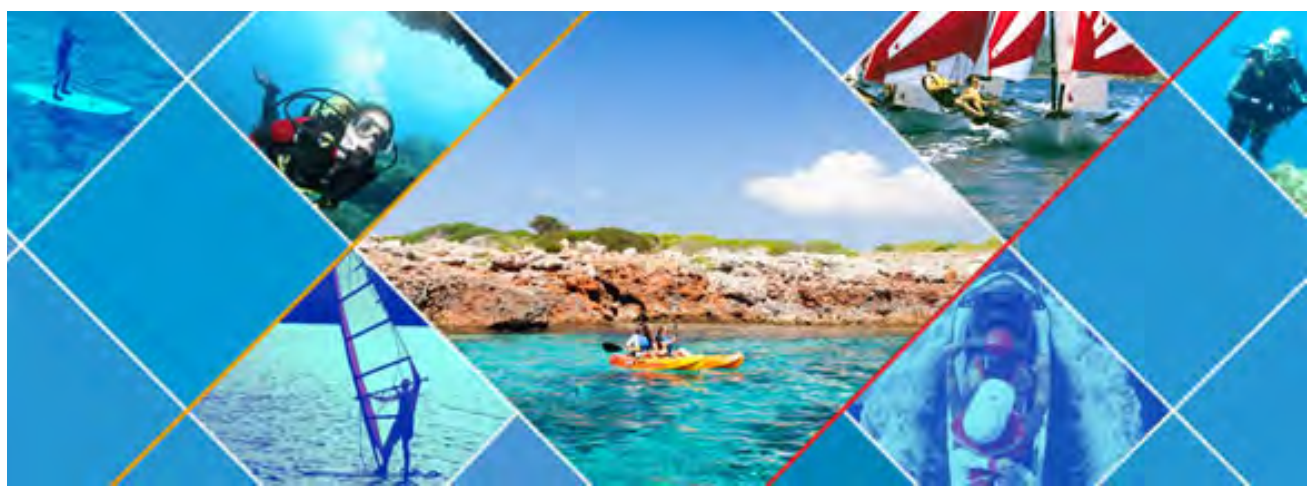

Figure 5.3 Big Game Fishing in Madeira Island

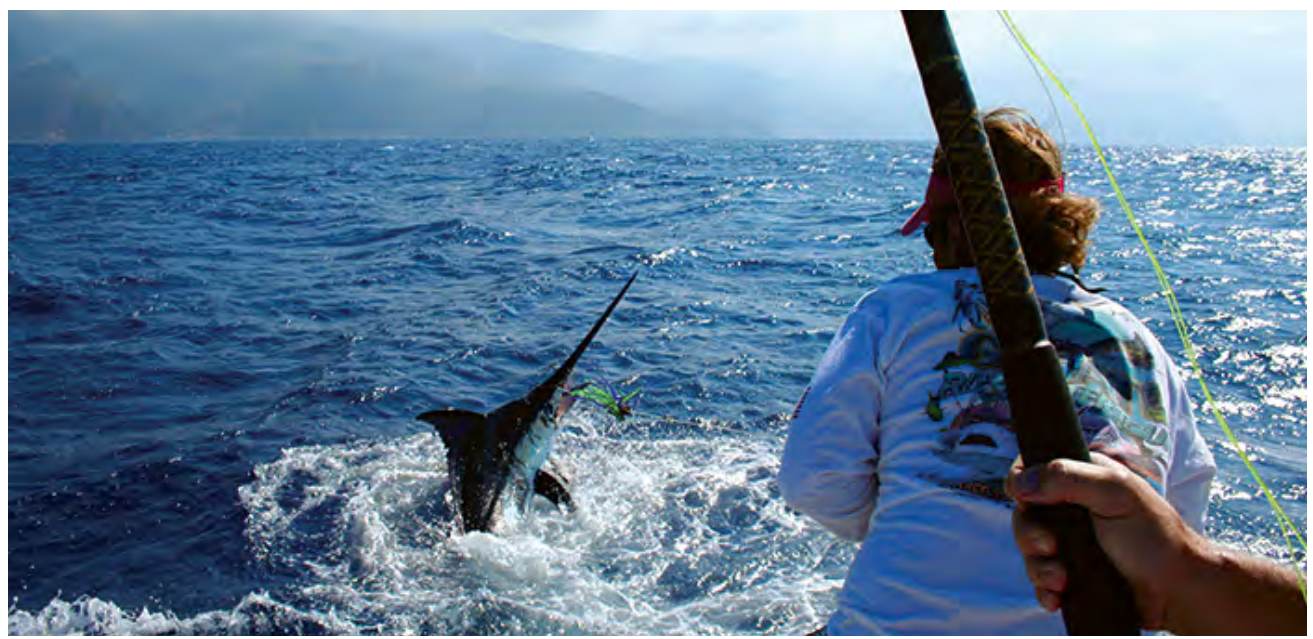

The following are the main nautical tourist products available on the market:

- Marinas;

- Nautical stations;

2 Source: http://www.enmenorca.org/es/asociacion-espanola-de-estaciones-nauticas

3 Source: http://www.visitmadeira.pt/en-gb/what-to-do/activities/search/sport-fishing(big-game-fishing 
- Sport fishing;

- Rowing and Windsurf;

- Cruises;

- Nautical charter companies - boat rental;

- School and diving centers.

Figure 5.4 Scuba Diving in Italy ${ }^{4}$

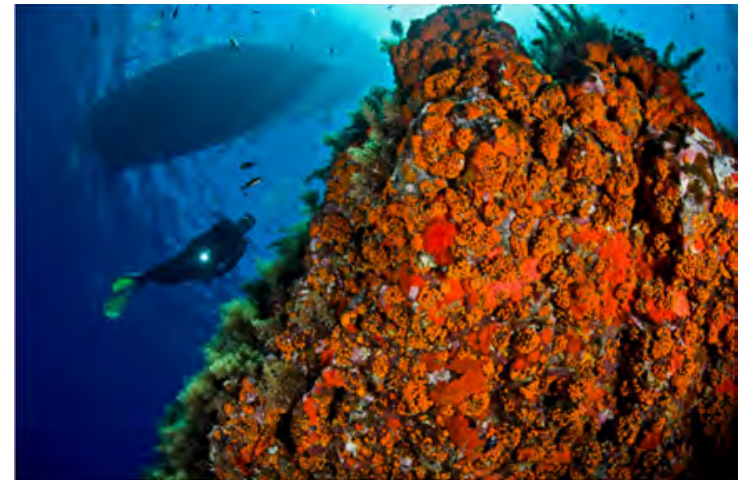

\subsubsection{Marina Definition}

It's not easy to define what a marina or a recreational port is, to this module, we will agree that a sports marina is a set of infrastructures exclusively dedicated to recreational and sport boating, supported by a hotel or a residential complex, integrated in a sheltered water plan and having the necessary support for vessels and crews. Sport marinas and recreational ports have in common a well-sheltered water plan, capacity for organization and parking of vessels, as well as a number of onshore services dedicated to crews. The distinction between a marina and a recreational port usually is made through the existence or not of a hotel or residential complex.

\subsubsection{Importance of marinas in the economy}

Marinas are much more than just businesses. They are attractive waterfront spots and usually extremely popular among inhabitants and tourists. As such they can make a city or municipality a pleasant place of living and add an extra to tourism destinations. The constructing and operation of marinas is, therefore, often not seen as something that has to pay for itself at the operational level. Especially from the public side, it is argued that they are long-termed investments

\footnotetext{
${ }^{4}$ Source: $h$ ttps://www.tribloo.com/en/destination/22/diving/italy.html
} 
Figure 5.5 Funchal Marina

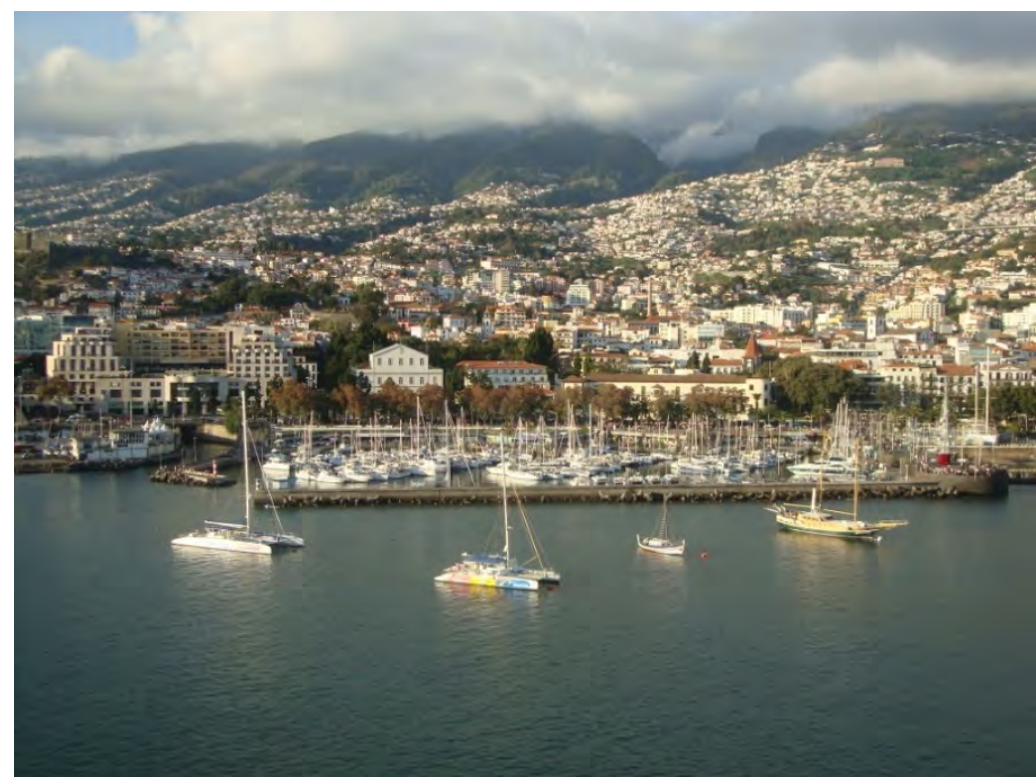

that are rather to create wider economic benefits. This creates subtle tendencies to generally exempting them from commercial considerations (PLANCO Consulting Gmbh, 2013).

For marina investments to become profitable, several determining factors need to be considered.

First, we need to know the local market and its potential. This implies knowing the characteristics of the country and nautical culture. It is central to be aware of the boat/population ratio, which can range from 1 boat to 6,50 people, in the case of Norway, up to 1 to 218, case of Spain (Table 5.1). Therefore, the population concentration of the area should be known.

It is important to establish destinations and habits of staying on site through the creation of leisure areas and investment in the local economy.

\subsubsection{Importance of the Manager's Role}

A marina must be managed effectively and efficiently so that these operations contribute to the local economy, protect the environment, and protect the safety and property of recreational boaters and those working in the industry (Fruth,1991).

A manager may contribute to the local economy by encouraging boating activity through efficient operations. If facilities are accessible, functional, and demanded by the public, then boaters will be attracted. The boaters will purchase boats, boating supplies, and boating services but they also would use adjacent 
Table 5.1 Number of recreational boats per 1000 inhabitants in some countries (ICOMIA, 2018)

\begin{tabular}{|l|c|c|}
\hline \multicolumn{1}{|c|}{ Country } & Population & Units per 1000 inhabitants \\
\hline Finland & 5.500 .000 & 210,91 \\
\hline Norway & 5.200 .000 & $9,52,85$ \\
\hline United Kingdom & 60.600 .000 & 29,88 \\
\hline France & 65.600 .000 & 7,60 \\
\hline Germany & 64.600 .000 & 5,85 \\
\hline Italy & 82.600 .000 & 4,58 \\
\hline Spain & 43.300 .000 & 16,10 \\
\hline Greece & 10.800 .000 & 15,25 \\
\hline EUROPE & 388.300 .000 & 237,57 \\
\hline Canada & 36.200 .000 & 147,62 \\
\hline New Zealand & 4.700 .000 & 2,34 \\
\hline Japan & 125.300 .000 & $\mathbf{1 2 , 4 8}$ \\
\hline China & 1.378 .000 .000 & 48,96 \\
\hline USA & 323.900 .000 & $\mathbf{2 . 6 3 0 . 9 0 0 . 0 0 0}$ \\
\hline TOTAL & & \\
\hline
\end{tabular}

facilities such as restaurants and other locais businesses. These expenditures contribute to increased profitability of locais businesses, and improved job market (Fruth,1991). ${ }^{5}$

Marina operations must be planned and supervised properly to prevent damage to the environment. Poor location of facilities, careless waterfront construction, and improper handling of fuel and other toxic substances can degrade water quality, disrupt the natural ecology of an area, and harm wildlife habitat and breeding areas. It is important for the manager to be aware of relevant guidelines and agency resources to ensure that these facilities are not hazards to the environment (Fruth,1991).

A manager must follow safety regulations and laws to ensure safe operations for customers and employees of a small boat harbour or marina area. These

\footnotetext{
${ }^{5}$ ICOMIA Recreational Boating Industry Statistics 2017
} 
regulations relate to navigation devices, handling of hazardous materials, electrical codes, and construction criteria (Fruth,1991).

\subsection{Marina planning}

The planning of a marina or a recreational port consists of several stages. In the diagram (Figure 5.6) below we have the representation of all the steps that may be present in a planning initiative.

In advance of lodging a formal planning application, it would also be important to consult formally with the Department of the Marine and Natural Resources, the relevant Port Authority and with fishing and other marine interests present in the área (Marine Institute, 2001).

Most substantial developments will require that a series of sub-studies be undertaken in order to prove the practicality of the project. These should also contain the necessary information to support the design of the development and the documentation for the necessary planning permissions and licenses.

The requirements will vary from one project to another, however any major project might typically include:

- Context study

- Site investigation and analysis

- Technical studies

- Economic Appraisal

These various studies are complementary and can usually be undertaken in parallel, however, in planning a development programme it is important to allow suficiente resources in terms of time and funding for their preparation. The scope of these investigations will depend upon the nature and scale of the development (Marine Institute, 2001).

\subsubsection{Context Studies}

Context studies will usually include description and analysis of the physical and social environment of the proposed project. The context study will also establish the planning context for the project and confirm the steps and documentation needed to progress the development to implementation stage. In this investigation the significance of any relevant Government policies, programmes and/or guidelines need to be considered. Other key documents will include the relevant Local Authority Development Plan and any Local Action Plans or special sectoral studies. For example, tourism or aquaculture or any plans likely to affect the development of the área and/or provide support or act as a constraint on the proposal (Marine Institute, 2001). 
Figure 5.6 Typical planning procedure for marina planning ${ }^{6}$

\section{PLANNING PROCEDURE}

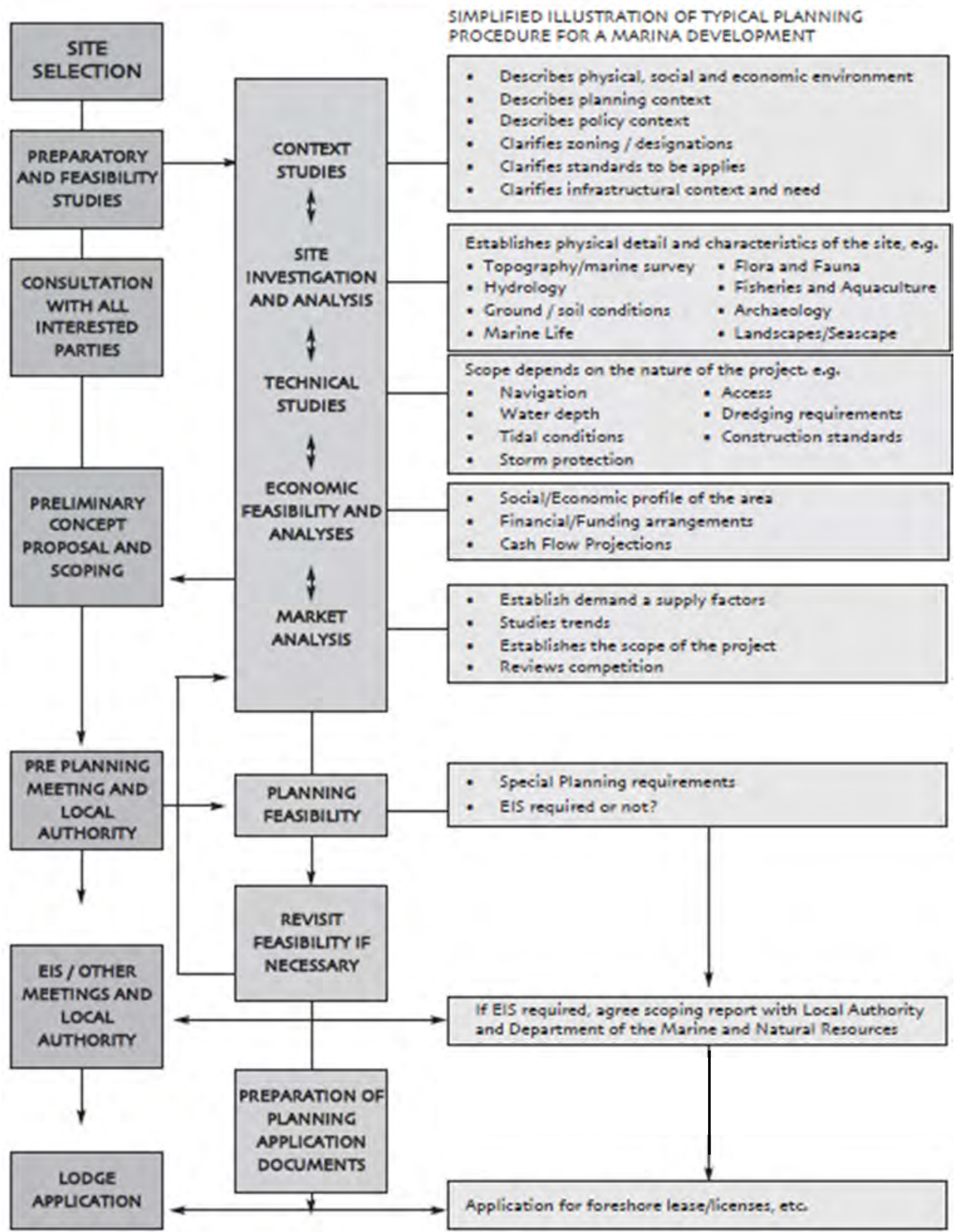

${ }^{6}$ Source Marine Institute, 2001 
Figure 5.7 Marina project ${ }^{7}$

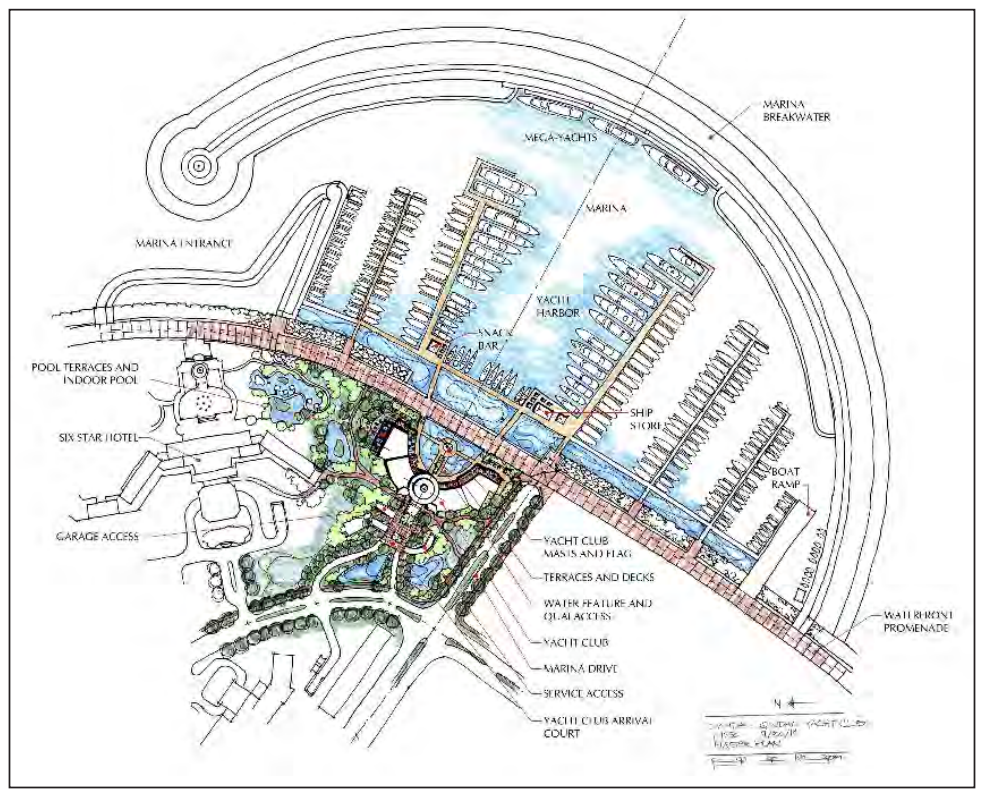

\subsubsection{Site investigation and analysis}

Site investigation and analysis concern the details of the physical and environmental characteristics of the subject site and might include, for example, topographical/marine survey, hydrology, assessment of ground conditions (soil testing), vegetation cover, fish and fisheries/ aquaculture, archaeology (marine and terrestrial) and landscape/seascape evaluation (Marine Institute, 2001).

Technical studies will be required to address such issues as water depth, tidal conditions, weather patterns, the need for dredging, navigation requirements, the need for storm protection, construction standards and access (Marine Institute, 2001).

A technical feasibility study will typically comprise the following elements:

- Topographic survey to provide details of the adjacent land;

- Hydrographic survey to provide information on water depths and impacts on navigation;

- Trial pit and borehole site investigation to provide information for foundations to structures and dredging operations;

- Tide, wave, wind and current review;

- Computer modelling to provide design information on existing regimes;

${ }^{7}$ Source: https://www.zehren.com/portfolio-view/qingdao-yacht-club/ 
- Investigation of shore based facilities;

- Conceptual/outline designs.

\subsubsection{Economic Appraisal}

A complete economic appraisal of projects is usually necessary to firstly determine whether the project is feasible, and secondly to establish what the optimum scale of development is (e.g. the number of berths and level of ancillary facilities, developed in the next unit Infrastructures).

The Economic Appraisal will have a number of elements:

- A thorough examination of the socioeconomic profile of the marinas catchment area is necessary to gauge the likely level of local demand for resident berths, which is typically crucial to the ongoing viability of most marina developments. Elements of this analysis would include an examination of population levels and trends within defined catchment areas (e.g. 1-20 miles, 1-40 miles), a review of economic growth and income levels, and analysis of trends in employment growth and unemployment (Marine Institute, 2001).

- It will also be necessary to review the market for marina-based activities in the area. This might require primary and secondary research to determine the levels of marine leisure activity among local residents, the location of this activity, or the propensity to take up marina activities if more facilities are provided. Information on visitor activity at other marinas in the area would also be pertinent, including analysis of future prospects in key visitor markets. In particular, it would be important to show the extent to which the project would provide additional visitor activity (e.g. by expanding the coastal network of facilities) rather than displacing activity at other marinas (Marine Institute, 2001).

- Activity projections will need to be developed, including projections for direct and indirect revenues/economic impact, based on the socio-economic and market analysis. The benefits would also need to be weighed up against the costs incurred in developing the project, and should provide guidance as to the optimum scale of development (Marine Institute, 2001).

A typical economic appraisal will examine the pattern and functioning of existing/proposed marine facilities in the area, market conditions, the socio-economic profile of the area, existing and potential participation in marine activities, cash flow, potential financing arrangements, returns on investment and phasing. This, together with the analysis of market demand will help identify the gap in the market and will assist in establishing the scope, size and type of facility that is required and that is most likely to succeed (Marine Institute, 2001). 


\subsubsection{Development Proposal and Pre-Planning Scoping}

Once the various feasibility studies have been completed it will be possible to prepare a preliminary development proposal or concept development plan for the site. It is at this stage that formal pre-planning discussions are entered into with the Local Authority. The situation with regard to Planning Permission is itself an important aspect of feasibility. This will allow the Local Authority to communicate any concerns relating to the proposal and, as noted above, these will need to be addressed in detail in the formal Planning Application. These discussions also give the developer an early indication of what the views of the Local Authority are on the development (Marine Institute, 2001).

During these pre-planning discussions the Department of the Marine and Natural Resources and the Local Authority the developer should seek to clarify whether or not an Environmental Impact Assessment will be required. If it is required, the scope will also have to be clarified. Certain marine developments have EIA as a mandatory requirement (Marine Institute, 2001).

\subsubsection{Environmental Impact Assessment}

Following the pre-planning consultations it may be necessary to amend the proposal or even, in certain circumstances, to consider abandoning the proposal outright. If the developer intends to continue with the development, the next stage will be the preparation of the documentation for the formal planning application. This documentation may include preparation of na Environmental Impact Assessment. The Local Authority may request an environmental impact statement if deemed necessary, not withstanding the statutory mandatory requirements (Marine Institute, 2001).

\subsection{Infrastructures}

The marina as we know it today is the result of an evolutionary process which has taken place since the 1960's. Technical improvements have been driven by the requirement for cost effective, convenient and reliable pontoon berthing systems and the increasing need for efficient use of land and water space, having due regard to environmental considerations (Marine Institute, 2001).

The establishment of a marina requires several infrastructures to support nautical users, which may vary according to the objectives and expectations of port management.

In general, a marina consists of berthing for pleasure craft, providing direct walkway access to each boat, a shipyard area, dedicated to the most basic vessel support services and an area for administrative and reception services (Marine Institute, 2001). 


\subsubsection{Access infrastructures}

A marina should have easy access by land and safe access of vessels to navigable waters.

Land access means all types of railways, highways, airports and other structures that prevent the isolation of recreational infrastructure, enabling an important connection with nearby cities.

The infrastructure must be served by good transport networks to put less pressure in the search for parking. This connection of the recreational infrastructure to the territorial environment is extremely important, it allows users to have the widest range of services. Marinas located adjacent to urban areas will have the greatest chance of success as the marina and the town will potentially benefit from each other's activity.

Vessel access to safe navigable waters is also essential as it is the essence of a recreational infrastructure and meets its first objective. It should be secure entry into the infrastructure, regardless of weather conditions, such as proper access to water, i.e. exit from recreational infrastructure. When the nautical infrastructure is inserted in a commercial port, a priori, access is guaranteed.

The requirement for water depth will therefore be related to boat size and type distribution.

The cost of dredging can be a significant element of the development costs and it may therefore be more economic to create areas of differing depths throughout the marina. Pontoon berths are generally arranged so that boat sizes are grouped and dredging can be designed to suit. The disposal of dredging material will require special attention. Material may be disposed of at a designated site at sea or at land. In either case a licence should be required from the Government Authorities (Marine Institute, 2001).

A minimum water depth of $2.7 \mathrm{~m}$ to $3.5 \mathrm{~m}$ will cater for the vast majority of leisure craft using marinas (Marine Institute, 2001).

\subsubsection{Berthing Facilities}

The berthing arrangement will reflect the size and shape of the marina enclosure and the distribution of boat size to be accommodated. The system of walkways and finger berths is accepted as providing the most efficient layout. It is the design of finger sizes, finger spacing and walkway spacing which has to be tailored to meet the requirements of each marina (Marine Institute, 2001).

In a very preliminary and not very precise way, it can be associated with capacity of a marina to the net area of the water plan, depending on the distribution of the number of total number of vessels per classe (Trigo Teixeiro,2001).

\section{Number of Berth Places $\times\left(80\right.$ to 100) $m^{2}=$ Water Layount Area}

The water layout area includes berthing places, fairways, entrance, and access channels. 
Generally marinas should cater for the full range of popular boat sizes and it is the distribution of these sizes which should be determined at the outset. Once pontoon berths have been installed there is only limited scope for adjusting the layout without major disruption to the anchoring system and services installation. Marina developers should investigate the trend in boat size distribution in the development area and compare with other establishments in similar socioeconomic/ boating activity áreas (Marine Institute, 2001).

The size of a boat can vary significantly, and the procedures required by a small sailing yacht or mega yacht can be quite different.

\subsubsection{Entrance channel}

The width of the entrance channel to a marina is dependent on a number of factors, the majority of which are the following:

- Exposure to wind, wave, and currents, which all reduce the manoeuvrability of boats.

- Number of boats in the harbour and usage levels.

- Type and size of boats. NOTE: Power boats are generally more manoeuvrable than sailing boats.

- Extent of navigation aids provided. For an entrance channel, the minimum width should be the greatest of- (a) $20 \mathrm{~m}$; (b) $(\mathrm{L}+2) \mathrm{m}$, where $\mathrm{L}$ is overa11 length of longest boat in the marina, in metres; or (c) $5 \mathrm{~B} \mathrm{~m}$, where $\mathrm{B}$ is the beam of the broadest mono-hull boat in the marina, in metres.

The preferred width of an entrance channel is $30 \mathrm{~m}$ or $6 \mathrm{~B} \mathrm{~m}$; whichever is the minimum. Widening of the channel may be necessary where the channel changes direction. Where benched breakwaters are used at a marina entrance such that the bench is submerged at higher tides, markers should be used to delineate the edge of the channel. In order to minimize the penetration of waves into a boat harbour, it is permissible to narrow the width of the entrance channel over a short length at protecting breakwaters. The minimum width of this narrow section shall be the greater of $15 \mathrm{~m}$ and $3 \mathrm{~B} \mathrm{~m}$, where $\mathrm{B}$ is the beam of the broadest mono-hull boat in the marina, in metres (NSW Maritime Authority,2001).

\subsubsection{Interior channels and fairways}

The channels within the marina are not as greatly influenced by the wind, waves, and currents at any site, as they are by the size, number and type of boats, and the frequency of boat usage. Any non-motorized sailing vessel or multi-hull vessel using the harbour will need to be considered when determining the interior channel and fairway widths. In some locations, there may be climatic conditions, 
such as prevailing winds, which should be considered when interior channel and fairway widths are being determined (NSW Maritime Authority,2001).

Where currents exceed $0.5 \mathrm{~m} / \mathrm{s}$, the width of interior channels and fairways (Figure 5.8) should be increased to allow for the effect of the current on a boat as it moves along the channel and turns into its berth. Where the proportion of multihulls using the marina is likely to be high, consideration should be given to increasing the width of the channels and fairways (NSW Maritime Authority,2001).

Figure 5.8 Widths of channels

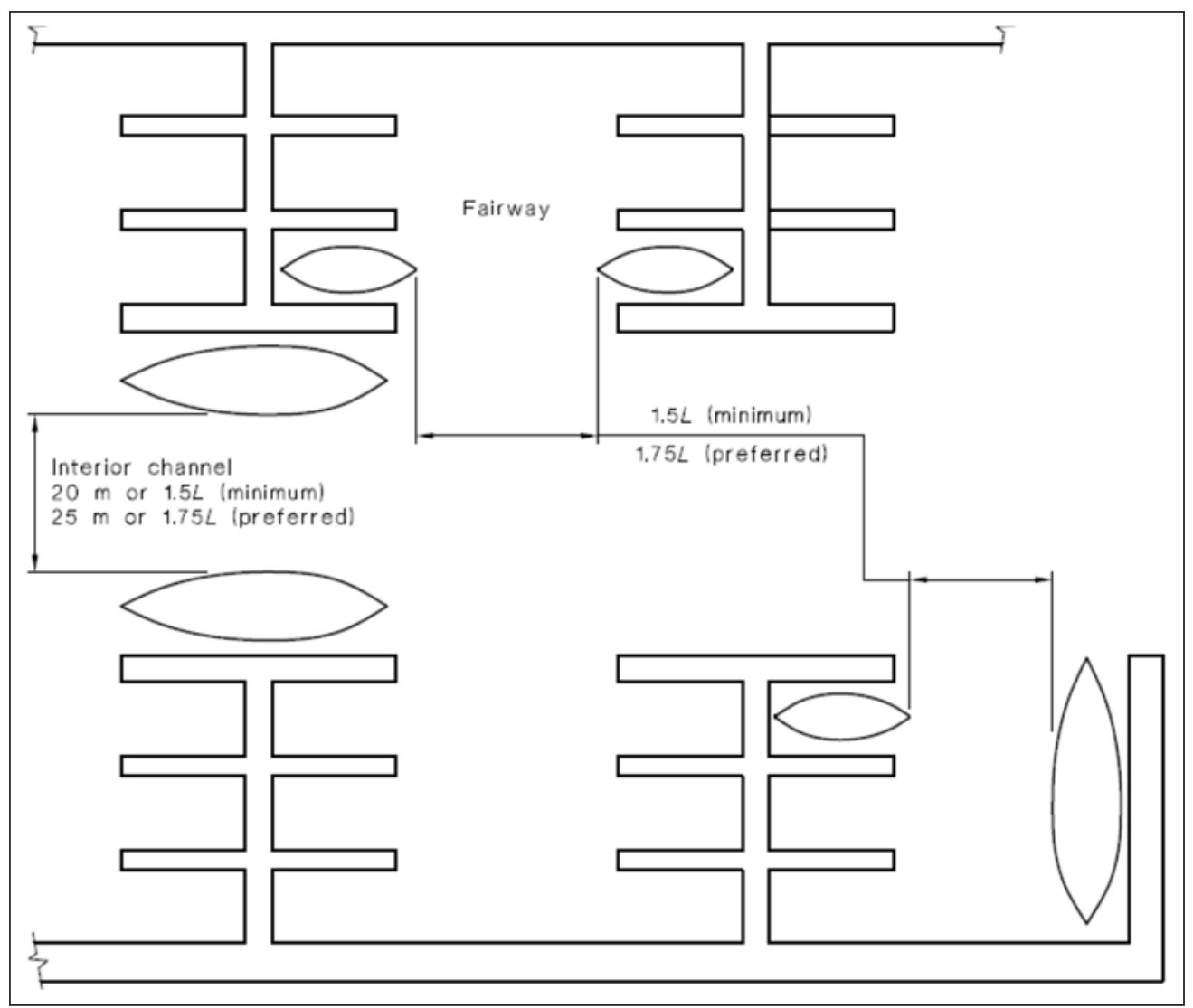

Source: NSW Maritime Authority,2001

\subsubsection{Berth dimensions}

Where more specific requirements are not available for the marina, the length, width and depth of berths should be determined. These design characteristics should be recorded on the marina drawings. 
Based on the widest beams of monohull boats currently being manufactured, the minimum berth widths (the clear width between fingers or piles) are shown in Figure 5.9. Berth lengths are taken to be the same as the boat length (NSW Maritime Authority,2001).

General expressions for berth width (b) are as follows:

(a) Double berth: $2 \times$ design maximum vessel beam $+1 \mathrm{~m}$ up to $20 \mathrm{~m}$ and + $1.5 \mathrm{~m}$ above $20 \mathrm{~m}$.

(b) Single berth: design maximum vessel beam $+1 \mathrm{~m}$ up to $20 \mathrm{~m}$ and $+1.5 \mathrm{~m}$ above $20 \mathrm{~m}$.

(c) Multihull vessels can either occupy a double berth, or wider berths can be included, which specifically allow for single or double multihull vessels. The beam of a multihull may be up to $0.7 \mathrm{~L}$.

These dimensions may need to be increased to allow for larger fenders.

The maximum length of boat for which each berth has been designed should be clearly marked on the marina layout drawing.

For alongside berths, the minimum space between boats should be $0.2 \mathrm{~L}$ up to 3.0 m (NSW Maritime Authority,2001).

Figure 5.9 Berth dimensions for monohull boat

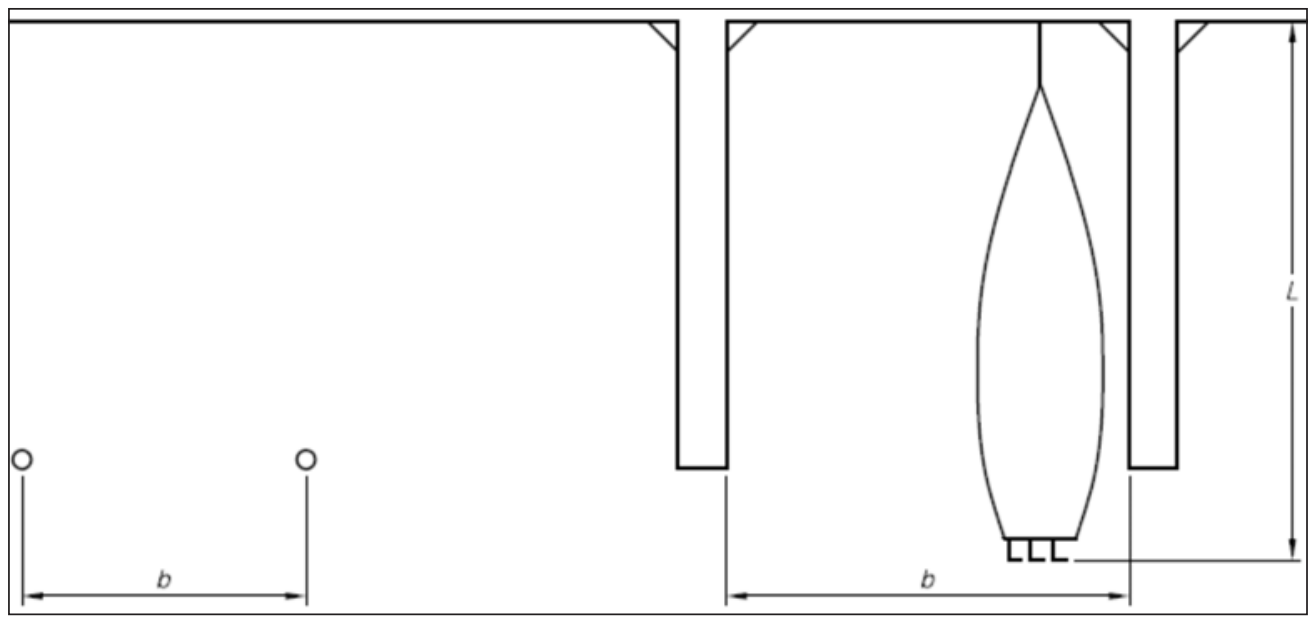

Source: NSW Maritime Authority,2001

\subsubsection{Mooring piles in double berths}

Mooring piles between each boat in a double berth configuration may be required where wind generated waves or boat wake exceed(s) $300 \mathrm{~mm}$ in height. The width of the double berth should be increased by the width of the pile (NSW Maritime Authority,2001). 


\subsubsection{Berths for hire charter yachts and power boats}

Where possible, berths for hire charter yachts and power boats should be located and designed so as to minimize risk of accidental collision by inexperienced crews departing and returning to the berth (NSW Maritime Authority,2001).

Table 5.2 Minimum berth dimensions for mono hull boats

\begin{tabular}{|c|c|c|c|}
\hline \multirow{2}{*}{ Boat length $(L), \mathrm{m}$} & \multirow{2}{*}{ Boat beam $(B), m$} & \multicolumn{2}{|c|}{ Width of berth $(b), \mathrm{m}$} \\
\hline & & Single berth & Double berth \\
\hline 6 & 2,8 & 3,8 & 6,6 \\
\hline 7 & 3,1 & 4,1 & 7,2 \\
\hline 8 & 3,4 & 4,4 & 7,8 \\
\hline 9 & 3,7 & 4,7 & 8,4 \\
\hline 10 & 4,0 & 5,0 & 9,0 \\
\hline 11 & 4,3 & 5,3 & 9,6 \\
\hline 12 & 4,4 & 5,4 & 9,8 \\
\hline 13 & 4,6 & 5,6 & 10,2 \\
\hline 14 & 4,8 & 5,8 & 10,6 \\
\hline 15 & 5,0 & 6,0 & 11,0 \\
\hline 16 & 5,2 & 6,2 & 11,4 \\
\hline 17 & 5,3 & 6,3 & 11,6 \\
\hline 18 & 5,4 & 6,4 & 11,8 \\
\hline 19 & 5,5 & 6,5 & 12,0 \\
\hline 20 & 5,7 & 6,7 & 12,4 \\
\hline 21 & 5,8 & 7,3 & 13,1 \\
\hline 22 & 5,9 & 7,4 & 13,3 \\
\hline 23 & 6,0 & 7,5 & 13,5 \\
\hline 24 & 6,3 & 7,8 & 14,1 \\
\hline 25 & 6,5 & 8,0 & 14,5 \\
\hline 27.5 & 7,0 & 8,5 & 15,5 \\
\hline 30 & 7,5 & 9,0 & 16,5 \\
\hline 35 & 8,7 & 10,2 & 19,0 \\
\hline 40 & 10 & 11,5 & 21,5 \\
\hline 45 & 10 & 11,5 & 21,5 \\
\hline 50 & 10 & 11,5 & 21,5 \\
\hline
\end{tabular}

Source: NSW Maritime Authority,2001 


\subsubsection{Walkways, fingers, and mooring points}

Walkways should be not less than $1.5 \mathrm{~m}$ wide. Consideration should be given to the need for trolleys passing each other and access and egress in emergencies. The clear width of walkways throughout their length, defined as the clear line-ofsight between any obstruction such as cleats, hose reels, piles, etc, should not be less than the clear width of the gangway that is connected to the walkway (NSW Maritime Authority,2001).

The minimum width of walkways should be:

(a) $1.8 \mathrm{~m}$, for walkways in excess of $100 \mathrm{~m}$ in length; or,

(b) $2.4 \mathrm{~m}$ for walkways in excess of $200 \mathrm{~m}$.

Unless a mooring pile is provided at the end of a pontoon finger, the length of a finger should be not less than $0.8 \mathrm{~L}$, where $\mathrm{L}$ is the overall length of the longest boat that may use the berths. Where a mooring pile is provided, the finger length may be reduced or the finger omitted. The width of fingers should be such that it is safe to board or leave the boat. Fingers may be of uniform width of $900 \mathrm{~mm}$, or be tapered to a minimum width of $600 \mathrm{~mm}$ (NSW Maritime Authority,2001).

A minimum of three mooring points should be installed along each side of a floating berth. For a double floating berth, two additional mooring points should be provided on the walkway for the lines of the two boats. For a fixed berth, two bow and two stern mooring points should be installed (NSW Maritime Authority,2001).

\subsubsection{Gangway requirements}

The clear width of gangways should be in accordance with Table 5.3.

Table 5.3 Clear Gangway widths

\begin{tabular}{l|c}
\hline \multicolumn{1}{c|}{ Number of berths } & Width (m) \\
\hline Up to 2 & 0.7 \\
\hline Greater than 2, up to 10 & 0.9 \\
\hline Greater than 10, up to 60 & 1.2 \\
\hline Greater than 60, up to 120 & 1.5 \\
\hline Greater than 120 & 1.8 \\
\hline
\end{tabular}

Source: NSW Maritime Authority, 2001

The maximum slope of a gangway and treadplate for a marina should not exceed 1:3.5. For private pontoons with no public access, the maximum slope should not exceed 1:3. The gangway should be in accordance with nacional and international standards (NSW Maritime Authority,2001). 
Where access for disabled persons is required, the slope of gangways and tread plates should not exceed 1:8. This is only satisfactory where assisted wheelchair access is provided. The maximum slope is the slope that would occur at a water level of $\mathrm{CD}$. The walking surface should be finished in accordance with nacional and international standards (NSW Maritime Authority,2001).

\subsubsection{Handrails}

At least one handrail should be provided on gangways for pontoons with up to 2 berths, i.e for restricted access residential marinas. For unrestricted access, gangways should have handrails on both sides (NSW Maritime Authority,2001).

\subsubsection{Pontoon Materials}

Pontoons in floating marina berthing systems are the components that provide the flotation capacity to support all loads that may occur during the service life of a marina. The heavier the combined loadings, the greater the required pontoon capacity to maintain required freeboard, cross slopes, etc (Schwarzenegger, A., Chrisman, M., \& Tsuneyoshi, R. 2005).

The marina designer has a choice of materials from which the various elements can be manufactured. Typically, a marina pontoon structure has three main components: deck, supporting structure and floatation units. The recommended material for the deck is either hardwood, treated redwood, or concrete. The pontoon structure should be galvanised steel, marine grade aluminium or timber (hardwood or treated redwood) (Marine Institute, 2001).

Floatation units should be high density expanded polystyrene encased in concrete or polyethylene tanks. In the case of heavy duty pontoons the deck, structure and floats may be an integral unit (Marine Institute, 2001).

When selecting pontoon equipment, the long term maintenance costs, as well as initial capital cost, should be considered (Marine Institute, 2001).

\subsection{Services logistics}

Pontoon services such as water, lighting and power, should be provided to all berths in a modern marina (Marine Institute, 2001).

Pontoon lighting should be provided by regularly placed service bollards. This should be low intensity but adequate to define the walkways at night time.

Electrical power should be available to each berth and this can be supplied from the service bollards. The question of metering electrical supply is a marina management issue. Some may make a separate charge whilst others may incorporate the cost in berth rental (Marine Institute, 2001). 
There is always the possibility of fire, personal injury or man overboard situations in the marina environment. Marinas should therefore provide equipment to deal with these situations.

Emergency cabinets on the pontoon walkways should be provided at regular intervals. Typically these cabinets should contain fire extinguishers, first-aid materials and a lifebuoy with line. Emergency ladders for the recovery of personnel from the water, should be provided at regular intervals along marina walkways (Marine Institute, 2001).

The design of marinas may need to include the following services

- Firefighting;

- Water supply;

- Lighting;

- Electricity;

- Fuel supply;

- Sanitary facilities;

- Contaminated waste disposal;

- Telephones;

- On-land stormwater control and disposal;

- Wireless Internet.

\subsubsection{Firefighting}

There is always the possibility of fire, personal injury or man overboard situations in the marina environment (Marine Institute, 2001). So it is required that marinas have equipment systems and sustainable water resources to suppress, control and extinguish fires on boats, docks, buildings, fueling stations and other marina service centers. It is recommended that the local fire authorities should be included in all stages of marina design for both new and alteration projects. This will help ensure that all code requirements are addressed, and will facilitate the smooth and effective inspection and completion of projects.

Fire hose reels should be located as follows (NSW Maritime Authority,2001):

- No part of a berth should be beyond the reach of the nozzle end of a fully extended reel. Hose reels should be suitable for operation by one person.

- The length of hose on any reel should be $36 \mathrm{~m}$.

- At least one reel should be located on the shoreline side of the first berth, and at the seaward end of each walkway.

- The maximum distance between any two reels should be $30 \mathrm{~m}$. Where more than two reels are required, they should be evenly spaced along walkways.

- At least two reels should be accessible from each berth. 
The two most hydraulically disadvantaged reels (operated simultaneously) should each provide a minimum water flow rate of $0.63 \mathrm{~L} / \mathrm{s}$ at a running pressure of not less than $275 \mathrm{kPa}$ (NSW Maritime Authority,2001).

Where the required flow rate and running pressure cannot be achieved at all times from the normal water supply, a booster pump should be provided which should (NSW Maritime Authority,2001):

- be self-priming;

- have the capacity to supply water at a minimum rate of $1.26 \mathrm{~L} / \mathrm{s}$ at the require running pressure; operate automatically upon the flow of water through any hose reel.

Stand-alone mobile fire pumps should be considered, to augment the hose reels and other fire prevention devices (NSW Maritime Authority,2001).

A fire hydrant should be provided adjacent to the head of each gangway.

Extinguishers suitable for other fire hazards should be provided at appropriate locations.

The inclusion of an audible fire alarm system should be considered.

All fire hose reels and booster connections should be properly maintained in accordance with nacional and international standards.

All staff should receive adequate instruction in the use of firefighting equipment and procedures to be followed in the event of fire (NSW Maritime Authority,2001).

\subsubsection{Water Supply}

Potable water is generally not required at each berth. Regularly placed water bollards with hose is the normal provision. However, the developer may consider that individual water supplies should be provided on berths aimed specifically at the top end of the market (Marine Institute, 2001).

Water services, if provided from public mains, should be in accordance with the requirements of the relevant authority. Flexible, non-corrodible, ultravioleta stabilized piping should be used (NSW Maritime Authority,2001).

\subsubsection{Ligthing}

Adequate lighting should be provided for safe pedestrian access to the berths, security of vessels and shore facilities, and safe navigation within the marina área (NSW Maritime Authority,2001).

Pontoon lighting should be provided by regularly placed service bollards. This should be low intensity but adequate to define the walkways at night time (Marine Institute, 2001). 
All lighting should be designed and located to minimize glare for vessels navigating in the vicinity (NSW Maritime Authority,2001).

\subsubsection{Electricity}

Marina electrical systems should be adequate to supply the power demands for boat slips, lighting, fuel stations, sewage pumpout stations, buildings, navigation aids, and maintenance and repair work (Schwarzenegger, A., Chrisman, M., \& Tsuneyoshi, R. 2005).

All electrical installations should comply with international and national standards and the regulations of the local supply authority. The use of earth leakage circuit breaker devices on all electrical circuits including marina berths, is necessary. One device should be included for each outlet (NSW Maritime Authority,2001).

Adequate power should be provided for all berths so that on-board generators do not have to be used.

\subsubsection{Fuel supply}

Where provided, fuel supply systems should comply with the requirements of the relevant authorities. Double containment fuel lines should be used over the water (NSW Maritime Authority,2001).

Equipment that can be rapidly deployed to contain and clean up any fuel spillage should be provided (NSW Maritime Authority,2001).

Access for fuel delivery vehicles should be designed to minimize disruption of other marina activities during delivery.

It is desirable that the fuel berth should be a separate structure from the marina berths and should be isolated to the extent that fire or explosion would have minimal opportunity to spread from the fuel berth to the marina berths or vice-versa (NSW Maritime Authority,2001).

\subsubsection{Sanitary facilities}

Sanitary facilities should be provided on a minimum basis of one for every 40 berths, although increased facilities and separate male and female facilities may be necessary depending on the level of marina usage. Shower facilities should be considered (NSW Maritime Authority,2001).

Restroom facilities must comply with all public health and safety requirements of local, state and federal agencies within whose jurisdictions such facilities are permitted, constructed, operated, maintained and managed (Schwarzenegger, A., Chrisman, M., \& Tsuneyoshi, R. 2005). 
Sanitary facilities in marinas should be located near the berths and parking areas, all of which must be linked together by accessible routes providing access to all marina features, services and primary functions (Schwarzenegger, A., Chrisman, M., \& Tsuneyoshi, R. 2005).

Access to and from these facilities should be provided so as to avoid to the maximum extent possible pedestrian traffic behind parked vehicles. This is of particular importance where small children are present. Also, a person in a wheelchair is not always readily visible in the rear view mirrors of parked vehicles including automobiles, trucks and recreational vehicles (Schwarzenegger, A., Chrisman, M., \& Tsuneyoshi, R. 2005).

\subsubsection{Waste Management}

Marinas may provide sewage pump-out facilities and facilities for disposal of other liquid wastes such as waste oil.

Garbage and solid refuse disposal facilities should be located a minimum practical distance from the head of the gangway. Garbage receptacles should have self-closing lids to prevent escape of rubbish by way of wind, birds or animals, and exclude rainwater entry (NSW Maritime Authority,2001).

\subsubsection{Telephones}

If required, telephone installations should comply with the relevant authority. Provision of a public telephone, to provide 24-hour service, should be considered (NSW Maritime Authority,2001).

\subsubsection{On-land stormwater control and disposal}

Contaminated run-off from hard-stand including boat maintenance areas should be capable of being isolated so that run-off can be collected, treated and disposed of, in accordance with the requirements of the relevant authority.

\section{References}

Fruth, L.L, (1991). A guide for marina and harbor managers, Thesis, Naval Postgraduate School, California.

ICOMIA, (2017). Recreational Boating Industry Statistics.

PLANCO Consulting Gmbh. (2013). Efficient and profitable marina operation, Practical advice for optimizing service provision, THE MARRIAGE PROJECT.

Marine Institute. (2001). Guidelines for planning a marina development. Dublin. 
NSW Maritime Authority, (2001). The Australian Standards Guidelines for design of marinas. Sydney.

Schwarzenegger, A., Chrisman, M., \& Tsuneyoshi, R. (2005). Layout and Design Guidelines for Marina Berthing Facilities.

Trigo Teixeira A. (2001). Curso Marinas e Portos de Recreio, Instituto Superior Técnico, 3 to 5 of December 2001. 

Authors' profile 



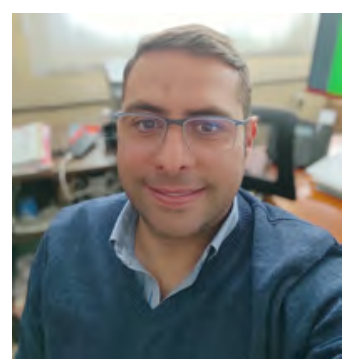

Juan Carlos Santamarta

Universidad de La Laguna

\section{Brief professional background}

Forestry engineer (UPM), PhD in Hydraulic and Energy Engineering (UPM) and PhD (international mention) in Applied and Environmental Geology Universidad de León (ULE). Civil Engineer, Energy Resources Engineer and Mining Engineer from the UPM. Associate Professor at the Universidad de La Laguna (Canary Islands, Spain) since 2008, he was a collaborating scientist at the Water Resources Research Center (WRRC) in the USA. Visiting Professor at George Mason University, College of Science, Virginia, USA. Collaborating researcher at the University Institute of Water and Environmental Sciences (IUACA) of the University of Alicante and adjunt researcher to the Water Institute of the Universidad de Barcelona. Professor of the PhD programme in Engineering and Management of the Natural Environment at the UPM. His research activity is summarised in 187 scientific publications (47 scientific articles, 55 book chapters, 19 edited books, 66 national and international conferences related to water and environment in volcanic islands. He has participated in 27 research projects. Taught more than 30 subjects related to water, environment, civil and industrial engineering. He has given more than 140 seminars and courses related to water in different Spanish and European universities and has directed more than 100 summer courses, university extension courses and professional technical courses. Dean of the Official College of Forestry Engineers in the Canary Islands. Award in Teaching Innovation in 2013 (quality mentions in 2012, 2014 and 2015), Canary Islands Research Award in Civil Engineering "Agustín de Betancourt" 2018. Award for excellence in the internationalisation of the Universidad de La Laguna (2021).Member of the WATER working group of the World Federation of Engineering Organizations (WFEO).

\section{Current professional status and contact}

Director Adjunto de la Sección de Ingeniería Agraria

Escuela Politécnica Superior de Ingeniería. Universidad de La Laguna

E-mail: jcsanta@ull.es 


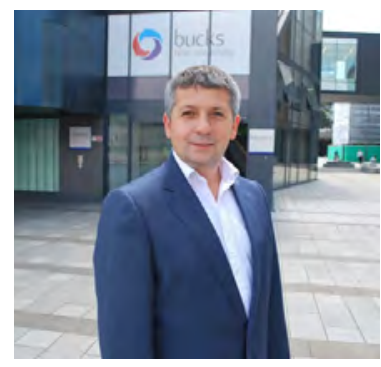

Florin Ioras

Buckinghamshire New University

\section{Brief professional background}

Forestry engineer (Transilvania University), PhD in Forest Ecology (Brunel University). Professor at Buckinghamshire New University (High Wycombe, UK) since 2010. Doctor Honoris Causa and Honorific Professor at Transilvania Universty, Romania. Lead PhD supervisor and examiner for programme in Management of the Natural Environment at BNU, UPM, UTB and EMU. His research activity is summarised in 133 scientific publications (91 scientific articles, 8 book chapters, 2 edited books, 32 national and international conferences related to management of natural resources). He has participated in 46 research projects. Taught more than 6 subjects related to water, environment, forestry engineering. He has given more than 80 seminars and courses related to water management in different European universities and has directed university extension courses and professional technical courses on environment sustainability.

\section{Current professional status and contact}

Director of Research and Enterprise

Buckinghamshire New University

E-mail: florin.ioras@bucks.ac.uk 


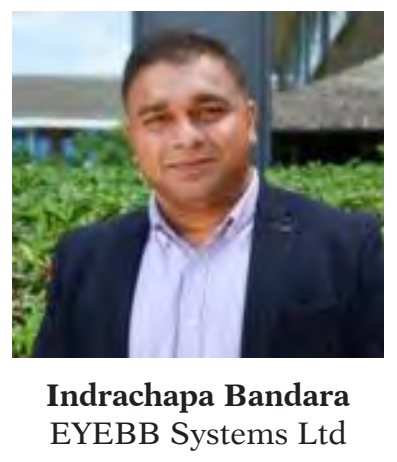

\section{Brief professional background}

A unique blend of expertise in Cybersecurity, Computer Networks \& Security, Internet of Everything (IoE), Internet of Things (IoT), Electronics Engineering and Video and Image Processing Skills along with in-depth renewable energy systems knowledge. PhD in computing and electronics (Brunel University). Visiting lecturer at Department of Continuing Education, Oxford University since 2015. Experience technology-enhanced Learning practitioner and published researcher. I have broad experience in training, supporting, consulting and developing computer networks in the commercial and educational sectors. Excellent experience in various research projects in cybersecurity, image processing, renewable energy and environmental management especially in international projects.

\section{Current professional status and contact}

Director

EyEBB Systems LtD

E-mail: i.bandara@eyebb.co.uk 


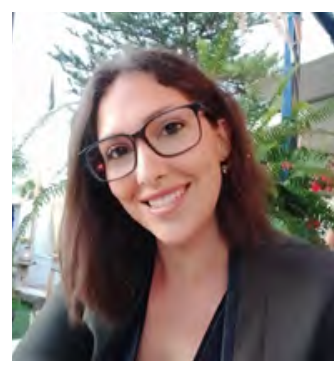

Noelia Cruz Pérez

Universidad de La Laguna

\section{Brief professional background}

Graduate in Building Engineering and Civil Engineering from the University of La Laguna. Master's degree in Water Technology and Management from the Polytechnic University of Catalonia and Master's degree in Regional Development from the ULL. Researcher in the Ingenia group.

Participation in several European projects related to the environment and the efficient management of resources in the Islands. Experience in calculating the carbon footprint and water footprint in different facilities, with international publications and contributions to conferences.

Management and collaboration with a wide network of national and international experts. Preparation of documentation for international project reports at a technical level, as well as management of the relationship with partners and experts.

\section{Current professional status and contact}

Researcher at the University of La Laguna, Coordinator of international $\mathrm{R}+\mathrm{D}+\mathrm{i}$ projects. E-mail: ncruzper@ull.edu.es 


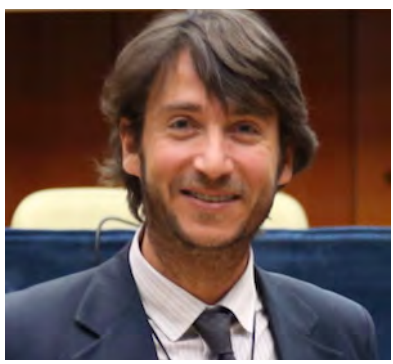

Manfredi Bruccoleri

University of Palermo - ITALY

\section{Brief professional background}

Dr Manfredi Bruccoleri is full professor of Management Engineering at the University of Palermo in Italy, where he teaches Business Economics and Operations and Business Process Management for bachelor and master students. He also taught Operations and Supply Chain Management at the TIAS Business School in the Netherland from 2016 to 2020. He is the Program Director of BSc and MSc in Management Engineering of the University of Palermo since 2019.

He holds a doctoral degree in Production Engineering and in 2001 he was visiting scholar at the School of Engineering of the University of Michigan (Ann Arbor). He collaborates with companies from different manufacturing and service industries for both teaching and research projects and coordinated several business process reengineering projects in different Italian companies and Public Administration. His research interests focus on healthcare operations management, behavioral operations, supply chain management, reverse logistics, business process management, social responsibility.

\section{Current professional status and contact}

Program Director of BSc and MSc in Management Engineering

University of Palermo

Department of Engineering, University of Palermo, Viale delle Scienze Ed.8, Palermo 90128, Italy, manfredi.bruccoleri@unipa.it, Phone: +39 09123861836 


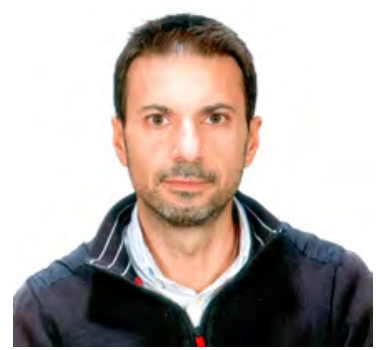

Nicholas Christofides

Frederick University

\section{Brief professional background}

Nicholas Christofides (PhD) holds a Ph.D. and M.Sc. in Electrical Engineering from the University of Manchester Institute of Science and Technology and a B.Sc. in Electronic and Electrical Engineering from the University of Birmingham. He is a member of the teaching and research staff of the department of Electrical Engineering, Computer Engineering and informatics teaching in the undergraduate and postgraduate programs. He also teaches in the inter-departmental postgraduate MSc in Sustainable Energy Systems program of the School of Engineering, Frederick University and in the Electrical and Electronics Systems Technician two-year diploma program of Frederick Institute of Technology. His research interests apply directly or indirectly with the decarbonized electricity market and which can contribute in optimizing the distributed generation from renewable energy sources such as photovoltaic systems. Dr Christofides has participated as a research associate in various research projects funded by the Research and Innovation Foundation, the MIARTDI and the EU. He is a reviewer in international journals and guest editor of the Energies Journal (MPDI). He has scientific publications in high impact international journals and more than 30 scientific papers in referred conference proceedings. He is a certified Energy Auditor, certified instructor for professional training (running vocational training programs for electrical contractors, electrical engineers and photovoltaic system installers) and Qualified Expert for the energy performance certificates of buildings.

\section{Current professional status and contact}

Assistant Professor, School of Electrical, Computer Engineering and Informatics, Frederick University

E-mail: n.christofides@frederick.ac.cy 


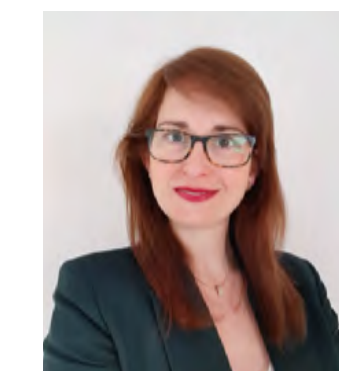

Jésica Rodríguez Martín

Universidad de La Laguna

\section{Brief professional background}

PhD in Civil Engineering, Environmental Technology programme (Cum Laude), with a Diploma of Advanced Studies in the Doctorate Programme "Territory and Environment" of the Department of Civil Engineering: Territorial Planning, Urbanism and Environment of the ETSICCP of the Polytechnic University of Madrid (UPM). At a professional level, he has carried out projects for a total value of almost $€ 11 \mathrm{~m}$, including project management and contracts for a total of $€ 30 \mathrm{~m}$. The projects include maritime works, hydraulic works and buildings in general, including projects related to aggregate extraction. She was in charge of the technical office of the company SATOCAN for 10 years. Currently working for the Cabildo de Tenerife, Consejo Insular de Aguas, supporting the management of important hydraulic works in Canary Islands. In 2019 he obtained the Honourable Mention in the Agustín de Betancourt Award for the best Civil Engineering work in the period 2014-2018 for the Marina Deportiva de Puerto de Tazacorte in La Palma, awarded by the Colegio de Ingenieros de Caminos, Canales y Puertos. At teaching and research level, she is adjunt professor at the Polytechnic School of Engineering of the Universidad de La Laguna, in the Department of Engineering and Architecture Techniques and Projects and adjunt professor in Universidad Europea de Canarias. Her research experience is developed in the research group of the ULL INGENIA with 53 publications, in book chapters, articles in journals and conferences.

\section{Current professional status and contact}

Dirección de obras de Ingeniería Civil y Docente e Investigadora Escuela Politécnica Superior de Ingeniería. Universidad de La Laguna E-mail: jrodrima@ull.edu.es 


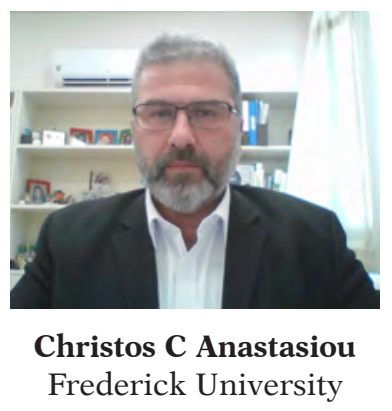

\section{Brief professional background}

An Associate Professor of Environmental Engineering in the Department of Civil Engineering at Frederick University, where he served as the Chair of the Department (2011 - 2016) and, subsequently, as the Dean of the School of Engineering (2016 - 2020). He obtained his BSc in Environmental Engineering Sciences (1996), and his MEng. in Environmental Engineering (1999), as well as a Graduate Certificate in Wetlands Science and Hydrology (1999) from the University of Florida. In 2002, he obtained his PhD in Civil Engineering (Environmental Systems) from North Carolina State University. Prior to his current post, he worked as an independent environmental consultant, was a faculty member at the American University of Beirut in Lebanon and was a faculty member and Academic Program Director at the Cyprus International Institute for the Environment and Public Health in Association with the Harvard School of Public Health. Dr Anastasiou teaches several courses in such areas as Environmental Engineering, Wastewater Treatment, Environmental \& Water Resources Management, Operations Research / Systems Analysis, and Sustainable Construction. He teaches courses in several Undergraduate and Graduate Programs of Study at Frederick University and at the Open University of Cyprus. Dr Anastasiou has completed a significant number of funded research projects, and has published work, related to such topics as water quality management, the development of novel wastewater treatment methods, and the adaptation and implementation of Sustainable Construction practices in the Mediterranean region. Dr Anastasiou is a registered professional Environmental Engineer with the Cyprus Chamber of Engineers, and he represents the Republic of Cyprus in the Socio-Economic Analysis Committee of the European Chemicals Agency..

\section{Current professional status and contact}

Associate Professor of Environmental Engineering Department of Civil Engineering. Frederick University

E-mail: c.anastasiou@frederick.ac.cy 


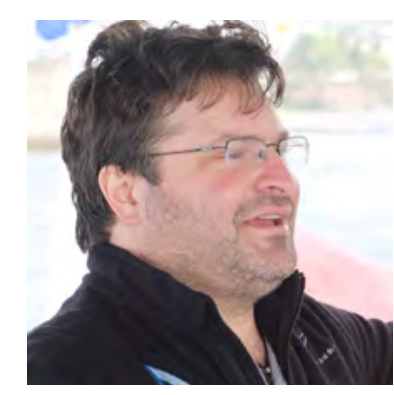

Sérgio Castro

Associação MarinaFunchal

\section{Brief professional background}

Degree in Biology, Scientific Branch at the University of Madeira;

Technician hired by the PESCPROF project (Deepwater Fisheries Resources of the Central-Eastern Atlantic) and monitor of the exhibition "Tesouros profundos do Oceano Atlântico" (Deep treasures of the Atlantic Ocean).

Volunteer in the activities developed at the Funchal Marine Biology Station (EBMF).

Collaboration in the organization of the XIX and XX International Regatta Canarias Madeira.

Collaborator in the organization of the Transat 6.50 International Regatta.

Collaborator in the organization of the European RS Championship: X.

MarinaFunchal Association employee since 2012;

Development of the Environmental Education Activity “À Descoberta do Mar da Madeira" (Discovering the Sea of Madeira), within the scope of the NAUTICOM project.

\section{Current professional status and contact}

Currently Head chief of Projects and Promotion Section Associação MarinaFunchal E-mail: marina@marinadofunchal.pt 


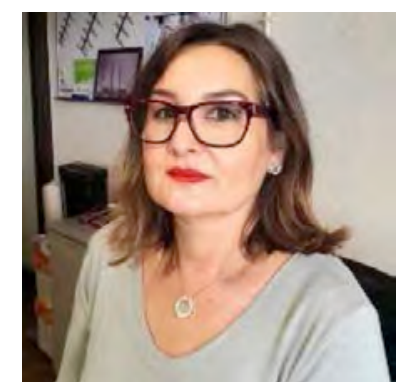

Maria José Rodriguez Da Silva

Associação MarinaFunchal

\section{Brief professional background}

Academic background in the area of Journalism and Tourism.

Administrative employee of the Regional Association of Sailing, Canoeing and Madeira.

Rowing (ARVCRM) from the year of its foundation 1990 to 1995.

Founder of SANAS Madeira (Madeiran Association for sea rescue).

Extensive experience in Recreational Nautical, having collaborated since young in the organization of several events and regattas organized by the Regional Association of Sailing, Canoeing and Rowing of Madeira (ARVCRM).

Organization of the 1st to the 6th Tour of Madeira in Canoa (Madeira Canoeing Tour) in 1992.

International Canoeing Judge.

Member of the refereeing team of the Crestuma International Marathon.

Collaborator in the organization of several passages of the International Transat 6.50

Regatta through RAM.

Head of Administrative Services at the Marina Funchal Association, since July 1, 1995.

\section{Current professional status and contact}

Head of Administrative Services at the Marina Funchal Association

E-mail: geral@marinadofunchal.pt 
Maritime transport emits around 1000 million tonnes of $\mathrm{CO}_{2}$ annually and is responsible for about $2.5 \%$ of global greenhouse gas emissions (3rd IMO GHG study). Shipping emissions are predicted to increase between $50 \%$ and $250 \%$ by $2050-$ depending on future economic and energy developments. For nautical boats the "end of use" (in Europe 80,000 boats, reach their 'end of use's each year) is one of the main challenges for the industry which poses a threat to the environment and a recycling challenge.

Staff qualifications, the inability to attract young workers remain one of the crucial points in Europe. To boost the recruitment of highly prepared staff requires initiatives addressing learning to make the Environmental management and security related sectors attractive and to transform both the academic kno-wledge and high-level basic and transversal competences to be useful and ap-plicable. This book seek to offer an adaptedcurriculum to equip the young generation with the specific, basic and transversal competences currently re-quired in the planning, climate change mitigation and vested industries.Book has been designed with the aim to support the development and the implemen-tation of an innovative practice, a new training path for the carbon neutral ma-nagement of sport marinas.

This initiative complies with one of the principal aims of the Erasmus+ pro-gram: Promoting synergies and cross fertilisation throughout the different fields of education, training and youth, removing artificial boundaries between the various actions and projects formats, fostering new ideas, such as a secto-ral multi campus, promoting cross border cooperation by attracting new actors from the world of work to collaborate with universities and VET, but above all, with the target of stimulating new forms of cooperation.

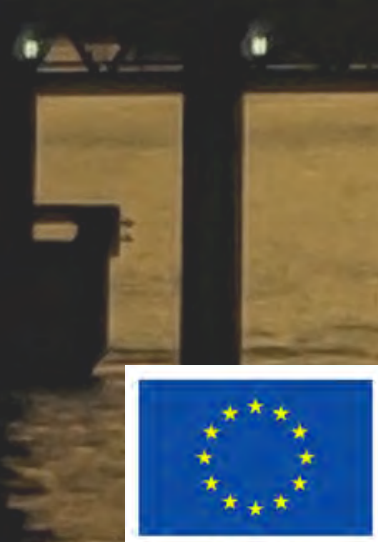

Lifelong

a
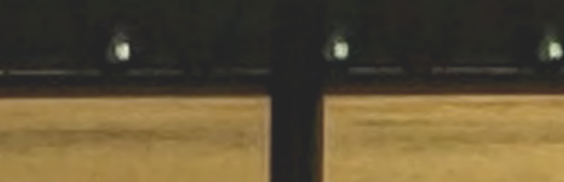

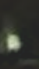
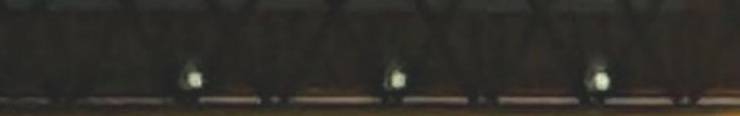